$$
\begin{gathered}
\text { JUSTICE ET INFRA-JUSTICE } \\
\text { DANS LE } \\
\text { MEXIQUE INDÉPENDANT }
\end{gathered}
$$





\section{JUSTICE ET INFRA-JUSTICE DANS LE MEXIQUE INDÉPENDANT}
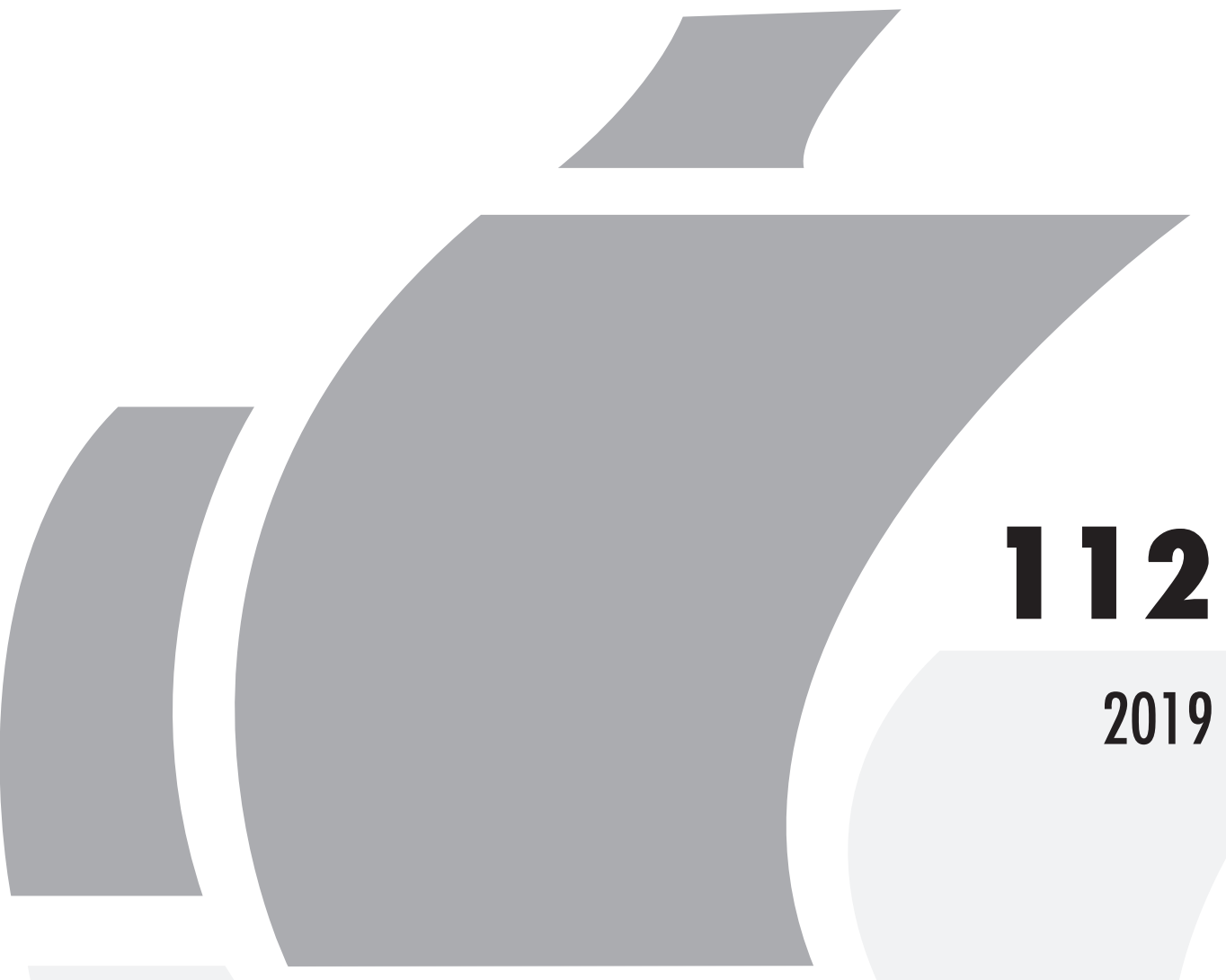

Revue publíe aVec le soutien de L'I IPEAT

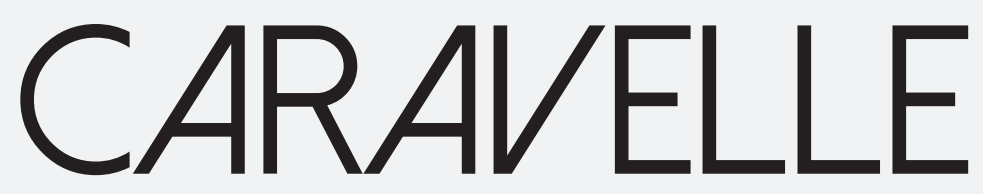


Secrétariat de rédaction et mise en pages : Lorédane Saint-Blancat

Mise en pages : Marion Hummel (marion.hummel@wanadoo.fr)

Résumés en anglais : Ana Vigne Pacheco

ISSN $1747-6753$

ISBN 978-2-8107-0642-6

(C) Presses universitaires du Midi, 2019

Université Toulouse - Jean Jaurès

5, allées Antonio Machado

31058 Toulouse cedex 9

Tous droits de reproduction, de traduction et d'adaptation réservés pour tous pays. Toute représentation ou reproduction intégrale ou partielle faite par quelque procédé que ce soit, sans le consentement de l'auteur ou de ses ayants cause, est illicite et constitue une contrefaçon (art. 335-2 et suivants du Code de la propriété intellectuelle, loi du $1^{\text {er }}$ juillet 1992). Les copies ou reproductions destinées à une utilisation collective sont interdites. 


\section{Présentation Justice et infra-justice
dans le Mexique indépendant}

Evelyne SANCHEZ

CNRS-FRAMESPA (UMR5136, Université Fédérale de Toulouse)

Daniela MARINO

INAH, Mexique

Le DOSSIER QUE NOUS PRÉSENTONS ici est le fruit d'un travail collectif. Il est issu du projet ECOS-Nord M16H01 intitulé "Justice et société au Mexique, XvIII $\mathrm{xxI}^{\mathrm{e}}$ siècles " né d'une réflexion sur le contexte proprement mexicain et que l'on peut résumer ainsi : si l'administration de la justice a, depuis le $\mathrm{XvI}^{\mathrm{e}}$ siècle, été un recours efficace dans la résolution des conflits, souvent sollicité au XIX ${ }^{e}$ siècle lors des nombreux litiges agraires qui ont accompagné la disparition programmée des terres collectives, la révolution de 1910 est-elle alors le reflet de la rupture du pacte tacite entre justice et société ? L'historiographie qui s'est développée ces dernières décennies sur l'administration de la justice - mais rare sur le sujet de la relation de celle-ci avec la société - a mis en exergue des évolutions qui témoignent pour la plupart d'une distanciation entre les juges et les justiciables. La modernisation de la justice a en effet débouché sur un double mouvement. Tout d'abord, l'autonomie de la sphère judiciaire dans le cadre de la séparation des pouvoirs et qui ne permet plus d'être co-acteur du gouvernement par la voie juridictionnelle. Ensuite, la professionnalisation partielle des tribunaux de proximité - limitée à ceux de $1^{\mathrm{re}}$ instance - suivie de l'introduction pendant le Porfiriat de codes de procédures ont obligés les justiciables à avoir recours à des conseillers juridiques et avocats, ce qui ne créaient pas seulement une distance relationnelle avec le juge, souvent sollicité autrefois directement, mais aussi économique puisque les services de ces intermédiaires avaient un coût. 
Cependant ces réflexions, tout en ouvrant des pistes, risquaient d'acter une contradiction. En effet, elles tendent à valider un peu rapidement l'idée d'une transition juridique réussie - de la casuistique à l'empire de la loi - soutenue par une professionnalisation tout aussi réussie du personnel des tribunaux (affirmée par les auteurs qui se réferent essentiellement à l'évolution de la réglementation) alors même que nous venons de souligner la place grandissante d'intermédiaires qui ont peu attiré l'attention des historiens, du moins dans cette fonction de médiation. Ce sont ces intermédiaires que nous avons résumé ici par le terme d'infrajustice, inspiré par l'ouvrage coordonné par Benoit Garnot ${ }^{1}$. Il désigne tous les personnages qui interviennent de manière ponctuelle ou suivie lors de procédures judiciaires et se distinguent donc des figures d'autorités qui facilitent la résolution de conflit de façon extra-judiciaire (curé de paroisse, président de communauté, anciens, etc.). Parmi ces personnes, nous pouvons citer les juges qui restent profanes et sont élus annuellement (juges locaux et juges de paix), les garants et casa de notificación, les avocats et tinterillos, les traducteurs, mais aussi tout le personnel subalterne des tribunaux (greffiers, secrétaires, concierge, factotum), les experts (arpenteurs, médecins légistes, etc.) qui au final formaient une véritable ruche indispensable au fonctionnement des tribunaux ${ }^{2}$. En d'autres termes, la justice qui devait désormais émettre des sentences motivées, en toute transparence, et gagner ainsi en légitimité, n'était accessible qu'à la condition de rémunérer un certain nombre d'intermédiaires. Certains d'entre eux étaient anciens, voire même en voie de disparition, tels les traducteurs étudiés ici par Soizic Croguennec dans le cas particulier de la justice des confins de l'Empire en Louisiane, et que la maîtrise du castillan par les populations indigènes rendait de moins en moins indispensables. Les fidéjusseurs, qui se portaient caution, sont en revanche des personnages permanents du paysage judiciaire. Comme le montre Mirian Galante, leur rôle pouvait être bien plus vaste puisqu'ils intervenaient aussi dans le choix de la sentence, pouvant atténuer celle-ci et assuraient le retour des accusés au sein de la société et des valeurs chrétiennes partagées au début du Xixe siècle.

Mais ce dossier fait surtout la part belle aux avocats et cela pour trois raisons principales. La première est pragmatique et stratégique car, plutôt que prétendre à un inventaire des "facilitateurs " de justice que l'espace d'un dossier ne permettrait pas de compléter, il nous a paru plus opportun de consacrer plusieurs textes à celui qui devint le pivot de la modernisation de la justice et le lien principal entre la justice et l'infrajustice. En effet, avec l'exigence d'une professionnalisation des juges de $1^{\text {re }}$ instance, mentionnée dès Cadix mais dans les faits longue à être mise en œuvre, les avocats sont devenus le vivier parmi lesquels les juges étaient recrutés,

1. Garnot, Benoît (dir.), L'infrajudiciaire du Moyen Âge à l'époque contemporaine, Dijon, Publications de l'Université de Bourgogne, 1996.

2. La liste n'est pas exhaustive. Nous laissons de côté dans ce dossier le cas très particulier des notaires habituellement classés parmi les auxiliaires de justice et qui, au Mexique au cours du XIxe siècle, étaient aussi juges de $1^{\mathrm{re}}$ instance. Ce cas est traité dans : Sanchez, Evelyne, El juez, el notario y el caudillo. Análisis de un juicio verbal en Tlaxcala durante la Revolución, La Casa de Velázquez, Collection Essais de la Casa de Velázquez (2019). 
ceux-ci devaient même avoir exercé trois à cinq ans, selon la réglementation en cours, avant d'être nommés magistrats dans un tribunal. On le voit, le seul critère de l'expérience était pris en compte, tandis que le fait d'avoir des liens noués avec de potentiels clients influents (puisque solvables) n'a à aucun moment été considéré comme un obstacle, malgré les effets de défiance que cela pouvait générer. Enfin, notre dernier motif tient au fait que nous avons identifié des liens de plusieurs sortes entre avocats (donc lettrés) et monde infrajudiciaire en tout ou partie profane (tinterillos dont la formation était inachevée, juges profanes) en travaillant soit sur la relation avocat-client (Evelyne Sanchez) soit sur la vocation de facilitateur voire de formateur d'un avocat qui prit l'initiative de créer des instruments permettant aux non lettrés de se mouvoir dans les méandres de l'administration judiciaire modernisée (texte de Daniela Marino). Dans tous les cas, c'est la question souvent oubliée de l'accessibilité de la justice - et donc de son coût - qui est traitée ici et qui est un point central de notre étude portant sur la relation entre justice et société.

Dans le contexte de l'histoire du Mexique contemporain marqué par la révolution, il nous a paru également important d'insérer dans ce dossier la question agraire. Là encore, c'est le rôle des avocats qui a été souligné tant par l'historienne Rocío Ortiz que par l'anthropologue Gabriela Torres-Mazuera. La première approfondit la question de l'accès à la justice pour les pauvres lors de litiges relatifs à la terre tandis que la seconde fait la démonstration du rôle ambigu des avocats qui, lorsqu'ils sont civils, tendent à faciliter la privatisation des terres collectives et, lorsqu'ils sont spécialisés dans les droits de l'Homme, proposent de nouvelles stratégies de défense des communs qui peinent à se faire entendre dans les tribunaux.

Enfin, puisque nous avons identifié de fortes permanences dans le fonctionnement de l'administration de la justice malgré le discours modernisateur et dans la mesure où la question agraire nous a paru essentielle pour comprendre l'évolution de la qualité de la relation entre justice et société, nous avons fait le choix d'inviter Ana Teruel à participer à cette discussion en proposant un texte décalé par rapport à notre terrain de recherche. Son séjour à Toulouse en mai 2018, dans le cadre de la Chaire Amérique latine, a permis d'organiser un séminaire sur le thème de l'ordinaire du fonctionnement des tribunaux en Amérique latine pour préparer ce dossier $^{3}$. Son texte constitue un important contre-point, d'autant plus qu'il analyse dans la longue durée - sur presque un siècle - l'évolution du recours judiciaire dans une région argentine touchée par les conflits agraires. Il permet en outre aux mexicanistes que nous sommes de dévier notre regard de la révolution mexicaine que nous avions constamment en ligne de mire au moment de l'élaboration de ce dossier. Qu'elle en soit ici vivement remerciée.

3. "La administración de justicia en América Latina, siglos XvIII-Xx. Aspectos cotidianos de los juzgados », 11 mayo de 2018, Maison de la Recherche, Université Toulouse 2 - Jean Jaurès. 11 mai 2018, Toulouse. 



\title{
Rendre la justice en Louisiane espagnole (1763-1803) : aménagements, improvisations et instrumentalisations
}

\author{
Soizic CroguenneC \\ MINEA, Université de Guyane
}

\section{Introduction $^{1}$}

À la suite du désastre de la Guerre de Sept Ans (1756-1763), Louis XV et le duc de Choiseul doivent faire face à ses conséquences sur le continent américain. Le Traité de Paris en 1763 marque ainsi la fin de la présence française en Amérique du Nord $^{2}$. La Grande-Bretagne obtient le Canada tandis que l'Espagne reçoit les vastes territoires louisianais. Un tel accord permet à la France de récupérer ses possessions antillaises et plus particulièrement Saint-Domingue. En ce qui concerne l'Espagne, le don de la Louisiane par la France vient récompenser la solidarité dynastique et compenser la perte de la Floride ${ }^{3}$.

La Couronne espagnole ne se presse pas pour prendre concrètement possession d'un territoire qui ne lui offre que peu de perspectives comme le souligne l'ambassadeur Jerónimo Grimaldi. Il déclare en effet accepter les conditions du Traité de Paris au nom de son roi « aunque conocía perfectamente que no haciamos sino adquirir una carga anual de 300000 piastras, a cambio de la utilidad negativa y lejana de poseer un país para que otro no lo poseyese ${ }^{4} »$. De fait, la présence espagnole en Louisiane n'a guère laissé de traces dans les mémoires collectives, et pour cause. Comme l'écrit David Narrett, "Spain had imperial dominion over Louisiana during

1. Article rédigé dans le cadre du projet ECOS Nord - ANUIES «Justicia y sociedad en México (siglos XVIII-XXI) ».

2. Havard, Gilles et Vidal, Cécile, Histoire de l'Amérique française, Paris, Flammarion, 2008, Collection Champs Histoire, p. 663-669.

3. Jiménez, Alfredo, El Gran Norte de México. Una frontera imperial en la Nueva España (1540-1820), Madrid, Editorial Tébar, p. 137. Voir aussi les travaux de Weber, David J., The Spanish Frontier in North America, New Haven, Yale University Press, 1992.

4. Andreu Ocariz, Juan José, Luisiana española, Zaragoza, Talleres Editoriales Librería General, 1975, p. 28. 
the years 1763-1803, but it was only minimally a colonizing nation in the region ${ }^{5}$ ". L'idée d'échec espagnol en Louisiane est donc un thème prégnant, que l'on observe dans l'historiographie espagnole ${ }^{6}$ ou étatsunienne . $^{7}$

Toutefois, il ne faut pas réduire l'expérience espagnole en Louisiane à ce seul sentiment d'échec. Par maints aspects, la période de l'Interregnum fait figure d'une expérience coloniale et impériale singulière marquée par un grand pragmatisme. L'administration espagnole a en effet été confrontée à une équation inédite pour elle en Amérique : comment administrer un territoire occupé par des populations européennes aux loyautés contrastées ? En raison de la présence de la population française et de la permanence des liens de toute nature avec l'ancienne métropole, il n'était pas possible pour l'Espagne d'imposer le même type de système que dans le reste de l'Empire. À la suite de la révolte de 1768 contre le premier gouverneur Antonio de Ulloa et de la répression menée l'année suivante par Alejandro O'Reilly, les concessions administratives et économiques - notamment le maintien des réseaux commerciaux avec les ports français et antillais - permettent aux Français de Louisiane d'adhérer au projet colonial espagnol. Ils sont ainsi étroitement associés à l'administration locale et aux relations diplomatiques avec les tribus indiennes alliées - Choctaws, Chicasaws ${ }^{8} \ldots$ La faiblesse du peuplement est un autre enjeu du développement de la Louisiane. Le contador Martín Navarro souligne dans ses Reflexiones politicas sobre el estado actual de la provincia de la Luisian $a^{9}$ la principale vulnérabilité de la région, c'est-à-dire le manque d'emprise démographique, handicap à la fois stratégique et économique. C'est pourquoi la couronne espagnole accueille dans un premier temps les Acadiens ayant fui leur région à la suite de la répression menée par les Anglais dans les anciennes possessions françaises ${ }^{10}$. Le gouverneur Bernardo de Gálvez (1778-1783) lance un ambitieux projet de colonisation en recrutant le Bataillon de Louisiane au sein de la population canarienne ${ }^{11}$. Martín Navarro envisage quant à lui le recours à des colons irlandais ou allemands ${ }^{12}$. Bien loin de la volonté de fermer l'empire colonial espagnol aux populations étrangères manifestée dès le $\mathrm{XVI}^{\mathrm{e}}$ siècle, les différents projets

5. Narrett, David, Adventurism and Empire: the Struggle for Mastery in the Louisiana-Florida Borderlands, 1762-1803, Chapel Hill, University of North Carolina Press, 2014, p. 1.

6. Dans son introduction, Juan José Andreu Ocariz regrette ainsi l'incapacité de l'administration espagnole du XVIII ${ }^{e}$ siècle à mettre en place un système colonial comparable à ce qui a été réalisé au XVI $I^{e}$ siècle. Voir Andreu Ocariz, Juan José, Luisiana española, Zaragoza, Talleres Editoriales Librería General, 1975, p. 5.

7. Voir le titre d'un des chapitres consacrés au XviII ${ }^{\mathrm{e}}$ siècle par Joe Gray Taylor dans Gray Taylor, Joe, Louisiana : a Bicentennial History, New York, WW Norton \& Co, 1976, "Colonial Louisiana: Study in Failure ».

8. Din, Gilbert C. et Harkins, John E., The New Orleans Cabildo: Colonial Louisana's First City Government, 1769-1803, Baton Rouge, London, Louisiana State University Press, 1996. Voir également les fiches de services présentes aux Archives des Indes : Archivo General de Indias (AGI), Santo Domingo, 2605, Hojas de servicio de empleados de Real Hacienda.

9. AGI, Papeles de Cuba, 2351, Ramo 13, Martín Navarro, Reflexiones politicas sobre el estado actual de la provincia de la Luisiana.

10. Hoffman, Paul, Luisiana Española, Madrid, Editorial MAPFRE, 1992, p. 219.

11. Din, Gilbert C., The Canary Islanders of Louisiana, Baton Rouge, Louisiana state university press, 1988.

12. AGI, Papeles de Cuba, 2351, Ramo 13, Martín Navarro, Reflexiones politicas sobre el estado actual de la provincia de la Luisiana, f. 6. 
de peuplement en Louisiane se veulent avant tout pragmatiques. Pour Madrid, la colonie a surtout une fonction géopolitique de région frontière qu'il faut peupler pour éviter une progression trop rapide des Anglo-américains vers l'Ouest. Le retour de la Floride sous l'autorité espagnole à partir de 1783 ainsi que l'apport de la pression démographique étatsunienne se traduit par la place grandissante d'une composante anglo-saxonne en Louisiane. Si l'on ajoute les populations indiennes voisines, on voit comment la Louisiane se construit comme une véritable mosaïque " multiethnique et multiculturelle ${ }^{13}$ ». L'administration et la justice espagnole doivent donc composer avec des contraintes géographiques, démographiques et culturelles fortes. Le pragmatisme et l'adaptation deviennent ainsi les maîtres mots après l'échec du premier gouverneur Antonio de Ulloa. Les réformes appliquées par Alejandro O’Reilly après 1769 ont permis la mise en place d'institutions espagnoles solides sur le plan administratif : le Cabildo de la Nouvelle-Orléans, l'administration fiscale, l'Hôpital royal... Sur le plan judiciaire, la même démarche est suivie depuis les alcaldes ordinarios chargés de la justice quotidienne jusqu'à la cour d'appel à La Havane ${ }^{14}$. Il résulte du développement de l'appareil administratif et judiciaire une documentation riche et dispersée, encore largement inexplorée pour la période espagnole en Louisiane. L'abondance de sources aussi bien à La NouvelleOrléans (Historic New Orleans Collection) qu'à Séville (Archivo de Indias) ou Mexico (Archivo General de la Nación) nous fournit un matériau d'une grande richesse et un éventail de situations particulièrement large : contrôle des idées menaçant les fondements de la royauté et de l'Église par l'Inquisition de Mexico, délinquance quotidienne dans les régions les plus éloignées, conflits personnels et économiques entre membres des différentes communautés en présence. La société louisianaise est, à l'instar de l'ensemble des sociétés coloniales, un monde hautement conflictuel et procédurier comme en témoignent les volumes identifiés aussi bien à Séville qu'à la Nouvelle-Orléans ${ }^{15}$. Dans From Chaos to Continuity: The Evolution of Louisiana's Judicial System, 1712-1862, Mark Fernandez souligne l'intérêt d'une approche du système politique louisianais par l'analyse de l'évolution de l'institution judiciaire à partir de l'époque coloniale ${ }^{16}$. Dans le cadre de cet article, archives militaires et inquisitoriales sont mobilisées pour une analyse sous plusieurs angles : aspect narratif, données anthropologiques sur l'identification et les trajectoires des individus concernés, détail des procédures et des intervenants... Il s'agit de se pencher à la fois sur la matérialité des procès analysés - procédé de rédaction et de traduction, statut des personnels mobilisés - et le contenu des discours - argumentation, serments prêtés, objet des conflits - pour voir comment le contexte louisianais affecte

13. Allen Smith, Gene et Hilton, Sylvia L., Nexus of Empire. Negociating Loyalty and Identity in the Revolutionary Borderlands, 1760's-1820's, University Press of Florida, Tallahassee, p. 4.

14. Ibid., emplacement 382.

15. Si l'on se concentre uniquement sur les procédures - civiles, pénales, militaires - concernant des conflits intercommunautaires, les sondages effectués à ce jour indiquent un volume de plusieurs centaines de dossiers pour la période espagnole.

16. Fernandez, Mark F., From Chaos to Continuity: The Evolution of Louisiana's Judicial System, 1712-1862, Baton Rouge, Louisiana State University Press, 2001, édition Kindle, emplacement 66. 
le fonctionnement d'une justice de confins et comment celui-ci, en retour, nous éclaire sur les réalités d'une société composite de frontière. En d'autres termes, audelà de la vision institutionnelle développée par Mark Fernandez, c'est davantage les rouages de ce système judiciaire dans le contexte d'une société multilingue «à la croisée des empires ${ }^{17}$ " qui nous intéresse pour bien comprendre "comment des populations de cultures différentes nouaient des relations et s'influençaient mutuellement dans leur vie quotidienne ${ }^{18}$ ». Le but du présent article est de faire le point sur les premiers résultats obtenus lors de sondages à Séville et Mexico en développant deux axes de réflexion. Nous explorerons ainsi dans un premier temps l'impact du multilinguisme sur le fonctionnement et les préoccupations de la justice militaire comme inquisitoriale avant d'analyser comment la position de la région comme carrefour aux confins des empires impose des adaptations permanentes des procédures, des personnels et des discours.

\section{Rendre la justice dans un monde multilingue}

Pour la justice espagnole en Louisiane, puis en Floride, l'enjeu principal est de composer avec une population diverse. La langue administrative, l'espagnol, est extrêmement minoritaire dans la vie quotidienne, contrairement au français, dominant, l'anglais et les langues indiennes. L'exercice de la justice reposant sur la communication orale - questions de l'enquêteur, déclarations des parties en présence, témoignages recueillis - comme écrite - transcription des entretiens, rapports, décisions de justice - le contexte multilingue, de même que la coexistence religieuse entre catholiques et protestants, a un réel impact sur les pratiques de l'appareil judiciaire militaire.

\section{La Louisiane à la croisée des Empires}

La société louisianaise se caractérise par sa grande diversité. De fait, il est intéressant de noter la manière dont les serments prononcés dans le cadre des procédures militaires reflètent de manière frappante la mosaïque de populations et de valeurs qui cohabitent dans la Louisiane espagnole de la fin du XviII ${ }^{\mathrm{e}}$ siècle. C'est ce que l'on peut le voir dans le document 1 ci-dessous. Ces échantillons viennent d'une série de sondages effectués dans la section Papeles de Cuba. Dans l'ensemble des procès étudiés à ce jour - un peu plus de vingt - il apparaît que les serments " différenciés » sont une pratique commune à la Nouvelle-Orléans, en Floride Occidentale (Mobile, Panzacola) et Orientale (San Marcos de los Apalaches).

17. Vidal, Cécile, Louisiana: Crossroads of the Atlantic World, Philadelphia, University of Pennsylvania Press, 2014. 18. Usner, Daniel, Indians, Settlers, and Slaves in a Frontier Exchange Economy: The Lower Mississippi Valley Before 1783, Chapel Hill, University of North Carolina Press, 1992, p. 6. 


\begin{tabular}{|l|l|}
\hline Statut / Religion du déclarant & \multicolumn{1}{|c|}{ Serment prononcé } \\
\hline Gens du commun & $\begin{array}{l}\text { hizo levantar la mano derecha y preguntado si juraba a Dios nuestro seńor y a la seńal de } \\
\text { la cruz que hizo con ella decir verdad }\end{array}$ \\
\hline Soldats (troupe) & le hizo levantar la mano derecha y preguntado juráis a Dios y prometéis al Rey decir verdad \\
\hline Officiers et nobles & $\begin{array}{l}\text { recibió dicho seńor juramento que hizo por Dios Nuestro Seńor y la Cruz de su Espada, } \\
\text { bajo el cual ofreció decir verdad }\end{array}$ \\
\hline Anglo-américains & $\begin{array}{l}\text { que le hizo por los Santos Evangelios y lo que creía de la Sagrada Biblia bajo del cual ofrecía } \\
\text { decir verdad }\end{array}$ \\
\hline Esclave anglo-américain & $\begin{array}{l}\text { e inmediatamente recibió juramento al testigo Colmenar por medio del interprete según } \\
\text { forma de su religión, de decir verdad en lo que fuere preguntado }\end{array}$ \\
\hline
\end{tabular}

Document 1 - Prêter serment dans une société multiculturelle ${ }^{19}$

Pour l'historiographie, l'incapacité du pouvoir espagnol à imposer ses codes aux populations louisianaises a longtemps été interprétée avant tout comme un signe de fragilité. Le pragmatisme espagnol vis-à-vis des populations françaises puis anglo-américaines - notamment au niveau des concessions commerciales ou encore religieuses - peut être considéré comme l'aveu de faiblesse d'un pouvoir colonial incapable d'affirmer son autorité en Louisiane. Les populations anglo-américaines de Floride sont en effet encouragées à rester dans l'Empire espagnol après 1783 à condition de se convertir au catholicisme. Dans les faits, cet impératif reste lettre morte et la Couronne ne peut guère s'opposer à l'installation et à la résidence de populations protestantes sur ses territoires ${ }^{20}$. L'installation des populations angloaméricaines favorise la création de réseaux commerciaux entre les ports étatsuniens et la Louisiane qui viennent s'ajouter aux liens avec les Antilles et la France. Plaque tournante qui relie l'intérieur du continent via la vallée du Mississippi au golfe du Mexique, la Louisiane, et plus particulièrement la Nouvelle-Orléans, se trouve ainsi au cœur des flux transatlantiques, caribéens et nord-américains. Dans le même temps, le territoire louisianais est aussi une région de confins, peu contrôlée par les différents pouvoirs coloniaux en présence et donc favorable aux circulations illicites de tous genres - fuite d'esclaves, désertions de soldats, contrebande. Dans le dispositif colonial espagnol, la Louisiane doit représenter un glacis protecteur de la Nouvelle-Espagne sur le plan géopolitique ${ }^{21}$. Toutefois, en raison de la présence de populations françaises et anglo-américaines et des flux qu' elles génèrent, la région apparaît bien plus comme un point de vulnérabilité sur le plan culturel et politique. Par exemple, ce territoire apparaît comme un point d'entrée des livres et donc des

19. Tableau réalisé à partir de AGI, Papeles de Cuba, 163A, Autos criminales contra los presidarios Francisco Caparza, José Aguiar, José López, José Morales y Domingo Pineda sobre la muerte violentada al de igual clase Manuel Morales / AGI, Papeles de Cuba, 163A, Testimonio de las últimas diligencias en el lance ocurrido entre el Capitán del Regimiento de Luisiana D. José LeBlanc y D. Arturo Morgan / AGI, Papeles de Cuba, 163A, Criminal contra el soldado Miguel Serrano / AGI, Papeles de Cuba, 163A, Criminal contra el marinero Manuel González.

20. Hoffman, Paul, Luisiana española..., op. cit., p. 220.

21. Hilton, Sylvia L., "Spanish Louisiana in Atlantic Contexts: Nexus of Imperial Transactions and International Relations "; Vidal, Cécile, Louisiana: Crossroads of the Atlantic World, Philadelphia, University of Pennsylvania Press, 2014, p. 68-86. 
idées réprouvées et interdites par l'Inquisition, qui peine à s'opposer à la circulation des idées et livres interdits. Sur un ensemble de vingt-trois dossiers de l'Inquisition identifiés aux archives de Mexico, la moitié concernent des suspicions d'hérésie et de discours politiques contestataires alimentés par les contacts entre Espagnols, Français et Anglo-américains dans le cadre louisianais. Quand ce ne sont pas les écrits de Voltaire qui parviennent en Nouvelle-Espagne via le Texas et la ville frontière de Natchitoches 22 , c'est un livre mettant en cause le principe monarchique et publié en 1794 par Santiago Felipe Puglia à Philadelphie, El Desengaño del Hombre, qui entre en Nouvelle-Espagne en suivant les circuits commerciaux depuis la côte est des États-Unis jusqu'à la Nouvelle-Orléans ${ }^{23}$. Les idées révolutionnaires passent également par la Louisiane pour pénétrer l'Empire espagnol comme le montre l'itinéraire du marchand français Jean Langouran qui développe ses activités entre Bordeaux, la Nouvelle-Orléans et l'Amérique Centrale. Favorable à la Convention, il ne se prive pas d'affirmer ses idées jusqu'à son arrestation à Tegucigalpa ${ }^{24}$. À travers les différents types de serments et la vulnérabilité face aux idées des Lumières, c'est tout un quotidien marqué par la diversité des langues, des systèmes de valeur et des religions qui apparaît.

\section{Justice et traduction}

Une première caractéristique de la justice louisianaise est un fonctionnement plurilingue qui affecte jusqu’à la matérialité des procédures. On observe ainsi un cheminement tortueux des procédures au fil des échelons, depuis le traitement local jusqu'à la Nouvelle-Orléans. Les articulations entre les niveaux locaux et régionaux sont nettement visibles dans la mesure où les plaintes et le recueil des témoignages sont tout d'abord rédigés dans la langue dominante de la communauté incriminée. La traduction intervient à l'échelon supérieur, si et lorsque la procédure atteint la Nouvelle-Orléans. Le processus de traduction, du français ou de l'anglais à l'espagnol, est ainsi révélateur de l'organisation concentrique de l'administration en Louisiane : le noyau espagnol s'appuie volontiers à l'échelle locale sur des intermédiaires français, anglais ou américains. Ce système est à la fois le signe d'une grande plasticité de la structure impériale mais aussi le symptôme de sa grande vulnérabilité dans la mesure où l'échafaudage ne tient que grâce à la coopération de ces intermédiaires selon le schéma décrit par Frederick Cooper et

22. Archivo General de la Nación (AGN), Inquisición, 1373, Exp6, Expediente formado con motivo de haber entregado el Capitán Bernardo Northolan, de las Milicias del puesto de Nachitoches, Provincia de la Luisiana, Dos tomos de la obra de Voltaire. El Br. D. Gavino Valdez remite, además, de los tomos de Voltaire la obra de Eusebio En 4 tomos en $8 \$$. San Antonio De Bejar, N. M.

23. AGN, Inquisición, 1346, Exp1, El adjunto libro impío y sedicioso que con el título El Desengaño del Hombre se ha impreso en Philadelphia. AGN, Inquisición, 1389, Exp22, Expediente formado con el edicto publicado en esta corte en 26 de octubre de 1794 prohibiendo el libro titulado El Desengaño del Hombre.

24. AGN, Inquisición, 1320, Exp2, Inventario y avalúo de los bienes secuestrados a don Juan Langouran, de nación francés, natural de la ciudad de Burdeos, Hereje. 
Jane Burbank ${ }^{25}$. C'est ainsi que les premiers témoignages au sujet d'une conspiration menée par Barton Hannon dans la région de Natchez sont recueillis en anglais par les officiers espagnols en place, le commandant Manuel Gayoso de Lemos et l'interprète Esteban Minor ${ }^{26}$. Une démarche similaire est observée à Opelousas lorsque Jorge (George) Stelly est retrouvé pendu à un arbre. La procédure est d'abord menée par les officiers français au service de l'administration avant d'être traduite en espagnol ${ }^{27}$. De telles pratiques permettent de tenir compte des contraintes imposées non seulement par une population diverse et éparpillée mais aussi par la composition même de l'administration coloniale. Toutefois, elles supposent également des frais de justice supplémentaires : il faut prendre en compte l'acte de traduction et prévoir l'entretien de traducteurs capables de manier l'espagnol, le français, l'anglais et les langues indiennes. Enfin, l'étape de la traduction combinée aux effets de la distance implique des délais dans le traitement des dossiers. Si l'on reprend l'enquête sur la mort de Jorge Stelly, la procédure commence à Opelousas - 200 kilomètres au nord-ouest de la Nouvelle-Orléans - en avril 1797 mais n'est traduite à la Nouvelle-Orléans qu'en novembre $1797^{28}$. La justice en Louisiane est donc une justice lente. La distance, le manque de personnels et la mosaïque de populations constituent autant d'obstacles.

Un deuxième type de contrainte est la difficulté à identifier les différents témoins, plaignants ou prévenus. Les approximations se multiplient dans les documents et il n'est pas rare qu'un même individu soit désigné de trois ou quatre manières certes proches mais distinctes, de la même manière que la justice de Nouvelle-Espagne hésite au moment d'assigner une calidad à ses interlocuteurs. C'est ainsi que le cajero d'une compagnie américaine de la région de San Marcos de Apalaches, au nord de la Floride, est tour-à-tour désigné sous les noms de Beli Hambly, Vily Hambly ou Bely Amble lorsqu'il est convoqué pour assurer la traduction entre officiers espagnols et témoins américains ou irlandais ${ }^{29}$. Derrière ces approximations, on peut prudemment suggérer que le cajero répondait au nom de Willy (William) Hambly. Ce sont des approximations que l'on retrouve dans la documentation judiciaire en Nouvelle-Espagne : il n'est pas rare qu'un même individu se voie attribuer différentes calidades ou des noms à l'orthographe incertaine ${ }^{30}$. Toutefois, dans ce cas précis, il n'est pas interdit de penser que le caractère multilingue de cette région vient renforcer les approximations dans l'identification des personnes à une

25. Burbank, Jane et Cooper, Frederick, Empires. De la Chine ancienne à nos jours, Paris, Payot, 2011.

26. AGI, Papeles de Cuba, 163A, Criminal contra el sectario anabaptista nombrado Janah (Barton Hannon) acusado de revoltoso y sedicioso contra el gobierno.

27. Historical New Orleans Collection (HNOC), WPA\#3701, Investigations into the death of Jorge Stelly who was found hung by his neck from a tree.

28. Ibid.

29. AGI, Papeles de Cuba, 163A, Sumaria información contra el teniente de milicias Eduardo Macabé.

30. Croguennec, Soizic, Sociétés minières et monde métis. Le centre-nord de la Nouvelle Espagne au XVIII siècle, Madrid, Editions de la Casa de Velázquez, 2015. 
époque où ces processus dépendent encore largement de l'interconnaissance ${ }^{31}$. Les traductions approximatives de l'identité des individus confrontés à la justice louisianaise permettent d'imaginer la communication difficile entre des personnes déclinant leur identité et les greffiers transcrivant ce qu'ils peuvent entendre, ou croient entendre ${ }^{32}$.

\section{Le rôle central du traducteur}

Les traducteurs occupent dès lors une place centrale dans la documentation judiciaire, servant d'interface indispensable entre la population et les autorités. Les interprètes font partie intégrante de la narration écrite des différentes procédures observées en tant qu'agent médiateur qui relaie les questions et les réponses entre les enquêteurs et les déclarants comme le montre une expression comme " the interpreter said that having asked him the question [the declarant] answered that... ${ }^{33}$ " Dans un monde colonial louisianais marqué par le multilinguisme, traducteurs et interprètes sont les rouages d'un système judiciaire dans lequel les différentes parties en présence ne se comprennent guère : sans une traduction honnête et fidèle des questions comme des réponses, il n'y a pas de bonne justice possible. C'est pourquoi le serment du traducteur apparait toujours en bonne place dans la théâtralité de l'interrogatoire. Il est ainsi demandé à l'interprète " de traducir fiel y legalmente en castellano cuanto en idioma inglés... ${ }^{34}$ "De fait, le lien n'est jamais direct entre l'enquêteur et le déclarant qui dépendent l'un et l'autre du travail du traducteur qui joue le rôle de médiateur entre les deux parties comme le montrent des expressions récurrentes telles que : "preguntado en castellano y traducido al inglés 35 ". L'importance de la médiation de l'interprète pour le bon fonctionnement de la justice laisse deviner toutes les sources de dysfonctionnement inhérentes à ce type de pratiques et plus particulièrement les traductions déficientes.

Ces situations de multilinguisme se retrouvent aussi bien à la Nouvelle-Orléans où la justice espagnole est confrontée à une population majoritairement française à laquelle se mêle une communauté anglo-américaine de plus en plus importante à la fin du XVIII ${ }^{e}$ siècle, que dans les régions de confins où les soldats espagnols sont bien souvent confrontés au monde anglo-américain et indien. Le noir libre Noël Carrière, commandant de la milice des pardos de la Nouvelle-Orléans doit ainsi passer par un interprète pour déposer sa déclaration dans le cadre d'un procès ${ }^{36}$.

31. Groebner, Valentin, Who are you? Identification, Deception and Surveillance in Early Modern Europe, Boston, MIT Press, 2007.

32. Il est intéressant de noter que ces problèmes de compréhension sont à l'origine d'un nombre de procédures pour insultes, la mauvaise maîtrise de la langue de l'autre menant à des conflits plus ou moins violents.

33. AGI, Papeles de Cuba, 163A, Criminal contra el sectario anabaptista nombrado Janah (Barton Hannon) acusado de revoltoso y sedicioso contra el gobierno, f. 427v.

34. AGI, Papeles de Cuba, 163A, Sumaria información contra el teniente de milicias Eduardo Macabé, f. 893r. 35. Ibid.

36. AGI, Papeles de Cuba, 163A, Diligencias contra José Leblanc, f. 1130v. 
De la même manière, les Indiens dénommés Sofolotke ${ }^{37}$ ou Maslogue ${ }^{38}$ ne peuvent être entendus par la justice espagnole que par l'intermédiaire des interprètes locaux.

Enfin, dans un monde colonial dans lequel les documents de toutes sortes sont rédigés en espagnol, français ou anglais selon les populations concernées, les interprètes revêtent un rôle crucial pour s'assurer de l'authenticité des pièces présentées et leur adéquation aux dires du déclarant. C'est ainsi que l'officier Pedro (Pierre) Bailly convoque un interprète pour assurer James Smith Yarbrough de l'authenticité de la signature apposée au bas d'une reconnaissance de dette par un débiteur décédé39. Au-delà de la sphère judiciaire, les interprètes et traducteurs constituent donc un rouage essentiel de la société louisianaise. Médiateurs linguistiques et culturels, ils agissent comme autant d'acteurs intermédiaires assurant non seulement le lien entre administration espagnole et populations locales, mais aussi entre les différentes communautés en présence. Le document 2 ci-dessous montre ainsi les interprètes officiels opérant dans les différentes places administratives.

\begin{tabular}{|c|c|c|c|c|}
\hline & Nom & Lieu d'exercice & Fonction & Langues pratiquées \\
\hline \multirow{10}{*}{1785} & Juan Joseph Duforest & & Interprete inglés & $\begin{array}{l}\text { Espagnol } \\
\text { Français } \\
\text { Anglais }\end{array}$ \\
\hline & Pas de nom & Plaza de la Movila & Interprete inglés & \\
\hline & Josef Boisdoré & Plaza de Panzacola & Interprete de la nación Chacta & $\begin{array}{c}\text { Espagnol } \\
\text { Français } \\
\text { Langues indiennes }\end{array}$ \\
\hline & Juan Baptista Roussève & Plaza de Panzacola & $\begin{array}{l}\text { Interprete retirado de } \\
\text { la nación Chacta }\end{array}$ & $\begin{array}{c}\text { Espagnol } \\
\text { Français } \\
\text { Langues indiennes }\end{array}$ \\
\hline & Pedro Landrenau & Punta Cortada & Interprete & $\begin{array}{c}\text { Espagnol } \\
\text { Français } \\
\text { Langues indiennes }\end{array}$ \\
\hline & Juan Baptista Brevel & Natchitoches & Interprete & $\begin{array}{c}\text { Espagnol } \\
\text { Français } \\
\text { Langues indiennes }\end{array}$ \\
\hline & Francisco de St Germain & Natchez & Interprete & $\begin{array}{c}\text { Espagnol } \\
\text { Français } \\
\text { Langues indiennes }\end{array}$ \\
\hline & Juan Baptista Saucier & Arcanzas & Interprete & $\begin{array}{c}\text { Espagnol } \\
\text { Français } \\
\text { Langues indiennes }\end{array}$ \\
\hline & Antonio Garzón & Plaza de Panzacola & $\begin{array}{c}\text { Interprete de la } \\
\text { nación Talapuche }\end{array}$ & \\
\hline & Luis Forneret & Plaza de Panzacola & Interprete de los Chactas & $\begin{array}{c}\text { Espagnol } \\
\text { Français } \\
\text { Langues indiennes }\end{array}$ \\
\hline
\end{tabular}

37. AGI, Papeles de Cuba, 163A, Compulsa del proceso contra el soldado José María Aldana, f. 993v.

38. AGI, Papeles de Cuba, 163A, Criminal contra el soldado José Méndez, f. 947v.

39. HNOC, WPA\#3824, Don Pedro Belly instituted proceedings to obtain an English interpreter for Don James Smith Yarbrough to prove that the signature of a deceased debtor was genuine. 


\begin{tabular}{|c|c|c|c|c|}
\hline \multirow{1}{*}{$\mathbf{1 7 9 3}$} & Juan Joseph Duforest & Nueva Orleans & Interprete inglés & $\begin{array}{c}\text { Français } \\
\text { Espagnol } \\
\text { Anglais }\end{array}$ \\
\cline { 2 - 5 } & Santiago Lassausaye & Plaza de la Movila & Interprete inglés & \\
\cline { 2 - 5 } & Luis Forneret & Nueva Orleans & Interprete & \\
\cline { 2 - 5 } & Antonio Garzón & Plaza de Panzacola & Interprete & \\
\cline { 2 - 5 } & Simon Favre & Plaza de la Movila & Interprete & \\
\cline { 2 - 5 } & Juan Spinis & Natchez & Interprete & \\
\hline & Juan Bautista Saucier & Arkansas & Interprete & \\
\hline
\end{tabular}

Document 2 - Le corps des interprètes en $1785^{40}$

Un rapide examen de la liste montre tout d'abord la place occupée par les Français dans le corps des interprètes au service de la Couronne espagnole : à l'exception d'Antonio Garzón installé à Pensacola, d'un certain Juan Spinis de Natchez qu'il est difficile d'identifier clairement et d'un anonyme qualifié « d'interprète anglais », la profession est dominée par les sujets de "nation française ». Ceux-ci se sont en effet placés comme intermédiaires indispensables dès les premiers temps de la domination espagnole en raison notamment de la pratique des langues indiennes et des contacts noués depuis le début du XVIII ${ }^{\mathrm{e}}$ siècle avec les populations indiennes voisines. De fait, on observe deux types de profils. Tous les interprètes pratiquent l'espagnol et le français et agissent ainsi comme médiateurs entre l'administration ou la justice espagnoles d'une part, et la majorité francophone de la colonie. Au-delà de ce tronc commun, on trouve les interprètes pratiquant les langues indiennes : si pour certains comme Jean-Baptiste Saucier, nous n'avons pas davantage de précisions, d'autres interprètes sont spécialisés dans la pratique d'une langue indienne bien précise. C'est le cas par exemple de Louis Forneret basé à Pensacola, qualifié d'interprete de los Chactas $^{41}$. La deuxième catégorie concerne quant à elle les interprètes faisant le lien avec la communauté anglo-américaine croissante au fil des années, au gré de la reconquête des Florides ${ }^{42}$ ou des installations de marchands et entrepreneurs - les aventuriers étudiés par David Narrett - venus de la côte Est ${ }^{43}$. C'est ainsi qu'il n'est pas surprenant de trouver un tel interprète à la Nouvelle-Orléans, port de plus en plus investi par les marchands anglo-américains.

Toutefois, en raison de la faiblesse du maillage administratif et de l'immensité des territoires théoriquement rattachés à la Couronne espagnole, sans oublier la grande fluidité socio-économique et socioculturelle de ces régions évoquée par

40. AGI, Santo Domingo, 2605, Hojas de servicio de empleados de Real Hacienda.

41. Les Chactas ou Choctaws, installés au Nord-Est de la Nouvelle-Orléans, sont des alliés des Français de Louisiane depuis le début du XvirI ${ }^{\mathrm{e}}$ siècle.

42. Les Florides ont été reconquises à la suite de la guerre d'Indépendance des Etats-Unis et de la signature du Traité de Versailles en 1783.

43. Narrett, David, Adventurism and Empire..., op. cit., p. 141. 
Daniel Usner ${ }^{44}$, cette poignée d'interprètes est loin d'être suffisante pour répondre aux besoins quotidiens. Il est donc régulièrement nécessaire de mobiliser les compétences de la population civile locale - avec les risques de partialité et d'approximations que le recours à un traducteur non professionnel implique. C'est ainsi que, pour recueillir le témoignage de Santiago (Jake) Campbell qui ne parle pas un mot d'espagnol, il est fait appel aux compétences du cajero Beli Amble qui, par sa fonction de commis, "connaît bien la langue espagnole 45 ». Dans une région éloignée comme San Marcos de los Apalaches, faire appel à un interprète officiel signifie la paralysie de la procédure judiciaire pour de nombreuses semaines, voire mois. Dans ce contexte, il est nécessaire de mobiliser les compétences locales lorsque le besoin se fait ressentir. Juan Sandoval, originaire de Nouvelle-Espagne, est ainsi nommé interprète en raison de sa pratique de la langue Mvscoke ou Muskogee/Creek:

compareció el intérprete de la nación Mvscoke que posee nuestro idioma Juan Sandoval natural de San Miguel el Grande en el reino de Nueva España que dijo sabia bien el español y la lengua Mvscoke y en virtud de esto lo nombró dicho señor por interprete... por no saber escribir el expresado interprete hizo una señal de cruz ${ }^{46} .$.

Nous n'avons guère de renseignements sur Juan Sandoval hormis son origine géographique - San Miguel el Grande dans la région de Oaxaca. Quoi qu'il en soit, il est surtout intéressant de noter que sa pratique de l'espagnol comme de la langue des Creeks n'est qu'orale car Juan Sandoval est probablement analphabète : incapable de signer son nom, il a recours au signe de la croix pour appuyer son serment. Nous voyons donc à travers le cas de cet interprète "improvisé " les difficultés du fonctionnement de la justice dans cette région de frontière. Les compétences locales et fort variables sont mobilisées pour faire face à la pénurie chronique de moyens humains qui caractérise l'administration espagnole en Louisiane et en Floride. Audelà du cas des interprètes, c'est une situation qui frappe l'ensemble du système militaro-judiciaire mis en place dans les régions de confins.

\section{Rendre la justice dans un carrefour impérial}

La Louisiane espagnole se caractérise par un maillage administratif et judiciaire faible, particulièrement vulnérable face à la répétition de faits divers souvent violents. De fait, les angles morts et les zones d'ombre sont légion, et les populations savent en tirer profit en termes de trafics et de défections. Comme Solange Alberro l'a montré pour le Nord de la Nouvelle-Espagne, les régions de frontière font figure de véritables "refuges ${ }^{47}$. Face à ces tendances, la plasticité que l'on peut observer

44. Usner, Daniel, Indians, Settlers, and Slaves..., op. cit., p. 8.

45. AGI, Papeles de Cuba, 163A, Sumaria información contra el teniente de milicias Eduardo Macabé, f. 889r.

46. AGI, Papeles de Cuba, 163A, Compulsa del proceso contra el soldado José María Aldana, f. 975r.

47. Alberro, Solange, "Zacatecas, zona frontera, según los documentos inquisitoriales, siglos XVI y XVII ", Estudios de Historia Novohispana, vol. VIII, 1985, p. 139-174. Plus récemment sur les dynamiques sociétés de 
s'appuie sur une longue tradition d'adaptation des justices d'Ancien Régime ${ }^{48}$. Mais elles ne se réduisent pas aux zones les plus éloignées et peuvent se retrouver jusqu'au cœur de la colonie, à la Nouvelle-Orléans.

\section{Les capacités d'adaptation d'une justice militaire de frontière}

Le document 3 ci-dessous montre ainsi la grande irrégularité du peuplement sur les territoires tenus par la Couronne espagnole, la Louisiane et les deux Florides. D’après le recensement de 1777 mené par le gouverneur Bernardo de Gálvez, le district de la Nouvelle-Orléans regroupe pratiquement la moitié de la population de la Louisiane.

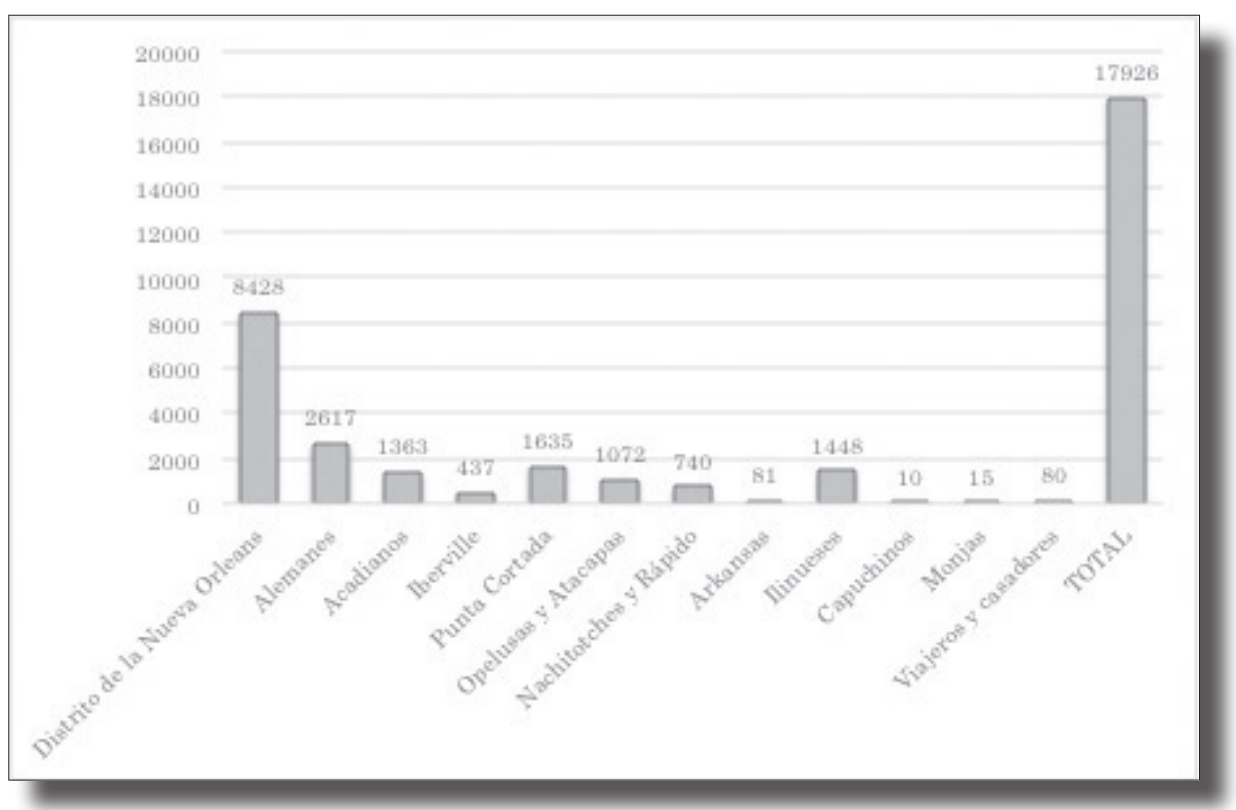

Document 3 - La population de la Louisiane en 1777 , un peuplement très inégal ${ }^{49}$

Le reste de la population se répartit sur un territoire couvrant le bassin du Mississippi et les côtes du golfe du Mexique jusqu'en Floride.

Dans les faits, si l'on sort du district de la Nouvelle-Orléans, la réalité du maillage administratif est assurée par un encadrement militaire appuyé sur un réseau de forts et de presidios. Dans ce contexte de société de frontières, essentiellement mascu-

confins, voir Planas, Natividad et Bertrand, Michel, Les sociétés de frontière, de la Méditerranée à l'Atlantique (XVI $-X V I I I^{e}$ siècle), Madrid, Editions de la Casa de Velázquez, 2011.

48. Cutter, Charles B., "Community and the Law in Northern New Spain" in The Americas, vol. 50, $\mathrm{n}^{\circ} 4$, apr., 1994, p. 467-480. ; Lorente Sariñena, Marta (coord.), De justicia de jueces a justicia de leyes: hacia la España de 1870, Madrid, Consejo General del Poder Judicial, 2007.

49. AGI, Papeles de Cuba, 2351, 1777, mayo 12, Padrón general de todos los individuos de la provincia de Luisiana. 
line, constituée pour bonne partie de soldats, presidarios $^{50}$ et autres marchands ou aventuriers, les occasions de conflits et de transgressions sont nombreuses comme le montrent la centaine de dossiers regroupés dans la section Papeles de Cuba à Séville. Parmi ces nombreux dossiers, on peut citer le cas du guarda almacén du fort de San Esteban Tombecbé qui joue sur les poids et les mesures pour détourner une partie des rations dues aux soldats et réaliser un profit personnel ${ }^{51}$. Ce type de délinquance n'est pas propre à la Louisiane, loin de là, mais la fonction de carrefour de la région ainsi que les changements de loyauté de la deuxième moitié du XVIII ${ }^{\mathrm{e}}$ siècle fournissent aux individus des opportunités et des outils - ici les poids et mesures ${ }^{52}$ - pour lancer des opérations en marge de la loi. Les procès concernant la violence quotidienne du monde des presidarios occupent enfin une place importante de la documentation judiciaire étudiée jusque-là pour ces régions. Pour traiter ces affaires, les ressources de la justice militaire sont particulièrement limitées. Au-delà des interprètes qui sont recrutés parmi la population locale, il est régulièrement fait appel aux quelques soldats lettrés pour jouer le rôle "d'escribano ". Dans le procès mené contre le soldat Miguel Serrano, c'est tout d'abord Agustín Blanco qui fait office d'escribano (scribe / greffier). Mais l'enquête montre que Blanco est lui-même témoin des actions de Miguel Serrano. Pour respecter l'impartialité de la procédure, il est donc remplacé par le soldat Aniceto Zabaleta qui est choisi " pour exercer la fonction d'escribano $o^{53}$ ». Dans un contexte d'alphabétisation encore limitée, les individus capables d'écrire constituent des ressources précieuses pour une administration civile comme militaire aux moyens limités. La pénurie de compétences est telle que l'enquête sur le meurtre de Francisco Navas n'est pas menée par le fiscal local mais le guarda almacén Francisco Javier Navarro faisant office de fiscal (procureur) ${ }^{54}$. Ces différents bricolages sont caractérisés par le risque accru d'erreurs et d'approximations. Il est en effet difficile d'attendre le même degré de rigueur et de précision chez un soldat faisant fonction de greffier que chez un véritable escribano de profession. Lorsque le soldat José María Aldana décline son identité et détaille son parcours depuis la Nouvelle Espagne, les dates inscrites sont pour certaines erronées - une version indique ainsi qu'il s'est engagé en 1890 (pour 1790) et Puebla de los Ángeles devient Puebla de los Angles, ce qui peut être surprenant car le soldat prenant les notes est lui-même espagnol ${ }^{55}$.

50. Le recours à la condemna a presidio pour différents crimes était un moyen de renforcer les garnisons dans les régions de confins. Agustín Bohorquez, accusé du meurtre de son ami Felix Ramírez au cours d'une rixe, est ainsi condamné à dix ans de service dans un presidio aux Philippines (AHEZ, Poder judicial, Criminal, Caja 02, Exp. 63).

51. AGI, Papeles de Cuba, 163A, Sumaria contra el sargento Bartolomé López.

52. Il y a en effet, 6,5 grammes de différence entre la livre espagnole ( $460 \mathrm{~g})$ et la livre anglaise ( $453,5 \mathrm{~g})$. En utilisant des poids anglais, Bartolomé López récupère une partie des rations pour ensuite les revendre à des intermédiaires indiens de la région.

53. AGI, Papeles de Cuba, 163A, Criminal contra el soldado Miguel Serrano, f. 850v.

54. AGI, Papeles de Cuba, 163A, Criminal contra Miguel Montenegro presidario de los de la dotación de esta plaza acusado de haber dado muerte al de la propia clase Francisco Navas la tarde del 27 de abril del presente año.

55. AGI, Papeles de Cuba, 163A, Compulsa del proceso contra el soldado José María Aldana, f. 966. 


\section{Honneur et provocation au temps de Carnaval : Joseph Leblanc vs Arthur Morgan}

Bien des caractéristiques évoquées dans les pages précédentes se retrouvent dans le long procès qui oppose le regidor Joseph Leblanc et le marchand américain Arthur Morgan ${ }^{56}$. De fait, ce conflit banal en apparence, au cours duquel les deux hommes s'accusent mutuellement d'agression et d'atteinte à l'honneur, permet d'apprécier la complexité des enjeux de justice dans la Nouvelle-Orléans du début du XIX ${ }^{\mathrm{e}}$ siècle.

À première vue, le conflit possède toutes les caractéristiques d'une affaire criminelle typique de la vie quotidienne d'Ancien Régime, opposant deux hommes à l'honneur chatouilleux et issus du même cercle des élites politiques et économiques locales. Joseph Leblanc a en effet effectué une carrière militaire avant d'être nommé regidor en 1799. Arthur Morgan est quant à lui un marchand anglais installé à Londres mais déployant ses réseaux entre l'Angleterre, les États-Unis et la Louisiane espagnole. D'après Leblanc, le duel qui oppose les deux hommes lors des festivités de Carnaval trouve son origine dans un problème de communication entre un Français et un Anglais qui ne se comprennent pas. Il affirme ainsi que : "dijo entonces Forstall que Morgan habia creído hubiese dicho yo que lo despreciaba como las suelas de mis zapatos, que ese venía de que no entendia bien el idioma francés. Yo le contesté que por estos casos debia dedicarse a estudiarlo57."

Si l'on en croit cette déclaration, la raison du duel est étroitement liée au contexte multilingue de la Louisiane, contexte qui favorise les incompréhensions et donc les conflits, dans une société fortement marquée par la culture de l'honneur et du duel ${ }^{58}$. Toutefois, le volume documentaire occupé par l'affaire - des centaines de folios - montre qu'il ne s'agit pas d'une affaire ordinaire. Au-delà de la recherche des responsabilités respectives, c'est l'argumentation de Joseph Leblanc qui doit retenir l'attention de l'historien. À travers son discours, on retrouve en effet une véritable instrumentalisation de la justice au service d'enjeux d'identification et d'appartenance dans un contexte de pression anglo-américaine croissante sur le plan démographique comme économique. Au fil de la procédure, on découvre en effet que des rivalités commerciales et des questions de dette sous-tendent ce qui semble être à première vue un conflit d'honneur ${ }^{59}$. Pour mieux comprendre cela, il est important de revenir sur le parcours d'Arthur Morgan entre possessions

56. AGI, Papeles de Cuba, 163A, Testimonio de las ultimas diligencias en el lance ocurrido entre el Capitán del Regimiento de Luisiana D. José LeBlanc y D. Arturo Morgan. HNOC, WPA\#3958, Criminal proceedings instituted against Captain Don Jose Leblanc. Defendant allegedly injured Don Arturo Morgan.

57. AGI, Papeles de Cuba, 163A, Testimonio de las ultimas diligencias en el lance ocurrido entre el Capitán del Regimiento de Luisiana D. José LeBlanc y D. Arturo Morgan, f. 550r.

58. Banks, Stephen, Duels and Duelling, Oxford, Shire, 2012 ; Guillet, François, François Guillet, La mort en face : histoire du duel de la révolution à nos jours, Paris, Aubier, 2008 ; Undurraga Schüler, Verónica, Los rostros del honor. Normas culturales y estrategias de promoción social en Chile colonial, siglo XVIII, Santiago, Centro de Investigaciones Diego Barros Arana, Dibam, Editorial Universitaria, 2012.

59. AGI, Papeles de Cuba, 163A, Testimonio de las ultimas diligencias en el lance ocurrido entre el Capitán del Regimiento de Luisiana D. José LeBlanc y D. Arturo Morgan, f. 665-666. 
britanniques et espagnoles. D'après sa déclaration, le marchand anglais est né en Louisiane et sa famille s'est installée à Pensacola pendant trois ans, lorsque la Floride occidentale était sous domination britannique. Son père, Patrick Morgan, s'est brièvement installé à la Nouvelle-Orléans et a fondé la compagnie Mathew and Morgan sur la Côte des Allemands. La famille Morgan repart finalement en Grande-Bretagne en $1780^{60}$.

Au moment de l'affaire, Arthur Morgan affirme être de passage à la NouvelleOrléans pour ensuite voyager aux États-Unis et régler les affaires de son père ${ }^{61}$. Sa projection commerciale transatlantique et transaméricaine entre Londres, les ÉtatsUnis et la Nouvelle-Orléans transcende les frontières et les empires, et il semble qu'il joue sur plusieurs tableaux sur le plan identitaire afin de servir ses intérêts économiques ${ }^{62}$. C'est ainsi qu'il se déclare "vecino y del comercio de esta ciudad ${ }^{63}$ " en vertu de sa naissance à la Nouvelle Orléans qui marque selon lui son appartenance à la communauté. La revendication de ce statut lui permet, entre autres, de bénéficier d'une certaine protection de la part des autorités et de la justice, et de se poser comme l'égal de ses interlocuteurs locaux en s'affirmant vassal du roi d'Espagne ${ }^{64}$. De fait, il agit comme bon nombre d'habitants de la région

both able and willing to modify their identities and loyalties. Nationality was only one of the components of a personal sense of identity, and individuals might consider changing it voluntarily for many different reasons, usually connected with expectations of personal gain or self-interest of some sort ${ }^{65}$.

Dans le même temps, il met aussi en avant sa position d'intermédiaire dont la liberté de circuler entre les empires ne doit pas être entravée. Il déclare ainsi que

es mal si se me detiene aqui pues no solamente se me priva de la libertad que tiene todo individuo para viajar y hacer sus negociaciones sino que igualmente se causarán por esto graves perjuicios ${ }^{66}$.

Arrêté à la suite de la plainte de Leblanc, il dépose une plainte et demande une sortie de prison sous caution pour pouvoir mener ses affaires à bien, ce que Leblanc refuse vertement. Pour le Français ayant réalisé sa carrière au service de la Couronne d'Espagne, les enjeux immédiatement liés au duel sont finalement très secondaires.

60. Ibid., f. 740-741.

61. Ibid., f. 636v-637r.

62. À ce sujet, voir par exemple les travaux de Manuel Covo, «Baltimore and the French Atlantic: Empires, Commerce, and Identity in a Revolutionary Age ", in Adrian Leonard et David Pretel (éd.), The Caribbean and the Atlantic World Economy: Circuits of Trade, Money and Knowledge, 1650-1914, Basingstoke, Palgrave Macmillan, 2015, p. 87-107.

63. Ibid., f. 636r.

64. Sur le statut de vecino, voir Herzog, Tamar, Defining nations. Immigrants and Citizens in Early Modern Spain and Spanish America, Yale, Yale University, 2003.

65. Allen Smith, Gene et Hilton, Sylvia L., Nexus of Empire..., op. cit., p. 5-6.

66. Ibid., f. 648r. 


\section{La stratégie de Joseph Leblanc : la négation des droits de son adversaire}

En premier lieu, la rhétorique déployée par Joseph Leblanc est frappante pour diverses raisons. Tout d'abord, il lance la procédure judiciaire seul, sans l'assistance d'un avocat. On ne peut que s'interroger vivement au sujet de cette stratégie. En raison de son appartenance aux élites locales, il est évident que le regidor a les moyens d'avoir recours aux services d'un avocat, plus à même de représenter ses intérêts. Il appartient également à une sphère sociale acculturée de longue date sur le plan juridique ${ }^{67}$. L'absence d'intermédiaire peut donc surprendre. De fait, si l'on suit son argumentation, il semblerait que les défaillances du maillage administratif et juridique ne soient pas seulement un phénomène associé au monde des confins et touche également un centre de pouvoir comme la Nouvelle-Orléans. Leblanc écrit en effet :

no obstante que la notoria falta de abogados aqui me ha privado de otra guía que la de mis tales cuales naturales luces para el seguimiento de esta causa [...] crei a que la equidad del tribunal supliría los defectos de mi impericia mediante la imposibilidad de dirigirme por letrado donde no lo hay ${ }^{68}$.

L'absence de représentation est donc ici un choix contraint si l'on en croit sa déclaration. Il est vrai que le procès entre Joseph Leblanc et Arthur Morgan se déroule dans un contexte quelque peu confus sur le plan administratif. Le Traité de San Ildefonso de 1800 consacre le retour de la Louisiane à la France. Toutefois, l'administration espagnole reste en place avec le gouverneur Manuel Salcedo jusqu'en 1803. La passation de pouvoir effective a lieu en 1803, quelques semaines avant la concrétisation de la vente de la Louisiane aux États-Unis ${ }^{69}$. À ce sujet, es improvisations évoquées dans la partie précédente ne seraient pas seulement un phénomène lié à la situation de zones de confins mais aussi un symptôme de la fragilité administrative lors de cette période de transition.

Dépourvu du conseil d'un avocat, Joseph Leblanc s'est donc lancé dans une procédure acharnée et peu maîtrisée au cours de laquelle sa stratégie se résume à nier littéralement le droit d'Arthur Morgan de se réclamer du statut de "vecino" de la Nouvelle-Orléans. Le marchand anglais est, aux yeux de Leblanc, un étranger qui ne peut pas développer ses affaires en Louisiane et encore moins jouir de la protection de la justice espagnole car il s'agit d'un « enemigo del estado que se dice vecino y el comercio de esta ciudad contra las reglas establecidas por su Majestad [...] sólo ha venido de los dominios británicos de donde es vasallo ${ }^{70}$... " Leblanc va jusqu'a confondre ses intérêts personnels et ceux de la Couronne en affirmant que Mor-

67. Sur le concept d'acculturation juridique, voir Garnot, Benoît, Histoire de la justice. France, XVIe-XXe siècle, Paris, Gallimard, 2009, p. 171, Collection Folio Histoire.

68. AGI, CUBA, 163A, Testimonio de las ultimas diligencias en el lance ocurrido entre el Capitán del Regimiento de Luisiana D. José LeBlanc, D. Arturo Morgan, f. 849.

69. Havard, Gilles et Vidal, Cécile, Histoire de l’Amérique française..., op. cit., p. 701-717.

70. Ibid., f. $651 \mathrm{r}$. 
gan «se ha abrogado el privilegio de comercio como español siendo manifiesto enemigo de nuestra nación, con las mismas facultades que se ha tomado para ajar, provocar e insultar a uno de sus individuos de honor, cual lo [es Leblanc] ${ }^{71}$ ".

Derrière cette argumentation souvent brouillonne ${ }^{72}$, ce sont les enjeux d'une justice au carrefour des empires qui attirent l'attention. La projection transatlantique et transaméricaine d'Arthur Morgan en fait un individu particulièrement mobile, capable de jouer avec les systèmes au gré de ses voyages. Pour Leblanc qui attend une réparation pour l'atteinte portée à son honneur et les frais de justice engagés, tout l'enjeu est de s'opposer au départ de Morgan tandis que le marchand anglais affirme que "que es mal si se [le] detiene aqui pues [...] se [le] priva de la libertad que tiene todo individuo para viajar y hacer sus negociaciones ${ }^{73}$ ".

\section{Conclusion}

Région de confins, angle mort délaissé de l'Empire espagnol de la deuxième moitié du XVIII ${ }^{\mathrm{e}}$ siècle, la Louisiane espagnole apparaît néanmoins comme une expérience coloniale singulière. Confrontée à une gestion permanente $\mathrm{du}$ "manque » et de la "distance ", l'administration espagnole a dû s'adapter à une situation complexe à bien des égards. Un travail initial à partir des archives inquisitoriales et de la justice militaire permettent de mettre en valeur la mosaïque sociale en montrant comment la pluralité des populations ainsi que la distance depuis les centres de pouvoir affectent le fonctionnement judiciaire de la colonie. Les traducteurs occupent une place centrale dans ce système - qu'il s'agisse de traducteurs officiels ou de marchands pratiquant les langues indiennes. De même, les procédures criminelles connaissent parfois un cheminement tortueux depuis l'enquête initiale menée dans la langue la plus communément parlée localement jusqu'à son traitement à la NouvelleOrléans, et la nécessaire traduction. La justice en Louisiane est donc une justice longue et coûteuse, en raison des étapes obligatoires pour le traitement des plaintes et des procédures. L'adaptation sous ses diverses formes devient alors indispensable pour assurer le fonctionnement d'une institution fragile. Toutefois, l'adaptation peut parfois céder le pas à une véritable improvisation comme on peut le voir avec Joseph Leblanc. Les risques d'approximation voire d'erreur - involontaires ou volontaires - sont réels, ce qui peut encourager les tentatives d'instrumentalisation de la justice espagnole au service d'intérêts personnels, français ou anglo-américains.

\footnotetext{
71. Ibid., f. $795 \mathrm{v}$.
}

72. À ce titre, les arguments invoqués par Joseph Leblanc ne sont pas sans rappeler les arguments utilisés par les créoles dans leurs conflits avec des castas ou des Indiens dans la région de Zacatecas au XviII ${ }^{\mathrm{e}}$ siècle. Voir Croguennec, Soizic, Sociétés minières et monde métis. Le centre-nord de la Nouvelle Espagne au XVIII siècle, Madrid, Editions de la Casa de Velázquez, 2015.

73. AGI, CUBA, 163A, Testimonio de las ultimas diligencias en el lance ocurrido entre el Capitán del Regimiento de Luisiana D. José LeBlanc, D. Arturo Morgan, f. 648r. 


\section{RÉSUMÉ/Mots-CLÉS}

La Louisiane espagnole (1763-1803), territoire élargi aux Florides occidentale et orientale après 1783 , représente une véritable mosaïque culturelle à la croisée des empires. L'examen des pratiques de la justice quotidienne permet de mettre en valeur cette mosaïque en montrant comment la multiculturalité, le multilinguisme ainsi que la distance depuis les centres de pouvoir affectent le fonctionnement judiciaire de la colonie.

Louisiane espagnole, Frontière, Sociétés multiculturelles, Justice, XVIII ${ }^{\mathrm{e}}$ siècle

\section{Resumen/Palabras Claves}

La luisiana Española (1763-1803) territorio que incluye las Floridas occidental y oriental después de 1783, representa un verdadero mosáico cultural en el cruce de los imperios. El estudio de las prácticas judiciales cotidianos permitesubrayar esta variedad mostrando cómo el multiculturalismo, el multilingüismo así como la distancia a partir de los centros afectan el funcionamiento judicial de la colonia.

Luisiana española, Frontera, Sociedades multiculturales, Justicia, Siglo XVIII

\section{ABSTRACT/KeYWORDS}

Spanish Louisiana (1763-1803), including both eastern and western Floridas after 1783 , is an exemplary cultural mosaic at the crossroads of empires. Examining daily justice is a way to shed light on this social mosaic while demonstrating how multiculturalism, multilinguism as well as the distance from the main centers of power have an impact on the working of the judicial system in this region.

Spanish Louisiana, Frontier, Multicultural societies, Justice, $18^{\text {th }}$ Century 


\title{
"... qu'il prenne également soin de sa conduite ». Les fidéjusseurs dans la justice locale, Tlaxcala, 1822-18241
}

\author{
Mirian GaLANTE \\ Universidad Autónoma de Madrid
}

DANS LA PROCÉDURE entAMÉE Au début du mois de juillet 1822 contre cinq Espagnols de San Lorenzo de Quapiaxtla (parti de Tlaxcala, Mexique) pour contrebande de mules et de tabac, le conseiller José Mariano de Urrutia recommandait au maire que « les prisonniers, pour avoir octroyé une caution avec des personnes connues, soient remis en liberté en leur faisant la morale et qu'on intimide le garant (fiador) pour qu'il prenne soin et veille sur leur conduite, qu'ils corrigent leurs habitudes et qu'ils travaillent pour assurer leur subsistance, car sinon, à la moindre plainte, cette cause serait relancée et ils seraient jugés avec toute la rigueur du droit $»^{2}$. Mais, en quoi consiste la figure du fidéjusseur ? quel rôle jouait-il dans les procès judiciaires?

Depuis quelques années, l'étude historique des agents impliqués dans les processus d'administration de la justice suscite un intérêt croissant. Quelques publications récentes ont spécialement souligné leur rôle d'intermédiaire dans un contexte interprétatif qui essaye de reconstruire les interactions continues entre les institutions et les autorités étatiques, les agences régionales, les élites locales et les citoyens des républiques latino-américaines. La littérature existante sur le sujet, en insistant sur leur capacité de négociation et leur aptitude pour se mouvoir dans un univers d'intérêts complexes et quelques fois contradictoires, a mis en exergue leur façon d'agir comme propagateurs des nouvelles valeurs juridiques et politiques et leur rôle dans « les processus d'appropriation et d'actualisation des notions de justice, de droits et de légalité dans les classes inférieures $»^{3}$. Des analyses sur les interprètes, les notaires ou les avocaillons sont ainsi apparues et reconstruisent, dans des

1. Recherche développée au sein des projets HAR2013-41596-P et HAR2014-5328-C2-2-P.

2. Archivo Histórico del Estado de Tlaxcala (AHET), Justicia Criminal, 1822 caja 1, exp. 1, 9 fs., 7v.

3. Salvatore, Ricardo D., Aguirre, Carlos et Joseph, Gilbert (ed.), Crime and Punishment in Latin America Law and Society Since Late Colonial Times, Durham, N. C, Duke University Press, 2001, 480 p. La citation, p. 20. 
chronologies et des régions latino-américaines différentes ${ }^{4}$, une vision de la justice comme un espace de négociation dans lequel se résolvent des questions en relation avec la discipline, l'ordre public ou la définition des valeurs sociales souhaitables, et aussi les manières dont les différents acteurs se présentent, sont classés et interagissent entre eux 5 . Souvent, les recherches menées dans des contextes régionaux très délimités se sont avérées très utiles pour reconstruire les réseaux institutionnels et sociaux de ces acteurs, les dynamiques entre la formalité normative (la loi) et sa mise en pratique, la circulation institutionnelle des dossiers, la reconstruction des cartes juridictionnelles ainsi que l'interaction entre le monde rural et le monde urbain et entre la justice profane y la justice lettrée.

Néanmoins, nous avons encore beaucoup à apprendre de certains agents qui ont eu un rôle clé dans le développement des procès judiciaires au quotidien. Ici, ils sont considérés comme " acteurs dans la justice » afin de souligner qu'il s'agissait de protagonistes rattachés à des figures juridiquement caractérisées, dont la participation aux causes ne dépendait ni de leur habilitation formative ou professionnelle comme juristes ni de l'exercice d'une fonction engageant des attributions juridictionnelles. Bien qu'ils ne soient pas experts du monde du droit, leur présence dans les jugements pouvait conditionner l'évolution de ceux-ci puisqu'ils suscitaient aux institutions et aux autorités judiciaires la confiance que leur personne garantissait, plus concrètement, le respect des principes et des procédés propres à la culture juridictionnaliste de l'époque. Cette conviction quant à leur valeur comme garants était due au fait qu'il leur était assigné une série d'attributs qui les rendaient dignes du crédit social dans la mesure où on considérait, par exemple, qu'ils représentaient une vie ordonnée, qu'ils étaient honnêtes, intègres, justes, observateurs des obligations sociales et spirituelles, experts dans certains domaines ou, simplement, parce qu'ils disposaient d'un capital (économique ou social) suffisant pour être responsable jusqu'aux dernières conséquences (monétaires ou non) des engagements souscrits (par eux ou par ceux auxquels ils étaient liés). Ils agissaient comme des intermédiaires qui accéléraient les processus d'administration de la justice, spécialement à

4. Guerrero, Andrés, La semántica de la dominación: el concertaje de indios, Ediciones Libri Mundi, E. GrosseLuemern, 1991, 336 p. et Administración de poblaciones, ventriloquía y transescritura: análisis históricos: estudios teóricos, Lima, IEP-FLACSO Ecuador, 2010, 546 p.; Gayol, Víctor, Laberintos de justicia. Procuradores, escribanos y oficiales de la Real Audiencia de México (1750-1812), 2 v., México, El Colegio de México, 2007 ; Aguirre, Carlos, "Tinterillos, Indians, and the State: Towards a History of Legal Intermediaries in Post-Independence Peru ", in Kirmse, Stefan B (éd.), One Law for All? Western models and Local Practices in (Post-) Imperial Contexts, Frankfurt, Campus Verlag, 2012, 300 p. ; Cunnill, Caroline, "Un mosaico de lenguas: los intérpretes de la Audiencia de México en el siglo xvi ", Historia Mexicana, v. 68, no 1 (269), juillet-septembre 2018, p. 7-44.

5. Sanchez, Evelyne, "Estrategias campesinas en el México revolucionario. El municipio y la construcción del empoderamiento de los pueblos de Nativitas (Tlaxcala, 1856-1921) ", Revista Complutense de Historia de América, v. 382, 2013, p. 229-253 ; Galante, Mirian, "Justicia liberal y "calidad”: indios en procesos judiciales en la región de Tlaxcala (México), 1822-1825 ", Nuevo Mundo Mundos Nuevos [http://journals.openedition. org/nuevomundo/72080, DOI : 10.4000/nuevomundo.72094 (consulté le 10/10/2018)]. 
l'échelon local, que ce soit en condition d'experts, de témoins, d'hommes de bien ou de garants (fiadores), entre autres ${ }^{6}$.

Dans ce dernier cas de figure, les fiadores ont eu une importance dans la définition de l'application des sentences du juge même s'ils n'intervenaient pas directement dans les procès, en conditionnant, parfois, ou en nuançant le type de peine ou la manière dont elle devait être accomplie. À l'origine, le fidéjusseur était la figure de garantie dans les accords et les contrats civils entre particuliers, pensée pour assurer le respect des obligations auprès de tiers dans le cas où son confié manquait à son engagement, mais sa responsabilité s'étendait également à l'infraction commise, auquel cas on considérait que le coupable avait une dette non seulement avec la victime mais aussi avec la société en général. Dans la pratique quotidienne, on avait recours à cette figure pour combler ou pallier les lacunes d'un système de justice propre à l'Ancien Régime, pour faciliter l'application de peines qui devaient s'ajuster à la logique casuistique encore existante à l'époque, ou pour proportionner des alternatives aux difficultés rencontrées par l'État pour que les peines soient effectives, une situation très répandue dans le contexte traité. Il s'agissait d'une figure dont la valeur était reconnue par une longue tradition juridique, dont la signification a été revalidée par les nouvelles institutions républicaines et dont la récurrente mise en œuvre reflétait son importance particulière dans les processus de résolution de conflits.

Sans ignorer l'intérêt de l'étude sur le lien personnel entre les personnes qui se portaient caution et les condamnés ou sur la place des premiers dans la construction de réseaux locaux, régionaux ou nationaux dans lesquels ils s'inscrivaient, l'intérêt de ce travail s'oriente plutôt vers une meilleure compréhension du rôle qu'ils ont joué dans l'application de la justice locale. Pour cela, les questions qui nous intéressent sont : qui les désignait et quelles responsabilités pesaient-elles sur eux ? Comment ont-ils contribué, s'ils l'ont fait, à la consolidation de l'autorité étatique comme instance d'administration de justice ? Des questions qui se réfèrent plus à la nature institutionnelle du fidéjusseur qu'à son ancrage social. À partir de cet objectif, nous explorerons, en premier lieu, la littérature juridique en vigueur relative à cette figure et observerons, en deuxième lieu, son mode de fonctionnement dans les procès judiciaires, autant dans les causes civiles que dans les causes criminelles, dans une région déterminée (Tlaxcala) à une époque de profondes transformations au niveau national, transformations qui affecteraient aussi la compréhension de la justice dans la structure des pouvoirs et son application habituelle. Un processus de changement lent au sein duquel des prêts de catégories étaient réalisés, des habitudes et des pratiques propres à une culture juridctionnaliste basée sur la reconnaissance des particularités de l'arbitre judiciaire, au moment même où on procédait à l'incorporation progressive des nouveaux principes libéraux comme l'empire de la loi, l'égalité juridique ou le fondement juridique des sentences, entre autres.

6. Sala i Vila, Nuria, "Justicia conciliatoria durante el liberalismo hispano en el Perú: el caso de Huamanga ", Anuario de Estudios Americanos, v. 69, n² 2, juillet-décembre 2012, p. 423-450. 


\section{Entre l'obligation personnelle et la confiance publique}

Bien que d'origine romano-wisigothe ${ }^{7}$, dans le contexte castillan la figure juridique du garant a été principalement formalisée dans les Partidas. La Nueva et la Novisima Recopilación n'auraient pas modifié la régulation du garant à l'égard du débiteur civil dans son essence puisque de manière générale "la législation dérivée de la réception médiévale du Ius commune » s'est maintenue jusqu'aux codifications du XIX ${ }^{\mathrm{e}}$ siècle ${ }^{8}$. De cette manière, même si elle a subi certaines adaptations quant aux particularités spécifiques du droit civil castillan et du droit royal espagnol à la fin du XVIII ${ }^{e}$ siècle dans des textes de large diffusion aussi en Amérique ${ }^{9}$, la continuité et la validité des Siete Partidas ont été amplement reconnues au Mexique tant par les juristes mexicains des $\mathrm{XIX}^{\mathrm{e}}$ et $\mathrm{XX}^{\mathrm{e}}$ siècles que par les historiens des institutions juridiques mexicaines ${ }^{10}$.

L'information relative aux fidéjusseurs est recueillie dans le titre 12 de la Quinta Partida. Concrètement, la Loi I définissait le garant comme «l'homme qui témoigne et promet à un autre de donner ou de faire quelque chose sur mandat ou à pétition de celui qui l'introduisait dans la fidéjussion " ${ }^{11}$. Cette figure se fondait sur la confiance que l'individu auquel le fidéjusseur était lié allait répondre à ses obligations, puisqu'en définitive tous deux (garant et débiteur) étaient obligés de respecter l'engagement pris, qu'il soit naturel et civil ou simplement naturel ${ }^{12}$. Tout homme pouvait être fidéjusseur, à condition qu'il ne soit pas dans l'incapacité de faire une promesse, comme c'était le cas des fous ou des oublieux, des enfants de moins de sept ans, des pupilles d'entre 7 et 14 ans (sauf dans le cas où ils tireraient profit de la promesse), des personnes d'entre 14 et 25 ans qui requéraient un tuteur (qui pourraient seulement s'engager dans la mesure où le pupille pouvait le faire, raison pour laquelle ils auraient en plus besoin de l'autorisation du tuteur) ${ }^{13}$. La loi 2 de la Partida signale d'une manière spécifique les hommes qui, n'étant pas dans l'incapacité de faire une promesse, ne pouvaient pas être garants en raison

7. Petit, Carlos, Fiadores y fianzas en Derecho romanovisigodo, Sevilla, Universidad de Sevilla, 1983, 209 p.

8. Daza Martínez, Jesús et Saiz López, Victoriano, « Beneficium ordinis, excussiones et divissionis. Elaboración doctrinal y configuración institucional de diversos modos de garantía personal en la tradición romanista: accesorio, solidario o subsidiario y recíproco-mancomunado ", Anales de la Universidad de Alicante, n 8, 1993, p. 75-116.

9. De Asso, Jordan I. et De Manuel, M., Instituciones del derecho civil de castilla, Madrid, 1792, livre 2, titre 18, "De las fianzas », p. 231 et ss., et J. Sala, J., Ilustración del derecho real de España, Valencia, 1803, t. 1, livre 2, titre 17, "De las fiaduras ", p. 370 et ss. Cifr. in Daza y Saiz, "Beneficium ordinis ", p. 115.

10. Une recherche résumée mais explicative sur le sujet, John T. Vance, « Old Spanish code of las Siete Partidas in Mexico ", American Bar Association Journal, v. 14, n 4, avril 1928, p. 219-224.

11. Quinta Partida, titre 12, loi 1: "Qué quiere decir fiador, et á qué tiene pro, et quién lo puede ser et por quién ", Las siete partidas del rey don Alfonso el Sabio, cotejadas con varios códices antiguos por la real Academia de la Historia, Madrid, Imprenta Real, tome III, 1807, p. 277 [http://www.cervantesvirtual.com/obra-visor/ las-siete-partidas-del-rey-don-alfonso-el-sabio-cotejadas-con-varios-codices-antiguos-por-la-real-academia-dela-historia-tomo-3-partida-quarta-quinta-sexta-y-septima--0/html/01fb8a30-82b2-11 df-acc7-002185ce6064. htm (consulté le 10/10/2018)].

12. Quinta Partida, titre 12, "De las fiaduras et de las cosas que los hómes facen por mandado dotri ó de su voluntad sin mandado de los dueños de ellas ", Las siete partidas, p. 276.

13. Quinta Partida, titre 11, loi 4, «Entre quéles personas puede ser fecha promisión », Las siete Partidas, p. 257. 
de leur condition : les chevaliers de l'armée du roi, puisqu'on " ne réquisitionnait pas le service dû au roi, en plus du fait que les hommes ne pourraient pas obtenir un droit venant d'eux si légèrement comme venant des autres "; les chevaliers ne pouvaient pas non plus être garants de ceux qui louaient ou avaient la garde des almojarifazgos, des rentes ou de tout autre droit du roi. Une situation similaire était imposée aux ecclésiastiques : il était spécifié que ni les évêques, ni les clercs réguliers, ni les religieux ne pouvaient être garants, pour éviter que soit « réquisitionné le service dû à Dieu " pour une fidéjussion, étant donné que cela causerait un grand dommage à l'Église. Les Partidas fixaient également un autre type d'indispositions dues à la condition des sujets : aucun serviteur ne pouvait être le fidéjusseur d'un autre, sauf s'il était propriétaire, puisque " pour les choses en relation avec le pegujal [lopin de terre] il pourrait bien être le garant d'un autre » ${ }^{14}$. D'autres circonstances pertinentes avaient un lien avec la relation familiale et de dépendance entre deux sujets qui, en soi, pouvaient bien être garants : ni un père ne pouvait l'être de son fils (et vice-versa) ni un seigneur de son serf (et vice-versa) ${ }^{15}$. À part quelques exceptions détaillées, la femme ne pouvait être garante ${ }^{16}$. Autrement dit, cette pratique était interdite aux individus qui avaient des obligations "supérieures " (qui pouvaient être exposées à des risques de par l'obligation de la fidéjussion) ou à ceux qui n'avaient pas de ressources financières, interdiction qui s'étendait au lien parental. Quiconque pouvait être fidéjusseur pouvait à son tour être confié ${ }^{17}$.

Sur leur présence dans les procès, la Partida spécifiait que le gagé était celui qui devait choisir un garant ou que celui-ci pouvait se présenter de lui-même au premier et, s'il n'était pas récusé, il pouvait agir comme tel. Une fois désigné, le garant pouvait exercer en tant que défenseur et, lorsque le jugement avait débuté, il ne pouvait cesser de l'être jusqu'à sa clôture et devait assumer la peine complète dans le cas ou son confié serait déclaré coupable ${ }^{18}$.

Certains manuels d'usage commun de plus ample diffusion entre les juristes en Amérique au début du XIx ${ }^{e}$ siècle, comme El manual del abogado americano publié en 1824 ou le Diccionario de legislación razonado de legislación civil, penal, comercial y forense du publiciste Joaquín Escriche, publié au Mexique pour la première fois en 1837 , répétaient l'idée selon laquelle le garant était « celui qui prend sur lui l'obligation d'autrui au cas où celui qui l'a contracté ne puisse pas s'en acquitter » ${ }^{19}$

14. Quinta Partida, titre 12, loi 2, "Quáles homes non pueden ser fiadores ", Las siete partidas, p. 277.

15. Quinta Partida, titre 11, loi 6, "Cómo non puede ser fecha promisión de premia entre padre et fijo, et siervo et señor ", Las siete partidas, p. 258.

16. Quinta Partida, titre 12, loi 3, "Por cuáles razones pueden las mujeres ser fiadores por otro ", Las siete partidas, p. 278.

17. Quinta Partida, titre 11, loi 1, "Qué cosa es promisión, et á qué tiene pro et en qué manera se face ", Las siete partidas, p. 255.

18. Quinta Partida, titre 12, loi 18, "Cómo el fiador puede defender en juicio á aquel que fió para adocirlo á derecho ", Las siete partidas, p. 286.

19. Escriche, Joaquín, Diccionario razonado de legislación civil, penal, comercial y forense: o sea resumen de las leyes, usos, prácticas y costumbres, como asimismo de las doctrinas de los jurisconsultos, México, Impreso en la oficina de Galván, 1837. 
et qu'il ne pourrait être ni soldat, ni évêque, ni agriculteur (qui pouvaient l'être seulement entre eux) ni, sauf dans des cas très spécifiques, une femme. Ces ouvrages recueillaient également les obligations que le garant acquérait et les bénéfices qu’il pourrait tirer (d'ordre, de division et de cession d'actions, entre autres). Dans la littérature relative à la pratique des principes du droit et des procédés judiciaires, on trouve aussi la présence des garants comme figures fondamentales non seulement pour accomplir l'obligation du débiteur civil, mais aussi comme stratégie pour éviter la prison dans les causes mineures des jugements criminels, une consignation qui était du ressort du juge ${ }^{20}$. Encore dans les années 1850, Juan Nepomuceno San Miguel, dans Curia filípica mexicana, détaillait comment, dans les délits qui ne demandaient pas de peine corporelle ou afflictive, exception faite de l'exil, le condamné pouvait échapper à la prison sous réserve d'avoir un garant qui assure être présent au jugement et se charge du paiement auquel il serait condamné. Il en était de même une fois la sentence rendue, sauf quand le condamné méritait une peine corporelle ou afflictive. Dans les cas où il était possible de faire appel à cette figure, le juge devait introduire les articles qui abritaient la possibilité de la liberté du prisonnier sous ces conditions; des articles qui devaient être ensuite révisés par l'accusateur et le procureur. On insistait sur le fait que pour les peines corporelles il ne devait en aucun cas être remis en liberté21.

Finalement, la figure du fidéjusseur oscillait entre l'obligation personnelle acquise par le sujet particulier qui assumait la cause d'autrui comme sienne et répondait en cas d'inexécution de la responsabilité contractée de la part du débiteur (envers des tiers ou la société en général), et la confiance publique basée sur le fait d'être une personne capable de répondre en cas de non-respect, d'infraction ou de commission d'un délit de l'accusé. Dans certains cas, comme nous le verrons par la suite, son intervention a facilité l'activation de mécanismes juridiques pour forcer l'engagement du débiteur. Dans d'autres cas, il est devenu gardien physique ou garant du comportement approprié de l'accusé envers les directrices chrétiennes et sociales en usage.

\section{Fidéjusseurs, garants et gardiens}

L'introduction de la figure du fidéjusseur dans les procès judiciaires ne suit pas un code unique et homogène, spécialement dans les causes criminelles. Encore dans les premières décennies du XIX ${ }^{\mathrm{e}}$ siècle les décisions de justice faisaient référence à cette figure en la renvoyant à la tradition juridique castillane, comme la ley sansimuss, le codde fidejusoribus et, plus particulièrement, le titre 12 de la cinquième des

20. De Ochoa, Juan Eugenio, Manual del abogado americano, livre 3, titre 27, art. 2, $1^{\text {re }}$ éd., Paris, librería de Jules Renouard, 1827.

21. Rodríguez de San Miguel, Juan Nepomuceno, Curia filípica mejicana. Obra completa de practica forense. En la que se trata de los procedimientos de todos los juicios, ya ordinarios, ya estraordinarios y sumarios, y de todos los tribunales existentes en la República, tanto comunes como privativos y privilegiados. Conteniendo ademas un tratado integro de la jurisprudencia mercantil, $1^{\text {re }}$ éd. México, Imp. de J. R. Navarro, 1850, p. 463 et 491. 
Siete Partidas. Le protocole d'acceptation des engagements et de la renonciation à de possibles exonérations, privilèges et lois (sa propre juridiction - fuero-, son domicile et voisinage l'interdiction à la renonciation générale) en sa défense se maintenait, tout comme la force de son obligation qui impliquait notamment l'hypothèque de sa personne et de ses biens existants et futurs ${ }^{22}$.

Dans la justice civile, la plupart du temps, sa présence était directement liée au paiement de dettes. Il était généralement présenté par le gagé, et le lien créé entre eux se maintenait jusqu'au moment de faire face à l'acquittement de ces dernières. Néanmoins, en certaines occasions, quand le débiteur avait un comportement qui ne s'ajustait pas à ses responsabilités, le fidéjusseur pouvait engager un recours contre lui en impliquant aussi les autres créditeurs. Pour autant le lien qui les unissait se rompait et, en faisant valoir ses droits, il devenait partie adverse, ce pourquoi il en appelait à l'intervention de l'autorité publique. En mars 1824, lorsque Tomás Figueroa, fidéjusseur et contrôleur des biens de José Manuel Paredes, s'est rendu compte que celui-ci dilapidait les biens qui lui restaient au lieu de faire face à son crédit et mettait donc directement les siens en danger, il envoya au maire de San Lorenzo Quapiaxtla une relation des propriétés de Paredes pour initier de toute urgence une vente aux enchères de celles-ci et récupérer ainsi l'argent qu'il avait déjà perdu en faveur de son débiteur ${ }^{23}$. La procédure commença selon l'article 7, chapitre 3 du décret du 9 octobre 1812 sur les Audiences et Tribunaux de première instance à son propre domicile au vu du caractère très urgent de la pétition ${ }^{24}$. Dans le procédé déployé, le garant agissait en qualité de lésé, comme créditeur du confié et rejoignait ainsi l'ensemble des demandeurs qui intervenaient dans la cause. À la demande d'un autre plaignant de Paredes, le maire de Quapiaxtla convoqua personnellement Figueroa pour qu'il livre les biens de Paredes qu'il avait confisqués (provenant des enchères du ranch de San Diego Quapiaxtla) et les dépose aux mains d'une personne "segura, lisa, llana y abonada " 25 jusqu'à ce que la prééminence qu'il avait sur ces biens soit résolue. D'autre part, on demanda à Paredes de nommer un expert. En août 1824, Paredes informa que la cession de biens était prête et fournissait une liste détaillée des sommes dues et de ses propriétés. Le maire convoqua finalement une assemblée de créditeurs à laquelle il demanda de nommer un expert (Mariano Iturbe), face aux doutes suscités quant à savoir si l'inventaire des possessions remis par Paredes était complet, pour qu'il évalue les propriétés du débiteur et procéder ainsi au partage de celles-ci en fonction de la hiérarchie des crédits dus.

22. La référence à la législation antérieure est fréquente dans les dossiers. À titre d'exemple, le détail de la cause sur la contrebande de mules et de tabac à San Lorenzo, Quapiaxtla, AHET, Justicia Criminal, 1822, caja 1, exp. 1 , fs. 9.

23. AHET, Justicia Civil, 1824, caja 3, exp. 29, fs. 49.

24. Colección de los decretos y órdenes que han expedido las Cortes Generales y Extraordinarias desde 24 de mayo de 1812 hasta 24 de febrero de 1813, Cádiz, Imprenta nacional, 1813, tome III, p. 128.

25. Dans ce cas concret, nous avons décidé de garder les termes originaux en espagnol, puisqu'il s'agit d'une expression qui renvoyait avec précision juridique à un type de fidéjusseur qui n’était soumis à aucune juridiction particulière. 
Néanmoins, c'est dans la justice criminelle que nous rencontrons une plus grande variété dans la manière d'introduire cet acteur dans la procédure. Si on observe les sources, le juge désignait un fidéjusseur à l'accusé ou au condamné dans des circonstances très variées, parfois pour garantir un meilleur contrôle sur ces derniers, même si dans la plupart des cas il le faisait pour tenter d'alléger la condamnation à la prison, que ce soit pour la mauvaise santé du condamné, parce que l'accusation ne semblait pas plausible ou que pour une raison concrète l'atténuation de la dureté de la peine du condamné était jugée nécessaire ${ }^{26}$. Dans ces circonstances, et en général, le garant avait l'obligation de présenter le débiteur en cas d'injonction judiciaire. Quelques fois ce n'était même pas le condamné ou l'accusé qui proposait un fidéjusseur mais le juge lui-même qui lui en assignait un, avec son consentement préalable. Dans ces cas précis, il semblerait que le garant était une extension de l'autorité publique, puisqu'il agissait comme un gardien hors de la prison, à qui on chargeait l'exécution de la condamnation en ce qui concernait l'absence de liberté de mouvement du condamné mais aussi la garantie que son comportement serait socialement et moralement approprié. Il est probable que plus la répercussion publique du délit commis était forte, plus l'accent était mis sur l'intervention nécessaire du fidéjusseur.

Une des circonstances les plus habituelles où le prisonnier ou sa famille sollicitaient au juge le recours au garant était quand le condamné était très malade et que les conditions carcérales ne garantissaient pas sa survie. La famille écrivait quelques fois au juge pour demander sa remise en liberté sous caution d'un sujet qui assurait que le prisonnier retournerait en prison après son rétablissement. Ce fut le cas de José Antonio García, impliqué dans une affaire de vol d'animal, dont l'était de santé navrant amena sa mère à solliciter au juge son emprisonnement dans une maison particulière où il serait gardé par un fidéjusseur jusqu'à sa récupération. Cette mesure lui fut concédée deux fois après qu'il soit passé par une expertise médicale consciencieuse qui ratifiait la gravité de son état ${ }^{27}$. Dans d'autres cas, la situation des prisonniers générait tant de pitié que même quelques intervenants dans le jugement s'offraient pour prendre soin d'eux. L'état lamentable de l'indienne Juana María, condamnée pour avoir collaboré à l'assassinat de sa belle-mère, conduisit l'interprète de l'affaire à se proposer comme fiador pour la prendre en charge, une circonstance dont le juge profita pour alléger une peine que, pour divers motifs survenus au long du procès, pouvait paraître excessive ${ }^{28}$.

Dans ce contexte républicain précoce, dans les procès ou des indiens étaient impliqués, la responsabilité de la personne qui se portait caution pouvait même se chevaucher avec celle d'autres figures de tutelle et de protection qui étaient désignées dans les procès judiciaires quand les indigènes étaient mineurs. Pour autant,

26. AHET, Justicia Criminal, 1822, caja 1, exp. 4, 35 fs., 17 r.

27. AHET, Justicia Criminal, 1822, ccaja 1, exp. 435 fs., 34 r.

28. AHET, Justicia Criminal, 1823, caja 4, exp. 4, 91 fs., 3 r. Plus d'information sur ce cas in Galante, Mirian, "Justicia liberal y "calidad" ". 
l'allusion à la condition misérable des accusés, de fort enracinement colonial et qui justifiait la nécessité de personnes qui veillent à leurs intérêts et aussi à leur bon comportement n'était pas un hasard ${ }^{29}$. Notamment dans les procès dans lesquels le condamné s'était éloigné ou avait même porté atteinte aux principes chrétiens, le fidéjusseur ne garantissait pas seulement l'accomplissement de la peine pour le délit commis mais apparaissait également comme le responsable de sa rééducation catholique et de la reconduction de ses habitudes de vie. Même si la législation libérale insistait sur le fait que les différences entre les populations devaient cesser, quelques pratiques propres de l'époque antérieure survivaient dans les premiers temps de la république. Une des situations les plus graves pour le scandale public était l'inceste, qui dans les Siete Partidas était condamné par la peine de mort des amants.

Au début de l'année 1822 à Santa Inés Zacatelco (Nativitas) une enquête pour inceste avait débuté suite au communiqué que le curé de la paroisse du village en question avait envoyé au maire José Cristóbal Martínez. Dans ledit document il annonçait une relation continue entre l'indien Mateo de la Cruz et sa belle-sœur María Cayetana, tous deux du même village, bien qu'il les ait préalablement avertis qu'ils devaient renoncer à un tel comportement ${ }^{30}$. Le maire les fit déclarer et se soumettre, plus tard, à une confrontation qui confirma non seulement le témoignage du curé mais reconnaissait également que leur relation existait déjà avant la mort du frère de Mateo et mari de María Cayetana. En qualité de juge suppléant il demanda un rapport de conseiller à Narciso Jiménez Barragán qui, selon le principe d'équité dans l'administration de la justice, expliqua le besoin de pondération de leur sanction en dépit de la réitération du délit et du fait que leur infraction était publique, et statua leur séparation pendant quatre mois. Il s'agissait pour le maire d'une punition indulgente, spécialement face à un crime pour lequel le voisinage demandait une correction et, en supposant qu'une fois ce temps passé ils "s'uniraient [de nouveau] et continueraient dans l'incontinence incestueuse qu'ils avaient menée ", il demanda à un nouveau conseiller, Manuel Zereijo,

[...] si du fait de leur situation misérable, en tant qu'indiens travailleurs des champs lui Mateo et elle veuve malheureuse, tous deux dépourvus de biens, il serait possible de transmettre l'information du procès ou de la représentation de ce tribunal à M. le Proviseur pour qu'il [... les] dispense et qu'ils puissent se marier ${ }^{31}$.

Une fois la sollicitude envoyée, le proviseur répondit négativement puisque la condamnée avait exprimé son désir de ne pas se marier avec son beau-frère lors de son interrogatoire. Le deuxième conseiller statua donc que la grâce récemment adoptée avec l'installation du Congrès Général leur soit appliquée et que Mateo soit

29. Cunill, Caroline, "El indio miserable: nacimiento de la teoría legal en la América colonial del siglo XVI ", Cuadernos Intercambio sobre Centroamérica y el Caribe, v. 8, nº 9, 2011, p. 229-248.

30. AHET, Justicia Criminal, 1822, ccaja 1, exp. 3, 19 fs., 2r y 2v.

31. AHET, Justicia Criminal, 1822, caja 1, exp. 3, fs. 19, 7 v. 
obligé de vivre dans un autre village de la circonscription, qu'il se centre sur son travail et qu'il vive sous caution du juge profane de ce village (José Ramos Mesa), et que Cayetana retourne chez elle non sans garantir auparavant qu' elle soignerait ses manières et sa conduite, " en chargeant sa personne à qui fusse son fidéjusseur pour qu'il s'occupe de celle-ci ».

José del Tránsito, procureur du village, fut proposé comme garant de Cayetana et allégua qu'il la « reçoit comme débiteur » et qu'il «s'occupera de son comportement et de sa conduite pour qu'elle vive dorénavant chrétiennement, sans permettre qu'elle récidive, ni qu'elle se fasse remarquer, ni qu'elle scandalise le voisinage et que s'il observait quelque chose et voyait Mateo il en rendra compte au tribunal pour que la punition correspondante lui soit imposée [...] et qu'elle retournera en prison si elle ne la respecte pas comme elle le dit ». Il assumait cet engagement sans échéance temporelle, chose atypique dans le cas des fidéjusseurs civils, même s'il avait clairement signalé que cette tutelle n'impliquait pas la saisie de ses biens ni ceux de la condamnée 32 .

Effectivement, le Manual de abogados signalait que la peine encourue pour inceste devait être punie comme l'adultère, ce qui supposait la réclusion de la femme, l'exil de l'homme et la confiscation de la moitié de leurs biens. Il est probable que la gravité du délit commis, la continuité du vice ou la qualité des accusés, qui étaient présentés comme de misérables indiens, amena le conseiller à considérer que les garants devaient être des personnes d'autorité dans leurs communautés. Dans un contexte où il continuait d'exister un arbitrage judiciaire, le juge chercha la justification normative qui s'adaptait à ce qu'il considérait comme une peine juste, qui ne devait pas s'arrêter à un exil de quatre mois ni impliquer la réclusion carcérale permanente de la femme. Une peine adaptée à l'envergure du délit et à la qualité des sujets fut donc proposée, et la figure qui rendait possible cette pondération de la sentence était le garant qui acquérait une attribution supplémentaire de policier et de gardien du comportement des accusés en accord avec la doctrine chrétienne. Cette assignation impliquait d'une certaine manière une tutelle, spécialement manifeste dans le cas de Cayetana, puisque le procureur insistait sur le fait qu'il garantirait la restitution de son mode de vie chrétien, en s'hypothéquant lui-même au cas où il n'y arriverait pas.

Pour en revenir au cas des accusés de contrebande de San Lorenzo Quiapiaxtla avec lequel nous avons débuté cet article, une fois que les cinq condamnés furent emmenés devant le maire, celui-ci décida de consulter le conseiller juridique en déclarant qu'il n'existait pas de prison sûre dans le village et que, par conséquent, il ne savait pas quoi faire d'eux. Le conseiller, en prenant en compte cette circonstance, décida que l'idéal était de les laisser en liberté sous caution étant donné qu'ils avaient purgé leur peine pour contrebande lorsque le tabac leur avait été saisi et que l'enquête semblait montrer qu'ils n'avaient pas volé les mules. De cette manière, dans un laps de temps très court, l'affaire fut résolue et tous furent placés sous la

32. AHET, Justicia Criminal, 1822, caja 1, exp. 1, 9 fs., 7v. 
responsabilité de Cayetano Córdova, qui non seulement devait s'assurer qu'ils se présenteraient au tribunal chaque fois qu'ils y seraient convoqués mais devait aussi s'occuper et veiller « sur leur conduite, à ce qu'ils corrigent leurs habitudes et travaillent pour assurer leur subsistance ${ }^{33}$.

\section{En guise de réflexion finale}

L'histoire sociale de la justice propose des interprétations très suggestives sur les procès judiciaires comme des espaces de négociation qui permettent de recomposer, entre autres questions, les dynamiques de configuration des acteurs sociaux et de l'institutionnalisation étatique ainsi que les interactions existantes entre elles. Dans ce contexte, la récupération du rôle des personnes qui agissent en tant qu'intermédiaires permet de pondérer les flux, les contenus et les résultats de ces relations, spécialement en ce qui concerne la résolution des conflits quotidiens à échelle locale. Toutefois, il reste encore quelques figures juridiques qui, sans être considérées " agents de la justice ", ont néanmoins rempli un rôle important (et multiple d'ailleurs) dans le déroulement quotidien des litiges. Leur talent leur permettait d'introduire, dans la résolution des conflits, des individus qui personnifiaient, pour différentes raisons, des valeurs génératrices de confiance et de respect dans les communautés où elles résidaient.

Dans le cas concret des fidéjusseurs, leur présence prolifique dans les dossiers judiciaires attire l'attention, tant dans les causes civiles que criminelles. Et ils le faisaient non seulement en tant que garants de la satisfaction effective des contrats civils, mais aussi comme cautions de l'accomplissement des sentences, dans un double aspect qui affectait autant les accusés que l'État : il permettait aux premiers d'obtenir une sentence moins grave et au juge, dans certains cas, de remédier à l'absence de prisons et, dans d'autres, de mieux ajuster la condamnation en tenant compte de certaines circonstances atténuantes dans la procédure qui pouvaient affecter les conditions des condamnés. Autrement dit, ils étaient nécessaires au bon fonctionnement de l'administration de la justice, d'un point de vue procédural et des fondements juridiques.

\section{RÉSUMÉ/Mots-CLÉS}

Fondé sur la reconstruction de la littérature juridique, mais aussi sur son application dans les affaires de justice civile et pénale dans la région de Tlaxcala (1822-1824), cet article propose une analyse de la fonction des "fiadores" (garants) en tant qu'acteurs pertinents dans les processus de résolution des conflits de portée locale. Ces personnes représentaient des valeurs socialement respectables (de confiance) tout en permettant un fonctionnement plus pondéré des mécanismes de la justice.

Culture juridique, Fiadores, Justice locale, Justice civile et pénale, Tlaxcala 


\section{Resumen/Palabras Claves}

A partir de la reconstrucción de la literatura jurídica, pero también de su puesta en práctica en casos de justicia civil y criminal en la región de Tlaxcala (1822-1824) en este artículo se propone una lectura de los fiadores como actores relevantes en los procesos de resolución de conflictos en ámbito local. Estos sujetos representaban valores socialmente respetables (confianza) al tiempo que permitían un funcionamiento más ponderado de los mecanismos de impartición de justicia.

Cultura jurídica, Fiadores, Justicia local, Justicia civil y criminal, Tlaxcala

\section{ABSTRACT/KeYWORDS}

Based on the reconstruction of legal literature, but also on its application in civil and criminal justice in the region of Tlaxcala (1822-1824), this article proposes an analysis of fiadores (guarantors) as relevant actors in local conflicts' resolution processes. These subjects represented socially respectable values (trustworthy) while allowing a more balanced functioning of justice mechanisms.

Legal culture, Fiadores, Local justice, Civil and criminal justice, Tlaxcala 


\title{
Abogados y apoderados en pleitos de tierras, Chiapas, 1833-1872
}

\author{
María del Rocío OrTIZ HerRera \\ Universidad de Ciencias y Artes de Chiapas
}

\section{Introducción}

En DÉCADAS RECIENTES EL ESTUDio sobre abogados en el México decimonónico ha cobrado interés. Algunos análisis nos han dejado ver que los abogados participaron activamente en la Independencia de México, primero como defensores del autonomismo temprano, y más tarde como creadores de las estructuras políticas y jurídicas de la incipiente nación, además de redactores de los documentos que le dieron sustento constitucional ${ }^{1}$. Al iniciar la vida independiente, esos trabajos han mostrado que los abogados contribuyeron a la construcción de la cultura jurídica del país y configuraron la sociedad y el Estado nacional. No sólo se desempeñaron como notarios, escribientes de juzgados, empleados en el poder judicial y en la procuración de justicia, sino también como senadores, diputados, gobernadores, ${ }^{2}$ asesores de empresas, profesores y periodistas ${ }^{3}$.

Si bien la historiografía del siglo xix se ha ocupado de analizar aspectos notorios del papel de los abogados en distintos órdenes de la vida del país, así como en el proceso de "racionalización" de la justicia y modernización del Estado, no ha abordado con el mismo interés su función como intermediarios entre la sociedad y el Estado. La importancia de los abogados como vínculo entre la sociedad y los órganos de impartición de justicia quedó estipulada en la normatividad de esos años

1. Pérez Perdomo, Rogelio, "Los abogados americanos de la monarquía española", Anuario Mexicano de Historia del Derecho, $\mathrm{n}^{\circ} 15,2003$, p. 590-592.

2. Véase Del Arenal Fenochio, Jaime, "Abogados en la ciudad de México a principios del siglo xx (la lista de Manuel Cruzado), Anuario Mexicano de Historia del Derecho, vol. X. p. 39-47; del mismo autor "La abogacía en Michoacán, noticia histórica”, Relaciones: estudios de historia y sociedad, n 23, v. 6, verano, 1985, p. 11-28.

3. Véase Tormo Camallonga, Carlos, "La abogacía en transición: continuidad y cambios del virreinato al México Independiente", Estudios de Historia Novohispana”, n 45, vol. 45, 2011, p. 81-122; Lira, Andrés, "Abogados, tinterillos y huizacheros en el México del siglo xix”, Memoria del III Congreso de Historia del Derecho Mexicano, México, Instituto de Investigaciones Jurídicas de la UNAM, 1984, p. 375-392. 
al postular como imprescindible la intervención de los profesionales del derecho en todo tipo de pleitos civiles y penales. Incluso, en el afán de que los individuos más pobres contaran con representantes legales, el Estado les asignó abogados especiales, y a partir de 1856, a raíz de la desamortización de los bienes comunales, las autoridades de algunos estados nombraron también abogados de indios para atender los litigios por la propiedad de las tierras ${ }^{4}$.

En el presente artículo quiero incursionar en el análisis del papel de los abogados en disputas por tierras durante el siglo xIx. Existe una amplia bibliografía que ha dado cuenta de las estrategias legales que emplearon los grupos subalternos para defender sus derechos sobre la tierra durante esos años, su capacidad de negociación con el Estado y el uso de las leyes y los procedimientos jurídicos para el logro de sus objetivos. Sin embargo, en esos trabajos la actuación de los abogados aparece solo de manera circunstancial y con excepción del estudio de José Alfredo Rangel Silva acerca de la defensa que realizó el abogado Wistano Orozco de las tierras comunales del centro de México ${ }^{5}$ no existe ninguno otro que aborde la temática. Tampoco se cuenta con estudios que analicen la intervención de los apoderados en disputas por tierras, un representante que también fue requerido por el sistema jurídico republicano para representar con poder legal a individuos o pueblos en demandas por tierras.

El objetivo de esta primera aproximación al tema consiste en identificar qué tan determinante fue la intervención de abogados y apoderados en la resolución de los litigios por tierras, las estrategias y argumentos jurídicos que emplearon y los intereses que defendieron. Se trata de indagar hasta qué punto abogados y apoderados protegieron los derechos de los propietarios pobres y de los campesinos que poseían tierras colectivas en pueblos con población mayoritariamente indígena.

Para efectos de este análisis se tomaron en cuenta solamente pleitos de tierras dirimidos en las instancias de justicia local, es decir, el tribunal de justicia, los juzgados de primera instancia y los ayuntamientos. Vale la pena aclarar que en Chiapas no existió un despojo masivo de las tierras colectivas en el siglo XIX, como han evidenciado diversos estudios recientes ${ }^{6}$, y por otra parte, los abogados no siempre estuvieron al alcance de los propietarios pobres y de los pueblos que poseían tierras en común. Por tales razones, los casos que aquí se estudian son algunos de los pocos que se localizaron en los archivos locales y en los que se menciona de manera explícita a los apoderados y abogados que en ellos intervinieron.

4. Del Arenal Fenochio, Jaime, "La abogacía en Michoacán, noticia histórica”, op. cit., p. 19.

5. Rangel Silva, José Alfredo, "Los comuneros, el abogado y el senador. Cultura política y orden liberal a fines del porfiriato”, Historia Mexicana, LXIV: 3, enero-marzo, 2015, El Colegio de México A. C., México, p. 937-1000. El artículo analiza la actuación del abogado Wistano Orozco en la defensa que realizó de los bienes comunales de los indios pames del estado de San Luis Potosí.

6. Confr. Fenner, Justus, "Pérdida o permanencia: el acaparamiento de las tierras colectivas en Chiapas durante el Porfiriato. Un acercamiento a la problemática desde los expedientes del juzgado de distrito (1876-1910)", Revista Pueblos y Fronteras Digital, n 3, 2007, p. 1-39 y Palomo Infante, Dolores, "Los ayuntamientos de los pueblos indígenas de Chiapas en el siglo xix y su relación con los asuntos de justicia", Anuario de Estudios Americanos, $\mathrm{n}^{\circ}$ 1, vol. 66, 2009, p. 37. 
En la primera parte expongo la relación entre los abogados y el Estado de Chiapas, en particular la labor que realizaron los gobiernos del siglo XIX para formar a los profesionales del derecho y el número de letrados en la entidad. En la segunda parte me refiero a las instancias de impartición de justicia que participaron en los juicios que son objeto de este estudio y la normatividad con la que se regularon las funciones de los abogados y apoderados en todo tipo de controversias. En la tercera parte analizo distintos litigios de tierras en pueblos indígenas en los que mediaron apoderados y abogados, para ejemplificar algunas de las dificultades que enfrentaron los labradores y propietarios pobres en la defensa de su patrimonio territorial ${ }^{7}$.

\section{La formación de los abogados y el Estado de Chiapas}

La revolución novohispana significó el traslado de la titularidad de la soberanía, entendida como el máximo poder de un pueblo, del monarca a la nación, por lo que la justicia, cuyo garante era el rey, en adelante sería administrada en nombre de esa nación, junto con la facultad de hacer y reformar leyes. En ese contexto, el Estado, como depositario de la soberanía, adquirió la responsabilidad de formar a los abogados ${ }^{8}$. Así, el siglo xIX significó la transición de los abogados como un grupo social cerrado, unido por lazos corporativos, a un colectivo profesional controlado por el Estado mexicano, mediante la educación y la reglamentación del ejercicio de la abogacía?

En concordancia con esos principios, en Chiapas el ejecutivo local estableció la primera cátedra de derecho auspiciada por el gobierno en 1825. Inicialmente la cátedra formó parte de los estudios que ofrecía la diócesis de Chiapas ${ }^{10}$, pero a partir de 1826 se trasladó a la Universidad Nacional del Estado Libre de las Chiapas ${ }^{11}$. La inestabilidad política y la escasez de recursos provocada por los enfrentamientos entre centralistas y federalistas dificultaron la creación de un mayor número de cátedras de derecho en los siguientes años. Fue hasta 1849, cuando el congreso local autorizó la apertura de la Academia de Derecho Teórico Práctico, con sede en la ciudad de San Cristóbal de Las Casas ${ }^{12}$. Más tarde, a principios de la década de 1850, se estableció la Cátedra Pública de Cánones y Derecho Natural ${ }^{13}$, al mismo

7. En la legislación agraria del Chiapas decimonónico se utiliza el término de "labradores" como sinónimo de campesinos que usufructuaban tierras de uso común, entre ellas los ejidos. Por ello, en este texto se empleará la palabra "labradores" para hacer referencia a los campesinos que poseían terrenos de ejido.

8. Tormo Camallonga, Carlos, "La abogacía en transición: continuidad y cambios del virreinato al México independiente", op. cit., p. 115.

9. Del Arenal Fenochio, Jaime, “Abogados en la ciudad de México a principios del siglo xx”, op. cit., p. 15-16.

10. Torres Aguilar, Morelos, Aproximaciones a la historia de la educación en Chiapas. Iniciativas de enseñanza en el siglo XIX, México, Universidad de Guanajuato y UNICACH, 2015, p. 111.

11. Santiago Cruz, Francisco, "Estatutos de la Universidad Literaria y Pontificia de Chiapas, en el año de su fundación de 1826. Estudio preliminar”, México, Editorial Tradición, 1976, citado en Agustín López Cuevas, Crónica de la Universidad Autónoma de Chiapas, México, UNACH, 2016, p. 114.

12. El Noticioso chiapaneco, t. II, San Cristóbal, 10 de mayo de 1849, p. 160.

13. Ibid., 23 de marzo de 1852, p. 165. 
tiempo que los diputados locales autorizaron diversos impuestos ${ }^{14} \mathrm{y}$ asignaciones directas ${ }^{15}$ para aumentar los ingresos de la universidad. Gracias a ello las condiciones de las cátedras de derecho mejoraron ${ }^{16}$.

Los esfuerzos del gobierno chiapaneco por formar abogados en el estado dieron como resultado que para 1872 el número de estudiantes de derecho sumara 46, de un total de 155 que estaban inscritos en la universidad ${ }^{17}$. Mientras que en la década siguiente los alumnos que cursaban estudios jurídicos en la Academia de Derecho Teórico-Práctico aumentaron a 189. De esa manera se logró que hacia 1887 existieran en Chiapas 78 abogados titulados, los cuales residían en su mayor parte en los departamentos de Las Casas y Comitán ${ }^{18}$. También se consiguió que para 1891, casi todos los juzgados de primera instancia del estado contaran con abogados titulados ${ }^{19}$. En esa década el número de profesionales del derecho continuó incrementándose: de 78 en 1887 aumentaron a 102 en $1897^{20}$.

Como podemos ver, el Estado de Chiapas realizó un esfuerzo sostenido por formar profesionales del derecho en la entidad. Sin embargo, es muy posible que muchos de ellos no tuvieran interés en litigar, sobre todo cuando se trataba de asuntos de poca valía, y prefirieran desempeñarse en cargos de la administración pública, o bien combinaran ambas actividades, con los vicios que ello suponía. Esa situación puede explicar por qué la mayoría de los abogados residían en San Cristóbal de Las Casas, capital política de Chiapas durante buena parte del siglo XIx, y en Comitán ${ }^{21}$, ciudad importante por su dinámica comercial. Si a esa problemática añadimos el hecho de que los honorarios que recibían los abogados podían alcanzar

14. El Órgano del Gobierno, Periódico Oficial de Chiapas, Año 3ํ , n 35, San Cristóbal, 23 de septiembre de 1854.

15. Archivo Histórico de Chiapas (en adelante AHCH), Memoria presentada por el C. Martin Quezada secretario del gobierno de Chiapas al honorable congreso constituyente, constitucional del estado libre soberano de Chiapas. Por el ciudadano secretario del gobierno del mismo, relativa a la época transcurrida, del tiempo en que cesó la administración dictatorial del General Santa Anna en el estado, a virtud del Plan de Ayutla reformado en Acapulco, a la fecha en que se instaló aquel honorable cuerpo, San Cristóbal, Imprenta del gobierno a cargo de Manuel M. Trujillo, año de 1857.

16. AHCH, Memoria de gobierno, 1861.

17. AHCH, Memoria que guardan los ramos de la administración pública en el estado libre y soberano de Chiapas, presentada por el secretario de gobierno a la legislatura, en noviembre de 1872, Edición del Espíritu del Siglo, Imprenta del Gobierno del Estado a cargo de Manuel F. Espinosa.

18. Ibid.

19. AHCH, Memoria que presenta el ciudadano Manuel Carrascosa como gobernador constitucional del estado libre y soberano de Chiapas a la H. Legislatura, en cumplimiento de un precepto constitucional correspondiente al segundo bienio de su administración, San Cristóbal de las Casas, Imprenta del Gobierno del Estado, dirigida por Guillermo Steinpreis, 1891.

20. AHCH, Discurso del Lic. Emilio Rabasa, gobernador del estado de Chiapas, ante la XVII Legislatura del mismo al abrir ésta su primer periodo de sesiones ordinarias, Tuxtla Gutiérrez, Imprenta del gobierno, dirigida por Félix Santaella, 1893.

21. En 1897 residían en San Cristóbal de Las Casas 51 abogados y en Comitán 20. En el resto de los departamentos políticos solamente radicaba un abogado. AHCH, Memoria presentada por el ejecutivo de Chiapas a la Honorable Legislatura Local, y que comprende el 1 de diciembre de 1895 al 15 de septiembre de 1897, Tuxtla Gutiérrez, Imprenta del Gobierno del Estado, dirigida por Félix Santaella, 1898. 
sumas importantes ${ }^{22}$, las posibilidades de los labradores o de los propietarios pobres para contratar abogados en realidad eran limitadas.

\section{Las instancias judiciales, los abogados y los asuntos de tierras}

En la época colonial, los indígenas acudían al Juzgado General de Indios para presentar sus denuncias por tierras, de hecho el mayor número de las quejas de los indios durante esos ańos fue por derechos de tierra y propiedad ${ }^{23}$. A partir de que la Constitución federal de 1824 proclamó la división de poderes, las controversias por tierras se convirtieron en una atribución del poder judicial ${ }^{24}$. En el caso de Chiapas, la primera ley agraria del periodo independiente, promulgada en 1826, dispuso que los conflictos entre denunciantes de tierras baldías o nacionales y campesinos en posesión de tierras colectivas o de ejido debían solventarse ante los "jueces respectivos" o bien apelar a las instancias designadas por la constitución si los juicios eran contenciosos ${ }^{25}$.

"Los jueces respectivos" a los que aludía la ley agraria de 1826 eran los juzgados de distrito, los cuales fueron creados para dirimir los pleitos entre campesinos que poseían tierras comunes y denunciantes de terrenos baldíos o nacionales. El primer juzgado de distrito en Chiapas quedó establecido en $1827^{26}$, aunque fue hasta 1853 cuando comenzó a funcionar ${ }^{27}$. Mientras tanto fueron los juzgados de primera instancia los encargados de atender los litigios correspondientes al juzgado de distrito, así como los que de por sí eran de su competencia, es decir, pleitos entre propietarios particulares, entre éstos y los usufructuarios de tierras colectivas, y entre éstos y propietarios particulares, por ser esos los asuntos contenciosos civiles sobre los cuales no tenían facultad los jueces especiales o las salas de la Corte Suprema de Justicia ${ }^{28}$.

22. Un arancel de los honorarios de los abogados de Chiapas de 1837 estipuló el costo de cada una de las actividades de los abogados, desde la revisión de expedientes, elaboración de documentos, incluyendo interrogatorios, participación en transacciones, asistencia a juicios, consultas verbales, etcétera, los cuales variaban según las fojas revisadas o elaboradas, las horas invertidas en las distintas actividades y el valor del asunto del litigio. Suprema Corte de Justicia de la República Mexicana, Arancel de honorarios y derechos judiciales que se han de cobrar en el Departamento de Chiapas por los secretarios y empleados de su Tribunal Superior, jueces de paz, escribanos, abogados, procuradores de número o apoderados particulares y demás curiales o personas que puedan intervenir en los juicios, conforme a lo prevenido en el Artículo 55 de la Ley de 23 de mayo de 1837, p. 24-27.

23. Borah, Woodrow, El juzgado General de Indios en la Nueva España, FCE, México, 1985, p. 131-139.

24. Baitenmann, Helga, "Ejerciendo la justicia fuera de los tribunales: de las reivindicaciones decimonónicas a las restituciones de la reforma agraria”, Historia Mexicana, vol. 66, n 4, abril-junio 2017, p. 2016-2017.

25. Gobierno del Estado de Chiapas, Colección de leyes agrarias y demás disposiciones que se han emitido con relación al Ramo de Tierras. Mandadas a reimprimir de orden del superior gobierno del Estado, Imprenta Joaquín Armendáriz, s./l., 1878, p. 3-5.

26. Ibid., p. 54.

27. Fenner, Justus, "Pérdida o permanencia: el acaparamiento de las tierras colectivas en Chiapas durante el Porfiriato”, op. cit., p. 7-8.

28. Ruiz Abreu, Carlos, Historia del H. Congreso del Estado de Chiapas, t. I, II y III, Chiapas, Congreso del Estado de Chiapas, LVIII Legislatura, 1994, p. 67. 
Los juzgados de primera instancia se localizaban en las cabeceras de los partidos y departamentos políticos. Durante buena parte del siglo XIX, esos juzgados no contaron con jueces formados en derecho, por lo que la Constitución de 1826 ordenó que en esos casos los jueces de primera instancia debían contar con el apoyo de los asesores del estado ${ }^{29}$. La Ley de Administración de Justicia de 1863 especificó que los juzgados de primera instancia debían entablar juicios verbales en todos los asuntos criminales y en los civiles no mayores a 300 pesos, mientras que los juicios escritos servían para tratar los asuntos civiles mayores a 300 pesos. Los juicios ordinarios tenían lugar en los casos civiles o criminales sólo cuando los ayuntamientos habían agotado la posibilidad de resolverlos por medio de la conciliación ${ }^{30}$.

En cuanto a los alcaldes, su función conciliadora quedó consignada en los decretos promulgados por los primeros constituyentes de Chiapas en $1825^{31}$. Más adelante, la Constitución del Estado de Chiapas de 1858 reconoció a los alcaldes como jueces menores y la de 1893 se refirió a los ayuntamientos como órganos del poder judicial ${ }^{32}$. La Ley de Administración de Justicia de 1863 aclaró que los alcaldes de las corporaciones municipales eran los responsables de atender las demandas con un valor menor a los 100 pesos, ${ }^{33}$ aunque era frecuente que los ayuntamientos turnaran algunos casos a los juzgados de primera instancia y viceversa, independientemente de su monto ${ }^{34}$. $\mathrm{Al}$ igual que los jueces de primera instancia, durante buena parte del siglo xix los alcaldes fueron iletrados, por lo que debían llevar a cabo sus funciones con el auxilio de los asesores del tribunal de justicia o bien con el apoyo de abogados residentes a quienes el gobierno obligaba a brindarles asesoría ${ }^{35}$.

Los abogados intervinieron en disputas por tierras ya sea como asesores del tribunal de justicia o representantes de las partes en conflicto. Existían dos tipos de asesores: los voluntarios, que generalmente eran abogados del pueblo nombrados por un juez letrado; y los asesores necesarios, es decir, los que designaba la ley para aconsejar a jueces letrados e iletrados en asuntos de justicia ${ }^{36}$. Casi siempre el tribunal de justicia del estado contó solamente con un asesor, por lo que el ejecutivo obligó a todos los abogados habilitados en el estado a brindar asesorías a los jueces menores, medida que a la larga generó descontento entre los propios abogados, ya que el pago de sus honorarios dependió de los litigantes y éstos no siempre tuvieron

29. Ibid.

30. Ley reglamentaria de la administración de justicia del estado libre y soberano de Chiapas, expedida por el Congreso del mismo el 15 de enero de 1863, Chiapas, Imprenta del Gobierno a cargo de Manuel María Trujillo, p. 9-10.

31. Gobierno del Estado de Chiapas, Colección de decretos del Congreso Constituyente de Chiapas, t. 1, Chiapas, Imprenta de la Sociedad, 1828, p. 86.

32. Ruiz Abreu, Carlos, Historia del Honorable Congreso del Estado de Chiapas, op. cit., p. 125 y 150.

33. Ley de la administración de justicia del estado libre y soberano de Chiapas, op. cit., p. 1-2.

34. Palomo Infante, Dolores, "Los ayuntamientos de los pueblos indígenas de Chiapas en el siglo xix y su relación con los asuntos de justicia", op. cit., p. 37.

35. AHCH, Fondo documental Fernando Castañón Gamboa, Expediente 198, Año 1861.

36. De Tapia, Eugenio, Febrero mejicano o sea la librería de jueces, abogados y escribanos, op. cit., p. 399-407. 
los recursos necesarios para pagar ${ }^{37}$. El asesor era designado por el ejecutivo del estado a propuesta de una terna hecha por el mismo tribunal de justicia ${ }^{38}$.

No se localizaron disposiciones relativas al nombramiento de abogados para pobres en la entidad, ni aún después de la ley de desamortización de las tierras colectivas de 1856, a diferencia de otros estados del país ${ }^{39}$. Las leyes del fuero común y constitucional de la entidad solamente designaron abogados del tribunal de justicia para defender a los reos pobres de la capital del estado - en ese entonces San Cristóbal de Las Casas ${ }^{4}{ }^{40}$. Por tal razón, los campesinos pobres que no podían solventar los gastos de un abogado debían sujetarse a la opinión de los asesores del tribunal de justicia, cuyo número también era reducido.

Otra figura legal imprescindible en los litigios de tierras eran los apoderados. Según la normatividad del periodo, los ciudadanos podían representarse a sí mismos ante los juzgados o bien mediante apoderados. Generalmente se elegían de entre las personas más instruidas y debían jurar y firmar la fianza de los documentos de la parte representada ante el secretario respectivo. La ley obligaba a los apoderados a presentar todas sus peticiones con la debida firma de un abogado, aunque en los juicios entablados por propietarios pobres y labradores este requisito muchas veces no se cumplión ${ }^{41}$.

\section{Los casos de estudio}

\section{El apoderado Cayetano Ramón Robles y las tierras del común de San Bartolomé de Los Llanos, 1833}

Un litigio que ilustra las dificultades que enfrentaron ejidatarios indígenas con los representantes legales es el de los munícipes de San Bartolomé (hoy Venustiano Carranza) y Cayetano Ramón Robles. Si bien las primeras leyes agrarias de Chiapas protegieron las tierras comunes o ejidos de los pueblos, como la Ley de 1826 que ordenó reducir a propiedad particular los terrenos baldíos o nacionales, con excepción de los ejidos, y la de 1827 que dispuso realizar la medición de los ejidos antes de vender los terrenos baldíos ${ }^{42}$, en los pueblos mayoritariamente indígenas donde se asentó población ladina, como ocurrió en San Bartolomé, el riesgo de que los indígenas fueran despojados de sus tierras fue una amenaza constante. En tal situación, los ayuntamientos - como administradores de los bienes comunales estaban facultados para defender las tierras de ejido y nombrar a los apoderados,

37. AHCH, Leyes vigentes para el procedimiento criminal den los tribunales del estado libre y soberano de Chiapas. Reimpresas de orden del Ejecutivo del mismo, Chiapas, Imprenta del gobierno, 1880.

38. Félix Zepeda, Juan, Enjuiciamiento penal del estado de Chiapas. De las leyes procesales vigentes en el fuero común y en el constitucional del estado, México, Imprenta de las Escalerillas, 1889, p. 185.

39. De Tapia, Eugenio, Febrero mejicano o sea la librería de jueces, abogados y escribanos, op. cit., p. 401.

40. Zepeda, Juan Félix, Enjuiciamiento penal del estado de Chiapas, op. cit.

41. Ibid., p. 407.

42. Gobierno del Estado, Colección de leyes agrarias y demás disposiciones que se han emitido con relación al Ramo de Tierras, op. cit., p. 3-6. 
aunque hubo ocasiones en que los labradores designaron a los apoderados sin dar aviso al ayuntamiento y sin saber que éstos cometerían diversos abusos en su contra, tal como ocurrió en este caso.

El pleito inició en 1833, cuando los munícipes de San Bartolomé denunciaron ante el juzgado de primera instancia, con sede en la cabecera del mismo pueblo, al señor Cayetano Ramón Robles por extorsión y abusos en contra de la población indígena del lugar ${ }^{43}$. Ramón Robles era dueño de varias posesiones importantes en la región, entre ellas las fincas Ixtapilla y Santa María Yerbasanta, los principales núcleos de población de San Bartolomé y Soyatitán, respectivamente ${ }^{44}$. Algunas de sus propiedades las había logrado ensanchar mediante permutas con indígenas de la zona, como el intercambio que realizó en 1842 de un terreno ubicado en Pinola (hoy Villa Las Rosas) por unos terrenos del ejido de Aguacatenango ${ }^{45}$.

Los munícipes denunciaron al señor Robles por haber forzado a los indígenas, con "argucias y engaños", para que le cedieran el poder de sus terrenos y así beneficiar a unos ladinos ${ }^{46}$, Toribio Castañeda y María de los Dolores Gomíz, que buscaban apropiarse de una parte del ejido del pueblo. De ahí su interés por representar a ambas partes, a los ladinos y a los indígenas a la vez ${ }^{47}$. Los funcionarios evidenciaron, además, que el apoderado extorsionaba a los indígenas exigiéndoles tres reales por individuo, en calidad de "despensas" para supuestos gastos de representación.

Pero lo más grave para los munícipes era que Ramón Robles sembraba la discordia entre la población nativa y los ladinos pobres, cuyo derecho a la tierra era el mismo que tenían los indígenas. De hecho, aseguraron que existía una orden de aprehensión en contra del apoderado, girada en diciembre de 1832, por intentar sublevar al pueblo, y aseguraron que también extorsionaba a los nativos de Aguacatenango, lugar en el que fungía como apoderado de un propietario particular que también pretendía usurpar las tierras de los indígenas ${ }^{48}$.

Para resolver la problemática, los ediles solicitaron al juez lo siguiente: que se anularan todas las diligencias llevadas a cabo por el señor Robles en los distintos tribunales y juzgados, no sólo por los presuntos actos delictivos que había cometido,

43. AHCH, Fondo Archivo de Comitán, Juzgado Civil, Caja 1, Expediente 44, año 1833, Asunto relacionado entre el ayuntamiento de San Bartolomé y don Cayetano Román de Robles por abuso de los indígenas, San Bartolomé, 26 de septiembre de 1833, 8 fs.

44. Barrera Aguilera, Óscar Javier, Las terrazas de Los Altos. Lengua, tierra y población en la Depresión Central de Chiapas, tesis de doctorado, México, El Colegio de México, México, 2017, p. 119, 151, 152, 250 y 423.

45. Ibid., p. 251.

46. Durante la época colonial y a lo largo del siglo xix, en Chiapas y Guatemala el término ladino servía para designar a personas que hablaban español como lengua principal y habían abandonado el uso de vestimenta que los identificaba con algún grupo indígena. Al respecto véase, por ejemplo, el artículo de Viqueira, Juan Pedro, "Indios y ladinos, arraigados y migrantes en Chiapas: Un esbozo de historia demográfica de larga duración", Caras y máscaras del México étnico. La participación indígena en las formaciones del Estado Mexicano, vol. II "Soberanías y esferas ritualizadas de intercambio", Zamora, El Colegio de Michoacán, 2011, p. 221-270.

47. AHCH, Fondo Archivo de Comitán, Juzgado Civil, Caja 1, Expediente 44, año 1833, Asunto relacionado entre el ayuntamiento de San Bartolomé y don Cayetano Román de Robles por abuso de los indígenas, San Bartolomé, 26 de septiembre de 1833, 8 fs. 
sino porque su nombramiento como apoderado era ilegítimo. Esto último debía hacerse del conocimiento de la prefectura del departamento político y del juzgado de primera instancia, además de publicarlo en el periódico oficial del estado. Cayetano Ramón Robles debía también declarar la cantidad de dinero que había recibido por las contribuciones de los indígenas y devolver el recurso de manera íntegra. Así mismo era necesario que el juzgado de primera instancia revisara el expediente en el que se había consignado al apoderado por los delitos de seducción y sublevación del pueblo de San Bartolomé, en el año de 1832, y hacer efectiva su aprehensión.

Lamentablemente el caso de San Bartolomé está inconcluso, pero lo que interesa aquí es que pone de relieve dos aspectos. El primero es que los procedimientos para nombrar a los apoderados de los ejidos de los pueblos, al menos durante las primeras décadas del periodo independiente, no fueron del todo conocidos por la población rural, lo que hizo posible que Cayetano Ramón Robles actuara al margen de la ley e intentara abusar de la población indígena. El segundo aspecto es que los ayuntamientos no solamente fungieron como jueces de los conflictos agrarios, como ya han mostrado algunos trabajos para el caso de Chiapas ${ }^{49}$, sino que también formaron parte de las disputas cuando los ejidos de los pueblos de su jurisdicción corrían el riesgo de ser usurpados y realizaron con éxito la defensa de su patrimonio territorial. De hecho, al final del acta de cabildo, los síndicos y regidores de San Bartolomé señalaron que los ejidos del pueblo ya habían sido remedidos y que en caso de nombrar a un apoderado "el propio cuerpo municipal lo verificaría" 50 . Resulta también evidente que los apoderados ladinos en pueblos indígenas utilizaron la representación legal que adquirieron, por convencimiento de los indígenas o por coerción, para beneficiar a otros ladinos o bien para ampliar las propiedades que tenían establecidas en esas poblaciones, tal como lo hacía Cayetano Ramón Robles.

\section{La disputa por terrenos de ejido de Teopisca, 1872}

Como señalamos con anterioridad, un problema de la abogacía en Chiapas durante el siglo XIX fue la escasez de los profesionales del derecho. Esa circunstancia y el hecho de que el gobierno del estado solamente nombró abogados para pobres en el caso de los reos de la capital del estado, provocó que existieran pocos abogados dispuestos a intervenir en litigios donde se disputaban bienes de escaso valor y también que esos juicios tardaran varios años en resolverse. Esto ocurrió en el pleito entre labradores del pueblo de Teopisca y un ladino, Januario Castro.

El 23 de noviembre de 1872, los labradores José María Úrsulo Navarro y Matías López denunciaron ante el juez de primera instancia de San Cristóbal de Las Casas al señor Januario Castro por el despojo de una porción del ejido del

49. Palomo Infante, Dolores "Los ayuntamientos de los pueblos indígenas de Chiapas en el siglo xix y su relación con los asuntos de justicia”, op. cit.

50. AHCH, Fondo Archivo de Comitán, Juzgado civil, Caja 1, año 1833, Expediente. s./n., Sesiones de la villa de San Bartolomé, noviembre 29 de 1833. 
pueblo. Señalaron que en 1870, el ayuntamiento de Teopisca les había repartido un terreno de ejido al oriente del municipio, de 14 varas de extensión, el cual colindaba con terrenos de Januario Castro, pero que a principios de noviembre de $1873 \mathrm{el}$ propio Januario Castro los había despojado de la posesión ${ }^{51}$. Dos de los testigos que se presentaron para su defensa aseguraron que el señor Castro los había despojado del ejido y que no era la primera vez que éste usurpaba terrenos de los vecinos del pueblo. Pero un tercer testigo, el ex síndico del ayuntamiento, dijo que si bien el ayuntamiento de Teopisca había dotado a los campesinos de un terreno de ejido en 1870, habían sido ellos los que invadieron el terreno.

Januario Castro, por su parte, aseguró que el ayuntamiento también le había dotado de una porción del ejido del pueblo, en el mismo año de 1870. Dotación que suponemos era indebida ${ }^{52}$, ya que los ayuntamientos no podían adjudicar terrenos de ejido a propietarios particulares, como era el caso de Januario Castro, quien desde años atrás acaparaba tierras a costa de las tierras comunales del pueblo ${ }^{53}$.

Lo importante aquí es que a partir de que el señor Castro solicitó al juez de primera instancia la asignación de un asesor del tribunal de justicia, el juicio comenzó a retardarse. No sólo porque los litigantes desconocieron una y otra vez a los abogados propuestos por el tribunal de justicia y el juez de primera instancia, sino porque algunos abogados no quisieron hacerse cargo del litigio. Así, en diciembre de 1872, Castro desconoció, sin razón aparente, al abogado Clemente Robles que había asignado el tribunal de justicia. Más adelante, el apoderado de los labradores, Antonio Durán, rechazó como asesor al abogado Joaquín Miguel Ramírez, quien había validado una visita realizada al terreno en disputa que responsabilizaba a los campesinos del despojo del terreno. El mismo abogado había aprobado también la petición del señor Castro para que el litigio se trasladara al ayuntamiento, una vez que se comprobó que el terreno tenía un valor menor a 100 pesos, lo que favorecía al propio Castro porque el síndico municipal había declarado a su favor. Por tales razones y bajo el argumento de que el abogado Ramírez había sido designado al margen del protocolo correspondiente, el apoderado de los inculpados se opuso a su nombramiento.

El juez inició entonces la búsqueda de un nuevo abogado. En agosto de 1873 invitó al licenciado Fernando Zepeda, pero el apoderado de los labradores se opuso

51. Archivo Judicial Regional Altos. Poder Judicial del Estado de Chiapas (en adelante AJRA-PJECH), Expediente 1609, fojas 32, Asunto José Navarro y otros contra Januario Castro, 1872.

52. La Ley de desamortización de los bienes comunales de 1856 y el artículo 27 de la Constitución de 1857, que afectaron a la propiedad ejidal, tuvieron un efecto tardío en Chiapas, por lo que en los años que transcurrió el juicio de los labradores de Teopisca se continuaron aplicando las leyes agrarias de la primera mitad del siglo xIx, que protegieron a los ejidos. Véase Palomo Infante, Dolores "Las Tierras en disputa: reflexiones sobre la Ley de desamortización en Chiapas a través del análisis de los pleitos, 1856-1900", en Antonio Escobar Ohmstede, Romana Falcón, et al., (coord.), La desamortización civil desde perspectivas plurales, México, El Colegio de México, El Colegio de Michoacán y CIESAS, p. 507-509.

53. En 1860, Januario Castro había disputado la posesión de los terrenos Yaxlumiljá perteneciente a varios labradores de Teopisca. Véase Barrera Aguilera, Óscar Javier, Las terrazas de Los Altos. Lengua, tierra y población en la Depresión Central de Chiapas, op. cit., p. 243. 
también a su designación. Se recurrió entonces a otro abogado, el licenciado Carlos Ballinas, quien rechazó el encargo por diversos "compromisos laborales", según dijo. Finalmente se pidió la asesoría del abogado Manuel Estrada, al que Durán también se opuso con el argumento de que el juez debía buscar, primero, abogados dentro del propio municipio de San Cristóbal y después en otros lugares, tal como lo estipulaba la legislación. Pero la tarea de localizar a un abogado del municipio de San Cristóbal que se interesara en el juicio no fue fácil y de hecho provocó que el juicio se suspendiera durante siete años. Fue hasta 1880 cuando el juzgado de primera instancia retomó el caso y el abogado que se encargó del litigio recomendó realizar un juicio de conciliación con las autoridades municipales para resolver el conflicto.

No sabemos si el juicio de conciliación se llevó a cabo, pues el expediente de este caso también está inconcluso. El hecho es que el litigio por ejidos de Teopisca se retrasó siete años, no solo porque el apoderado de los labradores rechazó varias veces a los abogados asignados al caso, sino también por la negativa del licenciado Carlos Ballinas para atender el caso y la dificultad de localizar un abogado del municipio de San Cristóbal que se hiciera cargo de él. Seguramente el escaso valor de los terrenos en disputa fue un factor que influyó en el poco interés de los abogados de San Cristóbal. Al final del expediente, el propio juez de primera instancia admitió que el retraso en el juicio del terreno se debía a "lo insignificante de su objeto intrínseco o por su complicación más bien perjudicial al despacho de causas de suyo preferentes" 54 .

\section{El asesor Flavio Antonio Paniagua y el litigio por los terrenos de Yollochen, Huistán, 1866}

Un obstáculo que también enfrentaron indígenas o ladinos pobres al momento de defender sus tierras fue la falta de recursos para sufragar los gastos de un profesional del derecho. En esa circunstancia, la única opinión profesional que recibían en los juzgados era la del asesor del tribunal de justicia que, como indicamos con anterioridad, era designado por el ejecutivo estatal a partir de una terna que proponía el tribunal de justicia. En ese sentido es posible que, en ciertos casos, el vínculo entre el ejecutivo y el asesor influyera para que las opiniones de este último favorecieran a unas personas o grupos y no a otros, sobre todo cuando los bienes que se disputaban alcanzaban un alto valor económico. Un ejemplo de lo anterior es el pleito por los terrenos denominados Yollochen, en Huistán, un municipio que se localiza en las Tierras Altas de Chiapas, habitado en su mayor parte por población indígena.

El litigio inició a finales de 1866 con una denuncia ante el juzgado de primera instancia de San Cristóbal de Las Casas que presentó el señor Mariano Armendáriz en contra de Antonio Ramos, Evaristo Román, Antonio Nájera y Toribio Trujillo 
por el presunto robo que éstos realizaron de los títulos de los terrenos Yollochen, del municipio de Huistán ${ }^{55}$. Se infiere que Armendáriz formaba parte de una familia de ladinos que había logrado acaparar una gran cantidad de tierras en el poblado, como lo demuestran los propios terrenos Yollochen, cuya extensión aproximada era de 3, 320 hectáreas. Los acusados, por su parte, probablemente indígenas o ladinos pobres, alegaban los títulos de la propiedad, bajo el argumento de que en 1857 habían comprado la mayor parte del terreno a su primer vendedor.

No era la primera vez que un grupo de pobladores de Husitán compraban una propiedad. A finales de la década de 1830, por ejemplo, unos ańos después de la promulgación de la Ley sobre terrenos baldíos de 1826, cuatro indígenas del lugar habían comprado la finca San Pedro Pedernal, con recursos que habían reunido de los vecinos, para adquirir terrenos que sustituyeran la posible pérdida de sus tierras comunales ${ }^{56}$. En el caso del litigio que nos ocupa, es posible que los acusados hubieran comprado una parte de los terrenos Yollochén para reemplazar los que hubieran podido perder en momentos de incertidumbre como la que generó la Ley de desamortización de los bienes comunales de 1856.

Unos meses antes de que Armendáriz presentara su denuncia, el 10 de abril de 1866, el propio Armendáriz y los incriminados se habían reunido en el ayuntamiento de Husitán para celebrar un juicio de conciliación. En esa ocasión los señores Antonio Ramos, Evaristo Román, Antonio Nájera y Toribio Trujillo habían acusado a Mariano Armendáriz de "esconder" los títulos de los terrenos Yollochén, los cuales, dijeron, les pertenecían porque en 1857 habían comprado la mayor parte de esas tierras. De acuerdo con el acta del juicio, los demandantes solicitaron al señor Armendáriz que les entregara los títulos del terreno, éste los entregó y les firmó un recibo.

A los pocos días, sin embargo, Mariano Armendáriz presentó ante el juzgado de primera instancia una denuncia por el robo "violento" de los títulos de los terrenos Yollochén. Alegó que durante el juicio de conciliación, los señores Antonio Ramos, Evaristo Román, Antonio Nájera y Toribio Trujillo lo obligaron a firmar un recibo por los títulos de los terrenos y que, además, los documentos le fueron arrebatados. Los inculpados, por su parte, insistieron que en el año de 1857 habían comprado la mayor parte de los terrenos Yollochén, a su primer vendedor, por lo que los títulos de la propiedad les pertenecían y como prueba de ello mostraron el recibo que Armendáriz les había firmado en el juicio de conciliación del 10 de abril.

Como los acusados no contaban con un representante legal, solicitaron al juez de primera instancia la asignación de un asesor del tribunal de justicia que contara con un punto de vista "objetivo". El juez consiguió que se nombrara como asesor al abogado Flavio Antonio Paniagua, un joven que años más tarde destacaría como

55. AJRA.PJECH, Expediente 1189, fojas 18, Asunto interdicto de despojo contra Antonio y Evaristo Román, 1866.

56. Palomo Infante, Dolores, "Los ayuntamientos de los pueblos indígenas de Chiapas en el siglo xix y su relación con los asuntos de justicia", op. cit., p. 44. 
novelista, cronista y procurador de justicia. Para iniciar el proceso, Paniagua solicitó pruebas al señor Armendáriz en su defensa, por lo que éste presentó a dos testigos que confirmaron su dicho: que en el juicio de conciliación los señores Ramos, Nájera, Trujillo y Román tomaron por la fuerza los títulos de la propiedad ${ }^{57}$ y que para no abandonar el ayuntamiento sin los documentos pidió que se le extendiera un recibo ${ }^{58}$.

No convencido con dichas declaraciones, el asesor del tribunal pidió más pruebas a favor de Armendáriz, ${ }^{59}$ pero éste se limitó a señalar que inicialmente había estado dispuesto a mostrarles los títulos de los terrenos a sus oponentes, pero que ellos habían abusado de su confianza ${ }^{60}$. Por su parte, los inculpados alegaron que desde un inicio el señor Armendáriz ocultaba los títulos de los terrenos Yollochén y que en el juicio de conciliación había quedado demostrado que las tierras no le pertenecían, puesto que él mismo les había entregado los documentos mediante un recibo firmado con su puño y letra ${ }^{61}$.

Como podemos ver, hasta ese momento del juicio, el abogado del tribunal de justicia se limitó a solicitar pruebas al señor Armendáriz, bien porque dudaba de sus declaraciones o porque intentaba defenderlo. De hecho, los propios incriminados acusaron al asesor de pretender "liberar de cargos" al señor Armendáriz, puesto que a ellos no les había requerido ni testigos ni otras pruebas a su favor. Lo cierto es que finalmente los inculpados retuvieron los títulos de los terrenos Yollochén, sin presentar más pruebas que el recibo firmado por el señor Armendáriz y del que no quedó claro, debido a que el juicio está inconcluso, si lo obtuvieron por medio de la coerción o no. En ese sentido, lo notorio del caso es que la falta de un abogado que defendiera de manera particular a los incriminados dejó abierta la posibilidad para que el fallo definitivo del juez los inculpara y de esa manera perdieran la parte de los terrenos de Yollochén, que según dijeron habían adquirido por compraventa casi diez años atrás.

\section{A manera de conclusión}

A lo largo del siglo xix, los abogados cumplieron un papel protagónico en la conformación del Estado nación. No sólo se desempeñaron como parte fundamental de la administración estatal, sino que contribuyeron a diseñar el aparato político republicano, así como a elaborar y reformar los cuerpos legislativos que le dieron legalidad a la naciente nación. Los abogados asumieron también su función de vínculo entre las estructuras judiciales y la sociedad, mediante el ejercicio del derecho en los litigios cotidianos de la población. Por tal razón fueron los responsables de

57. AJRA.PJECH, Expediente 1189, fojas 18, Asunto interdicto de despojo contra Antonio y Evaristo Román, 1866,9 de mayo de 1866.

58. Ibid., 11 de mayo de 1866.

59. Ibid., 17 de mayo de 1866.

60. Ibid., 4 de junio de 1866.

61. Ibid., 18 de mayo de 1866. 
aplicar los valores, procedimientos y rituales jurídicos establecidos legalmente para garantizar el orden social.

La historia judicial se ha centrado en analizar el papel de los abogados en la administración pública y en otros órdenes de la vida del país, así como lo relativo a su formación profesional, pero ha descuidado el estudio de su función como intermediarios entre la población y el Estado. En ese sentido este artículo ilustra el papel que desempeñaron los abogados y otros representantes legales, como los apoderados, en el acceso a la tierra, un ámbito de alta conflictividad durante el siglo xIX debido al riesgo que implicaron diversas leyes agrarias para la retención de las tierras colectivas. Los ejemplos aquí analizados muestran que para el caso de Chiapas los labradores y propietarios pobres de pueblos indígenas enfrentaron diversos obstáculos derivados ya sea de los abusos que cometieron sus representantes legales, del poco interés que algunos profesionales del derecho mostraron en litigios de escaso valor económico o bien debido a que los abogados que el Estado asignó para resolver algunos casos no garantizaron la retención del patrimonio territorial de los campesinos.

Como hemos visto, si bien durante buena parte del siglo xix el Estado de Chiapas realizó diversos esfuerzos para formar abogados en la entidad, no lograron cubrir del todo las necesidades de los labradores y propietarios pobres en sus intentos por defender sus tierras. No sólo porque a diferencia de otras entidades del país las autoridades chiapanecas no designaron abogados de pobres para atender los conflictos derivados de la aplicación de las leyes agrarias, sino también por el hecho de que la mayoría de los abogados titulados residían en dos de las ciudades más importantes del estado, donde muchos de ellos seguramente ocupaban cargos públicos y los costos de sus servicios eran altos. En esas condiciones algunos campesinos pobres enfrentaron dificultades para contar con los servicios de los profesionales del derecho, tal como ocurrió con los inculpados por el robo de los títulos de los terrenos Yollochén, en Huistán, y con los labradores de Teopisca, los primeros por carecer de un abogado que los representara y los últimos por la falta de abogados que asesoraran al juez de primera instancia para evitar el retraso del litigio por varios años.

Por otra parte, los casos estudiados nos demuestran la distancia que en ocasiones existió entre la norma legal y la práctica judicial en esos años. Por ejemplo, la facultad que tenían los ayuntamientos para realizar la designación de los apoderados de los ejidos -en su carácter de administradores de los bienes comunes- no siempre fue respetada, tal como sucedió con Cayetano Ramón Robles, quien fungió como apoderado de los indígenas de San Bartolomé sin la autorización del cuerpo edilicio. Tales omisiones ocurrían cuando los representantes legales buscaban afectar los intereses de los labradores, como lo hizo Ramón Robles en su intento por usurpar las tierras colectivas de San Bartolomé. Otro ámbito en que los ayuntamientos fueron eludidos, desconociendo con ello la normatividad establecida, fue en lo que respecta a su función judicial. En esos casos, el juego de intereses entre los funcionarios municipales y una de las partes en conflicto fue determinante para que los 
ayuntamientos cumplieran o no con la facultad que les concedía la legislación de atender las demandas con un valor menor a los 100 pesos. Ese fue el caso de los labradores de Teopisca, como vimos, quienes prefirieron presentar su demanda ante el juzgado de primera instancia, la cual no rebasaba los 100 pesos, en vez de dirigirla al ayuntamiento de Teopisca, cuyo regidor apoyaba abiertamente a su opositor, el señor Januario Castro. Finalmente, un tercer aspecto legal que con cierta frecuencia se pasaba por alto fue la disposición de que los apoderados presentaran sus peticiones debidamente firmadas por un abogado, ya sea porque las intenciones de los apoderados eran claramente fraudulentas, como las de Cayetano Ramón Robles, o por el difícil acceso al servicio de los abogados, por su escaso número o el elevado costo de sus honorarios, como al parecer sucedió con los labradores de Teopisca.

\section{Resumen/Palabras Claves}

El artículo examina el papel de abogados y apoderados en litigios por tierras en varios pueblos indígenas de Chiapas a lo largo del siglo XIx. Se detiene en analizar las estrategias que esos representantes legales emplearon en los juicios por tierras, así como los argumentos jurídicos que pusieron en juego, con la finalidad de mostrar algunas de las dificultades que enfrentaron campesinos indígenas y ladinos pobres a la hora de defender sus tierras ante los tribunales.

Justicia, Abogados, Apoderados, Tierras, Labradores

\section{RÉSUMÉ/MotS-CLÉS}

L'article étudie le rôle des avocats et des chargés de pouvoir dans les litiges relatifs à la terre dans plusieurs villages indigènes du Chiapas tout au long du XIX ${ }^{e}$ siècle. Il analyse en particulier les stratégies que ces représentants légaux ont employées au cours des jugements ainsi que les arguments juridiques entrés en jeu, dans le but de montrer quelques-unes des difficultés que les paysans indigènes et ladinos pauvres ont rencontré au moment de défendre leurs terres devant les tribunaux.

Justice, Avocats, Chargés de pouvoir, Terres, Petits paysans

\section{ABSTRACT/KEYWORDS}

The article examines the role of lawyers and legal representatives in land disputes in various indigenous towns of Chiapas throughout the nineteenth century. It analyses the strategies that these legal representatives employed in the land trials, as well as the legal arguments they brought in play, in order to show some of the difficulties faced by indigenous peasants and poor ladinos while defending their lands before the courts.

Justice, Lawyers, Delegated Authorities, Land, Farmers 



\title{
El Asesor Jurídico, una revista popular de jurisprudencia en vísperas de la Revolución (México, 1907-1909)
}

\author{
Daniela MARINO \\ INAH, México
}

\section{Introducción ${ }^{1}$}

EXISTEN NUMEROSOS ESTUDIOS SOBRE LA prensa en el siglo XIX mexicano, la mayoría centrados en los periódicos activos del porfiriato (1876-1911)². El mayor número de publicaciones existentes en este periodo, en la capital como en los estados, y una mayor especialización de las mismas son razones de peso para ello ${ }^{3}$. La relativa expansión educativa en contextos urbanos y la creciente difusión de conocimientos científicos y técnicos de la mano del paradigma modernizador y de "progreso" tuvieron un papel importante en la consolidación de revistas económicas y financieras ${ }^{4}$, agrícolas $^{5}$, médicas $^{6}$ y jurídicas ${ }^{7}$, entre otras. Para otro contexto, ha sido señalado

1. Investigación realizada en el marco del proyecto binacional "Justicia y Sociedad en México, siglos XVIII a XXI", Acuerdo México-Francia, SEP-CONACYT-ANUIES-ECOS NORD, 2017-2020.

2. La mayor parte de la historiografía ha utilizado la prensa como fuente histórica para diversos temas (la política y el género principalmente), pero solo en menor medida para realizar una historia de la prensa. Un esfuerzo reciente son los congresos y obras colectivas coordinadas por la Red de Historiadores de la Prensa y el Periodismo en Iberoamérica (Adriana Pineda (coord.), Recorridos de la prensa moderna a la prensa actual, UMSNHUAQ-Red HPPI, Morelia, 2015; Adriana Pineda y Fausta Gantús (coord.), Miradas y acercamientos a la prensa decimonónica, UMSNH-Red HPPI, Morelia, 2013).

3. Los avances técnicos, como la introducción del linotipo y la rotativa, modificaron y facilitaron la producción de los periódicos, aumentando su número; Toussaint, Florence, Escenario de la prensa en el porfiiriato, México, Universidad de Colima, Fundación Manuel Buendía, 1989.

4. Riguzzi, Paolo, "El surgimiento de la prensa financiera en México, 1870-1900", inédito [http://redestudiosprensa.mx/hdp/files/262.pdf].

5. Zuleta, Ma. Cecilia, "La prensa agrícola del porfiriato como fuente para la historia económica (ensayo de fuentes)", Signos Históricos, 12, dic. 1999, p. 65-66.

6. Azuela Bernal, Luz Fernanda, "Las ciencias médicas en las publicaciones del siglo xIx", Ciencia, 63:2, abriljunio 2012, p. 78-84.

7. No hemos encontrado estudios sobre publicaciones periódicas de contenido jurídico que trasciendan la enumeración cronológica. 
el rol de revistas vinculadas a corporaciones que desarrollaban "saberes expertos" o bien intereses particulares (médicos, higienistas, ingenieros, abogados, industriales), en la divulgación de los mismos para crearse una posición de autoridad y así influir en los diagnósticos y el diseño de políticas públicas en materias sensibles como la "cuestión social" o el debate proteccionismo-librecambio ${ }^{8}$. En el ámbito jurídico mexicano del periodo, la promulgación de ordenamientos encauzados a regular y modernizar diversos ámbitos de la vida nacional (y, en particular, el económico) refuerzan el argumento de la necesaria divulgación entre y más allá de los especialistas9.

Para explorar este último argumento, analizaremos una revista dirigida por dos abogados interesados en divulgar los conocimientos jurídicos y administrativos a actores legos de pequeñas localidades, así como en apoyarlos explicando procedimientos y proporcionando diversos formularios necesarios para cumplimentar trámites ante los juzgados y las oficinas de gobierno. Este bisemanario, titulado $E l$ Asesor Jurídico. Revista popular de jurisprudencia y legislación. Publicación dedicada especialmente a dar a conocer los FORMULARIOS útiles para toda clase de gestiones juridicas, administrativas, mercantiles y fiscales (en adelante: EA), es nuestra fuente principal. Estudiaremos a sus responsables, el carácter, formato, lenguaje y sus destinatarios, así como su interlocución con los lectores para determinar el alcance de su propuesta; a diferencia de las revistas jurídicas coetáneas, ésta no está dirigida a sus pares letrados ni a influir en el diseño de políticas estatales. Su objetivo declarado era apoyar a los hombres de pequeños poblados donde no residían abogados ni era posible, por tanto, obtener apoyo legal. Plantearemos la hipótesis de que, debido a los elevados índices de analfabetismo rural, este tipo de prensa era utilizada por los mediadores legos pueblerinos, más que por los mismos campesinos.

Queremos proponer, además, que tanto las mayores posibilidades de producción y difusión de la prensa en este periodo, como el contexto de abogados titulados que no encuentran acomodo laboral en la administración ni en los despachos, algunos de los cuales se volcaron al periodismo o a promocionar los ubicuos litigios agrarios del momento, se conjuntan en el caso del Lic. Del Castillo. Este habría diseńado la revista como un medio para ofrecer sus servicios profesionales, no en la capital, donde enfrentaba fuerte competencia, sino en las áreas rurales muy necesitadas de asesoramiento legal para afrontar los profundos cambios jurídicos en el sistema de propiedad del suelo, el subsuelo y los recursos asociados ${ }^{10}$. Pensamos que la

8. González Leandri, Ricardo y Suriano, Juan (ed.), La Cuestión Social y sus itinerarios de difusión a través de las publicaciones periódicas argentinas, 1870-1930, Rockville, Global South Press, 2017; Plotkin, Mariano y Jimena Caravaca, "Publicaciones especializadas y liberalismo periférico. Notas sobre la transmisión de ideas económicas en Argentina (1870-1890)", Revista de Indias, LXXIII: 257, enero-abril 2013, p. 55-80.

9. Durante el porfiriato (1876-1910) se completó la codificación civil, penal y de procedimientos, y se expidió importante legislación sobre comercio, instituciones financieras, minería, aguas, colonización y deslinde, ejidos, etc. Fix-Fierro, Héctor "Porfirio Díaz y la modernización del derecho mexicano", in Ávila, Raúl et al. (coord.), Porfirio Díaz y el derecho. Balance crítico, México, Cámara de Diputados-UNAM, 2015, p. 15-32.

10. Similares procesos de intensa transformación legal y litigiosidad respecto a propiedad y fiscalidad, paralelos a la relativa ausencia de letrados e instituciones estatales en las pequeñas poblaciones rurales (espacios llenados 
exploración de estos elementos nos permitirán concluir sobre aspectos claves que la historiografía sobre la justicia transicional decimonónica ha planteado: la profesionalización de los agentes jurídicos, la difusión de la cultura jurídica moderna más allá de la élite letrada y el acceso a la justicia de sectores amplios de la población.

\section{Las publicaciones jurídicas}

La edición de obras de compilación existe en Hispanoamérica desde 1603, cuando Juan de Hevia Bolaños publicó en Lima su Curia Philippica, el libro clásico de derecho procesal en el mundo moderno hispánico. En el siglo Xvin existían ya numerosos ejemplos que explicaban de modo práctico cómo llevar un juicio (Febrero, Sala, etc.) y en el siglo xix, tomando estos modelos, aparecen en México obras que mantenían lo que del derecho español seguía vigente y agregaban el derecho nacional que se iba promulgando (Febrero mejicano, Nuevo Febrero Mejicano, Novisimo Febrero Mejicano, Curia Filípica mejicana, Sala mejicano, Nuevo Sala mejicano, Novísimo Sala mexicano... $)^{11}$.

La prensa periódica especializada puede ser un derivado de esta literatura jurídica de añeja tradición, pero tiene también características propias de la modernidad. Observamos (cuadro 1) que ciertas revistas surgen ligadas a asociaciones modernas de abogados o a escuelas superiores de derecho y se perfilan como ámbitos de recepción y difusión de autores y corrientes europeas, así como del desarrollo académico y profesional colegiado de la élite jurídica de la capital y de un par de ciudades principales. Otros periódicos son editados por los gobiernos para cumplir con el precepto de publicidad de las leyes y las sentencias judiciales. Finalmente, existe un par de ejemplos de revistas "populares" o "prácticas" que mantienen la idea de explicar los procedimientos jurídicos y trámites administrativos, pero que ahora se destinan a la vulgarización de dichos conocimientos a un público más amplio, no necesariamente letrado, dada cuenta de la expansión de los trámites administrativos y presentaciones judiciales que la consolidación estatal requiere a los ciudadanos. El "perfeccionamiento" de la propiedad es uno de los tópicos en esta expansión.

Afirmamos, entonces, que las revistas jurídicas mexicanas aparecieron con la modernización jurídica. La segunda en editarse (El Derecho. Órgano de la Academia Mexicana de Jurisprudencia y Legislación) salió a la calle el 29 de agosto de 1868,

por procuradores legos y costumbres locales), han sido analizados en otros contextos latinoamericanos del periodo. Palacio, Juan Manuel, La paz del trigo. Cultura legal y sociedad local en el desarrollo agropecuario pampeano, 1890-1945, Buenos Aires, Edhasa, 2004, cap. 6: "Abogados”; di Gresia, Leandro, "Una aproximación al estudio de la cultura judicial de la población rural del sur bonaerense. Tres Arroyos, segunda mitad del siglo XIX", in D. Barriera (coord.), La justicia y las formas de la autoridad. Organización politica y justicias locales en territorios de frontera, Rosario, ISHIR-CONICET, 2010, p. 155-191; Bilot, Pauline, "Las causas por torcida administración de justicia: mirada letrada hacia prácticas legas en Chile, 1824-1875", SudHistoria, no 5, 2012, p. 99-123; Brangier, Víctor, A. Díaz y G. Morong, "Acusaciones contra jueces legos ante jueces de letras: uso social del avance de la justicia letrada, centro-sur de Chile, 1824-1875”, História Unisinos, 22: 1, enero-abril 2018, p. 75-87.

11. Soberanes Fernández, José Luis, "Prólogo", Curia Filípica Mejicana. Obra completa de práctica forense conteniendo además un tratado integro de la jurisprudencia mercantil, México, UNAM-Porrúa, 1991 [1858], p. VII-XIII. 
cuando estaban por promulgarse los primeros códigos civiles ${ }^{12}$. No solo la codificación fue un aliciente para estas revistas, que básicamente publicaban íntegros los textos de leyes, códigos, decretos y jurisprudencia, así como artículos de análisis doctrinario y de historia jurídica; con la promulgación de la Ley de Amparo el Congreso de la Nación determinó la publicación necesaria del Semanario Judicial de la Federación que, a partir de 1870, publica las ejecutorias de la Suprema Corte de Justicia ${ }^{13}$. El siguiente periódico más antiguo surge a mediados de 1873. El Foro fue una de las revistas académicas más respetada y de más larga vida, en cuyos consejos de redacción, renovados cada año, figuraron los abogados más prestigiosos de la capital.

Hemos sintetizado en el cuadro 1 la información sobre las publicaciones periódicas de derecho aparecidas en México desde la restauración de la República hasta fines del porfiriato, con excepción de los boletines oficiales (ver nota 14). Esta información puede resultar incompleta, sobre todo respecto a las revistas de los estados, pero la hemos incluido porque una de nuestras hipótesis es que El Asesor Jurídico fue tan bien recibido en provincia por la inexistencia de este tipo de publicaciones, así como por la dificultad de encontrar, o costear, asesoría legal profesional. La caracterización del público al que iba dirigida cada revista (contenida en la última columna), la hemos obtenido de la descripción de las mismas en los textos de Cruzado y García Moreno y de la revisión de ejemplares de varias de ellas en la Hemeroteca Nacional Digital.

\begin{tabular}{|c|c|c|c|c|c|c|}
\hline TÍTULO & CIUDAD & FECHAS & $\begin{array}{c}\text { PERIODICI- } \\
\text { DAD }\end{array}$ & DIRECTOR & $\begin{array}{c}\text { PRODUC- } \\
\text { TOR }\end{array}$ & PÚBLICO \\
\hline El Derecho & México & $\begin{array}{c}\text { ago } 1868 \text {-jun } \\
1870 \\
\text { ene } 1871- \\
\text { may } 1872 \\
\text { mayo } 1890- \\
1898 \\
\end{array}$ & semanal & $\begin{array}{l}\text { Agustín } \\
\text { Verdugo } \\
\text { y A. Ramos } \\
\text { Pedrueza }\end{array}$ & $\begin{array}{c}\text { Academia } \\
\text { Mexicana } \\
\text { de Juris- } \\
\text { prudencia y } \\
\text { Legislación }\end{array}$ & abogados \\
\hline El Foro & México & Jun 1873-1891 & diario & $\begin{array}{l}\text { Pablo Macedo y } \\
\text { Justo Sierra }\end{array}$ & Particulares & abogados \\
\hline El Litigante & Guadalajara & $\begin{array}{l}\text { Mar 1881- } \\
\text { 1894-?" }\end{array}$ & semanal & Cenobio Enciso & Particulares & abogados \\
\hline $\begin{array}{c}\text { Anuario de } \\
\text { Legislación y } \\
\text { Jurisprudencia }\end{array}$ & México & Feb 1884-1898 & quincenal & $\begin{array}{c}\text { Pablo y Miguel } \\
\text { Macedo }\end{array}$ & Particulares & abogados \\
\hline
\end{tabular}

12. Esta es la revista más antigua de las 15 activas en 1894 de las que da cuenta Manuel Cruzado, Memoria de la Bibliografía Jurídica Mexicana, México, Antigua Imprenta de E. Murguía, 1894, cap. IV. No obstante, en la Hemeroteca Nacional Digital de México se encuentra El Observador judicial y de legislación. Periódico que contiene todas las leyes y decretos dados por el Exmo. Señor Presidente Provisional D. Antonio López de SantaAnna, desde la época de nuestra regeneración política. Establecido á impulso del Exmo. Señor Ministro de Justicia e Instrucción pública Don Crispiniano del Castillo, impreso por Vicente García Torres, fue un boletín oficial de legislación que apareció semanalmente durante 1842 y 1843, bajo la dirección del "licenciado Y. de T.".

13. Igualmente, El Boletín Judicial fue creado por el Código de Procedimientos Civiles del Distrito y Territorios Federales de 1884, debiendo publicar las listas de acuerdo y avisos judiciales de los tribunales y juzgados de lo civil y menores de la capital; Anales del Ministerio Público se publicaba por el gobierno federal en obediencia al reglamento de 1891 . 


\begin{tabular}{|c|c|c|c|c|c|c|}
\hline $\begin{array}{c}\text { Foro Vera- } \\
\text { cruzano }\end{array}$ & Jalapa & $1886-?$ & ? & $\begin{array}{l}\text { M. García } \\
\text { Méndez }\end{array}$ & Particulares & abogados \\
\hline $\begin{array}{l}\text { La Escuela de } \\
\text { Jurisprudencia }\end{array}$ & México & 1887 & quincenal & ? & $\begin{array}{c}\text { Escuela } \\
\text { Nacional de } \\
\text { Jurisprudencia }\end{array}$ & $\begin{array}{l}\text { abogados, } \\
\text { estudiantes }\end{array}$ \\
\hline $\begin{array}{c}\text { Revista de } \\
\text { Legislación y } \\
\text { Jurisprudencia }\end{array}$ & México & $\begin{array}{c}\text { Feb 1889-dic } \\
1890 \\
\text { Jul } 1893-1909\end{array}$ & $\begin{array}{c}\text {-1895: } \\
\text { quincenal } \\
1895-: \\
\text { mensual }\end{array}$ & $\begin{array}{c}\text { Emilio } \\
\text { Rabasa y } \\
\text { V. M. Castillo }\end{array}$ & Particulares & abogados \\
\hline $\begin{array}{l}\text { Guía Práctica } \\
\text { del Derecho }\end{array}$ & México & $\begin{array}{c}\text { May 1889- } \\
\text { dic } 1890 \\
\text { Ene } 1891-1897\end{array}$ & semanal & $\begin{array}{l}\text { Antonio de } \\
\text { J. Lozano }\end{array}$ & $\begin{array}{c}\text { Colegio } \\
\text { Nacional de } \\
\text { Escribanos } \\
\end{array}$ & $\begin{array}{l}\text { popular, aboga- } \\
\text { dos, escribanos }\end{array}$ \\
\hline $\begin{array}{c}\text { El Foro } \\
\text { Guanajuatense }\end{array}$ & Guanajuato & ¿-1894-? & semanal & $\begin{array}{l}\text { Zenón } \\
\text { Guerrero }\end{array}$ & $\begin{array}{l}\text { Cátedra de } 6^{\circ} \\
\text { año Derecho } \\
\text { Colegio Civil } \\
\text { de Guanajuato }\end{array}$ & $\begin{array}{l}\text { abogados, } \\
\text { estudiantes }\end{array}$ \\
\hline $\begin{array}{c}\text { El Foro } \\
\text { Jalisciense }\end{array}$ & Guadalajara & Junio 1892-? & quincenal & $\begin{array}{c}\text { José López } \\
\text { Portillo y Rojas }\end{array}$ & Particulares & abogados \\
\hline $\begin{array}{c}\text { El Foro } \\
\text { Michoacano }\end{array}$ & Morelia & Sept 1892-? & quincenal & $\begin{array}{c}\text { Melchor } \\
\text { Ocampo M. }\end{array}$ & Particulares & abogados \\
\hline $\begin{array}{c}\text { El Foro } \\
\text { Colimense }\end{array}$ & Colima & Feb 1893-? & mensual & Demetrio Sodi & Particulares & abogados \\
\hline Gaceta Judicial & Veracruz & ¿-1894-? & $?$ & $\begin{array}{l}\text { Enrique M. } \\
\text { Reyes }\end{array}$ & Particulares & abogados \\
\hline $\begin{array}{c}\text { La Ciencia } \\
\text { Jurídica }\end{array}$ & México & $\begin{array}{l}1897-1898 ? \\
1900-1902 ?\end{array}$ & quincenal & $\begin{array}{l}\text { Agustín } \\
\text { Verdugo }\end{array}$ & Particulares & abogados \\
\hline $\begin{array}{l}\text { Anales de la } \\
\text { Legislación } \\
\text { Federal }\end{array}$ & México & Ene $1898-1908$ & mensual & $\begin{array}{l}\text { 1898: Antonio } \\
\text { de J. Lozano. }\end{array}$ & Particulares & abogados \\
\hline $\begin{array}{l}\text { Revista Jurídica } \\
\text { Popular }\end{array}$ & ? & 1905 & ? & $\begin{array}{l}\text { J. R. del Cas- } \\
\text { tillo y Vicente } \\
\text { Villada C. }\end{array}$ & Particulares & popular \\
\hline Gaceta & San L. Potosí & 1906-? & mensual & ? & $\begin{array}{l}\text { Soc. Potosina } \\
\text { de Abogados }\end{array}$ & abogados \\
\hline $\begin{array}{c}\text { El Asesor Jurí- } \\
\text { dico. Revista } \\
\text { popular de } \\
\text { Jurisprudencia }\end{array}$ & México & $\begin{array}{c}\text { Feb 1907-dic } \\
1909\end{array}$ & $\begin{array}{l}\text { 1907: mensual } \\
\text { 1908-09: } \\
\text { quincenal }\end{array}$ & $\begin{array}{c}\text { José R. del } \\
\text { Castillo y José } \\
\text { Peón del Valle }\end{array}$ & Particulares & popular \\
\hline
\end{tabular}

Cuadro 1 - Periódicos jurídicos mexicanos 1868-1910**

Fuente: Cruzado, Manuel, op. cit., cap. IV; García Moreno, Victor, op. cit.; Hemeroteca Nacional Digital de México. * En FECHAS, 1894? significa que aparece en el libro de Manuel Cruzado (1894) pero no conocemos el año en que dejó de publicarse; ¿ 1894? Significa que, además, Cruzado no especificó la fecha de inicio de la publicación. ** Se excluyeron los periódicos oficiales, que respondían a una obligación de publicidad de las leyes: Semanario Judicial de la Federación, Boletín Judicial (Distrito Federal), Anales del Ministerio Público (federal), Boletín del Ministerio Público (Jalisco).

\section{El Asesor Jurídico}

A fines del porfirismo, el abogado José R. del Castillo dirigió por tres años una empresa bastante original para la época: publicar una revista jurídica práctica, destinada a ampliar la cultura jurídica de los usuarios, así como de los operadores políticos y del derecho en provincia y facilitarles todos los formularios necesarios para acometer diversos procedimientos del orden civil, penal y mercantil. Con ello continuaba con su propio ejemplo de 1905 y, posiblemente, el de Anto- 
nio de Jesús Lozano (cuadro 1) ${ }^{14}$. Los dos primeros años, codirige la revista el también abogado José Peón del Valle. En septiembre de 1908 se incorpora como editor responsable Cirilo R. del Castillo (quien no usa título de Licenciado y seguramente es familiar de nuestro abogado), en diciembre de ese año se retira J. Peón de la co-dirección pues ha sido electo diputado nacional y, a lo largo del primer semestre de 1909, el nombre de J. del Castillo va dejando sucesivas secciones de la revista, que pierde el carácter consultor y solo publica leyes in extenso, formularios jurídicos y notas sobre diversos temas (incluso, en el segundo semestre de 1909, un folletín por entregas de tema criminal).

El Asesor Jurídico apareció en febrero de 1907 de forma mensual. El 15 de febrero de 1908 se publica el primer número de su segundo ańo (el $\left.n^{\circ} 13\right)$, en el que su director anuncia que, ante la buena acogida de los lectores, la revista se publicaría quincenalmente, periodicidad que mantuvo todo ese año y el siguiente. En el último número de 1909 (el no 58, de 30 de diciembre) se incluye un índice general del tomo II (correspondiente a 1908 y 1909), y el editor anuncia que José R. está regresando de un viaje por Baja California y EEUU (razón por la que se había retirado la sección de consultas), así como los temas que se tratarían en el siguiente año. No hemos podido ubicar ningún número de ese tomo III, por tanto no sabemos si José del Castillo reasumió la edición de la revista. El corpus analizado lo constituyen entonces cuarenta y seis números del tomo II, que se encuentran resguardados en la Hemeroteca Nacional de México.

\section{Los editores y el contexto político}

Si en 1905 J. del Castillo editó con V. Villada la Revista Jurídica Popular y de principios de 1907 a fines de 1909 EAJ, con J. Peón y C. del Castillo, en la década siguiente publicaría sus tomos de formularios: en 1910, los necesarios para llevar adelante todos los procedimientos de un juicio civil ${ }^{15}$; en 1916 , los requeridos

14. No hemos podido encontrar la Revista Jurídica Popular que, según V. García Moreno, J. del Castillo dirigió con Vicente Villada Cardoso en 1905. Este era hijo del Gral. José Vicente Villada: periodista, héroe militar durante la Intervención francesa y gobernador por 15 años, hasta su muerte, del Estado de México. Villada Cardoso ocupó diversos puestos administrativos y legislativos desde la gestión de su padre en el Estado de México (fue diputado estatal de 1901 a 1905) y era diputado nacional en 1910 (es uno de los dos diputados que dirigen al representante de Francisco I. Madero el oficio notificándole no ha lugar la anulación de las elecciones); "Oficio de la Cámara de Diputados declarando no haber lugar a la anulación de las elecciones federales de 1910”, firmado por Vicente Villada Cardoso y A. de la Peńa y Reyes, 27 de septiembre de 1910, en González Garza, Federico, Revolución Mexicana: mi contribución político-literaria, México, INEHRM, 1985, p. 191.

15. Castillo, José R. (del), Práctica de enjuiciamiento civil: formularios de toda clase de juicios, incidentes, recursos, sentencias, pedimentos y diligencias del orden civil. Obra escrita conforme a la legislación del Distrito Federal y territorios y anotada en concordancia con los códigos civil y de enjuiciamiento civil de todos los Estados de la república, México, Librería de la Viuda de Ch. Bouret, 1910, 768 p. 
para sustanciar juicios criminales ${ }^{16}$, así como el libro de Formularios hereditarios ${ }^{17}$; y en 1920, su Práctica mercantilis.

Su obra editorial se complementa con dos libros históricos: en 1904 escribe uno refutando el panfleto de Francisco Bulnes en contra de Benito Juárez ${ }^{19}$, lo que lo ubica como liberal juarista, muy probablemente nacido hacia o antes de 1870 , uno de varios elementos coincidentes con abogados de su generación, algunos de los cuales, a diferencia de él, destacarán en la construcción del orden posrevolucionario, como Andrés Molina Enríquez y Luis Cabrera ${ }^{20}$. Por otra parte, en 1915 publica un recuento histórico del fin del régimen de Porfirio Díaz, en el que intenta cierta ecuanimidad, reconociendo algunos aciertos del estadista, pero crítico con las últimas decisiones del dictador y, particularmente, con su entorno, en especial contra los científicos ${ }^{21}$. El título de este libro denota un interés por acomodarse en el nuevo régimen, aunque, sin la alusión a Díaz ni a los científicos, es de reconocer que estas ideas estaban ya presentes en EAJ. Esta obra nos brinda algunos datos de su biografía y del co-director de la revista, José Peón del Valle; prácticamente toda la información que existe sobre él. En 1902 trabajaba como abogado consultor en el Ministerio de Guerra, cuando su titular, el Gral. Bernardo Reyes, se vio forzado a renunciar y retornar a la gubernatura de Nuevo León. Por la lista de M. Cruzado, sabemos que él también dejó su puesto, pues en 1903 es defensor de pobres en el ramo penal ${ }^{22}$. Ya no era un burócrata en 1905, cuando publica la revista con Vicente Villada, ni a principios de 1907, cuando, con José Peón, inaugura El Asesor Jurídico. Por el texto fúnebre dedicado a Villada padre sabemos que su familia era de Michoacán, de la región Pátzcuaro-Uruapan; tal vez él mismo nació allí, ya que por M. Cruzado sabemos que no estudió en la Escuela Nacional de Jurisprudencia.

16. Castillo, José R. (del),) Práctica de enjuiciamiento criminal: obra que contiene todos los formularios y explicaciones necesarias para formar una perfecta "instrucción criminal", con un apéndice de formularios de enjuiciamiento militar, con 172 formularios en juicios criminales, México, Porrúa, 1916, VII + 501 p.

17. Tip. El Siglo xx, 1916, 120 p.

18. Castillo, José R. (del), Práctica de enjuiciamiento mercantil: El libro más útil para los comerciantes y los hombres de negocios. Contiene el estudio de las operaciones más usuales entre los comerciantes, con más de 200 formularios de toda clase de documentos; con todas los pedimentos, promociones, actuaciones... que se tramitan en los juicios mercantiles, tanto para promover como actor, como para defenderse como demandado, México, Porrúa, 1920, 298 p.

19. Castillo, José R. (del), Juárez, la intervención y el imperio. Refutación a la obra "El verdadero Juárez" de Bulnes, México, Herrero Hermanos editores, 1904. El año siguiente publica el texto final de Mayo 6 de 1904. Corona fúnebre del Sr. Gral. D. José Vicente Villada, Gobernador del Estado de México, Toluca, Of. Tip. del Gob. en la Escuela de Artes y Oficios, 1905, p. 124-129, texto laudatorio donde le llama "mi paternal amigo y mi protector".

20. Sus socios en las revistas que publicó nacieron en 1866 (José Peón del Valle, quien se tituló de abogado en 1893 y falleció en 1924) y en 1876 (Vicente Villada C.).

21. Castillo, José R. (del), Historia de la revolución social de México. Primera etapa: la caída del general Diaz. Apuntes y observaciones para formar la historia politica de México desde 1908 a 1915, México, s./d., reeditada en facsimilar por INEHRM, 1985. Este libro de 1915 tuvo bastante eco: lo citan Díaz Soto y Gama, Antonio, Historia del Agrarismo en México (s./f.), México, Era, 2002; López Portillo y Rojas, José, Elevación y caída de Porfirio Díaz, 1921; y Arenas Guzmán, Diego, El periodismo en la Revolución mexicana, de 1876 a 1908, México, INEHRM, 1966, entre otros.

22. Del Arenal Fenochio, Jaime, "Abogados en la ciudad de México a principios del siglo xx (la lista de Manuel Cruzado)”, in Anuario Mexicano de Historia del Derecho, vol. X, 1998, p. 39-47. 
Sobre su socio tenemos más información, pues era hijo del médico y famoso poeta yucateco José Peón Contreras, y se involucró en política tras la coyuntura abierta por la entrevista Díaz-Creelman en 1908. Ese ańo, aparece como segundo vicepresidente del naciente Partido Demócrata, encabezado por Benito Juárez (h) y cuyo primer vicepresidente era Manuel Calero, creado por abogados y periodistas porfiristas para difundir los principios democráticos y mantenerse neutral en la pugna por la vicepresidencia, si bien buen número de sus miembros eran partidarios de Bernardo Reyes ${ }^{23}$. En diciembre de ese año, Peón del Valle desaparece como co-director de la revista: en las elecciones de 1908 los tres demócratas han ganado diputaciones federales. Peón es vicepresidente de la Cámara cuando Díaz renuncia en 1910 y, de hecho, él y Benito Juárez (h) son los únicos diputados que votan en contra.

Aunque no tenemos información sobre que Castillo se hubiera involucrado directamente en política, corroboramos que sus relaciones sociales se inscriben dentro del reyismo ${ }^{24}$. Por otra parte, sus socios sí: como hemos visto, son diputados federales en la última legislatura porfirista, y probablemente en el mismo bando, puesto que Benito Juárez (h), junto con P. Díaz (h), son dos de las figuras políticas prominentes en los funerales del Gral. Vicente Villada, a los que también asiste Andrés Molina Enríquez (otro favorecido por B. Reyes), entre otros políticos, intelectuales y empresarios. Al terminar su encargo, Peón del Valle viaja a Europa y fallece en Nueva York en 1924. Vicente Villada Cardoso se queda en el país y ya no participará en política, ni destaca tampoco en el foro. Como para otros porfiristas, la Revolución significó un cambio de suerte. Las nuevas élites posrevolucionarias o habían sobresalido en la lucha contra el régimen, o serían jóvenes sin compromisos políticos previos: pensamos en la famosa "generación de 1915" de la Escuela Nacional de Jurisprudencia: los abogados Manuel Gómez Morín, Daniel Cosío Villegas, Lucio Mendieta y Núnez, Vicente Lombardo Toledano, entre otros; todos ellos constructores de instituciones culturales en el México posrevolucionario.

José R. del Castillo no quedó en ninguno de los dos grupos. Aunque su nula militancia política, su moderada crítica social agraria sin despegarse del modelo de propiedad liberal (en el mismo tenor que A. Molina Enríquez y L. Cabrera, por ejemplo) y sus dos libros de historia lo situaban del lado correcto tras la Revolución, entre 1910 y 1920 sólo registra actividad editorial, para desaparecer después.

De los dos co-directores, José del Castillo realiza la mayor parte del trabajo editorial $y$, además, es el único que se anuncia profesionalmente en la revista. Por otra parte, el interés por la revista radica en la originalidad de la propuesta y en lo que implica para

23. Guerra, François X., op. cit., tomo II, p. 105-110 y 118-119.

24. Aunque los partidos políticos estuvieron prohibidos durante el porfiriato, al interior del gabinete se formaron dos grupos: los "científicos", dirigidos por el Secretario de Hacienda, José Ives Limantour, y los “reyistas", liderados por el Gral. Bernardo Reyes, quienes se disputan la influencia sobre el presidente y, a partir de 1903 (cuando se crea la figura de vicepresidente) se enfrentarán por la postulación del candidato a acompañar a Díaz en la fórmula electoral. El alejamiento de Reyes de la cartera de Guerra, y de la capital, obedeció a dicha rivalidad y al temor de Díaz ante el creciente apoyo político de dicho personaje. En 1903, Díaz se reeligió acompañado de un vicepresidente "científico". 
entender la difusión de la cultura jurídica liberal codificada, así como en el crecimiento de un sector medio de abogados, notarios, jueces y otros intermediarios jurídicos y en el interés creciente de personas legas por los asuntos jurídicos que afectaban sus actividades económicas. Asimismo, para ahondar en las salidas laborales para los abogados del periodo, como el periodismo y el patrocinio de litigios, fundamentalmente agrarios.

\section{El contenido}

La revista publicó su segundo volumen ininterrumpidamente durante 1908 y 1909, de manera quincenal. El formato de la revista consistía de 20 páginas, en doce de las cuales se publicaban textos sobre temas jurídicos y administrativos (aunque también leyes recientemente promulgadas ${ }^{25}$, artículos de difusión científica sobre agricultura y ganadería ${ }^{26}$, y otros sobre temas referidos a la "cuestión social" 27 ) y en las ocho restantes, formularios. Los textos eran explicativos, en lenguaje sencillo, acompañados en ocasiones de modelos de cartas u oficios para trámites específicos (los que llama 'formularios') sobre temas diversos, pues, como señala en el primer número de este volumen:

Aquí se hace necesaria la multiplicidad de asuntos de diaria práctica, los que se nos presentan de continuo, estudiados y presentados sencillamente, sin altos ni hondos estudios jurídicos, sino en una forma usual, fácil de conocer, llana, y con los formularios precisos para su aplicación.

Para del Castillo, más que un sabio estudio sobre testamentarías, por ejemplo,

... a nuestros abonados les es más útil una serie de formularios que les enseñe cómo se denuncia un intestado; cómo se pide el examen de testigos; cómo se pide el nombramiento de albacea; cómo se aseguran los bienes de la herencia; cómo se pide la nulidad de un testamento; cómo se hacen los inventarios...

En la intención de difundir y vulgarizar los conocimientos de los abogados a un público carente de dicha formación, al menos en su aplicación más práctica, encontramos similitudes entre esta propuesta y algunas revistas agrícolas analizadas por M. C. Zuleta (ver nota 5), más que con las revistas jurídicas del periodo que se dirigen a sus pares letrados ${ }^{28}$. En criterio de nuestro abogado, "nunca se han publicado esta clase de formularios”; al hacerlo, se estaba beneficiando

25. Por ejemplo, a partir del no 35, de 15/01/1909, se reproduce la Ley Orgánica del Poder Judicial de la Federación.

26. Por ej., a partir del no 33, de 15/12/1908, se publica una serie de artículos sobre la "Homeopatía aplicada a las enfermedades de los animales domésticos". Ver también: "La necesidad de obtener agua de regadío para las tierras. Hay que hacer progresar la agricultura", $E A J$, no 26, 31/08/1908, p. 157-159.

27. "El socialismo que acá se conoce resulta perjudicial ente los hombres de campo. Un tema de palpitante actualidad" y "Lo que opinamos acerca del trabajo del obrero mexicano", EAJ, no 34, 30/12/1908, p. 281283 у $295-297$.

28. Incluso la Guía práctica del Derecho de Antonio Lozano (cuadro 1), pese a incluir también "formularios", se dirigía a los abogados y notarios y no a un público general, como se desprende de los temas y lenguaje especializado de las notas. 
... a infinidad de personas que no pudiendo pagar los honorarios que cobran los abogados por esta clase de juicios, se abstienen de iniciarlos a la muerte de las personas de quienes son herederos, ocasionándose con esto un defecto gravísimo para la propiedad. Con nuestros formularios y las indicaciones que se nos pidan en consulta, creemos que bien se pueden iniciar y terminar toda clase de juicios de sucesión, erogándose únicamente los gastos fiscales necesarios ${ }^{29}$.

Vale la pena destacar este punto, pues como muestra E. Sanchez en este dossier, el costo de la asesoría legal de un abogado titulado solía ser muy oneroso, incluso para sectores medios. Así, si efectivamente la expansión de la cultura escrita y de las comunicaciones entre capitales y zonas rurales permitía el acceso de sectores medios alfabetizados al consumo de esta literatura jurídica práctica, se facilitaría que ellos mismos solventaran muchos trámites iniciales en una presentación administrativa o judicial. O tal vez, el manejo de esta literatura por quienes resultaban electos para ocupar un cargo municipal por un año (presidente municipal, síndico, regidor, conciliador, administrador de rentas, etc.), podía convertirlos en consultores cercanos, por no decir "tinterillos".

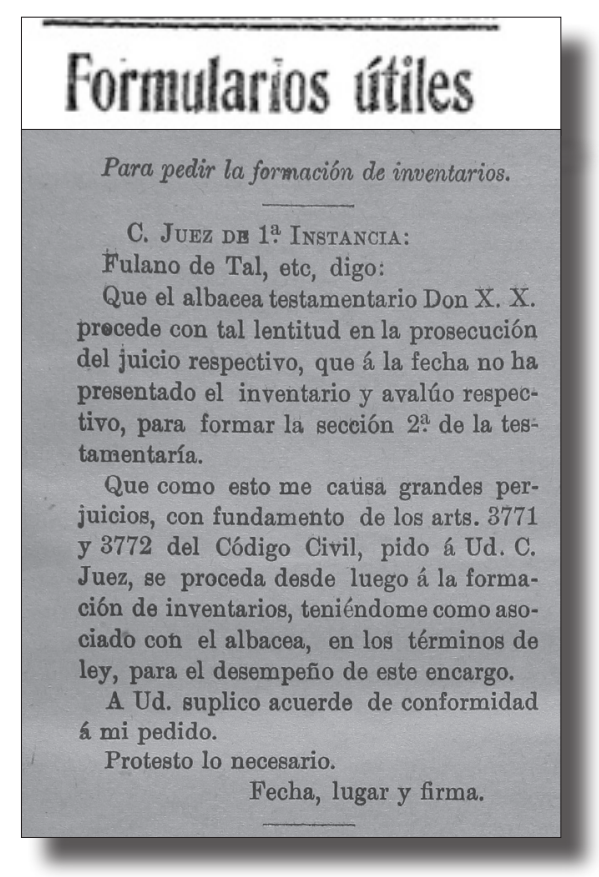

Imagen 1 - Ejemplo de formulario en $E A J$ Fuente: El Asesor Jurídico, no 19, 15-05-1908, p. 81.

Podemos ver (imagen 1) a qué se refieren los abogados-periodistas con "formulario": un formato ejemplo de carta a presentar ante la autoridad para cum- 
plimentar un trámite administrativo o jurídico. El formato, además de resolver la redacción en correcto castellano (aspecto nada desdeñable atendiendo al nivel educativo de la población mexicana de la época, particularmente la rural), incluye elementos que el oficio debe contener para ser aceptado y cumplir con su cometido: a cuál autoridad debe dirigirse, qué se debe solicitar específicamente y cuál es el sustento jurídico que debe incluirse para validar su pertinencia. El abogado proporciona un doble conocimiento: uno general, el dominio del español escrito; y uno específico, el dominio de la argumentación y el vocabulario jurídicos. Y todo esto, por el valor de 35 centavos.

A estos formularios genéricos, se sumaba la posibilidad de que el lector enviara una consulta específica que del Castillo respondería en el siguiente número anexando, de ser el caso, el formulario respectivo. Los requisitos para obtener estas ventajas eran sólo dos: saber leer y estar suscripto a la revista. Muchos de sus lectores, además de aprovechar esta asesoría para sí mismos, adquirían un capital cultural que podía redituarles ingresos si se desempeñaban como gestores y asesores de sus vecinos que no sabían leer y escribir. Este capital podía además completar, y asesorar, la experiencia adquirida por los notables locales que, por un año, ejercían en su municipio como presidente municipal, regidor, síndico, juez conciliador o de paz, administrador de rentas, etc. Estos cargos no requerían formación profesional, sólo demostrar la vecindad y saber leer y escribir, y generalmente eran ocupados por una minoría de hombres de sectores medios (propietarios, agricultores, comerciantes) que se rotaban entre los distintos cargos y aún, en el porfiriato, se reelegían por varios años sucesivos ${ }^{30}$. A ellos también se dirigía la revista.

Por ejemplo, desde el número 15 se publica la columna "Para los jueces de paz. Cómo deben practicar las primeras diligencias en toda clase de delitos". El juez de paz o juez conciliador era un vecino, lego, solo autorizado a resolver casos civiles y criminales leves, con la obligación de ejecutar las primeras diligencias de los graves y enviar las testimoniales al juez de primera instancia ${ }^{31}$. En dicho número, el delito considerado es el robo y, además de algunas recomendaciones de procedimiento, se publican los formularios que el juez municipal debe cumplimentar para resolverlo: denuncia, comprobación del cuerpo del delito, pruebas sobre la responsabilidad del acusado (indagatorias, careos), valoración de la cosa robada y sentencia. En los siguientes números se ocupará de fraude, lesiones, primeras diligencias en homicidio, delitos sexuales, juicio de conciliación, etc. El uso que estos personajes hacían de la revista se manifiesta en la sección de consultas, como aquélla que inquiere por el procedimiento a seguir cuando el citado a juicio verbal para responder una demanda no ha comparecido. En su respuesta, del Castillo reproduce el artículo 1082 del Código de Procedimientos Civiles, que indica la

30. Marino, Daniela, Huixquilucan: Ley y justicia en la modernización del espacio rural mexiquense, 1856-1910, Madrid, CSIC, 2016, p. 140-157.

31. Ibid. 
ruta a seguir, al tiempo que inserta un formulario de comparecencia y otro de auto del juez manifestando la rebeldía del citado ${ }^{32}$.

La presencia de estos intermediarios jurídicos en los pueblos rurales ha sido destacada por historiadores, aludiendo a los motes peyorativos (tinterillos, chupatintas, leguleyos, etc.) e incluso descripciones lombrosianas, que recibían de periodistas urbanos, propietarios y agentes estatales cuando el apoyo que brindaban a campesinos, comuneros o arrendatarios estorbaba los intereses de aquéllos, pero sobre todo analizando la importante función social que cumplían en lugares donde no llegaban procuradores e intérpretes estatales ni abogados titulados, o bien estos eran difícilmente costeables ${ }^{33}$.

En contraparte, la revista se enviaba a suscriptores de la ciudad y de provincia a un costo de $\$ 2.25$ por semestre o $\$ 4.25$ por año; el costo de los ejemplares sueltos era de 35 centavos. $\mathrm{Y}$, de los lugares donde no era posible realizar giros, se aceptaba el envío de timbres postales por el mismo valor. Esta apreciación sobre llegar a pequeñas poblaciones se hacía explícita en la revista:

Hemos estado remitiendo nuestra Revista en muchas poblaciones á personas que desempeñan los empleos de Jueces de $1^{\text {a }}$ Instancia, Presidentes Municipales, Jueces de Paz, Tesoreros Municipales, Jefes Políticos, Receptores de Rentas y Administradores del Timbre ${ }^{34}$.

... existen todavía infinidad de pueblos, ¡la mayoría! donde la propiedad comunal y los Egidos permanecen indivisos. Ahora bien, para esas poblaciones, y para sus vecinos desvalidos, para los proletarios es para quien escribimos estos artículos ${ }^{35}$.

Asimismo, aunque no se precisa el tiraje, en la revista se hablaba de una recepción excepcional:

La concesión que hacemos a nuestros subscriptores, de contestarles por carta particular sus consultas, mediante el envío de 25 cs. en timbres postales, nos ha llevado, en el año próximo pasado, a resolver seis mil trescientas diez y siete consultas ${ }^{36} \ldots$

32. EAJ, no 27, 15-09-1908, p. 178-179, consulta de J. M. de Villa de Cos, Zacatecas.

33. Estudios clásicos son: Lira, Andrés, "Abogados, tinterillos y huizacheros en el México del siglo xix", Memoria del III Congreso de Historia del Derecho Mexicano, México, UNAM, 1984, p. 375-392; para Ecuador: Guerrero, Andrés, "De protectores a tinterillos: La privatización de la administración de poblaciones indígenas (dominadas)", A. Guerrero y Heraclio Bonilla (ed.), Los pueblos campesinos de las Américas. Etnicidad, cultura e historia en el siglo XIX, Bucaramanga, UIS, 1996, p. 193-211. Más recientes: Aguirre, Carlos, "Tinterillos, Indians, and the State: Towards a History of Legal Intermediaries in Post-Independence Peru”, Stefan B. Kirmse (ed.), One Law for All? Western models and Local Practices in (Post-) Imperial Contexts, Frankfurt, Campus Verlag, 2012, p. 119-151; Palacio, Juan Manuel, op. cit.; Di Gresia, Leandro, op. cit., y el artículo de E. Sanchez en este dossier.

34. $E A J, \mathrm{n}^{\circ} 13,15 / 02 / 1908$, p. 6.

35. "Los terrenos que deben repartirse. Necesidades de los pueblos. Olvidos en que se tiene la ley. Abusos que se deben corregir", $E A J$, no 17, 15/04/1908, p. 50. Si bien, era mucho más improbable que hasta ellos llegara la revista.

36. $E A J, \mathrm{n}^{\circ} 13,15 / 02 / 1908$, p. 1. 
No tenemos manera de comprobar esos datos, pero la persistencia de la revista y la reducción de su periodicidad (de mensual a quincenal) indica cierto éxito editorial. Además de los ingresos obtenidos por su venta, recibía, ocasionalmente, otros por los libros ofrecidos (la revista no tenía avisos publicitarios externos). En todos los números recomienda y ofrece el envío de libros especializados con una pequeña comisión, por ejemplo al pie de varios artículos de la sección "Modelos de diversas escrituras públicas":

El Asesor Jurídico recomienda especialmente a sus lectores la obra del distinguido señor Lic. Agustín Silva y Valencia, titulada "Manual del Notario", cuyo precio es el de $\$ 3.50$ en esta capital. La enviaremos certificada y franca de porte a toda persona que nos remita $\$ 4.00$ en giro postal ${ }^{37}$.

En casi todos los números promociona "La Nueva Ley del Timbre con las últimas reformas" que enviarán a "toda persona que nos remita 50 centavos en timbres postales" 38 . Inclusive, "el primer tomo de los Formularios de El Asesor Jurídico está ya a la venta. Vale \$ 3.50 elegantemente empastado. Fuera de México, franco de porte y certificado, se lo remitiremos a toda persona que nos envíe CUATRO PESOS en giro postal"39.

Pero los mayores ingresos que esperaba recibir derivaban de utilizar la revista como la plataforma de promoción de sus servicios profesionales, a través de su "Agencia de negocios judiciales y administrativos", que publica como anuncio en la última página de cada número:

Se encarga de toda clase de asuntos judiciales, tanto del ramo civil y penal como en el federal; de gestionar composiciones de terrenos; titulación de minas; patentes de invención y marcas de fábrica; adquisición de caídas de agua para fuerza motriz; consolidación de derechos sobre aprovechamiento de aguas; reparto y adquisición de Egidos, etc., etc., ante la Secretaría de Fomento. Toma especial cuidado en los juicios de amparo que vienen en revisión a la Corte Suprema de Justicia de la Nación.

En algunas notas encontramos la propaganda de sus servicios. Por ejemplo, en una nota titulada "Tierras de común repartimiento", en la que denuncia la mala fe de muchas autoridades municipales que, al momento de realizar la desamortización de dicho tipo de tierras según los dictados de la legislación de la Reforma, se asignaron, a sí mismos o familiares o prestanombres, tierras de dicha calidad a las que no tenían derecho. Explica cuándo se puede pedir el recurso de nulidad, aconseja el recurso administrativo sobre el judicial y, a la hora de resaltar la importancia de

37. "Compra venta con hipoteca”, EAJ, no 18, 30/04/1908, p. 67; "Testamento abierto. No causa más timbre que el de protocolo", $E A J, \mathrm{n}^{\circ} 16,31 / 03 / 1908$, p. 47.

38. Por ej. EAJ, no 14, 29/02/1908, p. 13; EAJ, no 35, 15/01/1909, p. 308.

39. $E A J$, no $^{\circ} 18,30 / 04 / 1908$, p. 72 . 
que el recurso esté bien preparado por un abogado honesto, no vacila en ofrecer sus servicios para la tarea ${ }^{40}$.

En otro artículo sobre el derecho de los indígenas a la propiedad de los terrenos de común repartimiento y ejidos ya individualizados por las leyes de reforma y los decretos porfiristas de 1890, recalca la necesidad de los vecinos indígenas injustamente despojados de conseguir primero los títulos de dicha propiedad anteriormente comunal para, luego sí, litigar contra los actuales ocupantes ilegales. Reseña la legislación que establece sus derechos, así como (sin citarlo explícitamente), fragmentos de uno de los votos más claros de Ignacio Vallarta al respecto (en 1882, como presidente de la Suprema Corte), al tiempo que aconseja:

Los interesados pueden dirigirse directamente al Director del Archivo General de la Nación, pidiéndole la busca de títulos. Por nuestra parte, aceptaremos con mucho gusto los encargos de esta especie que se nos hagan, poniendo en relación directa a los interesados con el Director del Archivo. De esta suerte cesarán los abusos que hemos denunciado. Así es como queremos beneficiar a nuestros subscriptores, siéndoles útiles en dos formas: Primera, consiguiéndoles los títulos deseados. Segunda, libertarlos de las explotaciones de que han sido víctimas hasta la fecha ${ }^{41}$.

En otro tipo de casos, como los juicios hereditarios, abordados en una serie sobre "Perfeccionamiento de la propiedad", coloca una nota al pie donde advierte: "La Dirección de 'El Asesor Jurídico' se encarga de asesorar y dirigir toda clase de juicios testamentarios y de intestamentaría, cobrando honorarios sumamente módicos" ${ }^{\prime 2}$. En un artículo destinado a la figura del albacea, luego de asustar, literalmente, a los lectores sobre los terribles abusos que puede cometer este representante, se ofrece indirectamente:

En mi larga práctica profesional, como Agente del Ministerio Público y Juez, y como abogado postulante he visto tantos casos de infamias por parte de algunos albaceas, que escapan al castigo de las leyes; que al escribir este artículo no puedo menos que recordarlos, e inspirado en la práctica aconsejar útilmente a mis lectores tengan el más cuidadoso tino para nombrar albacea ${ }^{43}$.

Es en estos comentarios donde encontramos pruebas de su interés por aprovechar la situación contenciosa de la propiedad agraria para lograr ser contratado como litigante, albacea, asesor o gestor legal.

40. "Tierras de común repartimiento", EAJ, no 28, 30/09/1908, p. 190, nota al pie.

41. "La propiedad de los indígenas en los terrenos de comunidades. Los títulos de los pueblos", EAJ, no 18 , 30/04/1908, p. 64.

42. "Los herederos (1)", EAJ, no 14, 29/02/1908, p. 13-15.

43. "IV. Los juicios de sucesión. Los albaceas", EAJ, no 16, 31/03/1908, p. 37. No he encontrado pruebas de que efectivamente hubiera ocupado dichos cargos. Como he mencionado, solo testimonio de que fue defensor de pobres y la edición de otra revista entre su salida de la Secretaría de Guerra y el lanzamiento de EAJ. 
En este sentido, cabe retomar la reflexión realizada por E. Sanchez en este dossier, sobre si existe alguna utilidad en diferenciar entre abogados titulados y "tinterillos". En el mismo sentido, J.M. Palacio (op. cit.) denomina directamente "abogados" a los procuradores legos de los pueblos bonaerenses que cubren los espacios que no atendían los letrados. En otro lugar, llamé la atención sobre que, en ciertas circunstancias, las autoridades podían asignar el mote de "tinterillo" incluso a abogados titulados, en caso de que estos estuvieran patrocinando a una comunidad contra notables locales que se veían molestados en este cuestionamiento a sus derechos de propiedad ${ }^{44}$. En el caso de José del Castillo, la falta de un empleo formal deriva en su acercamiento al periodismo jurídico de divulgación como herramienta para promover sus servicios en localidades en las que no abundan los abogados. No obstante, hasta ahora no existe un estudio sobre las características del mercado de trabajo urbano para los abogados a principios del siglo xx que correlacione el número de egresados con la oferta laboral. Un estudio así nos permitiría ratificar o descartar el argumento - socorrido en la historiografía sobre la crisis del porfiriato acerca de las dificultades de los jóvenes licenciados de clase media para encontrar, o mantener, un empleo asalariado en el gobierno o un bufete establecido, lo que, en los últimos años del régimen (y particularmente a raíz de la crisis económica de 1907-1908), además de alimentar los grupos políticos anti-reeleccionistas, pudo haber orillado a los letrados a probar suerte en el periodismo, la política, y/o en campos que se veían como contenciosos y, por tanto, donde era factible ofrecerse como litigantes y asesores.

\section{La recepción}

En la primera página de cada número de la revista se puede leer cuáles eran los "Derechos de los suscriptores":

[...] a que les resolvamos gratuitamente y en carta particular las consultas que nos hagan, previo envío de 25 centavos en timbres postales. Sin hacernos ese envío sus consultas serán resueltas gratuitamente en el cuerpo de cada publicación, dándoles cuando se trate de asuntos de interés general los formularios convenientes. Toda consulta que nos llegue hasta el día 10 o 20 de cada mes será resuelto en el número correspondiente al día 15 o día último del mes. Las consultas podrán ser sobre cualquier punto de derecho o relativas a los trámites de un litigio, a las gestiones de cualquier asunto fiscal o administrativo, o a NEGOCIOS PARTICULARES ${ }^{45}$.

Eventualmente, algunas notas hacían referencia a estar respondiendo la consulta de un lector indeterminado ${ }^{46}$, pero a mediados de 1908 , se plantean brindar mayor

44. Marino, Daniela, "Ahora que Dios nos ha dado padre... El Segundo Imperio y la cultura jurídico-política campesina en el centro de México", in Historia Mexicana, LV/4, abril-junio 2006, p. 1384-1390.

45. Este anuncio desaparece a partir del no 44, de 30/05/1909.

46. Ejemplos: "De alguna población del Estado de Veracruz nos preguntan cuáles son las obligaciones de los Síndicos de los Ayuntamientos", EAJ, no 26, 31/08/1908, p. 167; “Adjudicación de terrenos de comunidad de menos de \$200. Como hemos recibido varias cartas pidiéndonos la publicación de la Ley que señala el 
atención a los suscriptores. Desde el no 20 y hasta el no 32 se publica el apartado "Sección de consultas", que incluía entre cuatro y ocho consultas de los lectores y sus respuestas.

Respecto de los temas sobre los cuales requerían la opinión del Lic. Del Castillo, podemos mencionar que la mayoría eran temas procesales (cómo y ante quién presentar determinado recurso, qué contratos se hacen en documento privado y cuáles en escritura pública, en qué casos se puede solicitar amparo, si se puede presentar un testigo que no habla español, cómo denunciar un bien mostrenco), aunque también se presentaban dudas conceptuales (¿qué se entiende por efecto suspensivo y efecto devolutivo en una apelación?), otras respecto al alcance de la ley (¿la condenación al pago de costas alcanza al pago de honorarios de un procurador no titulado?, ¿qué parentescos de consanguinidad reconoce la ley?). Los temas de consulta más frecuentes se referían a sucesiones, testamentarías y derecho de familia en general; a temas diversos sobre propiedad (como, un par de casos sobre tierras desamortizadas); deudas, pagarés y otros temas mercantiles; también encontramos casos de los estados del norte referidos a explotaciones mineras. De las consultas administrativas, muchas tenían que ver con el cobro del impuesto del timbre, así como procedimientos que debían llevar a cabo jueces de paz, síndicos y presidentes municipales (¿cómo se puede obligar a quien no ha comparecido a un juicio de conciliación cuando se le citó?, ¿`cómo se puede cobrar el impuesto predial de bienes desamortizados cuyos dueños fallecieron sin descendencia y cuyo valor es inferior al adeudo?).

En un par de las 55 consultas publicadas, J. del Castillo afirma no comprender la pregunta que se le hacía, lo que permite presumir un deficiente manejo del lenguaje de los remitentes. Del resto, podemos deducir que los consultantes eran vecinos de pequeñas y medianas localidades, algunos en funciones locales (jueces de paz, síndicos, presidentes municipales, administradores del timbre), otros propietarios, mineros o comerciantes con preguntas sobre la gestión de trámites administrativos y judiciales sobre sus respectivos intereses económicos, así como algunos individuos y parejas preocupados por no haber legitimado a sus hijos, o bien por conocer los procedimientos para heredar o compartir una herencia. Son minoría las consultas que involucran el ramo criminal: uno por estupro, otro por difamación. En resumen, la mayoría parece pertenecer a sectores medios y humildes de los pueblos, pero no completamente desposeídos.

El número de consultas, clasificadas por estados, junto con la lista de suscriptores morosos que se publicó en dichos números (cuadro 2) proporciona una idea del alcance geográfico que tuvo su difusión.

repartimiento de terrenos de un valor menor de 200 pesos, accedemos gustosos a la petición...”, EAJ, no 13 , 15/02/1908, p. 7; "El juez en sus distintas y delicadas funciones. Vamos a contestar debidamente la consulta que varios abonados nos hicieron en días pasados por medio del Correo...”, EAJ, no 33, 15/12/1908, p. 277. 


\begin{tabular}{|c|c|c|c|}
\hline ESTADO & CONSULTAS & MOROSOS & TOTAL \\
\hline PUEBLA & 5 & 5 & 10 \\
\hline Territorio Federal de Tepic & 6 & 1 & 7 \\
\hline SAN LUIS POTOSÍ & 5 & 2 & 7 \\
\hline JALISCO & 5 & 1 & 6 \\
\hline CHIHUAHUA & 5 & - & 5 \\
\hline HIDALGO & 5 & - & 5 \\
\hline GUERRERO & 2 & 3 & 5 \\
\hline DURANGO & 3 & 1 & 4 \\
\hline TAMAULIPAS & 1 & 3 & 4 \\
\hline Sin datos & 4 & - & 4 \\
\hline MORELOS & 2 & - & 2 \\
\hline NUEVO LEÓN & 2 & - & 2 \\
\hline VERACRUZ & - & 2 & 2 \\
\hline ZACATECAS & 1 & - & 1 \\
\hline MEXICO & 1 & - & 1 \\
\hline GUANAJUATO & 1 & - & 1 \\
\hline CHIAPAS & 1 & - & 1 \\
\hline QUERÉTARO & 1 & - & 1 \\
\hline CAMPECHE & 1 & - & 1 \\
\hline SONORA & 1 & - & 1 \\
\hline OAXACA & 1 & - & 1 \\
\hline TABASCO & 1 & - & 1 \\
\hline QUINTANA ROO & 1 & - & 1 \\
\hline MICHOACÁN & - & 1 & 1 \\
\hline TOTAL & 55 & 19 & 74 \\
\hline
\end{tabular}

Cuadro 2 - Número de consultas y suscriptores morosos, por estado Fuente: El Asesor Jurídico, $n^{\circ} 20$ a 32.

Las consultas nos permiten dar cuenta de cierta amplitud geográfica, con énfasis en el centro norte y occidente del país. Más importante aún es saber que las localidades de donde llegaban las cuestiones eran de pequeñas y medianas poblaciones, desde menos de 700 habitantes (la más pequeña que aparece: Zaragoza, en Nuevo León) ${ }^{47}$ hasta una municipalidad que ronda los 40000 habitantes (Salvatierra, en Guanajuato $)^{48}$. La media se ubica en 8400 habitantes y la frecuencia

47. Llegaron consultas de individuos de dos localidades submunicipales, de las que carecemos de cifras: el Mineral San Andrés de la Sierra, del municipio Santiago Papasquiaro, en Durango, y del pueblo de Mixtlán, municipio de Mascota, en Jalisco. La localización de los lugares citados se corroboró en: Guía postal de la República Mexicana. Julio de 1911-junio de 1912, México, Tipografía Económica, 1911; y los datos de población se obtuvieron en INEGI, "Tercer Censo de Población de los Estados Unidos Mexicanos, 1910. Tabulados básicos. IV: Número de habitantes de la República, por entidades federales, distritos, partidos y municipalidades...” [http://www.beta.inegi.org.mx/proyectos/ccpv/1910/default.html].

48. La ciudad de Salvatierra contaba con 10262 habitantes en el censo de 1910, los otros 30000 residían en localidades menores o en unidades rurales, dentro de la misma municipalidad. Existen casos similares, como la villa de Tepatitlán (Jalisco) con 5500 habitantes, cuando el municipio ascendía a 27 900; mientras que en el extremo opuesto, no había mucha diferencia de población entre el municipio y la localidad de Parral (Chihuahua): el primero de 16000 habitantes y la cabecera de 14000 , y que pese a su tamaño y ser la segunda localidad más poblada del estado, solo tenía categoría de "pueblo". Pese a estas discrepancias sobre el tamaño 
(gráfica 1) se inclina hacia poblaciones de menos de 10000 almas. Con esto se confirma que, efectivamente, la revista llegaba a municipios pequeños, algunos de ellos contaban con una villa o incluso ciudad, pero la mayoría ostentaba la categoría de pueblo, no era cabecera de distrito y no tenía por tanto juzgado de primera instancia, ni mucho menos una escuela de derecho ni asociación colegiada de abogados. Eran pueblos y villas de cierta entidad demográfica y, por tanto, también dinamismo económico.

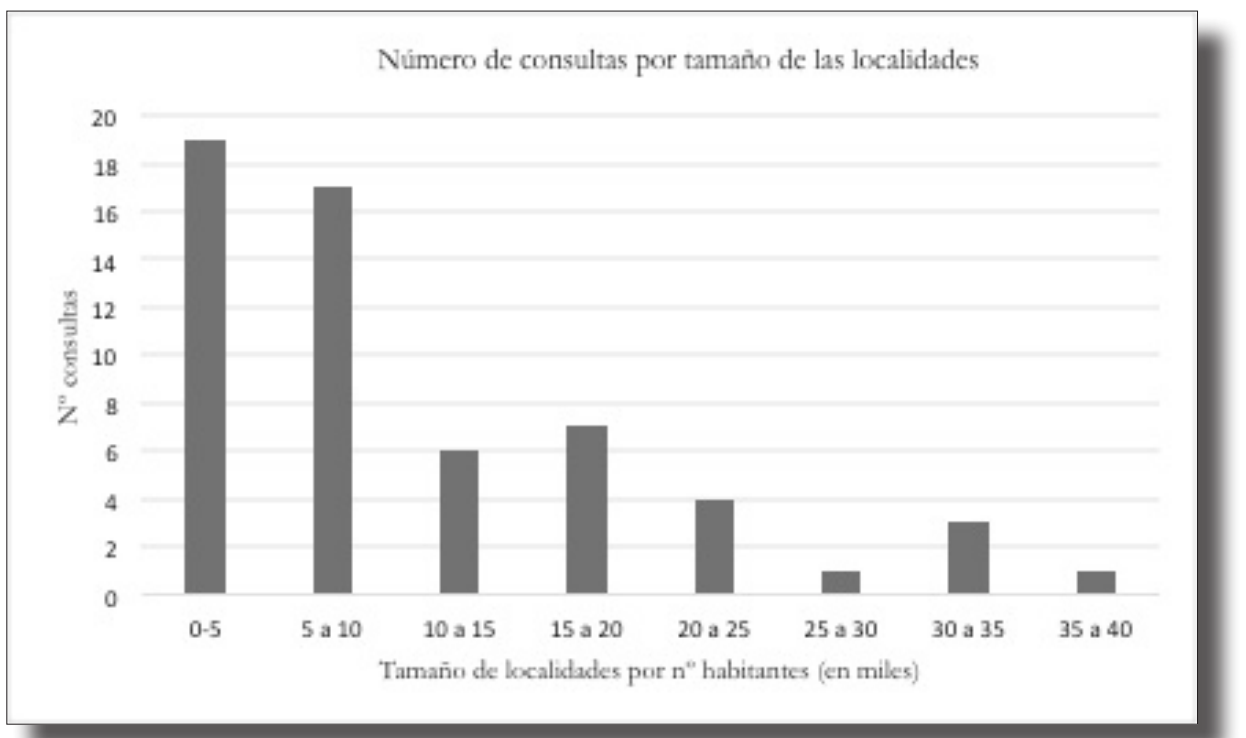

Gráfica 1 - Número de consultas y suscriptores morosos, por localidades (según cantidad de habitantes)

Fuente: El Asesor Jurídico, mayo-noviembre 1908, no 20 a 32; Guía postal de la República Mexicana. Julio de 1911-junio de 1912, op. cit.; INEGI,

"Tercer Censo de Población de los Estados Unidos Mexicanos, 1910”, op. cit.

\section{Conclusiones}

Regresando a los objetivos iniciales, podemos hacer algunas precisiones. En primer lugar, que la revista constituyó una oportunidad laboral para J. del Castillo, luego de perder su empleo de asesor ministerial y no poder continuar una carrera judicial. Esto, a través de la venta de la revista y de otras publicaciones promocio-

de algunas localidades de nuestras fuentes, elegimos dejar los datos de los municipios por dos razones: 1. La mayoría de las cartas enviadas a la revista da el nombre de la municipalidad, sin especificar si se refiere a la cabecera, y muy pocos casos sólo dan el nombre del estado, con lo cual, tenemos un dato comparable para la mayoría de los lugares citados. 2. La tabla del INEGI informa solo de los habitantes por poblaciones de más de 4000 habitantes, así que la mayoría de los lugares citados no aparecen en dicha tabla. Si contáramos con todos los datos, la gráfica 1 debería ajustarse a la baja. Es decir, los tamańos de las poblaciones a donde llegaba la revista serían aún menores. 
nadas en la misma pero, sobre todo, usándola como escaparate donde demostrar sus conocimientos jurídico-administrativos en la resolución de consultas específicas y en la facilitación de modelos de cartas y oficios necesarios para solicitar y cumplimentar requerimientos ante diversas autoridades, a la vez que ofrecer directamente sus servicios como asesor jurídico y litigante. En el primer aspecto tuvo más éxito que en el segundo; de allí seguramente que decidiera emprender un viaje de algunos meses al norte de la República y los EEUU, mientras dejaba encargada la edición de la revista a un familiar.

Respecto al éxito que sí cosechó en el plano editorial, Del Castillo supo ver una demanda de información y asesoramiento jurídico-administrativo por parte de sectores pueblerinos alfabetizados de pequeños propietarios, emprendedores y funcionarios locales, lo que da cuenta de una expansión de la cultura jurídica necesaria para ejercer y relacionarse con el crecimiento de las agencias estatales y de sus actividades de fiscalización y judicialización de diversos campos económicos y civiles de la vida de las personas. La revista cumplió en ampliar la cultura jurídica de individuos y operadores jurídico-administrativos en el campo, si bien no cumplió las expectativas de Del Castillo sobre procurarle los ingresos suficientes para subsistir.

Respecto de la situación agraria, encontramos varias consultas sobre "perfeccionamiento de la propiedad" en relación al derecho de familia y testamentarías, pero pocas sobre conflictos agrarios relacionados con desamortización, deslinde o ejidos. Del Castillo publica una serie de notas sobre la desamortización de tierras de común repartimiento y ejidos, donde deja ver su ideología liberal con enfoque social: no se aparta del modelo ideal de la propiedad privada individual, pero critica los abusos cometidos por poderosos locales en contra de los indígenas al momento de hacer los repartos e indica medidas legales, tanto por la vía judicial como por la administrativa, para hacer valer los derechos conculcados. La paradoja es que los ex-comuneros no son quienes compran y leen su revista, sino precisamente el sector al que acusa de haberles quitado sus tierras.

\section{Resumen/Palabras Claves}

El propósito de este artículo es determinar si la cultura escrita estaba ganando espacios dentro de la tradicional mediación personal realizada por actores pueblerinos en la resolución de conflictos. Para ello, analizaremos una publicación creada por abogados interesados en divulgar los conocimientos jurídicos y administrativos a actores de pequeñas ciudades y localidades, así como apoyar a los pueblos en el manejo de procedimientos y formularios para lograr el éxito en sus gestiones agrarias.

Divulgación del derecho, Revista jurídica, Apoyo legal, Derecho de propiedad, Porfiriato 


\section{RÉSUMÉ/Mots-ClÉS}

Le but de ce travail est de déterminer si la culture s'imposait dans la médiation personnelle traditionnelle faite par les acteurs des petites villes dans la résolution des conflits. Pour cela, nous allons analyser un périodique créé par des avocats visant à diffuser les connaissances juridiques et administratives aux acteurs des petites villes et villages, et à soutenir les communautés dans le maniement des procédures et des formulaires pour réussir dans leurs gestions agraires.

Divulgation du droit, Revue juridique, Conseil juridique, Droit de propriété, Porfiriat

\section{ABSTRACT/KeYWORDS}

The purpose of this paper is to determine whether the written culture was winning recognition within the traditional personal mediation made by small-town actors in the resolution of conflicts. Therefore, we will analyze a gazette created by lawyers interested in spreading legal and administrative knowledge to actors of small cities and towns, as well as to support rural communities in the handling of procedures and administrative forms to achieve success in their agrarian affairs.

Legal culture, Legal press, Legal advice, Property rights, Late Porfirian Mexico 


\section{L'accès à la justice locale pendant la révolution mexicaine : avocats et tinterillos dans les tribunaux de $1^{\text {re }}$ instance}

Evelyne SANCHEZ

CNRS-FRAMESPA (UMR5136, Université Fédérale de Toulouse)

\section{Introduction $^{1}$}

Depuis ENVIRON TROIS DÉCENNIES, L'ANALYSE DES sources judiciaires est de plus en plus présente dans l'historiographie. Dans le cas mexicain, cette affirmation générale doit être nuancée tant il est vrai que leur accès - ou non-accès - varie d'une entité à l'autre de la république, en particulier lorsque l'on travaille sur les $\mathrm{XIX}^{\mathrm{e}}$ et $\mathrm{XX}^{\mathrm{e}}$ siècles. Elles ont néanmoins permis plusieurs approches qui vont de l'étude de l'administration de la justice à l'analyse de réseaux, en passant par l'histoire de la criminalité et des conflits agraires (liste non exhaustive). Deux aspects retiennent ici notre attention, le premier largement traité par l'historiographie dans un débat encore largement ouvert est celui d'une justice de transition dont la professionnalisation du personnel serait un aspect essentiel. Le second, grand absent des études actuelles, porte sur la question de l'accessibilité de la justice pour la société, question centrale alors même que la Révolution qui éclata en 1910 semble démontrer que les recours institutionnels avaient échoué dans leur mission de résolution des conflits.

La justice transitionnelle est l'un des thèmes privilégiés de l'historiographie hispano-américaine. Si elle semble largement influencée par les études sur les transitions démocratiques tant en Espagne que dans le Cône Sud, son contenu revêt des aspects différents mais complémentaires selon les auteurs lorsqu'elle sert de grille de lecture sur l'évolution de l'administration de la justice. D'un côté, C. Garriga et F. Morelli la considèrent d'abord comme le passage d'une justice de type juridictionnel, c'està-dire dans laquelle la casuistique offre de larges compétences et champ de manœuvre

1. Cette recherche s'inscrit dans le projet Ecos-Nord num. M16H01 intitulé « Justice et société au Mexique, $\mathrm{XVIII}^{\mathrm{e}}-\mathrm{XXI}^{\mathrm{e}}$ siècles " auquel participent les institutions suivantes : La Casa de Velázquez, FRAMESPA-CNRS UMR 5136), CIESAS et ENAH. 
au juge, à l'empire de la loi comme seule référence possible ${ }^{2}$. Concrètement, les juges ont désormais l'obligation de motiver leurs sentences. Comme l'affirme D. Marino, le juge n'est plus alors qu'un technicien de la $\mathrm{loi}^{3}$. D'autres auteurs envisagent la transition sous l'angle de la modernisation de la justice qui se serait appuyée sur deux principaux instruments - la promulgation des codes civils et pénaux et des codes de procédure ; la professionnalisation des personnels de justice et en particulier des juges et l'un des grands principes des démocraties libérales, la séparation des pouvoirs ${ }^{4}$. En apparence, cette approche semble être le simple pendant empirique de la réflexion plus théorique mentionnée plus tôt puisqu'en somme, pour que la loi s'impose et soit appliquée à tous, il faut disposer de procédures et de références communes ainsi que des juges compétents pour les appliquer. Cependant, cette approche pose plusieurs problèmes souvent liés aux terrains des chercheurs. Soulignons tout d'abord que les efforts de professionnalisation de l'administration de la justice se sont concentrés sur les tribunaux de $1^{\text {re }}$ instance (juzgados), puisque les juges locaux et juges de paix - respectivement des municipalités et des pueblos - continuaient à être des profanes et que les tribunaux de $2^{\mathrm{e}}$ instance et de cassation (Tribunal Supremo de Justicia) et la Cour Suprême Fédérale étaient déjà dotés de juges lettrés. Or, l'accès aux sources émises par les juzgados est particulièrement difficile voire impossible dans certains Etats (celui de Veracruz par exemple), et quelques auteurs enthousiasmés par le travail législatif du Porfiriat ont été tentés de voir dans la nouvelle réglementation une modernisation efficace alors que les pratiques des tribunaux en donnent une image beaucoup plus relative. Le second problème lié à la délimitation du terrain est précisément l'intérêt particulier porté au Porfiriat comme point d'arrivée du processus transitionnel. Or, le moment choisi pour placer la césure chronologique d'une transition est essentiel et peut influencer la lecture des faits observés. Ainsi, la stabilité des juges titrés et de leur personnel dans les tribunaux de $1^{\text {re }}$ instance avant la Révolution peut faire penser que le pari de la professionnalisation était gagné. Mais si l'on inclut dans la période d'étude celle de la Révolution, prise dans un sens large soit jusqu'en 1940, alors le Porfiriat apparaît plutôt comme une parenthèse. Et même pendant celle-ci, l'objectif de la professionnalisation était atteint mais qui se hasarderait à prétendre qu'il en était de même avec celui d'une autonomie de la justice par rapport au pouvoir de l'exécutif ? En somme, pour pouvoir trancher la question de la transition juridique il nous faut multiplier les analyses portant sur les pratiques dans les tribunaux qui devaient en être les fers de lance, soit les juzgados de $1^{\text {re }}$ instance.

2. Garriga Acosta, Carlos, « Justicia y política entre Nueva Espańa y México. De gobierno de la justicia a gobierno representativo ", Gayol, Víctor, Formas de gobierno en México. Poder político y actores sociales a través del tiempo, vol. I, México, El Colegio de Michoacán, 2012, p. 33-79. Morelli, Federica, « Pueblos alcaldes y municipios: la justicia local en el mundo hispánico entre Antiguo Régimen y liberalismo ", Historia Crítica, n 36, jul.-dic. 2008, p. 36-57.

3. Marino, Daniela, « Los pueblos indígenas y el nuevo modelo liberal. Justicia, política, propiedad. Centro de México, 1821-1876 ", Gayol, Víctor (coord.), Formas de gobierno en México. Poder politico y actores sociales a través del tiempo, vol. II, México, El Colegio de Michoacán, 2012, p. 417-446.

4. Speckman Guerra, Elisa, Crimen y castigo. Legislación penal, interpretaciones de la criminalidad y administración de la justicia (Ciudad de México, 1872-1910), México, El Colegio de México, UNAM, 2002. 
La seconde question mentionnée plus haut concerne la relation entre l'administration judiciaire et la société. Celle-ci peut faire l'objet de plusieurs approches, en termes de confiance/défiance souvent soulevées en analyse de politiques publiques actuelles, en termes d'instrumentalisation et enfin d'accessibilité. C'est sur ce dernier point que nous nous concentrerons ici. Dans le projet dans lequel s'inscrit cette recherche, nous avons proposé d'analyser les liens possibles entre des mécanismes institutionnels grippés de résolution de conflits et l'insurrection révolutionnaire. Or, la professionnalisation du personnel de justice avait des conséquences immédiates sur son accessibilité. Pour pouvoir parler au juge, il fallait désormais pouvoir argumenter que l'affaire qui lui était présentée relevait bien de sa compétence en faisant référence aux articles du code, ce qui impliquait l'intervention d'un avocat pour les plus fortunés, d'un tinterillo ou compter sur la disponibilité du greffier (secretario de juzgado), largement débordé par l'ampleur de sa tâche. L'intervention d'un tiers, outre qu'elle créait en soit une distance entre le juge et le justiciable supposait aussi un coût financier, ce qui limitait d'autant plus l'accès à la justice.

Plutôt qu'une étude peu profonde - faute de place - de l'ensemble des personnels qui peuplaient les tribunaux de $1^{\text {re }}$ instance, c'est-à-dire juges, greffiers et autres employés subalternes (au nombre de 5 dans chacun des six tribunaux de l'État de Tlaxcala), les avocats et les experts, nous nous centrerons sur les avocats et leurs relations avec leurs clients. Cette délimitation de notre objet permet en effet de prendre à bras-le-corps le problème de la professionnalisation des juges puisque ceux-ci devaient être licenciés en droit et avoir exercé pendant un minimum de trois ans en tant qu'avocats avant de pouvoir être nommés dans un tribunal. Le montant de leurs honoraires, qui induit le profil de leurs clients, pose également la question de l'accès à leur service, renforcé encore par leur opposition affichée au travail des tinterillos, conseillers juridiques non titrés qu'il nous faudra aussi prendre en compte. La relation avocat-client et le profil de chacun se trouvent donc au cour de cette étude. Ce faisant, elle permet une approche précise de la question $\mathrm{du}$ monde infrajudiciaire et de ses limites. Ces dernières sont parfois claires : les experts judiciaires et les casas de notificación font clairement partie de cette ruche qui gravite autour des tribunaux et permettent le fonctionnement de la justice. Si nous prenons comme critère la non-professionnalisation des personnes, d'autres limites sont théoriquement aussi claires : juges locaux et juges de paix tombent du côté de l'infrajudiciaire ; nous savons aussi que les employés subalternes des tribunaux de première instance n'avaient aucune formation juridique car, à Tlaxcala, la plupart avaient occupé un poste dans l'administration fiscale ${ }^{5}$. D'autres limites sont beaucoup plus poreuses. Ainsi, les notaires habituellement considérés comme appartenant à l'infrajudiciaire se trouvent être aussi juges de première instance à partir des années 1870-1880, c'est-à-dire que les deux fonctions de juge et de notaire étaient incarnées par une seule et même personne ${ }^{6}$. En cas de vacance ou simple

5. Archivo Histórico del Estado de Tlaxcala (AHET), Fondo Revolución-Régimen Obregonista, Serie Justicia y Gobierno (Rev-RO, Just-Gob), Caja 215, Expediente 2, 146 fs. Año de 1917. Interrogatorios.

6. Sanchez, Evelyne, El juez, el notario y el caudillo. Análisis de un juicio verbal en Tlaxcala durante la Revolución, Essais de la Casa de Velázquez, 2019. 
absence du juge de première instance, celui-ci était remplacé par le juge local de sa municipalité. Enfin, et c'est ce qui retiendra notre attention ici, la césure que la littérature prétend claire entre, d'un côté les avocats titrés, et d'un autre côté les tinterillos méprisés et parfois honnis par les premiers, est beaucoup moins nette si on y regarde de plus prêt. C'est aussi cela que la relation avocat-client permet de déceler.

Pour mener à bien ce travail, j'ai eu recours à la lecture de procès, souvent de $1^{\text {re }}$ instance mais aussi de ceux présentés en appel au Tribunal de l'État. Cela peut paraitre contradictoire vis-à-vis des réflexions précédentes, mais il n'en est rien. En effet, lorsque l'on faisait appel d'une sentence prononcée en $1^{\text {re }}$ instance, le dossier était extrait du juzgado et inséré dans celui du Tribunal. Il faut donc nécessairement consulter ce dernier pour pouvoir avoir accès au premier. Les demandes présentées par les licenciés en droit pour obtenir leur titre professionnel auprès de l'exécutif de l'État ainsi que la correspondance de quelques avocats avec le ministre de l'intérieur de l'État (Secretario de Gobierno) complètent les informations des procès.

Le texte qui suit est organisé en trois parties. Nous établirons tout d'abord les profils des avocats et de leurs clients, puis nous aborderons la question du coût de leurs services pour finir par l'épineux problème du monde de "l'entre-deux ", ce continuum qui semble avoir existé entre les avocats formels et les tinterillos vilipendés.

\section{Avocats et justiciables}

Qui étaient les avocats qui intervenaient dans les tribunaux, pour la plupart ruraux, du petit Etat de Tlaxcala? Certes, nous sommes loin des avocats de renommée nationale - Andrés Molina Enríquez, Ignacio Vallarta, Antonio Caso - les plus connus alors du public et aussi des historiens ${ }^{7}$. Pour autant, qu'ils vivent dans la ville proche de Puebla ou même de Mexico et étaient recrutés par les propriétaires des haciendas tlaxcaltèques, ou qu'ils vivent dans les villages ouvriers et ruraux du Nord de l'État, tous sont décrits comme «trigueños", soit blancs, cheveux noirs ou châtains, et élégamment vêtus de tissus et chaussures importés d'Europe. Avant les lois de Réforme et la suppression des appartenances ethniques dans les recensements, ils seraient donc définis comme essentiellement créoles, avec quelques métis. La documentation mentionne rarement ces détails et si nous les connaissons, c'est grâce aux descriptions fournies par les autorités lorsque les avocats étaient arrêtés pour des raisons diverses (fraude, insulte à un employé du Tribunal, violence commise sur un muletier, etc.). Ainsi, le Lic. Ignacio Cejudo y Ormachea, avocat de Mexico, engagé par l'hacendado et industriel Ricardo Carvajal, fils d'un avocat venu à son secours après son arrestation pour outrage envers les magistrats du Tribunal Suprême de Justice de Tlaxcala, portait un costume bleu de cachemire français et des bottines

7. Cruz Barney, Óscar, Fix-Fierro, Héctor y Speckman Guerra, Elisa (coord.), Los abogados y la formación del Estado mexicano, México, UNAM, Ilustre y Nacional Colegio de Abogados de México, Instituto de Investigaciones Históricas, 2013 [https://biblio.juridicas.unam.mx/bjv/detalle-libro/3535-los-abogados-y-la-formacion-delestado-mexicano]. 
en cuir jaune de Russie ${ }^{8}$. Ainsi n’avait-il rien à envier dans son apparence à son prestigieux client, ce qui ne lui a pas valu l'indulgence du juge : sa condamnation à 5 mois de prison a été prononcée et ratifiée en appel, commuable en une amende de un peso par jour de prison évité.

Les avocats de province étaient tout aussi élégants et étaient également engagés par la famille Carvajal. Ainsi, le Lic. Leonardo Ballesteros, originaire d'Oaxaca et avocat à Tlaxcala au service d'Emilio Carvajal, portait au moment de son arrestation un costume noir de cachemire français, une chemise anglaise et des bottes de cuir importées des États Unis? ${ }^{9}$. Les avocats des pueblos, en soit assez rares, avaient moins d'allure s'il faut en croire la description du Lic. José Corona lors de ses trois arrestations (en 1886,1891 et 1905$)^{10}$. Des doutes subsistent sur son origine, puisqu'il déclarait en 1891 être né dans la ville de Huamantla puis, en 1905, dans le village de Tzompantepec tandis qu'il résidait d'abord sur son rancho de San Nicolás Cuatlapanga, puis à Santa Cruz Tlaxcala (l'âge déclaré en ces deux occasions confirme qu'il s'agissait bien de la même personne). Décrit comme un trigueño portant la moustache et au visage piqué de vérole, ses vêtements ne comportaient aucune pièce importée, rien qui ne paraissait affirmer son statut ni professionnel (avocat) ni social (ranchero). Parmi ses clients - lorsqu'il n'était pas occupé à sa propre défense - ne se trouvent ni de grands propriétaires terriens ni d'industriel mais au contraire des représentants de pueblos contre un hacendado ${ }^{11}$. La diversité sociale des avocats paraît donc correspondre à celle des clients ce qui pourrait laisser croire que chacun pouvait aspirer à engager les services d'un professionnel du droit en cas de besoin, mais il n'en est rien.

Les avocats qui opéraient dans les tribunaux tlaxcaltèques ne sont qu'exceptionnellement issus des villages, la plupart venaient de Puebla et les quelques tlaxcaltèques que nous connaissons vivaient dans les capitales de districts où sont installés les tribunaux, avec un net avantage pour la capitale de l'État. Le cas de José Corona en offre un contre-exemple convaincant. Les dossiers qui le concernent le présentent en effet comme une personne dont les revenus dépendaient essentiellement de sa propriété foncière, somme toute assez modeste. Il possédait ainsi un rancho où il cultivait des agaves destinés à être transformés en pulque, sorte de bière locale destinée à un marché populaire, il fournissait également la fabrique textile de San Manuel en bois pour activer les machines à vapeur. Bref, nous sommes loin du professionnel dédié à temps plein aux activités judiciaires ${ }^{12}$.

8. AHET, Procuraduría General de Justicia (PGJ), C. 10, Exp. 15. Año de 1902.

9. AHET, PGJ, C. 11, Exp. 1. Año de 1902.

10. Archivo Histórico del Tribunal Superior de Justicia del Estado de Tlaxcala (AHTSJET), Distrito de Cuauhtémoc, Justicia criminal, 1891 et AHET, PGJ, C. 16, Exp. 18. Ańo de 1905.

11. AHET, PJG, C. 16, Exp. 18. Año de 1905.

12. En 1904, la jeune veuve María del Villar expliquait que son défunt mari, le Lic. Trinidad Rojas, installé dans la ville de Tlaxcala, lui avait légué la propriété du rancho de Miraflores en plus d'une bibliothèque bien fournie en littérature et ouvrages de jurisprudence. José Corona ne représente donc pas un cas isolé. AHET, PGJ, C. 16, Exp. 11. Año de 1904. Distrito de Hidalgo. Contra el Señor Lic. Leonardo Ballesteros por fraude de que lo acusa dońa María del Villar viuda de Rojas. 
À l'autre bout de l'échelle sociale se trouve un autre type d'avocat qui ne tirait pas non plus l'essentiel de ses revenus de cet exercice professionnel. Il s'agit des hacendados qui possédaient eux-mêmes une licence en droit et un titre professionnel. Ainsi, les deux frères Bernardo et Alfredo Caso y Casulo, propriétaires à eux deux de cinq haciendas situées dans le sud-ouest de l'État de Tlaxcala et de nationalité espagnole - bien que nés au Mexique - étaient tous les deux avocats. L'inventaire des biens réalisé après la mort de Bernardo totalisait 432943 pesos et incluait l'hacienda de San Antonio Michac où il était né et qu'il avait hérité de son père ${ }^{13}$. Ainsi pouvons-nous écarter l'hypothèse - en soit improbable - d'un avocat soudainement enrichi ; Bernardo était le fils d'un hacendado espagnol qui l'avait sans doute encouragé à suivre avec son frère des cours de droit afin de devenir avocat. Les Carvajal n'avaient certes pas fait les mêmes efforts mais n'avaient pas hésité à s'allier à des professionnels au moyen de stratégies matrimoniales. Ainsi, Elodia Carvajal y Bras de Fer s'était-elle mariée au Lic. Eugenio Sánchez tandis que sa sœur avait épousé un médecin ${ }^{14}$. Reste à expliquer pourquoi ces élites de la terre et de l'industrie s'intéressaient à l'acquisition de titres professionnels alors qu'il leur était si facile d'engager ceux qui dédiaient réellement leur temps à son exercice.

Nous posons ici l'hypothèse que la réponse se trouve dans la qualité de la relation entre avocats et clients fortunés. Plusieurs dossiers judiciaires montrent en effet que ces derniers avaient tout lieu d'être déçus par les résultats obtenus par leurs représentants devant les tribunaux. L'élégant Lic. Ignacio Cejudo y Ormaechea avait été engagé par Ricardo Carvajal pour mener à bien une procédure en référé afin de récupérer des droits sur le cours d'eau qui lui étaient contestés par les habitants du village de la Trinidad Tenexyecac. Non seulement le référé fut perdu, mais les termes de l'appel présenté par Cejudo étaient si offensants que l'avocat fut condamné pour outrage. Cela n'aurait été qu'une avarie en marge de l'affaire si, au cours de l'appel, les intérêts de l'hacendado n'avaient été totalement marginalisés des discussions menées par les magistrats, concentrés sur le jeune avocat qui avait affirmé et rendu public son franc mépris pour les juges de province, avant que la sentence en faveur du village soit réitérée. Ce faisant, c'est Carvajal qui était venu au secours de son avocat en lui portant caution pour le sortir de prison! Nul doute que l'hacendado ait regretté d'avoir eu recours au service d'un juriste plus préoccupé de faire accepter son statut par les provinciaux - avant d'être représenté par son père lui aussi avocat - que des intérêts de son client.

Cette affaire semble être tirée d'une parodie, pourtant les dossiers judiciaires déposés par les clients pour se plaindre de leurs avocats sont nombreux ${ }^{15}$. Ainsi,

13. Archivo General de Notarías del Estado de Tlaxcala (AGNT), Copias de protocolo, distrito de Zaragoza, 1925. 14. AGNT, Copias de protocolo, distrito de Zaragoza, 1906.

15. Une aventure semblable est arrivée à son fils. Emilio Carvajal, défendu par Leonardo Ballesteros, a vu son affaire " oubliée » lorsque son avocat s'est mis à insulter un employé du tribunal d'appel alors qu'il tentait de joindre une pièce au dossier. Les employés du tribunal sont alors mobilisés comme témoins, l'avocat doit se procurer son propre défenseur et l'on ne sait plus rien de Carvajal qui a dû renoncer à son appel. AHET, PGJ, 
Manuel Carvajal y Bras de Fer se plaignait en 1901 de l'avocat, le Lic. Refugio Reyes, qu'il avait engagé dans un jugement verbal contre son père Ricardo, hacendado mentionné dans l'affaire précédente ${ }^{16}$. Le conflit avait été rapidement conclu entre les deux hommes par le versement de 302 pesos du père au fils, confiés à l'avocat de ce dernier. Or, celui-ci ne remit pas cette somme à son propriétaire légitime, arguant qu'il le conservait en guise d'honoraires, ce qui était chèrement payé pour un simple jugement verbal, et a fortiori alors que ce dernier avait été interrompu par un accord entre les parties. Ce litige finit lui aussi par un accord, dont les termes ne nous sont pas connus. Pour autant il fut aussi coûteux et mobilisa au total pas moins de quatre avocats : Refugio Reyes en tant que défenseur initial, Leonardo M. Ballesteros engagé par Manuel contre Reyes, Francisco Grajales engagé par Carvajal père et enfin Demetrio Narváez engagé pour défendre Reyes. Rien n'est dit sur les honoraires de cette seconde affaire. Nous arrêterons là les exemples, les litiges présentés brièvement justifient en soit l'intérêt des élites sociales et notamment foncières à compter parmi leurs membres quelques avocats réellement dévoués à leur cause ${ }^{17}$.

Mais si les avocats ne formaient pas une catégorie socio-professionnelle homogène, il en allait autant de leurs clients qui ne peuvent être réduits aux strates socio-économiques les plus élevées de la société locale. Qui étaient donc les clients susceptibles de pouvoir payer les services d'un avocat titré et qui se situait aux limites de cet ensemble bigarré ? Pour répondre à ces questions, nous éviterons de partir de catégories préétablies, qu'elles soient socio-professionnelles ou socioéconomiques ("classes moyennes " par exemple). Nos sources nous permettent en effet de partir des relations avocats-clients et de retracer les contours de ces derniers tout en précisant leur qualité. Parmi les procès consultés se trouvent aussi bien des affaires menées à leur terme que certaines interrompues ainsi que des plaintes déposées par des avocats contre leurs anciens clients pour défaut de paiement. Ces différents procès permettent ainsi de dessiner d'une manière assez précise qui était en mesure d'accéder à une représentation professionnelle devant la justice dans les tribunaux ruraux de première instance ainsi que dans les affaires jugées en seconde instance et en cassation.

C. 11, Exp. 1. Año de 1902. Juzgado de Hidalgo. Contra el Señor Lic. Leonardo Ballesteros, por ultrajes al oficial $2^{\circ}$ del Supremo Tribunal.

16. AHET, PGJ, C. 8, Exp. 15. Ańo de 1901. Juzgado de $1^{\mathrm{a}}$ instancia del distrito de Hidalgo. Expediente criminal contra el Lic. Refugio Reyes por abuso de confianza de que lo acusa el C. Manuel Carvajal Bras de Fer.

17. Le fait d'engager un avocat de Puebla posait également le problème de sa disponibilité pour traiter des affaires de l'Etat voisin. En 1901, un client de Rafael Rosete expliquait les mesures qu'il devait prendre pour être certain d'être représenté par un juriste : «Sabiendo que mi defensor el Licenciado Rafael Rosete tenía urgentes ocupaciones en Puebla, y tememos de que no pudiera atender a la apelación interpuesta por Don Quirino Sánchez, había nombrado además con tal carácter al Señor Don Miguel Aguila; hoy que ya no existe ese temor, afirmo el nombramiento en favor del expresado seńor Rosete ». AHET, PGJ, C. 8, Exp. 3, Año de 1901. 
Si nous commençons par les clients solvables, nous rencontrons sans surprise des propriétaires d'haciendas, de ranchos, de moulins et de fabriques ${ }^{18}$. En plus de ces individus, se trouvent aussi des compagnies, celle de chemins de fer mais aussi les sociétés d'actions propriétaires des grandes fabriques textiles ${ }^{19}$. Parmi les clients collectifs, se trouvent également les pueblos dont l'existence juridique était censée avoir disparu avec les lois de Réforme mais qui continuent à présenter des demandes collectives en les déguisant à peine voire pas du tout, en désignant un représentant du village parmi ses membres, lui-même " $y$ socios » représentés par un avocat ${ }^{20}$.

Parmi les individus moins fortunés se trouve une femme propriétaire d'une maison qu'elle louait 40 pesos par mois, montant élevé puisqu'il correspond au prix d'achat d'une mule, et qui était meublée de plusieurs objets importés dont un piano d'Allemagne ${ }^{21}$. Des couples engageaient également un avocat pour régler les modalités de leur séparation. Ainsi, la femme de Guillermo Stankiewiecz, polonais engagé comme administrateur de la fabrique textile de San Manuel, avait chargé un cabinet d'avocats de Puebla de négocier sa pension alimentaire et la séparation des biens des époux ${ }^{22}$.

Reste, pour délimiter le groupe des clients potentiels, à en poser les limites. Celles-ci sont visibles grâce à ceux qui, évaluant mal leurs ressources ou la facture qu'ils allaient recevoir, ont été incapables de la payer dans sa totalité. Les sources consultées mentionnent des personnes qui résidaient souvent dans les principales villes de l'Etat (celle de Tlaxcala et de Santa Ana Chiautempan) et aussi des dettes héritées. Lorsque l'avocat avait été engagé par un père ou un mari défunt, il devenait

18. À titre indicatif, citons pour les hacendados les procès suivants : AHET, PGJ, Tribunal Superior de Justicia (TSJ), C. 3, Exp. 2, Año de 1898. Relativo al recurso de casación promovido por el Lic. Cosme A Zafra contra la sentencia pronunciada en el Toca a la causa instruida en el Juzgado de Zacatelco contra José de Jesús Sánchez por homicidio así como algunas constancias relativas al juicio de amparo. Sur les rancheros voir : AHET, Rev-RO, Just-Gob, C. 130, Exp. 10, 2 fs. Año de 1912. Varios vecinos (21) de Calpulalpan, se quejan de que el Lic. Manuel M. Lazcano, les ha quitado los títulos de sus terrenos, colindantes con el rancho de Cuecillos. Sur les propriétaires de moulin et fabrique voir : AHET, PGJ, TSJ, C. 2, Exp. 18. Ańo de 1880. Juicio verbal promovido por el C. Pantaleón Lara contra Don Tomás Marshall, sobre levantamiento de una presa.

19. Sur la compagnie de chemin de fer, voir la nomination du Lic. Fernando González Roa pour représenter la Compañia de Ferrocarriles Nacionales de México devant le gouvernement de l'Etat de Tlaxcala. AHET, Rev-RO, Just-Gob, C. 216, Exp. 47, 2 fs. Año de 1917. Sur les industriels, voir : AHTSJET, Distrito de Cuauhtémoc, Justicia civil, 1890. El Sr Lic. Librado López por la Sociedad García Teruel y Cía, contra el Lic. José Corona por falta de cumplimiento de contrato.

20. C'est le cas pour les trois litiges suivants : AHET, Rev-RO, Just-Gob, C. 223, Exp. 67, 1 f. Año de 1917. Ocurso presentado ante este Gobierno por el Lic. Sebastián Escobar en representación de los Sres Prudencio Escobar y socios, vecinos de Atlahpa, quejándose de que han sido despojados de todos sus bienes raíces. AHTSJET, Distrito de Hidalgo, Justicia civil, 1912. Cuaderno de pruebas de Marciano Vázquez en el juicio verbal reivindicatorio del terreno denominado "Xalac", promovido por Fidencio Juncos y socios, vecinos de Atlihuetzia. AHET, Justicia civil, C : SN, Exp. 23, 2 fs. Año de 1852. Manuel Jurado con su patrono Lic. José María Inclán; contra el común del pueblo de San Juan Huatzingo también con su patrono el Lic. Pedro Herrera.

21. AHTSJET, Distrito de Cuauhtémoc, Justicia civil, 1913. Diligencias precautorias sobre requerimiento y aseguramiento de bienes, promovidas por el seńor Licenciado Arnulfo Hernández como apoderado de la Señora Adelaide Quiroz. v. de Farfán contra el Señor José María Pavón.

22. AHTSJET, sin clasificación. Testimonio del poder especial otorgado por la Señora Luisa Ambiel de Stanckiewiez a favor de los Señores Licenciados Nicolás Meléndez y Leonardo M. Ballesteros, vecinos de Puebla, 1903. 
difficile pour ses héritiers d'en payer les services. Ceci complique le travail de l'historien car les plaintes déposées par les avocats ne mentionnent pas la profession ou les biens de la personne qui les avait engagés originellement. Prenons ici deux exemples. En 1911, Sebastiana Conde, dans la ville de Tlaxcala, réclamait 300 pesos au Lic. Ausencia Cruz car son père avait vendu une maison à ce dernier. A court d'argent, elle expliquait au gouverneur ne pas pouvoir faire les frais d'un procès. En réponse à cette accusation, l'avocat affirmait, en en apportant la preuve, que Nicolás Conde l'avait engagé et avait fini par lui céder la propriété de la maison en guise d'honoraires ${ }^{23}$. En 1918, le Lic. Manuel Gutiérrez, avocat renommé qui fit une longue carrière en tant que magistrat du Tribunal Suprême de Justice de l'État et fut également élu syndic de la ville de Tlaxcala, avait été remercié par sa cliente Felicitas Trujillo, de Santa Ana. Manuel avait commencé à gérer le jugement d'intestat des biens du père de Felicitas et, quand celle-ci se rendit compte du montant de ses honoraires, ne tarda pas à le remplacer par un juriste moins gourmand et dont le nom n'est pas précisé (sans doute un tinterillo) ${ }^{24}$.

On le voit, lorsque les clients des avocats titrés ne sont pas collectifs, un très petit nombre de personnes pouvaient prétendre louer leurs services. Ceux qui le pouvaient étaient parfois si déçus des résultats qu'ils préféraient qu'un des membres de leur famille porte la robe. Surtout, une famille modestement installée, avec maison et peu de dettes, pouvait sombrer dans la pauvreté si elle commettait l'erreur d'engager l'un de ces magistrats pour organiser la transmission des biens qui ne tardaient pas à disparaitre. Le recours au conseiller juridique informel (et interdit), le tinterillo, pouvait dans cette situation devenir un recours indispensable. Mais avant d'en arriver là, nos sources nous permettent de connaître plus précisément le coût de la justice.

\section{Le coût de la défense autorisée}

Si la question des frais de justice est souvent mentionnée, elle est en revanche rarement évaluée dans son contexte pour apprécier l'accessibilité du recours judiciaire. Il faut dire que la documentation est rare. Sur quelque 200 procès consultés, seulement cinq en font mention de manière assez précise. Reprenons le cas du Lic. Manuel Gutiérrez renvoyé lorsque sa cliente s'est rendu compte du montant de ses honoraires, en 1918. Pour les services rendus, il lui réclame 60,70 pesos. Rien ne paraît excessif dans les montants présentés (peut être revus à la baisse dans un esprit de conciliation ou dans l'espoir d'être payé) : 8,20 pesos pour réviser le dossier du procès d'intestat de 182 pages, 25 pesos pour 10 plaidoiries devant le juge, cela témoigne plus de la complexité du dossier que de l'avarice de l'avocat. L'insolvabilité de certains clients était sans doute due aussi au manque de prévision des autres

23. AHET, Rev-RO, Just-Gob, C. 122, Exp. 7, 7fs. Año de 1911.

24. AHET, PGJ, C. 37, Exp. 22, Año de 1918. Incidente de costas en el juicio de intestado del Señor Pomposo Trujillo. 
dépenses auxquelles ils devaient faire face au cours d'un procès. Celles-ci pouvaient véritablement exploser lorsqu'un client de Tlaxcala faisait appel à un avocat de Puebla. Pour se faire, Ignacio Ruiz, propriétaire du rancho d'Amelco situé dans la municipalité de Xaltoca, district de Cuauhtémoc, a dû se faire recommander pour être accepté par le Lic. Nicolás Meléndez comme client. Son ami, Francisco Muñoz Guerrero a écrit à ce dernier en exposant sa situation : Ignacio était l'exécuteur testamentaire de sa mère défunte et les cohéritiers, qui avaient leur propre avocat, contestaient sa gestion, or le défenseur en charge de l'affaire semblait incapable de le sortir de ce mauvais pas. Quant à la facture de Meléndez, Muñoz indiquait :

Ya le dije, y está conforme en pagar a Ud sus honorarios con arreglo al arancel de Puebla, es decir: sus viajes, dietas, todas las conferencias que Ud tenga, sus cartas y demás trabajos que Ud le haga y que el arancel de acá no considera. De suerte que, si Ud acepta el patrocinarlo, como lo espero, ya sabe dicho Señor Ruiz a qué atenerse respecto al pago de honorarios y trabajos extraordinarios ${ }^{25}$.

Meléndez a représenté Ruiz pendant plus de trois ans et finit par lui réclamer 2585,45 pesos, somme considérable alors que Ruiz estimait ne lui devoir que 304 pesos. Le juge, quant à lui, estimait qu'une facture raisonnable devait se monter à 1056 pesos. Au-delà des chiffres, deux choses importent ici. Tout d'abord le type de relation instaurée entre avocat et client. Non seulement Meléndez avait accepté de se charger du dossier après l'intervention d'un intermédiaire mais il n'hésitait pas à rappeler à son client la qualité de leur relation. Ainsi répondit-il : "no encuentro la razón de por qué no me ha de pagar: pues no soy su dependiente para escribirle de balde, ni es él nada mío, para que ponga yo hasta los timbres de correos de mi bolsa " ${ }^{26}$. Voilà une attitude qui justifiait amplement le désir des élites de compter parmi elles un juriste qui ne lésinerait pas à défendre leur cause. Le second aspect qu'il convient de relever est le coût du seul fait d'avoir engagé un avocat de Puebla, ville située à $40 \mathrm{~km}$ du tribunal de Tlaxcala. 28 voyages entre les deux villes, pourtant reliées par une ligne de chemin de fer, étaient estimés à 672 pesos. Par comparaison, les 26 écrits pour 72,50 pesos et les inventaires dressés pour 61,50 pesos représentent peu de choses. L'autorité des avocats issus des prestigieux collèges de Puebla et de Mexico avait un coût que même un ranchero, héritier aisé contesté, ne pouvait affronter.

Un procès était donc un véritable investissement puisque tout, depuis l'enquête, en passant par l'établissement de la preuve (les copies de chaque document sont coûteuses et impliquent souvent des déplacements), l'étude du dossier par le tribunal (25 pesos en $1^{\text {re }}$ instance) et jusqu'au relevé de la sentence, était payant et alourdissait le coût supporté par le justiciable. Ces coûts annexes sont rapportés par deux documents tardifs révélateurs du fonctionnement des tribunaux. Le premier date de 1925, il est peu précis et donne des chiffres probablement gonflés dans le but d'obtenir un

25. AHET, PGJ, STJ, C. 14, Exp. 13. Año de 1903. Carta de recomendación de Francisco Muñoz Guerrero al Lic. Nicolás Meléndez, Tlaxcala, el 21 de mayo de 1899.

26. Ibid. Tlaxcala, el 25 de febrero de 1903. 
maximum de dédommagement car il s'agit d'une demande de prise en charge des frais de justice par la partie adverse. Il indique néanmoins que, dans une affaire de vol de trois animaux, la personne lésée a dû d'abord financer l'enquête, l'expédition de certificats attestant sa propriété et les émoluments de la personne qui l'a conseillée au cours du procès, c'est-à-dire un tinterillo car son nom est occulté dans tout le document. La somme investie atteindrait les 600 pesos ce qui est peu probable ${ }^{27}$. Le second procès, civil cette fois, date de 1932 et inclut un document annexé qui détaille sur quatre pages l'ensemble des frais dans le cadre d'un procès suivi dans un tribunal de $1^{\text {re }}$ instance, parti en appel au Tribunal de l'État puis à la Cour Suprême et revenu enfin en $1^{\text {re }}$ instance ${ }^{28}$. Comme l'écrit A. Follain dans le cas de la France moderne, «le système ne fonctionne qu'à la condition que le justiciable ouvre sa bourse ", mais il est intéressant de noter ici que cette réalité perdurait alors que la vénalité des charges qui expliquait autrefois les coûts élevés de l'administration judiciaire n'existait plus ${ }^{29}$.

Dans le procès de 1932, un avocat avait été engagé, qui facturait ses entretiens entre 15 et 25 pesos. Si un tel luxe avait été possible, c'était parce qu'un tinterillo s'était chargé de produire les écrits les plus simples, laissant à l'avocat le soin de rédiger les demandes en appel, véritable investissement. Ainsi, se dessine une justice "professionnalisée ", dont les magistrats se crispent parfois sur leurs prérogatives et manifestent souvent leur mépris pour leurs collègues non titrés devenus illégaux à la veille de la Révolution, mais qui n'en sont pas moins conscients du rôle indispensable joué par ces intermédiaires ${ }^{30}$. C'est en effet grâce à eux que les groupes populaires ont encore accès à la justice et grâce à eux que les classes moyennes rurales peuvent encore s'offrir les services d'un avocat pour certaines tâches délicates.

\section{Avec ou sans titres, et les entre-deux}

L'historiographie latino-américaine a consacré très peu de pages à la question des tinterillos ${ }^{31}$. Elle a de bonnes raisons à cela car l'interdiction qui pesait sur cette profession ne créait pas seulement un risque pour celui qui l'exerçait mais

27. AHTSJT, Justicia civil, Distrito de Zaragoza, 1925. Juicio sumario sobre responsabilidad civil promovido por la Sra Asunción Hernández contra Reyes Tlalpa o Carmen Silva y Donato Cornelio o Nicolás García.

28. AHTSJT, Justicia civil, Distrito de Zaragoza, 1932. Incidente de costas promovido por el Sr Román Sánchez, contra el Sr Macario Sánchez Pineda. L'inventaire fait état de 169,65 pesos de dépenses générales (déplacements, copies de documents, frais de tribunal) auxquels s'ajoutent 200 pesos d'honoraires de l'avocat.

29. Follain, Antoine, «L'argent : une limite sérieuse à l'usage de la justice par les communautés d'habitants ( $\mathrm{XVI}^{\mathrm{e}}$ $\mathrm{XVIII}^{\mathrm{e}}$ siècle) ", Les juristes et l'argent. Le coût de la justice et l'argent des juges du XIVe au XIXe siècle, B. Garnot éd., Dijon, Editions Universitaires de Dijon, 2005, p. 29.

30. Les tinterillos se voient menacés de peine de prison et d'amendes par la loi de 1909. AHET, Rev-RO, JustGob, C. 115, Exp. 12, 5 fs. Año de 1910. La H. Legislatura del Estado expidiendo la ley sobre tinterillos o agentes intrusos. Tlaxcala, 15 de enero de 1910.

31. Lira, Andrés, "Abogados, tinterillos y huizacheros en el México del siglo XIX ", in Soberanis Fernández José Luis (coord.), Memoria del III Congreso de Historia del Derecho Mexicano (1983), México, UNAM, 1984, p. 375-392. Aguirre, Carlos, «Tinterillos, Indians, and the State: Towards a History of Legal Intermediaries in Post-Independence Peru ", in Stefan B. Kirmse, edit., One Law for All? Western Models and Local Practices in (Post-) Imperial Contexts, Frankfort, Campus Verlag Gmbh, 2012. Becker, Marc, « En busca de tinterillos. Intermediarios en el mundo indígena ecuatoriano durante el siglo xx ", in Procesos. Revista ecuatoriana de Historia, n 37, Quito, 2013, p. 97-124. 
aussi pour toute procédure qui pouvait être rendue caduque, poussant aussi bien les tinterillos eux-mêmes que leurs clients à taire leur intervention. Dresser un portrait de cette "profession » est donc une démarche à risque au cours de laquelle il faut deviner qui l'exerce habituellement ou ponctuellement et à quel moment du montage du dossier son intervention était requise. Pour autant, les quelques articles qui s'y réfèrent ont-ils raison d'insister sur l'affrontement voire la persécution subie par ces conseillers juridiques informels de la part d'avocats titrés ? Certes, les rares sources qui mentionnent ces personnages clefs du monde infrajudiciaire sont justement les accusations portées par les avocats à leur encontre. Ces derniers les disent incompétents, avides de gagner quelque argent en encourageant une culture procédurière des pauvres, hantant les tribunaux de $1^{\text {re }}$ instance à la recherche de clients à berner. La lecture de procès conforte cette image : les tinterillos n'y sont mentionnés que pour discréditer les arguments de la partie adverse. C'est donc sur la base d'une opposition entre avocats et tinterillos que s'est constitué le discours historiographique, par ailleurs peu bavard. Cependant, nous l'avons vu plus haut, avocats titrés et défenseurs "sous le manteau " travaillaient parfois sur une même affaire, pour un même client et, s'ils hantaient réellement les tribunaux, c'était bien le signe que personne ne les arrêtait. Malgré la loi votée en janvier 1910 contre eux, aucune procédure à leur encontre n'apparaît parmi les quelque 200 procès consultés et force est de constater que, au vu des émoluments des avocats, les archives judiciaires seraient certainement moins fournies si leurs activités avait été réellement entravées.

Les sources des archives de l'État de Tlaxcala nous offrent une image plus complexe que celle proposée par la littérature et les pamphlets mobilisés jusqu'à présent pour nous dépeindre ces individus peu connus. Plutôt qu'une opposition franche entre avocats et tinterillos, ces sources décrivent plutôt un continuum entre les deux statuts malgré les efforts réalisés par l'État au cours du dernier tiers du XIxe siècle pour faciliter l'accès aux titres universitaires et l'enregistrement au barreau. Ainsi, le Colegio de Abogados de Tlaxcala fut fondé en 1874 pour répondre aux besoins locaux ${ }^{32}$. Avant cela, les avocats devaient obtenir leur titre au collège de Puebla ou de Mexico. Cela dit, à en croire le président de cette institution, les diplômes y étaient bradés et étaient la risée des collèges concurrents qui jouissaient d'une réputation installée si bien que, titrés ou non, les avocats tlaxcaltèques peinaient à être pris au sérieux ${ }^{33}$.

Il est difficile de reconstituer les listes de diplômes et titres professionnels données par, respectivement le Colegio de Abogados et l'État de Tlaxcala (l'aspirant avocat devait en effet d'abord obtenir son diplôme à la fin de ses études de droit puis, muni de celui-ci, il devait faire une démarche administrative pour obtenir ce qui

32. Cruz Barney, Óscar, "El Colegio de Abogados de Tlaxcala: 1874 ", Revista Mexicana de Historia del Derecho, XXIII, 2011, UNAM, Instituto de Investigaciones Jurídicas, p. 129-158.

33. AHET, PGJ, STJ, C13, Exp. 33. Año 1876. Discurso de traspaso de la presidencia del Colegio de Abogados de Eduardo Escudero a su sucesor, Tlaxcala, el 2 de enero de 1876. 
aujourd'hui encore est appelé " cédule professionnelle»). En effet, toute une série de diplômes et cédules a disparu des archives pendant la Révolution si bien que si l'on trouve des tinterillos qui travaillaient comme avocats, on peut également trouver des avocats qui, faute de pouvoir démontrer leur appartenance à leur corporation, risquaient d'être relégués au rang de tinterillos. Francisco R. Gómez s'est ainsi trouvé dans une situation inconfortable quand, après avoir fait la demande d'un certificat prouvant les études faites dans le Colegio, il reçut la réponse suivante du ministre de l'Intérieur :

Habiendo sido destruido parte del archivo anterior de este Gobierno y no habiéndose encontrado documento alguno que compruebe que usted haya presentado certificados de estudios y otros, ante la asociación que se llamó Colegio de Abogados, no puede expedírselo la copia certificada que solicita ${ }^{34}$.

Cette question a commencé à inquiéter les avocats à partir de 1914 à en juger par le nombre de demandes de cédules sollicitées auprès de l'État cette année-là (voir tableau suivant). Non seulement le gouvernement était à la recherche de nouveaux juristes non compromis pendant l'Ancien Régime mais les besoins connaissaient une croissance exponentielle : les occupations de terre et les violences liées à la Révolution multipliaient le nombre des procès et bientôt les commissions agraires mises en place dès la promulgation de la loi agraire du 6 janvier 1915 allaient devoir organiser très vite des recrutements.

\begin{tabular}{|c|c|c|c|}
\hline Avocats & $\begin{array}{c}\text { Mention } \\
\text { obtenue }\end{array}$ & $\begin{array}{c}\text { Coût de l'inscription } \\
\text { au barreau }\end{array}$ & $\begin{array}{c}\text { Sources: AHET, Unidad Histórica, Fondo S. XX, } \\
\text { Sección Secretaría General de Gobierno, }\end{array}$ \\
\hline Lic. Juan Robles & Majorité & $\$ 100$ & C. 11 , Exp. 33, 7fs. Año de 1914. \\
\hline Lic. Taurino Castańeda & Unanimité & $\$ 100$ & C. 12, Exp. 15, f. 7. Año de 1914. \\
\hline Lic. Florencio Padilla & Unanimité & $\$ 100$ & C. 162, Exp. 3, 4fs. Año de 1914. \\
\hline Lic. Roberto Jiménez & Unanimité & $\$ 100$ & C. 162, Exp 4, 5fs. Año de 1914. \\
\hline Lic. Julio A. Delgado y Corona & Unanimité & $\$ 100$ & C. 162, Exp 5, 7fs. Año de 1914. \\
\hline Lic. Luis M de Lizaola & Majorité & $\$ 200$ & C. 162, Exp 6. Año de 1914. \\
\hline Lic. Francisco Gómez & Unanimité & $\$ 100$ & C. 162, Exp 7, 7fs. Año de 1914. \\
\hline Lic. Juan Bretón & $?$ & $\$ 100$ & C. 162, Exp 32, 3fs. Año de 1914. \\
\hline
\end{tabular}

Tableau - Avocats titrés en 1914

Ces nouveaux espaces ouverts aux juristes ont pu encourager l'occupation de certaines fonctions par des individus dépourvus de titres universitaires. C'est en tous les cas ce que laisse entendre la chasse aux sorcières qui s'ouvrit en 1930 dans l'État de Tlaxcala. A l'origine de cette affaire se trouve le lic. Eduardo Sandoval, installé à Apizaco, siège du tribunal du district de Cuauhtémoc, qui envoya une lettre de dénonciation rédigée dans des termes qui n’avaient rien de nouveau :

34. Carta del Secretario General de Gobierno a Francisco R. Gómez, Santa Ana Chiautempan, 03/02/1915. AHET, Rev-RO, Just-Gob, C. 169, Exp. 51, 1 f. Año de 1915. 
desde hace algún tiempo, he venido observando, que en los distintos Juzgados de Primera Instancia y Locales de esta Entidad, existe gran número de individuos, de los llamados TINTERILLOS, quienes, sin tener ninguna de las autorizaciones necesarias [...] se dedican a patrocinar maliciosamente a la gente humilde de nuestro pueblo, quienes estafan inicuamente; y lo que es peor, que dados los ningunos conocimientos que de la Ciencia del Derecho tienen tales TINTERILLOS, cuando han conseguido explotar a sus víctimas, las abandonan en los momentos más difíciles ${ }^{35}$.

Sandoval reprend scrupuleusement les mêmes arguments que ses collègues avaient utilisés au cours du $\mathrm{XIX}^{\mathrm{e}}$ siècle ${ }^{36}$. Mais si l'accusation a porté ses fruits, c'est pour une tout autre raison. Comme le montre le tableau des titres d'avocats distribués en 1914, ceux-ci rapportaient quelque argent à la trésorerie publique de l'État et, dans une bien moindre mesure, de la Fédération. Or, la Révolution avait fortement perturbé la levée des impôts - notamment fonciers - et l'État était à la recherche de revenus. Le bureau du ministre de l'Intérieur s'est ainsi mis à croiser des listes : d'une part celle des personnes dénoncées et identifiées par le Tribunal Suprême de l'État et d'autre part celle remise par le trésorier en charge de collecter les sommes acquittées lors des demandes de cédules professionnelles ${ }^{37}$. Contactés par le Trésorier dans la foulée de cette enquête pour payer leur contribution - ce qui montre au passage que la professionnalisation des avocats (et donc des juges) préoccupait beaucoup moins l'État que ses caisses vides - les avocats mis en accusation rédigèrent des réponses qui en disent long sur la totale absence de contrôle exercé par les autorités publiques. Ainsi, le Lic. Aldelaido Villegas Andrade expliquait :

No había yo presentado mi referido título, en virtud de abrigar la creencia de estar bastantemente identificado en esta Entidad Federativa, con motivo de que desde el año de 1918 comencé a servir como Juez de primera instancia de los Distritos de Tlaxco, Apizaco, Zacatelco, Tlaxcala y Huamantla respectivamente, y, por ahora, como Defensor de Oficio adscripto al Tribunal Superior de Justicia, para lo cual, desde la época mencionada quedó registrado mi título en la Secretaría del expresado Poder Judicial del Estado ${ }^{38}$.

Pris en faute, l'État finit par négocier le paiement de 15 pesos en échange de l'inscription de l'avocat sur un nouveau registre. De son côté, Cosme Zafra, de

35. L'usage des majuscules du texte original est respecté. AHET, Unidad Histórica, Fondo S. XX, Sección Secretaría General de Gobierno C. 221, Exp. 31, 7 fs. Año de 1930.

36. Voir Lira, Andrés, op. cit.

37. La première liste mentionnait les Lic. Mauro Angulo, Lic. Adelaido Villegas Andrade, Moisés Chumacero,

Rosendo Carro, Francisco Cuatecontzi, Jesús M. Vázquez, Antonio Carrasco et Pedro Mendieta. La seconde citait pour le seul district de Juárez (Huamantla) les Lic. Miguel López y López, Juan de Dios Flores y Conrado Lezama, habitants de la ville de Puebla; Lic. Moisés Huerta y Jesús M. Miranda, habitants du District Fédéral; le Lic. Manuel León de la ciudad de Apizaco et Lic. Adelaido Villegas Andrade de Santa Ana Chiautempan. AHET, Unidad Histórica, Fondo S. XX, Sección Secretaría General de Gobierno, C. 221, Exp. 31, 7 fs. Ańo de 1930.

38. AHET, Unidad Histórica, Fondo S. XX, Sección Secretaría General de Gobierno, C. 241, Exp. 40, 9 fs. Año de 1930. 
Puebla, présenta son titre universitaire obtenu dans cette dernière ville en 1884 , enregistré à Tlaxcala en 1898, à Veracruz en 1910 et dans le District Fédéral au cours de la même année. Passablement agacé par les réclamations du Trésorier, il finit par obtenir de ne rien payer ${ }^{39}$. Mais les exigences abusives ne se trouvent pas exclusivement du côté de l'État. Ainsi, Manuel León exerçait le métier d'avocat dans le district de Tlaxco sans avoir jamais fait les démarches pour obtenir sa carte professionnelle. Cependant, le gouvernement avait accepté, en 1917, de lui fournir un certificat sans recevoir aucune contrepartie ni même vérifié ses titres et c'est donc sans surprise qu'on le retrouve dans les listes de $1930^{40}$. Mais il y a plus. En 1912, le gouverneur de Tlaxcala recevait une lettre de Maximiliano Lara Chabert et Antonio Dromundo, installés à Mexico, pour le moins surprenante. Ces deux personnages expliquaient être au courant que l'État manquait de ressources et proposaient d'y payer le prix de leur carte professionnelle bien qu'ils pensaient demeurer à Mexico où se trouvait leur clientèle. Sans inquiétude et sans diplôme, ils justifiaient leur demande en argumentant que :

Tenemos hecho algunos estudios de jurisprudencia, una larga práctica de más de diez años en los Tribunales, como postulantes, una regular clientela, muy buenas referencias, y un despacho establecido en esta Capital en la $3^{\text {a }}$ calle de Doncellas n/o 79, donde estamos a la orden de Ud. ${ }^{41}$.

La réponse du gouverneur, s'il en donna une, ne se trouve pas dans le dossier. Quelle qu'elle fût, cette situation montre que l'opposition entre avocats et tinterillos, bien qu'affirmée souvent dans la littérature, ne reflète en rien la réalité car non seulement les limites étaient floues entre les deux statuts mais les seconds étaient indispensables pour que les premiers aient une chance d'étendre leur clientèle audelà des seules élites, elles-mêmes peu satisfaites de leur service.

\section{Conclusions}

L'historiographie a déjà montré, dans le cas du discours sur créoles et Espagnols à la veille de l'indépendance, qu'il faut se méfier d'une opposition discursive destinée à occulter des liens étroits peu compatibles avec les nouvelles exigences de légitimité. L'objectif annoncé de moderniser l'administration de la justice au moyen d'une professionnalisation de son personnel capable d'assimiler les nouveaux codes de procédure et d'appliquer ainsi une même justice pour tous, délégitimait les conseillers juridiques qui, pendant des décennies, avaient facilité l'accès à la justice aux secteurs populaires. Les avocats titrés avaient gagné en pouvoir car, non seulement ils devenaient les seuls défenseurs légaux, mais ils étaient aussi

39. AHET, Unidad Histórica, Fondo S. XX, Sección Secretaría General de Gobierno, C. 237, Exp. 1, 5 fs. Año de 1930.

40. AHET, Rev-RO, Just-Gob, C. 212, Exp. 59, 2 fs. Año de 1917.

41. AHET, Rev-RO, Just-Gob, C. 131, Exp. 70, 2 fs. Año de 1912. 
ceux parmi lesquels les juges de $1^{\text {re }}$ instance devaient être recrutés. Par ailleurs, de nouveaux espaces s'ouvraient à eux, notamment les commissions agraires. Cependant, l'observation des pratiques judiciaires nuance très largement ce bilan officiel : bien des avocats devaient tirer une part de leurs revenus d'activités annexes, les élites étaient si peu satisfaites de leur travail qu'elles préféraient se former elles-mêmes à cette profession et les tinterillos étaient des alliés indispensables pour permettre l'accès à la justice - au coût prohibitif- des individus moins fortunés. L'État, censé veiller sur la compétence des personnels de justice, fermait opportunément les yeux sur ces disfonctionnements et ne les ouvrait que pour saisir une chance de renflouer sa trésorerie. Se montrer plus ferme aurait sans doute été contreproductif puisque cela aurait empêché la justice de réguler bon nombre de conflits, créant ainsi une situation explosive. L'imbrication entre monde judiciaire et infrajudiciaire semble donc aussi solide en cette première moitié de $\mathrm{xx}^{\mathrm{e}}$ siècle qu'elle ne l'était cent ans plus tôt : une bonne raison pour s'interroger sur ladite " transition juridique ».

\section{RÉSUMÉ/MOTS-CLÉS}

L'administration de la justice a connu, au cours de la seconde moitié du XIx siècle, une réforme formelle visant à sa modernisation au moyen de la professionnalisation de son personnel. Cet article limite l'analyse aux avocats, parmi lesquels les juges de $1^{\text {re }}$ instance étaient recrutés, et à leurs pratiques. Il propose un profil de ceux qui intervenaient dans les tribunaux ruraux tlaxcaltèques, et surtout une analyse des relations, souvent conflictuelles, qu'ils entretenaient avec leurs clients. Finalement, il montre que le coût de la justice était si élevé que le recours aux tinterillos, conseillers juridiques désormais illégaux, était indispensable pour pouvoir accéder aux tribunaux et qu'il existait un continuum entre tinterillos et avocats qui rend inopérante l'analyse en termes d'opposition entre les deux statuts.

Avocats, Justice, Révolution mexicaine, Tinterillos, Tribunaux ruraux

\section{Resumen/Palabras Claves}

La administración de la justicia ha conocido, en el transcurso de la segunda mitad del siglo XIx, una reforma formal con el objetivo de modernizarla mediante la profesionalización de su personal. Este artículo limita el análisis a los abogados, entre los cuales se designaban a los jueces de $1^{\text {ra }}$ instancia, y a sus prácticas. Propone un perfil de los que intervenían en los juzgados rurales tlaxcaltecos y un análisis de las relaciones, a menudo conflictuales, que entretenían con sus clientes. Finalmente, muestra que el costo de la justicia era tan elevado que el recurso de los tinterillos, ilegales, era indispensable para tener acceso a los juzgados y que existía un continuo entre tinterillos y abogados que hace inoperante el análisis en términos de oposición entre los dos estatutos.

Abogados, Justicia, Revolución mexicana, Tinterillos, Juzgados rurales 


\section{ABSTRACT/KeYWORDS}

In the second half of the 19th Century, the administration of justice experienced a formal reform aiming to modernize it through the professionalization of its personnel. This article analyzes only the lawyers and their practices, as first instance judges were recruited among them, It offers a profile of those involved in the rural courts in Tlaxcala, and especially an analysis of the often confrontational relations they had with their clients. Finally, it shows that the cost of justice was so high that the use of tinterillos, now illegal jural advisors, was essential to gain access to the courts and that there was a continuum between tinterillos and lawyers that makes the analysis ineffective in terms of opposition between the two statutes.

Lawyers, Justice, Mexican Revolution, Tinterillos, Rural Courts 



\title{
Tierras ejidales ¿Mercancía o territorios indígenas? Intermediación legal y nuevas interpretaciones disonantes de la legislación agraria en el México contemporáneo
}

\author{
Gabriela TORRES-MAZUERA \\ Centro de Investigaciones y Estudios Superiores \\ en Antropología Social, Mérida, Mexique
}

\section{Introducción ${ }^{1}$}

En 1992 fue reformado el Artículo 27 de la Constitución mexicana que rige los bienes y recursos de la nación, incluyendo la tierra, el subsuelo y las aguas. La reforma tuvo varios objetivos entre los que destacan: finalizar la distribución de tierras vía la reforma agraria (1915-1992) iniciada tras la revolución mexicana y promovida por el Estado a todo lo largo del siglo xx. También se propuso abrir al mercado legal aquellas tierras dotadas como ejidos que hasta ese momento tenían el carácter de inalienables, las cuales junto con las comunidades restituidas a pueblos de antecedente colonial conformaban 103 millones de hectáreas o el $51 \%$ del territorio nacional.

La reforma al Artículo 27 debilitó varios de los principios que justificaron la diferenciación que existía, en el ámbito legal y jurisdiccional, entre la propiedad privada y la propiedad comunal y ejidal, aunque no eliminó la distinción entre ambas. Hasta entonces, la interpretación imperante entre campesinos y funcionarios agrarios de la legislación agraria vigente que regulaba la propiedad de ejidos y comunidades (Ley Federal de la Reforma Agraria, 1971) enfatizaba la función social que ambas formas de tenencia debían desempeñar. A diferencia de la propiedad privada definida como un derecho individual y absoluto, la propiedad ejidal y comunal establecía la prevalencia, con ciertos límites, a los intereses individuales, al mercado y la especulación, de ahí que las tierras dotadas y restituidas a pueblos y grupos de campesinos fuesen definidas legalmente como inalienables, intransmisibles, imprescriptibles, inembargables e indivisibles.

La propiedad ejidal y comunal estaba asociada además a ciertos principios de justicia social y economía moral campesina sintetizados en la consigna zapatista de 
"la tierra es de quien la trabaja" popularizada en el medio rural. De acuerdo a esta última, el beneficiario del reparto agrario debía ser campesino, residente permanente del ejido y miembro activo de la comunidad. La regulación y dominio de ejidos y comunidades residía, no en los sujetos agrarios individuales (ejidatarios y comuneros) sino en la asamblea general integrada por estos. Con la emisión de una nueva Ley Agraria en 1992 se eliminaron las obligaciones de trabajarla y residir en los núcleos agrarios. También se afianzaron los derechos individuales de ejidatarios que en la actualidad guardan mayores similitudes que diferencias, en términos de derechos y obligaciones, con respecto a los pequeños propietarios De ahí que, para algunos especialistas, la propiedad ejidal y comunal, actualmente, está en crisis ${ }^{1}$. Ante este panorama, cabe preguntarse sobre los principios sociales que hoy en día justifican la tenencia ejidal y comunal. Diversos actores han dado respuesta a estas preguntas en distintos campos sociales en los que se crea, recrea y negocia lo que entendemos como propiedad social en México².

En otro trabajo me centré en explicar la respuesta que ejidatarios y comuneros han dado a esta situación en un contexto específico: la Península de Yucatán entre el 2011 y $2015^{3}$. El principal hallazgo de esta investigación etnográfica fue la variedad de versiones que coexisten en un mismo núcleo agrario en cuanto a las obligaciones y derechos respecto a las tierras ejidales y comunales y las significaciones contrastantes respecto al tipo de propiedad y comunidad política que representa el ejido a nivel local.

En el presente texto, me interesa explorar las interpretaciones que funcionarios de la Procuraduría Agraria, institución que conforma lo que llamaré el "sector agrario”, así como magistrados de los Tribunales Agrarios y abogados litigantes hacen de la Ley Agraria y la propiedad ejidal y comunal. El punto de partida es similar al de mi investigación anterior y lo enuncio de la siguiente manera. La Ley Agraria (1992) en sus principios contrarios a los del Artículo 27 constitucional de 1917, ha detonado una proliferación de desfases entre lo que establece la ley, lo que dicta la costumbre y lo que en realidad se hace. Estos desfases son posibles dado las lagunas o ambigüedades existentes en la misma Ley sobre varios aspectos

1. Agradezco los comentarios de los dos dictaminadores anónimos y de David Recondo los cuales contribuyeron a mejorar sustancialmente este trabajo. También agradezco a dos proyectos en los cuales desarrollé ideas y argumentos aquí presentados: “Justicia y Sociedad en México, siglos xviII a xxı”, Acuerdo México-Francia, SEP-CONACYT-ANUIES-ECOS NORD” y al proyecto: Laboratoire Mixte International, "Mobilités, gouvernances et ressources dans le bassin mésoaméricain” financiado por el IRD (Francia) y CIESAS (México). Sobre la crisis de la propiedad social véase: Azuela, Antonio, "Property in the Pos-Post-revolution: Notes on the Crisis of the Constitutional Idea of Property in Contemporary Mexico", in Symposium: Latin American Constitutionalism: Section V: Constitutional Approaches to Property Rights, Texas Law Review 89 Tex. L. rev. 1915, 2010. Asimismo la discusión de Pérez Castañeda, Juan Carlos y Mackinley Horacio, "Existe aún la propiedad social agraria en México?", in Polis México, vol. 11:1, 2015, p. 45-82.

2. Sobre la definición de la propiedad desde la noción de campos sociales véase Benda-Beckmann, Franz, BendaBeckmann, Keebet, y Wiber, Melanie "The properties of property", in Franz Benda-Beckmann, Keebet BendaBeckmann y Melanie Wiber (ed.) Changing Properties of Property, New York-Oxford, Berhahn Books, 2006.

3. Torres-Mazuera, Gabriela, La común anomalía del ejido posrevolucionario. Mercantilización de la tierra y disonancias normativas en el sur de Yucatán, México, CIESAS-Casa Chata, 2016. 
relativos a la definición misma de la propiedad social y sus titulares, y lo que en la práctica cotidiana se concibe como correcto e incorrecto, justo e injusto con relación al acceso, uso y disfrute, y transferencia de la tierra ejidal/comunal. Las contradicciones en principios inscritos en la Ley Agraria y la Constitución mexicana permiten márgenes de interpretación que en muchos casos son ad hoc a la apertura de un mercado de tierras ejidales y comunales, pero también posibilitan nuevas formas de defensa de la tierra ejidal y comunal y del territorio, adjetivado muy recientemente como indígena. Esto último, gracias al giro multicultural de las mismas legislaciones nacionales que se dio a la par de la reforma agraria de 1992, así como a la internacionalización del debate jurídico activado con la firma de tratados internacionales por parte del gobierno mexicano.

El argumento central que desarrollaré en lo que sigue, es que en el marco de una reforma legal de carácter neoliberal y multicultural que desvirtúa principios de derecho social inscritos en una constitución surgida tras una lucha revolucionaria, el papel de la intermediación resulta más importante que nunca. Esta intermediación que consiste en una interpretación activa sobre el tipo de propiedad que es el ejido, la realizan los ejidatarios y comuneros, los funcionarios del gobierno y los jueces y abogados quienes avanzan definiciones contrastadas de lo que es o debería ser el ejido y la propiedad social en México.

Este trabajo está compuesto por tres apartados apoyados en información recolectada principalmente en el estado de Yucatán: En el primero explico la participación de los funcionarios agrarios en las reinterpretaciones en torno a la tierra ejidal. Para ello me centro en la actuación de visitadores agrarios quienes son los funcionarios "de campo" más cercanos a los ejidatarios. Analizo cómo éstos actores fueron centrales en la implementación del Programa de Certificación de Derechos Ejidales y Titulación de Solares Urbanos (PROCEDE), para luego, en un segundo momento, contribuir a los procesos de privatización y mercantilización de las tierras ejidales. En una segunda parte, analizo la intermediación desde la perspectiva de los magistrados agrarios y abogados. Inicio con un panorama sobre el tipo de controversias que se resuelven en el Tribunal Unitario Agrario (TUA) 34 con sede en Mérida y la interpretación de los magistrados agrarios y abogados litigantes sobre la conflictiva agraria en la región. Me interesa resaltar la aproximación particular al Derecho agrario de estos últimos, el lenguaje que usan y la ética de trabajo que tienen en su trato con ejidos y ejidatarios, para luego contrastarlo, en una tercera parte, con la aproximación de abogados formados en derechos humanos que promueven demandas y amparos en defensa de los ejidos y comunidades con población indígena con un nuevo lenguaje legal. Aunque aún son pocos los casos que llegan con este enfoque a los tribunales agrarios, son emblemáticos por la forma en que resignifican el ejido como territorio indígena.

Este texto se apoya en la información etnográfica y documental que he venido recabando entre el 2011 y 2018 en Yucatán y el dialogo entablado en ese periodo con un conjunto de abogados, magistrados, funcionarios del sector agrario, así 
como ejidatarios y demás vecinos de los ejidos de la entidad. También se apoya en la observación de las audiencias que se celebraron en el TUA 34 que realicé entre 2011 y 2012.

\section{La Procuraduría agraria: mediación para el despojo}

El proceso de reparto agrario derivado de la revolución mexicana trajo consigo una complejidad de procedimientos que fueron regulados por un ensamblaje institucional, igualmente complicado y cambiante. En la actualidad las dependencias con mayor injerencia sobre la vida de ejidos y comunidades son: la Procuraduría Agraria (PA) y el Registro Agrario Nacional (RAN), ambos órganos desconcentrados de la Secretaría de la Reforma Agraria (hoy Secretaría de Desarrollo Agrario, Territorial y Urbano, SEDATU) y los Tribunales Unitarios Agrarios (TUAS) ${ }^{4}$.

La Procuraduría Agraria tiene, en teoría, el rasgo de ombudsperson agrario, debido a que tiene a su cargo la defensa de los derechos de los ejidatarios, comuneros y demás sujetos agrarios por medio de funcionarios de base llamados "visitadores agrarios" . En 2017 la PA tenía 851 visitadores a nivel nacional. Los estados con mayor presencia de estos son: Veracruz con 84, Chiapas con 70, Oaxaca con 59 y Yucatán $23^{6}$. El perfil de estos visitadores es variado, entre estos se encuentran agrónomos, antropólogos, sociólogos y abogados. Estos últimos prestan sus servicios de asesoría jurídica para la resolución y conciliación de conflictos a sujetos agrarios (ejidatarios y comuneros) y núcleos agrarios (ejidos y comunidades).

La labor más importante de esta dependencia ocurrió entre 1992 y 2006 cuando se implementó el programa Procede dirigido a emitir títulos de propiedad a ejidatarios y comuneros y delimitar con gran precisión los límites de los núcleos agrarios. La ejecución de PROCEDE por parte de la Procuraduría Agraria implicó la contratación de nuevo personal y amplios recursos técnicos y económicos. Los visitadores agrarios jugaron un papel fundamental en la toma de decisiones de las asambleas ejidales respecto a la parcelación o no de los ejidos y la aceptación de

4. El sector agrario está conformado también por la SEDATU, el FIFONAFE y le Tribunal superior agrario, todos ellos con muy poca presencia en ejidos y comunidades. A propósito de la evolución de las instituciones de procuración de justicia agraria, véase Gallardo R., "La procuración de justicia agraria en México", Estudios agrarios, vol. $10 \mathrm{n}^{\circ} 27,2004$.

5. De acuerdo al reglamento interno que la rige, las principales tareas de la Procuraduría agraria son: 1) Asesorar a los sujetos agrarios en la realización de los contratos, convenios o cualquier otro acto jurídico que celebren entre sí o con terceros en materia agraria; 2) Coadyuvar y, en su caso, representar a los sujetos agrarios en asuntos y ante autoridades agrarias; 3) Promover y procurar la conciliación de intereses de los sujetos agrarios en las materias reguladas por la Ley Agraria, como vía preferentemente para la solución de los conflictos; 4) Actuar como árbitro en los casos en que las partes no lleguen a un avenimiento y designen a la institución con ese carácter; 5) Orientar a los sujetos agrarios y, en su caso, gestionar a su nombre ante las instituciones públicas competentes, la obtención de permisos, concesiones, licencias o autorizaciones administrativas necesarias para la explotación o aprovechamiento de las tierras, bosques, aguas o cualquier otro recurso; 6) Asesorar y representar a los sujetos agrarios ante las autoridades administrativas o jurisdiccionales, a fin de obtener la regularización de la tenencia de la tierra y la certificación y titulación de sus derechos.

6. Infomex, Solicitud de información n 1510500018517, Procuraduría Agraria 08/01/2017. 
nuevos sujetos agrarios, ya que eran estos quienes explicaban a las asambleas los beneficios o riesgos que suponía dicha titulación.

En el caso de Yucatán, el PROCEDE pasó de forma exitosa de acuerdo con sus promotores, con el $89.94 \%$ de ejidos titulados en $2010^{7}$. Sin embargo, la particularidad yucateca fue que el $80 \%$ de las asambleas ejidales decidieron conservar más del 76\% de su superficie como de uso común y no dividirla legalmente. Si bien, parte de las razones por las cuales no se aceptó la parcelación individual con el Programa tienen que ver con una estrategia por parte de muchos ejidatarios para evitar la enajenación de las tierras colectivas que por ley siguen siendo inalienables, es indudable que los visitadores agrarios tuvieron mucho que ver en el asunto, aunque no precisamente por las mismas razones, como veremos a continuación.

El PROCEDE fue muy ambicioso desde la perspectiva de cobertura territorial: llegar a todos los ejidos del país en un periodo relativamente corto. En Yucatán el momento cumbre del programa fue entre 1994 y 1999 cuando los visitadores agrarios lograron titular entre 100 y 111 ejidos al año. Los visitadores agrarios que participaron en el programa y que entrevisté en 2011, coincidieron en señalar que las metas del programa fueron muy altas para la capacidad de las delegaciones estatales de la Procuraduría Agraria, de ahí que se buscó la manera de simplificar el trabajo. Fue así como se optó por mantener el uso común de los ejidos, ya que esto implicaba mucho menor trabajo de mediciones y generación de documen$\operatorname{tos}^{8}$. De acuerdo a esta versión, los mismos funcionarios agrarios trastocaron los objetivos últimos del programa: Un ex funcionario que trabajó en el RAN durante el paso de Procede en Yucatán, incluso afirmó que "se les orilló a los ejidatarios para que no parcelaran" 9 . A esto se ańade las interpretaciones divergentes entre los visitadores agrarios sobre el objetivo principal de Procede ${ }^{10}$. Desde la perspectiva de algunos, el Programa consistía en promover la parcelación individual de las tierras ejidales y la regularización de esta. En cambio, para otros, el programa debía únicamente legalizar los parcelamientos de facto que existían en los ejidos previos al paso del Programa. Esta perspectiva era compartida por funcionarios de RAN-Mérida, tal como lo explicó uno de ellos: "Los visitadores agrarios 'vendían la idea' a los ejidatarios de que con el programa de Procede, nada iba a cambiar a fin de que lo aceptaran, y por esta razón lo que era más convincente de hacer era [sólo] medir los límites del ejido" ${ }^{11}$. Esta divergencia de interpretaciones se sumó, así, a la presión institucional ejercida sobre dichos funcionarios, con los resultados particulares en el estado.

Hoy en día, muchos de los ejidos de Yucatán que no parcelaron sus tierras de forma gratuita con el programa PROCEDE, lo están haciendo pagando un

\footnotetext{
7. http://www.pa.gob.mx/estados/estadisticas/yuc.htm

8. Entrevistas con tres visitadores agrarios, residencia Tekax noviembre 2010.

9. Entrevista con Tomás González, Mérida, 20/06/2012.

10. Véase también in Torres-Mazuera, op. cit, 2016.

11. Entrevista con Fernando Torres, RAN-Mérida 22/04/2010.
} 
alto precio en tierras o dinero, a empresas deslindadoras conformadas, en muchos casos, por ex funcionarios de la PA o el RAN que en su momento participaron en el Programa. Las nuevas parcelaciones de los ejidos son generalmente promovidas por empresarios interesados en las tierras ejidales que con la ayuda de los visitadores agrarios se aproximan a las asambleas ejidales para proponer la compra de tierras de uso común.

De acuerdo con la Ley Agraria, las tierras de uso común ejidal son inalienables, aunque la asamblea ejidal puede decidir un cambio de destino de cierta fracción del uso común y transformarlo en parcela ejidal que es sujeta de enajenación. Hoy en día, las tierras de uso común son cotidianamente vendidas a empresarios foráneos por las asambleas ejidales con asesoría de visitadores agrarios, quienes trastocan los procedimientos legales, para hacer estas tierras enajenables y privadas. Para ello promueven la parcelación legal o cambios de destino de las tierras de uso común. Los nuevos parcelamientos no respetan ningún principio de equidad ni de justicia social que, de acuerdo a visitadores agrarios entrevistados, estuvo presente durante el parcelamiento legal con Procede. Por otra parte, la asignación de las nuevas parcelas se hace a "ejidatarios-empresarios" que de forma inmediata hacen el cambio a dominio pleno de dichas parcelas. Estos procedimientos son realizados en un sólo movimiento, lo cual atenta contra ciertos candados establecidos en la Ley Agraria pero son facilitados por los visitadores agrarios, en particular la entrada a empresarios foráneos a los ejidos como ejidatarios o posesionarios, que por ley deberían ser avecindados o residentes del núcleo agrario, sin claramente serlo ${ }^{12}$.

La Procuraduría Agraria ha acumulado una lista larga de denuncias por parte de ejidatarios, ejidos y comunidades y organizaciones indígenas, quienes afirman que han sido los delegados y visitadores agrarios quienes han favorecido el proceso de despojo de tierras a indígenas y campesinos. Queda claro que la intermediación en este proceso es clave: los visitadores agrarios son los principales agentes en contacto con ejidatarios y comuneros que permiten la primera aproximación entre empresarios y sujetos agrarios. Son también ellos quienes ofrecen asesoría e información en el ámbito local, favoreciendo un ejercicio muy individualizado de la propiedad ejidal que no considera a la asamblea general de ejidatarios en la toma de decisiones, afianza la autoridad de facto de los comisarios ejidales (representantes de la asamblea general de ejidatarios) y posibilita la enajenación y arrendamiento de tierras ejidales de uso común.

12. Sobre el rol de los visitadores como intermediarios y facilitadores del despojo en ejidos véase también Garibay Claudio, et al., "Corporación minera, colusión gubernamental y desposesión campesina. El caso de Goldcorp Inc. en Mazapil, Zacatecas.” in Desacatos, n 44, 2014, p. 113-142. y Torres-Mazuera Gabriela, Fernández Mendiburu Jorge, Gómez Godoy Claudia, Informe sobre la jurisdicción agraria y los derechos humanos de los pueblos indígenas y campesinos en México, Fundación por el Debido Proceso, 2018. 
- Simplificación de trámites para la compra-venta de tierras ejidales: Conjunto de acciones agrarias en una sola asamblea que deberían realizarse en varias (cambio a destino, reconocimiento de avecindados que no radican en la comunidad y de nuevos sujetos agrarios).

- Asambleas calificadas siempre en la $2^{\mathrm{a}}$ o $3^{\mathrm{a}}$ convocatoria que permiten excluir a parte de los derechohabientes opuestos a los proyectos. Asambleas calificadas realizadas en regiones indígenas que no cuentan con un traductor.

- Actas en blanco que los comisarios ejidales hacen firmar a ejidatarios para luego ser utilizadas en el aval de las enajenaciones de tierra que no cuentan con el consenso de las Asambleas generales.

- Destitución de autoridades agrarias que muestran oposición a proyectos de desarrollo promovidos por inversionistas foráneos.

Tabla - Estrategias de despojo promovidas por los visitadores agrarios en Yucatán Fuente: Entrevistas con los abogados Lourdes Euan (Chablekal, 23/03/2016), Dalia Piña (Mérida 18/03/2016) y Rodolfo Macossay (Mérida, 01/013/2014).

\section{Los magistrados agrarios y los abogados litigantes en los Tribunales unitarios agrarios: controversias administrativas y negociaciones sobre la tierra ejidal como mercancía}

Los Tribunales Agrarios fueron creados con la reforma legal de 1992 para la impartición de justicia en materia agraria y para otorgar certeza en la tenencia de la tierra ejidal y comunal. Estos órganos están dotados de plena jurisdicción, aunque no están integrados al Poder Judicial de la Federación, entre otras razones, por actuar como autoridad substituta del Ejecutivo Federal en la resolución de los asuntos de "rezago agrario", es decir aquellos referidos a solicitudes de dotación o restitución de tierras previas a 1992 que se encontraban en trámite en la Secretaría de la Reforma Agraria. Su autonomía se constriñe a su capacidad jurisdiccional, pero no administrativa, de ahí que su ejercicio puede quedar supeditado a criterios que remiten a los objetivos y prioridades del poder ejecutivo, como son la "paz social" o el "interés público"13. Los tribunales agrarios están integrados por magistrados propuestos por el Ejecutivo Federal y designados por la Cámara de Senadores o, en los recesos de ésta, por la Comisión Permanente y se componen del Tribunal Superior Agrario y los tribunales unitarios agrarios (a la fecha se contabilizan 57 en todo el país) ${ }^{14}$.

De acuerdo con Hernández Palacios (2018), exmagistrado del Tribunal Superior Agrario "aunque el número de asuntos que conocen los Tribunales Unitarios ha ido en aumento, en los últimos años la mayoría de ellos (cerca del 70\%) se refieren a sucesiones, nulidad de actas de asamblea de Procede (correcciones de nombre), controversias posesorias (para legitimar cesiones de derechos) y jurisdicción 
voluntaria, siendo la principal promovente, la Procuraduría Agraria"15. Esta situación ha "rutinizado" la labor jurisdiccional. Los asuntos "menores" que llegan cotidianamente a los tribunales consumen mucha energía y gasto para el gobierno y para los mismos ejidatarios, y magistrados, en tanto que los grandes conflictos pocas veces llegan o se resuelven en los tribunales ${ }^{16}$.

Más importante aún para la discusión de este trabajo, los principios de "derecho social" que suponía el derecho agrario han ido diluyéndose en la práctica de un buen número de Tribunales Unitarios. Los magistrados han optado por una interpretación basada en criterios y principios del derecho civil y mercantil, más que en una de Derecho social que enfatiza la dimensión redistributiva y proteccionista con la que deberían abordarse las controversias agrarias.

Un tipo de asuntos que llegan más a menudo al tribunal tiene que ver con conflictos entre vecinos de los mismos ejidos asociados a ventas de tierras. En estos casos los magistrados promueven la conciliación, ya que un litigio agrario es muy costoso por las pruebas periciales y de documentación, además de que son muy largos (más de 2 años). Algunos de estos litigios llegan a costar más que el valor de la tierra en disputa ${ }^{17}$.

Desde los ańos 2010, otro tipo de controversia se desahoga con mayor frecuencia en el TUA $34^{18}$. La nueva conflictiva tiene que ver con la venta de tierras ejidales a empresarios foráneos. Estos litigios se presentan como la anulación de actas de asamblea que autorizan cambios de destino de tierras de uso común ejidal y su enajenación. A este respecto, la perspectiva de magistrados y abogados que litigan en el TUA 34 es desencantada: los juicios agrarios son una estrategia por parte de los ejidatarios para obtener una mayor ganancia económica y no tanto una defensa colectiva por la tierra ejidal ${ }^{19}$. Esto es posible porque la mayoría de las ventas de tierras presentan muchas irregularidades por las razones explicadas en el apartado anterior, aunque la norma es que los ejidatarios demandantes no buscan recuperar sus tierras, sino aumentar el precio pagado por los empresarios. Magistrados y abogados que entrevisté entre 2011 y 2018 ofrecieron varios ejemplos a este respecto,

15. Hernández Palacios, "Balance sobre la institucionalidad agraria” manuscrito inédito, 2018 (s./p.).

16. Entrevistas con Luis Hernández Palacios, Magistrado supernumerario del TSA, Mérida Yucatán. 20/11/2011; 23/04/2018 Ciudad de México; Juan José Pérez Palma, Magistrado agrario del TUA 34 14/10/2011 y 07/05/2012, Mérida.

17. Entrevista con Juan José Pérez Palma, TUA 34, Mérida, 20/06/2011.

18. En 2016 Yucatán ocupaba el tercer lugar a nivel nacional en litigios por la tierra, después de Baja California y Quintana Roo. Estos conflictos se debían, según al ex secretario de la Secretaría de la reforma agraria, a la especulación, fuente de más de 1900 conflictos (Infolliteras, "Yucatán y Quintana Roo, a la cabeza en conflictos por la tierra, dice Jorge Carlos Ramírez Marín” 5 de marzo, 2016 [http://infolliteras.com/articulo. php?id=31115]).

19. Entrevistas con Luis Hernández Palacios, Magistrado supernumerario del TSA, Mérida Yucatán, 20/11/2011; 23/04/2018 Ciudad de México; Juan José Pérez Palma, Magistrado agrario del TUA 34 14/10/2011 y 07/05/2012, Mérida; Lic. Martín Montejo, abogado de la PA residencia Mérida, TUA Mérida, 12/03/2014, Lic. Lourdes Euan, Chablekal, 23/06/2016; Lic. Dalia Piña, Mérida, 09/06/2017, Rodolfo Maccosay, Mérida, 20/05/2013. 
destaca el caso de la compra de tierras del ejido de Chablekal en el municipio de Mérida para la construcción de un club de golf ${ }^{20}$.

Entre las pautas de esta práctica identificamos que quienes demandan son generalmente grupos pequeños de ejidatarios, muchas veces, emparentados entre sí que contando con mayor información o asesoría legal (algunos de ellos poseen familiares que laboran en alguna institución del sector agrario o son abogados) se negaron a firmar las actas de asamblea donde se establece el cambio de destino y la enajenación de las nuevas parcelas ejidales. Esto les permite denunciar las irregularidades procedimentales, a fin de negociar con los empresarios un mayor pago a cambio de su anuencia para la venta de tierras de uso común. Un aspecto importante a destacar es que estas negociaciones no serían posible si todos los ejidatarios como colectivo organizado exigieran un mayor precio a pagar, por la simple razón de que el precio de la tierra subiría demasiado y los empresarios dejarían de obtener la ganancia esperada. Una demanda colectiva por parte de los ejidatarios obligaría a los empresarios a devolver las tierras ejidales y eso, hasta la fecha, no ha sucedido en Yucatán.

Muchas de las controversias cuyo objetivo es la ganancia económica para los ejidatarios son promovidas por los mismos abogados que litigan en el TUA 34. En Mérida existen una veintena de abogados litigando en este espacio (cinco de los cuales laboran como visitadores agrarios en la PA). La mayoría de estos abogados cuenta con una formación en derecho civil y mercantil lo cual los predispone a una interpretación de la tierra ejidal en términos de mercancía o bien individual y a los ejidatarios, como meros clientes potenciales. En esta aproximación, la propiedad ejidal es una modalidad de propiedad privada mucho más que una forma excepcional de propiedad. Generalmente los abogados de este perfil de formación profesional suelen apoyarse en la supletoriedad del derecho civil para la argumentación jurídica en los juicios agrarios, lo que conlleva un razonamiento jurídico particular: se presupone la igualdad entre las partes contratantes (ejidatarios y empresarios), se privilegia el derecho individual de los ejidatarios como propietarios en detrimento de los derechos colectivos de los núcleos agrarios (en particular cuando se discuten derechos y obligaciones asociados a la tierra ejidal) y se involucra a fedatarios públicos y notarios para la acreditación y certificación de contratos al interior de los ejidos ignorando la autoridad de la asamblea ejidal.

Los abogados que litigan en el TUA 34 en Mérida cobran sus honorarios ya sea con un porcentaje de tierras ejidales o un porcentaje de las ganancias que se espera ganar con sentencias a su favor. Algunos abogados que han asesorado y promovido activamente las parcelaciones de tierras de uso común en ejidos metropolitanos de Mérida se han convertido ellos mismos en agentes inmobiliarios que contribuyen a la compraventa de parcelas ejidales en los alrededores de la ciudad de Mérida.

20. Sobre este caso véase: Torres-Mazuera Gabriela y Fernández Mendiburu Jorge "Los pobladores mayas de Chablekal vs. El ejido de Chablekal: una aproximación a la nueva demanda de la tierra ejidal como territorio indígena en México" in Teresa Sierra y Santiago Bastos, Estado y pueblos indígenas en México. La disputa por la justicia y los derechos, México, Colección México-Ciesas, 2017. 


\section{El ejido como territorio indígena: nuevo lenguaje legal en el ámbito de los Tribunales agrarios}

A diferencia del modelo desarrollista de las reformas agrarias a lo largo del siglo xx para el cual la principal función de la tierra repartida debía ser la productividad agropecuaria, de lo que se desprendía que la tierra debía de ser para quien la trabajara, hoy en día surge un nuevo enfoque que reconoce la importancia de la tierra como territorio donde se recrea la identidad colectiva de pueblos originarios. La nueva aproximación enfatiza el valor de aquellos territorios habitados "ancestralmente" por grupos indígenas que lograron, por distintas razones, preservar una gran biodiversidad. ${ }^{21}$ Es así que, desde la década de 1990, inicia un proceso de reconocimiento formal por parte de diversos gobiernos de territorios "indígenas" a los que tienen derecho histórico pueblos originarios y otras poblaciones étnicas como las afromestizas ${ }^{22}$.

En México, la definición de la propiedad social sienta algunas bases para avanzar en la vía del reconocimiento de territorios indígenas, en particular en lo referente a las comunidades (agrarias), aunque el Artículo 27 reformado en 1992 y la Ley Agraria no especifican con claridad la vía para hacerlo. De ahí que no es hasta muy recientemente que la demanda de personas indígenas de un ejido debe ser tomada en cuenta por los tribunales agrarios.

Entre las reformas legales que posibilitan las nuevas demandas están la ratificación en 1991 por parte de México del Convenio 169 de la Organización Internacional del Trabajo, la reforma del Artículo $2^{\circ}$ constitucional en 2001 que obliga al Estado mexicano a reconocer y garantizar el derecho de los pueblos y las comunidades indígenas a la libre determinación. Finalmente, en 2011, el Congreso de la Unión aprobó una reforma constitucional en materia de derechos humanos que obliga a jueces y magistrados a considerar en el ejercicio de sus funciones el derecho internacional y de manera específica, el contenido en los Tratados Internacionales de Derechos Humanos. En esta nueva coyuntura legal, los pobladores auto-identificados como indígenas de ejidos y comunidades deben ser tomados en consideración en sus demandas por los tribunales agrarios.

La nueva exigibilidad jurídica del territorio indígena en el contexto ejidal y comunal es posible gracias a las reformas legales pero se hace efectiva gracias a la intermediación de abogados que se especializan en la defensoría de derechos humanos y trabajan en asociaciones de la sociedad civil sin fines de lucro. En efecto, el derecho al territorio indígena no resulta un derecho evidente ni obvio para los residentes de los núcleos agrarios, muchos de los cuales hasta muy recientemente se auto-identifican como indígenas. Es así como parte de la labor de las organizaciones

21. A ese respecto, véase, por ejemplo, Boege Eckart, El patrimonio biocultural de los pueblos indígenas de México, México, INAH-CDI, 2008.

22. Véase a este respecto: Gros, Christian, "Des territoires multiculturels?" in Cahiers des Amériques Latines, $n^{\circ} 45,2005$, p. $31-50$. 
en las que trabajan estos abogados es la de acercarse a las comunidades y ejidos y llevar a cabo no solo defensoría sino trabajo de educación o sensibilización en torno a los derechos humanos y los derechos de los pueblos indígenas. Más importante aún, parte del trabajo que realizan es generar una conciencia entre los habitantes de ejidos y comunidades sobre el valor de la tierra ejidal como patrimonio colectivo.

Un caso emblemático de este nuevo enfoque legal en Yucatán es la demanda por despojo territorial contra el comisario ejidal de Chablekal, la asamblea de ejidatarios y la PA que realiza un grupo de hombres y mujeres autoidentificados como indígenas y originarios de Chablekal, asesorados por el Equipo Indignación, asociación civil local, ubicada en el mismo poblado. En este ejido dotado en 1927, el 74.1\% de las tierras habían sido vendidas por el ejido al momento de la demanda (PHINA, Actas de asamblea ejido Chablekal). De acuerdo con los pobladores indígenas demandantes, una buena parte de esas tierras eran "monte" al cual históricamente habían tenido acceso como vecinos del pueblo. En su demanda argumentan que "los ejidatarios no son los únicos dueños de las tierras y el territorio de nuestro pueblo" (Comunicado de Chablekal, 31 de agosto de 2014). También argumentan que:

[...] la tierra [del ejido] hace referencia a una porción de superficie terrestre sujeta a la propiedad privada, misma que ha sido históricamente protegida para los campesinos a través de la figura del ejido. Mientras el ejido requiere de tierras para existir, el pueblo indígena necesita de un territorio. Las tierras del ejido ocupan parte del territorio de Chablekal, pero no es el pueblo a pesar de que lo que ocurra en el ejido tiene una repercusión comunitaria (Demanda legal de los pobladores y pobladoras de Chablekal contra el comisario ejidal, la asamblea ejidal de Chablekal y la Procuraduría Agraria, 2 de septiembre de 2014).

Esta demanda revela una de las más graves consecuencias de concebir la tierra ejidal exclusivamente en términos de propiedad: su posible alienación y la consecuente desintegración territorial en detrimento de los pobladores ejidales. También expone una de las principales exigencias de los movimientos indígenas e innovaciones en materia legal indígena en Latinoamérica: la protección del territorio en tanto bien comunitario e inalienable. En México, esta demanda regresa además al asunto de la autodeterminación, históricamente presente en las demandas de diversos movimientos indígenas y campesinos, que se fue desdibujando frente a la conformación de un discurso agrarista hegemónico a lo largo del siglo xx.

Uno de los principales retos de los pobladores demandantes del ejido Chablekal es demostrar su interés jurídico frente al Tribunal agrario 34, que en un inicio se niega a reconocerlo. Esta demanda involucra un peritaje antropológico, primero que llega a dicho tribunal con sede en Mérida, en un contexto regional donde un $62.7 \%$ de la población del estado se autoidentifica como indígena ${ }^{23}$. 
Los abogados en derechos humanos entrevistados para este trabajo identificaron dos rutas de lucha legal cuando se trata de la defensa al territorio indígena y tierras ejidales y comunales en México: el juicio agrario y el amparo ${ }^{24}$. Entre las ventajas del juicio agrario identifican la suplencia de la queja y la dispensa de la fianza como medida cautelar ${ }^{25}$. Sin embargo, la impresión de los entrevistados respecto a los Tribunales Unitarios Agrarios es que están "detenidos en el tiempo," cerrados a una interpretación progresista del derecho. De ahí que, en las sentencias agrarias, raramente se vean reflejadas sentencias o la jurisprudencia producida por la Corte Interamericana en Derechos Humanos en referencia al reconocimiento de territorios indígenas. La apuesta de estos abogados es conseguir que los tribunales agrarios se pronuncien desde el derecho indígena y la forma de obligarlos es llevando las controversias a los juzgados federales. De ahí que muchos de los casos que estos abogados llevan hayan sido resueltos por la vía civil ${ }^{26}$.

\section{Conclusiones}

En la actualidad existe un contraste entre las interpretaciones de abogados civilistas y aquellos defensores de derechos humanos que litigan frente a los Tribunales agrarios: los primeros abogan por mejores ganancias económicos para sus clientes, ya sean ejidatarios o empresarios foráneos; los segundos reinterpretan la propiedad ejidal como un derecho humano al territorio indígena al que tienen derecho no solo los sujetos agrarios sino todos los residentes del núcleo agrario auto-identificados como indígenas. Uno de los ejes de la disputa que se resuelve en los tribunales es entonces el interés jurídico de los nuevos demandantes "indígenas" sobre tierras ejidales o comunales, estas últimas concebidas por algunos como predios privados, aunque reivindicadas por otros, como territorios indígenas.

La defensa de la tierra ejidal como territorio indígena ha cobrado notoriedad en la discusión académica y en los medios de comunicación alternativos, generando cierta sobrerrepresentación de los conflictos agrarios planteados en estos términos. En el presente trabajo hemos descrito la novedad e importancia de la nueva discusión, sin embargo, no hay que olvidar que la mayoría de los litigios que se resuelven en los Tribunales Unitarios Agrarios son de carácter procesual y cuando involucran conflictos por la enajenación de tierras, la aspiración de los involucrados suele ser la ganancia económica más que la defensa del territorio indígena.

24. Entrevista con Lic. Hugo Aguilar, Oaxaca, 01/09/2017; Entrevista con Lic. Carmen Herrera, Abogadas y Abogados por la Justicia y los Derechos Humanos, Mérida, 17/01/2017; Entrevista con Lic. Gerardo Martínez, Centro Profesional Indígena de Asesoría, Defensa y Traducción Asociación Civil, Oaxaca, 31/08/2017, Entrevista con Lic. Juan Antonio Aguilar Proyecto de derechos económicos, sociales y culturales, A. C., Ciudad de México, 13/10/2017; Entrevista Lic. Rubén Ávila, Asociación Jalisciense de Apoyo a Grupos Indígenas (AJAGI) Chablekal, 28/11/2016.

25. Entrevista con Lic. Juan Antonio Aguilar Proyecto de derechos económicos, sociales y culturales, A. C., Ciudad de México, 13/10/2017.

26. Entrevista con Lic. Hugo Aguilar, Oaxaca, 01/09/2017; Entrevista con Lic. Carmen Herrera, Abogadas y Abogados por la Justicia y los Derechos Humanos, Mérida, 17/01/2017. 


\section{Resumen/Palabras Claves}

La conflictividad asociada a las tierras dotadas y restituidas como ejidos y comunidades durante el reparto agrario en México (1915-1992) va en aumento. Sus causas son variadas, pero destacan los procesos de privatización y mercantilización de estas tierras, dinamizados en 1992 con una reforma legal que permite su enajenación. El argumento de este trabajo es que en un contexto de reformas legales de corte neoliberal y multicultural que desvirtúan, pero no eliminan los derechos sociales asociados a la tierra ejidal y comunal, el papel de la intermediación de funcionarios del sector agrario, magistrados y abogados resulta más importante que nunca cuando se trata de su defensa como territorio o su transferencia como mercancía.

Ejido, Magistrados agrarios, Defensa del territorio, Despojo de la tierra

\section{RÉSUMÉ/Mots-ClÉS}

Les conflits associés aux terres octroyées et restituées en tant qu' ejidos et comunidades au cours de la Réforme agraire au Mexique (1915-1992) sont en augmentation. Leurs causes sont variées, mais elles mettent l'accent sur les processus de privatisation et de marchandisation de ces terres, revigorés depuis 1992 avec une réforme juridique qui permet leur aliénation. L'argument de ce travail est que dans un contexte de réformes juridiques néolibérales et multiculturelles qui déforment, mais n'élimine pas les principes des droits sociaux associés à l'ejido et aux terres communales, le rôle de l'intermédiation des fonctionnaires agraires, des magistrats et des avocats devient plus important que jamais, lorsqu'il s'agit de leur défense (en tant que territoire) ou de leur dépossession (en tant que marchandise).

Distribution agraire, Ejido, Magistrats agraires, Défense du territoire, Dépossession des terres

\section{ABSTRACT/KeYWORDS}

Conflicts associated with granted and restored lands, as ejidos and communidades, during Mexican agrarian reform (1915-1992) are increasing. There are various causes, all specifically related to the processes of privatization and commodification of these lands, invigorated in 1992 with a legal reform that allows their alienation. The argument of this work is that the role of the intermediation in case of agrarian conflict by agrarian officials, magistrates and lawyers is more important than ever. This, in a context of neoliberal and multicultural legal reforms that distort but don't eliminate the principles of social rights associated with ejido and communal lands, when it comes to their defense as territory or their transfer as merchandise.

Ejido and agrarian distribution, Agrarian magistrates, Territory defense, Land dispossession 



\title{
Adaptarse para resistir El reclamo de tierras en una región de los Andes argentinos en la primera centuria republicana
}

\author{
Ana A. Teruel \\ UE CISOR- CONICET/UNJu, Argentina
}

El 2 I DE ABRIL DE 1877, la Suprema Corte de Justicia, el más alto tribunal de la República Argentina, se pronunció en un fallo que se suponía pondría fin, en Jujuy, a las rebeliones y los pleitos ocasionados por la propiedad de la tierra reivindicada por los descendientes de los "pueblos de indios" coloniales ${ }^{1}$. El fallo decidía sobre el dominio de unas 600 mil hectáreas $^{2}$ e, indirectamente, sobre la suerte de 779 familias $^{3}$ de campesinos indígenas arrendatarios de un único hacendado que se adjudicaba la propiedad de las tierras de dos antiguos pueblos de indios: Casabindo y Cochinoca en la Puna de Jujuy.

El pleito respondía a la demanda que había iniciado la provincia de Jujuy

contra D. Fernando Campero, que se dice descendiente de los marqueses del Valle de Tojo, alegando que esos territorios [de los pueblos de indios mencionados] pertenecieron originariamente a la Corona de Espańa y que por consecuencia de su emancipación y del régimen político que se dio, han pasado por derecho de reversión al dominio de la Provincia demandante ${ }^{4}$.

Paradójicamente, los indígenas eran el gran ausente en la causa que motivó el fallo, a pesar de haber protagonizado tres ańos antes una rebelión que comenzó

1. Agradezco los aportes de los evaluadores anónimos que con sus sustanciales sugerencias contribuyeron a este artículo, cuyo contenido, sin embargo, es de mi responsabilidad.

2. Calculamos la extensión de las tierras de Cochinoca y Casabindo pertenecientes a Campero tomando como referencia la superficie del departamento en 1895 .

3. Cifra proporcionada por el Primer Censo de la República Argentina. Año 1869. Buenos Aires, Imprenta del Porvenir, 1872.

4. Fallo de la Corte Suprema de Justicia de la Nación. La Provincia de Jujuy contra D. Fernando Campero, sobre reivindicación. Buenos Aires, abril 21 de 1877. Reproducido en Carrasco, Morita, Los derechos de los pueblos indigenas en Argentina, Buenos Aires, Vinciguerra, 2000, p. 219-234. 
con la denuncia de falsedad de los títulos de Campero y que puso en jaque a los terratenientes locales y al gobierno de la provincia. El hacendado fundaba su derecho de dominio en la posesión de "la merced en propiedad y pleno dominio de la susodicha encomienda de Casavindo [sic] y Cochinoca" 5 que le fuera entregada en 1705 al marques del Valle de Tojo para goce propio y de sus sucesores, a lo que sumaba como argumento la prescripción inmemorial por posesión continua de dichas tierras en el transcurso de 150 ańos.

Además de sentar que ni Campero ni sus antecesores tuvieron derecho de propiedad sobre los fundos en litigio, la sentencia del más alto tribunal de la Nación afirmaba un principio que fue fundamental en el desarrollo a posteriori del conflicto: "por las leyes de encomienda, la posesión de la tierra en que ellas estaban situadas pertenecía a los indios encomendados, y el dominio directo a la Corona siendo del encomendero únicamente la administración y beneficio" ". Con ello, sumado al principio del derecho de reversión del dominio directo de la Corona a la provincia, quedaba descartada la posibilidad, por vía judicial, de reconocimiento de derechos de pleno dominio a los descendientes de los pueblos originarios. Sin embargo, este pronunciamiento de la Suprema Corte de Justicia no detuvo las denuncias de los nativos cuestionando los fundamentos de la propiedad de los fundos que habitaban en calidad de "arrenderos".

El camino esporádicamente pasó por los tribunales, pero con mayor frecuencia los procedimientos corrieron por distintas vías administrativas y políticas, en un abanico de acciones que abarcaban desde la súplica a las autoridades, la denuncia por falsedad de títulos y la resistencia al pago de arriendos, políticas que parecían más efectivas si se conjugaban con los intereses del fisco y si se aprovechaban las disputas en el juego de poder entre las élites gobernantes.

El núcleo del problema a abordar acá es la suerte de los derechos de propiedad, específicamente de las comunidades indígenas en el largo proceso de desvinculación, desarticulación - y frecuentemente de expropiación - de la propiedad colectiva de la tierra en el siglo XIx. El tema ha dado lugar a una vasta bibliografía en América Latina, especialmente en México, y en Bolivia y Perú. En Argentina, la imagen de país "blanco y europeo" sin población indígena - excepto en las fronteras de expansión colonial republicana en el Chaco y Patagonia - incidió en el "descubrimiento" más tardío del problema, centrado especialmente en el espacio que correspondía a la Gobernación del Tucumán ${ }^{7}$, que fue el que más literatura originó al respecto. En ocasión de este artículo, el análisis se situará en la provincia más septentrional de Argentina, recostada sobre la cordillera de los Andes, en la frontera con Bolivia y entrecruzará la cuestión de la desvinculación de la propiedad comunal y la expropiación con la de las formas y los mecanismos judiciales y extrajudiciales a los que

5. Ibid., p. 211.

6. Ibid., p. 217.

7. La Gobernación del Tucumán abarcaba las jurisdicciones territoriales de las actuales provincias argentinas de Córdoba, La Rioja, Catamarca, Santiago del Estero, Tucumán, Salta y Jujuy. 
acudieron los campesinos en defensa de los derechos afectados. Sin pretender entrar en el terreno de la historia de la justicia, me asomo a ella desde otro espacio, pues como destaca Barriera, "muchos recortes disciplinares pueden verse interpelados o enriquecidos a partir de la diagonal que obliga a trazar el estudio de lo judicial en subdisciplinas consolidadas" 8 .

\section{La cuestión de la propiedad comunal indígena y los derechos de propiedad en Jujuy}

En Argentina decimonónica, la cuestión de cómo encarar la propiedad comunal indígena era problema sólo de algunas provincias y no tuvo una trascendencia nacional semejante a la de México o Bolivia, así como tampoco hubo una legislación nacional dedicada a la desamortización. En tanto herencia de las diferentes estructuras prehispánicas y coloniales, había regiones donde subsistían comunidades dotadas de tierras durante la colonia, y que conservaron ese status hasta las primeras décadas republicanas (caso de algunas zonas en el Noroeste), frente a otras donde la propiedad y/o la posesión no fue reconocida nunca. Por ello, si hay algo en lo que los historiadores concordamos en relación al estudio de las transformaciones de la propiedad indígena en la larga duración, es su variación local, por lo que hemos aprendido que el ámbito adecuado para su análisis no es el nacional sino el regional, sin que ello implique perder de vista los marcos legales generales.

Desde fines de la colonia la circunscripción que luego dio origen a la provincia de Jujuy contaba con el 55\% de indígenas tributarios entre su población ${ }^{9}$, lo que significaba el porcentaje notoriamente mayor de la Gobernación Intendencia de Salta del Tucumán, a la que perteneció durante los últimos decenios virreinales. Jujuy se destacaba también porque casi la totalidad de los pueblos de indios habían sido establecidos con dotación de tierras comunales, a diferencia de lo que destacan Farberman y Boixados ${ }^{10}$ para el resto del territorio de la gobernación, donde la visita del Oidor Luján de Vargas (1693 y 1694) puso en evidencia que los indios -radicados mayormente en haciendas y estancias- raramente disponían de tierras para su usufructo.

En cercanías a "la raya" que separaba el Tucumán de Charcas (luego límite entre Argentina y Bolivia), a $3.400 \mathrm{msnm}$ en la región conocida como altiplano andino o Puna, se emplazaban los pueblos de indios de Casabindo y Cochinoca. Estos habían constituido la más grande encomienda del Tucumán, cuya existencia se mantuvo hasta la revolución de mayo de 1810. Al comenzar el siglo XIX en

8. Barriera, Darío G., “¿Qué nos enseña la historia de las instituciones judiciales? Algunos apuntes sobre la lenta historia de la separación de funciones”, in Bandieri, Susana y Fernández, Sandra (coord.), La historia argentina en perspectiva local y regional. Nuevas miradas para viejos problemas, t. II, Buenos Aires, Teseo, 2017, p. 134.

9. Censo de 1778 en Rojas, R. (recop.), Archivo Capitular de Jujuy, t. I, Buenos Aires, Imp. Coni, 1913.

10. Farberman, Judith y Boixados, Roxana, "Sociedades indígenas y encomiendas en el Tucumán colonial. Un análisis comparado de la visita de Luján de Vargas”, Revista de Indias, vol. LXVI, no 238, 2006, p. 601-628. 
dichos pueblos se contabilizaban 580 tributarios originarios ${ }^{11}$ (varones adultos entre 18 y 51 ańos, con derecho a la tierra), los que junto a sus familias y a los indios forasteros sin tierras sumaban 6.845 personas $^{12}$. En la Quebrada de Humahuaca, el corredor natural que une el valle de Jujuy con el altiplano y con Bolivia, se emplazaban los pueblos de indios de San Antonio de Humahuaca, San Francisco de Tilcara, Santa Rosa de Purmamarca y San Francisco de Paula de Uquía, que en 1806 reunían 483 tributarios, entre originarios y forasteros, los que con sus familias suponían unas 1.700 personas ${ }^{13}$.

Así la provincia de Jujuy se inauguró, tras su separación de Salta en 1834, con una importante proporción de población indígena ${ }^{14}$, lo que a la vez que la caracterizó durante todo el siglo, también la diferenciaba del entorno metropolitano del país, más aún cuando en el último tercio del siglo xIx la masiva inmigración europea cambió la composición étnica de la región de la pampa y el litoral atlántico.

La desamortización de la propiedad comunal indígena comenzó en Jujuy en un período bastante temprano, apenas iniciada la organización de la provincia tras su autonomía en 1834. Sin embargo, las disposiciones al respecto no alcanzaron a las tierras de los pueblos de la Puna. ¿Por qué razón? La causa más invocada por los historiadores fue señalada la primera vez por Madrazo ${ }^{15}$, al afirmar que en las primeras décadas del siglo xIx el encomendero de los indígenas de Casabindo y Cochinoca, Marqués del Valle de Tojo, dejó de cobrarles tributo en atención a la prohibición establecida en 1811 por el gobierno revolucionario con sede en Buenos Aires. Sin embargo, les impuso el pago de arriendo en las propias tierras de sus pueblos. La cuestión también produjo la inquietud de Doucet quien refirió a los Marqueses como "avezados alquimistas o ingenieros de transformaciones institucionales, [que] según las conveniencias de los tiempos, convirtieron a arrenderos en tributarios o a ex tributarios en arrenderos" y al caso como un "singular, fascinante

11. En el virreinato del Perú (y luego entre los que los sucedieron tras su fragmentación) había una importante distinción entre dos categorías de indígenas tributarios: "originarios" y "forasteros" - categorías inexistentes en Nueva España - que diferenciaba entre aquellos indios con plenos derechos comunitarios y a la tierra (los originarios) y otros con derechos y obligaciones variables según épocas y regiones. Para más detalles en términos comparativos entre ambos virreinatos, véase Pollack, Aaron, "Hacia una historia social del tributo de indios y castas en Hispanoamérica. Notas en torno a su creación, desarrollo y abolición”, Historia Mexicana, v. $66, \mathrm{n}^{\circ} 1,2016$, p. $65-160$.

12. Padrón de la encomienda del Sor Marqués del Valle de Tojo practicado por Dn Francisco Poveda como apoderado fiscal de Revisita de Indios Casabindo en diciembre 21 de 1806 en Archivo Histórico de Jujuy (AHJ), Fondo Marquesado de Tojo (MT), caja 7, carpeta 227; y Gil Montero, Raquel, Caravaneros y trashumantes en los Andes meridionales. Población y familia indígena en la puna de Jujuy, 1770-1870, Lima, Instituto de Estudios Peruanos, 2004.

13. Padrón de Indios tributarios de la ciudad de Jujuy y pueblos de su comprensión, año 1806; en Archivo Histórico de Jujuy (AHJ), Colección Ricardo Rojas (RR), Caja XL, Legajo 3.

14. En 1869, cuando se realiza el Primer Censo Nacional de la República Argentina, el 30.5\% de la población de la provincia (que en total sumaba 40.379 habitantes), habitaba la región de la Puna, que era mayoritariamente indígena.

15. Madrazo, Guillermo, Hacienda y encomienda en los Andes. La puna argentina bajo el Marquesado de Tojo, siglo XVII a XIX, Buenos Aires, Fondo Editorial, 1982. 
y desconcertante caso de mutación institucional" ${ }^{16}$. Si efectivamente ocurrió de esa forma, entonces se explica que el gobierno de la provincia no contemplara allí la desamortización y desvinculación pues ya no habría propiedad indígena comunal en la Puna, sino sólo naturales arrendatarios en tierras de la familia Campero, descendiente del Marques de Tojo.

Antes de abordar directamente las consecuencias jurídicas de esa cuestión, nos detendremos momentáneamente en la desamortización de las tierras de los pueblos de la Quebrada de Humahuaca, pues allí se sentará un principio posteriormente reafirmado por la Suprema Corte de Justicia, en su fallo de 1877.

En 1835, la Asamblea Constituyente que estaba en plena tarea en la provincia, pues acababa de constituirse como tal al separase de Salta, recibió del gobernador la siguiente consulta: el Juez General de Humahuaca informaba que los indígenas querían vender a foráneos terrenos del pueblo, y solicitaba instrucciones. En el debate que se originó respecto a la naturaleza de las tierras de los pueblos de indios, el diputado Manuel Ignacio del Portal argumentó que:

Toda venta o enajenación de una cosa supone título de propiedad, sólo el dueño legítimo de una cosa puede enajenarla o venderla, pero no el usufructuario, arrendatario o mero poseedor. Hasta hoy los indígenas han sido considerados en esa clase con respecto a esas tierras de comunidad. Las leyes de Indias prohíben la venta expresamente concediéndoles únicamente el derecho de posesión, usufructo [...]: es verdad que alguna de ellas se ha vendido con licencia de los Gobernadores antiguos aprobada por los virreyes, pero ha sido con la calidad precisa de haber hecho constar ante ellos que la dicha venta [recaía] en beneficio de la misma comunidad; con esto se prueba que los reyes se reservaron el derecho de propiedad ${ }^{17}$.

La discusión sobre el estatus jurídico que habían tenido durante la colonia las tierras de los pueblos de indios se produjo en muchas de las nuevas repúblicas, sin embargo, no todas arribaron a las mismas conclusiones en torno a los derechos de propiedad de los indígenas y, por ende, las políticas variaron desde su reconocimiento (aun cuando se intentara desvincular la propiedad comunal para convertirla en propiedad privada), a la expropiación ${ }^{18}$. En Jujuy los legisladores argumentaron que las antiguas tierras comunales eran fiscales por derecho de reversión y, a través de una ley de 1839, optaron por la enfiteusis en la Quebrada de Humahuaca, como una solución intermedia frente a la más extrema que podía implicar el despojo absoluto. Inspirada en las Siete Partidas, que los legisladores citaban textualmente

16. Doucet, Gastón, "Perduración y transformaciones de los pueblos de indios coloniales, sociedades indígenas y economías coloniales en el Tucumán colonial. Comentarios", in Farberman, Judith y Gil Montero, Raquel (comp.), Los pueblos de indios del Tucumán colonial: pervivencia y desestructuración, Bernal, Argentina, Universidad Nacional de Quilmes y EDIUNJu, 2002, p. 270.

17. Archivo de la Legislatura de Jujuy (ALJ). Libro Primero de Actas de la Honorable Junta General Constituyente de la Provincia de Jujuy, Sesión del 7 de mayo de 1835, fs 54.

18. Trato la cuestión con detalle en Teruel, Ana A., "En torno al conocimiento histórico de los derechos de propiedad de la tierra en la frontera argentino-boliviana", Estudios Sociales del NOA, no 14, 2014, p. 63-86. 
en el decreto reglamentario de 1839, la enfiteusis se basaba en el dominio dividido: el "dominio útil”, que a criterio de los legisladores era el que siempre habían detentado los indígenas, y el "dominio directo", que había detentado la Corona y ahora pasaba al fisco provincial. Por lo tanto, los indígenas tendrían derecho preferencial al solicitar, a título individual, la concesión de los terrenos que ocupaban, bajo el pago de un canon a la provincia -cuyo monto era aproximadamente equivalente al antiguo tributo. La enfiteusis, a pesar de contravenir las disposiciones del Código Civil Argentino, dictado en 1869, se mantuvo en la práctica hasta finales de siglo XIX. Gradualmente dio origen a la plena propiedad, en un largo proceso que comenzó en 1860 con la ley de venta de tierras públicas que permitía a los particulares (fueran o no enfiteutas), comprar al Estado el dominio directo ${ }^{19}$.

La aplicación de la enfiteusis en la Quebrada de Humahuaca produjo una estructura agraria en la que predominaban las pequeñas parcelas que coexistían con propiedades medianas y unas pocas, pero grandes haciendas herencia de mercedes coloniales y, en algunos casos, de la acumulación de fundos tras la desamortización republicana ${ }^{20}$. Si bien la regularización de los derechos de propiedad fue un largo proceso que originó pleitos y reclamos, la conflictividad social en las zonas de enfiteusis de la Quebrada de Humahuaca fue infinitamente menor que en la Puna.

Por el contrario, la Puna se caracterizaba por la gran concentración de tierras en manos de unos pocos propietarios -en su mayoría absentistas-, al punto de que 15 hacendados ejercían el dominio territorial de la región y controlaban el $97 \%$ del valor fiscal de la tierra ${ }^{21}$. La pequeńa y mediana propiedad agraria era inexistente. Allí el conflicto y la rebelión fue moneda cotidiana. Es que no sólo se trataba de una estructura de la propiedad sumamente inequitativa, sino de las condiciones serviles a las que estaban sometidos los arrendatarios.

\section{Conflictividad social, procesos judiciales y otras formas de reclamo por la tierra}

Ya hicimos mención a la situación que había convertido en "arrenderos" a los indígenas antiguamente encomendados a la familia Campero (otrora Marqueses del Valle de Tojo), la que residía habitualmente en sus fundos de Bolivia, pero gerenciaba activamente la explotación de sus propiedades, movilizando mano de obra y producción de un lado a otro de la frontera. Campero poseía otras ricas haciendas en Jujuy, entre ellas Yavi, de más de 100 mil hectáreas. Se trataba del terrateniente más

19. Fandos, Cecilia y Teruel, Ana A., “¿Cómo quitarles esas tierras en un día después de 200 años de posesión?” Enfiteusis, legislación y práctica en la Quebrada de Humahuaca (Argentina)”, Bulletin de l'Institut Français d'Études Andines, 41 (2), 2012, p. 209-239.

20. A la par de la enfiteusis, el gobierno de Jujuy había dispuesto que las tierras de las ex comunidades mas alejadas de sus pueblos cabecera, fueran puestas en arrendamiento por la provincia. Con la ley de ventas de 1860 se convirtieron en propiedades privadas y varias de ellas en nuevas haciendas.

21. AHJ, Catastro de las Propiedades Urbanas y Rurales de la Provincia de Jujuy, Año 1872. Comprende los cuatro departamentos de la Puna existentes en ese momento: Cochinoca, Yavi, Rinconada y Santa Catalina. 
poderoso de la región ${ }^{22}$, que junto a otros propietarios de "haciendas de arrenderos", como las bautizó Madrazo ${ }^{23}$, ejercían su dominio sobre hombres y tierras. El trabajo pionero de ese autor $y$, a posteriori, muchos otros de Gustavo Paz ${ }^{24}$, ilustran las relaciones sociales en la región y la condición semi servil de sus "arrenderos", cuyo régimen, similar al del "colono" en Bolivia o al del "huasipunguero" en Ecuador, conservaba características señoriales, entre ellas la "obligación de servicio personal" en las tierras del "patrón", en una cantidad variable de días y trabajos al año.

Paz da cuenta de las múltiples peticiones que eran elevadas al gobernador presentando quejas sobre los abusos a los que los sometían los "patrones" o autoridades locales. Las demandas más tempranas, de mediados de siglo, se dirigían al gobernador como "padre de pobres y huérfanos", "padre de nosotros" 25 . Su tono es similar al que encuentra Marino, en México, en el período del Imperio de Maximiliano; cuyo discurso "rescata el estilo y las alocuciones utilizadas en tiempos virreinales [...] implorando como súbditos desvalidos e ignorantes" 26 . En efecto, tal como Agüero pone en relieve, "tanto en el campo de lo que hoy llamamos "derecho privado" como en el de las instituciones político administrativas, se han indicado numerosos aspectos que delatan el peso del legado jurídico colonial durante la primera mitad del siglo XIx" 27 . Uno de esos aspectos es el de las atribuciones judiciales que mantuvieron los gobernadores de provincia, cuyo "poder de juzgar y poder de mandar" siguen siendo inseparables, como marca Tio Vallejo para el caso de Tucumán en la década de $1830^{28}$.

Por otra parte, hasta mediados del siglo XIx la presencia de las instituciones gubernamentales en la Puna era precaria y reducida. La lectura de la documentación de la época permite inferir una escasa injerencia de las autoridades provinciales en esa región, que además durante la guerra que enfrentó a la Confederación Argentina y Chile contra la Confederación Peruano-boliviana, fue zona de conflicto y llegó a ser ocupada por las tropas bolivianas en 1838. Cuando la guerra finalizó, en 1839, el territorio de la Puna fue recuperado y poco después se instalaron los jefes políticos, que tenían también atribuciones judiciales, en cada uno de los cuatro

22. Para la dimensión territorial y poderío del marquesado véase, además del libro de Madrazo, ya citado, Teruel, Ana A., "El Marquesado del Valle de Tojo. Patrimonio y Mayorazgo en Bolivia y Argentina”, in Revista de Indias, vol. 77, no 267, 2016, p. 379-418.

23. Madrazo, Guillermo, 1982.

24. Ibid. y Paz, Gustavo, Resistencia y rebelión campesina en la Puna de Jujuy, 1850-1875, Boletín del Instituto de Historia Argentina y Americana Dr. Emilio Ravignani, tercera serie, no 4, 1991, p. 63-89.

25. Paz, Gustavo, 1991, p. 72-73.

26. Marino, Daniela, Huixquilucan. Ley y justicia en la modernización del espacio rural mexiquense, 1856-1910, Consejo Superior de Investigaciones Científicas, Madrid, 2016, p. 225.

27. Agüero, Alejandro, "Formas de continuidad del orden jurídico. Algunas reflexiones a partir de la justicia criminal de Córdoba (Argentina), primera mitad del siglo xix”, Nuevo Mundo Mundos Nuevos [Débats, mis en ligne le 23 mars 2010 : https://journals.openedition.org/nuevomundo/59352 (consultado 12/12/2018)].

28. Tío Vallejo, Gabriela, "Papel y grillos, los jueces y el gobierno en Tucumán, 1820-1840", Nuevo Mundo Mundos Nuevos [Débats, mis en ligne le 23 mars 2010 : https://journals.openedition.org/nuevomundo/59266\#ftn10 (consultado 13/12/2918)]. 
departamentos (Rinconada, Yavi, Santa Catalina y Cochinoca) y, como autoridad superior, el Subdelegado de la Puna.

Hacia mediados de siglo, los legisladores de Jujuy consideraron que para evitar los inconvenientes y perjuicios que se originaban para los pobladores de la Puna que debían recorrer una larga distancia para llegar a la capital cuando decidían apelar sentencias, "de manera que no muchas veces prefieren esos infelices abandonar sus acciones y derechos" ${ }^{29}$, se hacía necesario crear un Juzgado de Primera Instancia en esa región. Sin embargo, dicho Juzgado se instaló recién en 1864 y si bien tuvo una duración efímera, el examen que realizó Fandos de las causas que allí se tramitaron, en algo más de un ańo de existencia, nos alerta sobre la ausencia de demandas relativas a la propiedad de la tierra, contrariamente a las referidas a abusos de poder de hacendados y de funcionarios ${ }^{30}$.

¿Cómo explicar que en el Juzgado de una región álgida en conflictos por la propiedad no se tramitara ninguna causa referida a ella? Por una parte, hasta la década de 1860, según lo que reconstruyen Madrazo y $\mathrm{Paz}^{31}$, los reclamos que los campesinos elevaban al gobernador tampoco estaban centrados en cuestionamientos a derechos de propiedad de los terratenientes, sino en cuestiones como el pago de impuestos, de multas, arriendos o abuso de autoridad. Por otra parte, las crecientes presiones fiscales como la creación del impuesto a la propiedad de la tierra, en 1853 (que se tradujo en un aumento en los arriendos) y al ganado en 1863, más los impuestos aduaneros que gravaban el habitual intercambio con Bolivia, en un contexto de crisis provocado por ciclos de sequía y mortalidad por epidemias ${ }^{32}$, incidieron sobre la frágil economía campesina, que a veces se veía dificultada de cumplir con el canon de arrendamiento, razón por la cual podían ser incautados los animales o bien las familias desahuciadas.

Todo ello contribuye a explicar las razones por las que los campesinos arrenderos querrían poner fin a ese régimen. Pero ¿por qué las denuncias que cuestionaban los títulos de propiedad de los hacendados se desatan en el último tercio del siglo? Sostengo que la clave se halla en la oportunidad de hacerlo - con éxito - que brindó la sanción, en 1864, de la primera ley de tierras públicas, por la que se establecían los procedimientos de denuncia para su reconocimiento. Dicha ley establecía:

Art. $1^{\circ}$. Se reputan tierras públicas: $1^{\circ}$ los terrenos baldíos o no poblados que no tengan dueño conocido; $2^{\circ}$ los que aun estando poblados se encuentran poseídos por particulares sin legítimo título [...].

Art. $3^{\circ}$. La denuncia de ellos se hará ante el gobierno de la provincia quien la tramitará administrativamente con arreglo a los incisos siguientes: $1^{\circ}$. Hecha la

29. Citado en Fandos, Cecilia, "Justicia y Territorialidad Indígena. La Experiencia del Juzgado de Primera Instancia de la Puna Jujeña (1850-1870)", Claves. Revista de Historia, vol. 4, n 6, 2018, p. 55.

30. Ibid., p. 43-72.

31. Madrazo, Guillermo, 1982 y Paz, Gustavo, 1991.

32. Gil Montero, Raquel, 2004. 
denuncia mandará fijar edictos llamando a todos los que se crean con derechos al terreno denunciado [...].

Art. 4. Todos los que en consecuencia de los edictos de los que habla el artículo anterior se crean con derecho al terreno denunciado, presentarán sus títulos ante el Gobierno de la Provincia quien procederá del modo siguiente: $1^{\circ}$ si a su juicio fuesen bastante para declararlo propietario suspenderá todo procedimiento sobre el particular, $2^{\circ}$ si por el contrario, adolecieren de algún defecto que dé lugar a dudas sobre la legitimidad del reclamo, dejando a salvo el derecho del interesado, para que lo deduzca en forma ante los tribunales ordinarios de la provincia, según el art. 87, Inc. 1 de la Constitución provincial, se limitará a dar el terreno denunciado en arrendamiento o enfiteusis, a quien lo solicite o desee poseerlo en esa condición no pudiendo de ningún modo proceder a su venta antes de resuelto judicialmente el reclamo mencionado.

Art. 5. No presentándose persona alguna a hacer valer sus derechos dentro del término fijado por los edictos, el Gobierno declarará de propiedad pública el terreno denunciado $[. . .]^{33}$.

Si tenemos en cuenta los pronunciamientos gubernamentales previos, a favor de la teoría de dominio directo ejercido por la Corona y la teoría de la reversión de derechos que se implementó con las tierras de las comunidades de la Quebrada de Humahuaca, podemos suponer que los campesinos arrendatarios pensaran que tenían mayores posibilidades de éxito si denunciaban las tierras de su interés como propiedad de la provincia y no de sus extintas comunidades. Así ocurrió cuando 25 arrendatarios de Cochinoca y Casabindo, en setiembre de 1872, denunciaron esas tierras como fiscales. Lo interesante es que los mismos demandantes, a principios de ese año, habían presentado al gobernador una denuncia por cobros de tributos indebidos por parte de los administradores de Campero. Dado que el mandatario se declaró incompetente en esa cuestión y pasó las actuaciones al juez ordinario de la Puna, cambiaron su estrategia y desistieron de continuar la vía judicial.

Recibida la denuncia de las tierras como fiscales, el gobernador Pedro J. Portal, dio inicio al trámite administrativo establecido por la ley de 1864 convocando a la presentación de títulos de quienes se considerasen con derechos. En esa instancia Campero no se presentó "sino que cuestionó la vía empleada, sosteniendo que la contienda debía ser planteada en sede judicial. El juez lo admitió así, pero el gobierno rechazó la resolución y siguió conociendo administrativamente hasta dictar resolución el 29 de noviembre de 1872 "34 que declaraba las tierras de Casabindo y Cochinoca pertenecientes a la provincia por derecho de reversión.

A partir de esta resolución de la provincia, arreciaron las denuncias de títulos fraudulentos, no sólo relativos a las propiedades de Campero, sino de otras en la Puna y de Humahuaca. La ola de denuncias fue seguida de la negativa a pagar

33. Ley del 24 de noviembre de 1864. Compilación de Leyes y Decretos de la Provincia de Jujuy. Jujuy, Imprenta tipográfica de José Petruzzeli, t. II. 1887, p. 391-392.

34. Fidalgo, Andrés, ¿¿De quién es la Puna?, Jujuy, Talleres El Diario, 1988, p. 17. 
arriendos en un in crescendo de enfrentamientos de los arrendatarios contra capataces, autoridades locales y patrones. Paralelamente el conflicto llegaba también a los tribunales. En 1873, Doroteo Calisaya, radicó una demanda ante los tribunales de Jujuy contra Fernando Campero, reclamando la posesión de tierras en Pampa de Moreta. En la demanda planteaba que el Juez de la Puna, a quien atribuía relaciones de negocios y una manifiesta amistad con los apoderados de Campero, entorpecía su accionar, motivo por el cual interpuso una recusación en su contra, la que fue admitida por el fiscal general. En respuesta y argumentando su calidad de ciudadano extranjero, Campero pidió que el caso salga de la órbita de la justicia provincial y pase a manos del juez federal ${ }^{35}$. Por otra parte, el mismo terrateniente acudió al Juzgado Federal de Jujuy en dos causas promovidas contra sendos arrenderos, a quienes pretendía desalojar por su negativa a pagar el canon ${ }^{36}$. Campero, abogado y ciudadano boliviano de influencia política en su país - había sido senador nacional y candidato a la presidencia - procuraba llevar a los tribunales federales todas las causas que lo involucraban ${ }^{37}$, quizás esperando un tratamiento diferencial por parte de las autoridades nacionales.

La tensión aumentó a raíz de un conflicto intra élite por la sucesión presidencial, a lo que se sumó la brecha entre los adherentes y detractores de las reivindicaciones indígenas, y los mismos indígenas arrendatarios que adhirieron a una de las facciones (la mitrista). El nuevo gobernador, José María Álvarez Prado, perteneciente al sector contrario, dispuso en 1874 la anulación del decreto que expropiaba Casabindo y Cochinoca disponiendo que el caso pase a la Suprema Corte de Justicia. "Agradó mucho a Campero esta determinación, en prueba de lo cual, obsequió al gobernador Álvarez Prado un bastón con puño de oro y escudo grabado"38, aunque la sentencia de la corte, tres años más tarde, seguramente defraudó sus expectativas al declarar nuevamente fiscales las tierras en cuestión, según lo explicamos en los comienzos de este artículo.

Por otra parte, el decreto del mandatario fue más leña para el fuego de la Puna; la rebelión se generalizó y sumó a los sectores dirigentes adversarios del gobernador. Finalmente, las tropas gubernamentales derrotaron en enero de 1875, en Quera, a los rebeldes, produciendo más de 200 muertes $^{39}$.

Los reclamos y denuncias no cesaron con la derrota de la rebelión, por el contrario, las presentaciones abundaron en la década siguiente, obligando a los propietarios a demostrar la legitimidad de sus títulos. Los demandantes citaban las leyes de Indias

35. El caso está narrado en Alvarado, Martín, Funcionamiento de la justicia penal y formación de los sistemas penitenciarios en Jujuy (1810-1867), Jujuy, Universidad Nacional de Jujuy, 2017, p. 70-71.

36. Fidalgo, Andrés, ¿De quién es la Puna?, Jujuy, Talleres El Diario, 1988.

37. Desde la sanción de la Constitución Nacional de 1853 quedaba establecido el poder judicial de la Nación ejercido por una Corte Suprema de Justicia y por tribunales inferiores radicados en el territorio nacional. Entre las causas de competencia originaria de la Corte, figuran las que atañen al litigo entre una provincia y un ciudadano extranjero.

38. Sánchez de Bustamante, Teófilo, "Historia de Jujuy", Academia Nacional de la Historia, Historia Argentina contemporánea 1862-1930, Buenos Aires, El Ateneo, 1967, p. 136-137.

39. Para un análisis de la rebelión, véase Paz, 1991. 
y aportaban comprobantes del pago de tributos al rey, vinculando el tributo con el derecho al usufructo de la tierra, y cuestionando la validez de las mercedes de tierras en los casos concretos que los afectaban. En un interesante expediente del ańo 1881, originado en la denuncia como fiscales de las tierras de Tejada, Condor y Cofradía, interpuesta por tres arrenderos, se menciona que en 1874 la denuncia ya había sido desestimada por fallo judicial. El gobernador, tras seguir los procedimientos establecidos, consideró legítimos los títulos presentados por el propietario y maliciosas las demandas, condenando a quienes las iniciaron a hacerse cargo de los costos. La cuestión no terminó allí, pues luego de ser las partes notificadas, la rebeldía continuó y los propietarios afirmaban no poder ni pisar la hacienda ${ }^{40}$.

A medida que se arribaba a las postrimerías del siglo xix y avanzaba el xx, no sólo las fórmulas comenzaban a adaptarse al lenguaje del régimen republicano, sino también se evidenciaba el conocimiento de las normas de la Constitución Nacional y del Código Civil en vigencia desde 1871. Así lo hacía constar un político comprometido con la defensa de los derechos de los reclamantes:

tienen predilección por el estudio de Códigos y leyes, muchos los conocen de memoria especialmente la Constitución de la Nación y la Provincial, que para ellos es algo así como un catecismo, esta preocupación por el estudio de códigos y leyes, sin duda emana de la idea de reivindicar sus tierras, que está encarnada en todos ellos desde que tienen uso de razón ${ }^{41}$.

Esta preparación de los indígenas para litigar, no ocurría de manera aislada. Del otro lado de la frontera, en Bolivia, se había organizado uno de los movimientos más notorios por su efectividad en defensa de los derechos de las comunidades indígenas amenazadas por las leyes desamortizadoras. Los "caciques apoderados", término que conjugaba la autoridad étnica con la representación legal de la comunidad ante la justicia, era la respuesta de los comuneros para efectivizar la defensa de sus derechos a la tierra, recurriendo a los títulos habidos durante la colonia (y a los archivos que los contenían, incluso en el de Sevilla) además de reclamar aquellos que los concernían específicamente en tanto "hombres", "personas" y "bolivianos"42. La experiencia de las comunidades indígenas bolivianas sin duda impactó en la Puna de Jujuy, con la que compartían antecedentes históricos comunes dado que las primeras reducciones de indios que habían sido dotadas de tierras en la región, abarcaban fundos que luego, en el período republicano, quedaron a ambos lados de la frontera.

La década de 1920 resultó propicia para plantear nuevamente los reclamos. En el contexto del arribo del Partido Radical al gobierno (1918), uno de sus dirigentes

40. AHJ, Caja de documentos año 1881, no 1 .

41. Tanco, Miguel A., "El problema de la tierra en todas partes y en particular en Jujuy", in Forma en que debe quedar el problema de la Unión Cívica Radical, Jujuy, septiembre 9 de 1924, p. 32.

42. Gotkowitz, Laura, La revolución antes de la Revolución. Luchas indígenas por tierra y justicia en Bolivia, 1880-1952, La Paz, Plural Editores, 2011, p. 26-27. 
más populares, Miguel Aníbal Tanco, en plena campaña para la gobernación, organizó en 1924 en la Puna, una célula partidaria que recogía y hacía públicas las demandas de los indígenas y las denuncias contra los propietarios a los que se acusaba de abusos y títulos fraudulentos ${ }^{43}$. En más de cuarenta manifiestos y petitorios de los que se habían impreso más de 3.000 volantes, los campesinos se dirigían a las autoridades provinciales (gobernador o sus ministros) o, excepcionalmente, al presidente de la Nación. Los peticionantes, cuyos nombres se encuentran al pie de los manifiestos, se referían a sí mismos como "humildes pobladores de la raza primitiva", "humildes y campesinos tristes", "nativos aborígenes", "pobladores nativos de olvidadas regiones", o simplemente "naturales" o "vecinos" de algún paraje. Todas estas expresiones se enunciaban junto a otras que remitían a la condición de argentinos amparados por las leyes por ser "tan ciudadanos argentinos como cualesquier otro de la Capital Federal» a la vez que invocaban el Art. 17 de la Constitución Nacional: "ningún servicio personal es exigible sino en virtud de la ley o de sentencia basada en ley"; además de exigir ser "tratados como ciudadanos" y no "hostilizados como esclavos" ${ }^{44}$.

Nuevamente los campesinos arrendatarios solicitaban que las tierras que ocupaban se declarasen fiscales, tal como había ocurrido en las décadas de 1870 y 1880 . Es obvio que las demandas arreciaban cuando la coyuntura era más propicia, pero ¿qué ganarían los arrendatarios al declararse las tierras fiscales? Lo que lo obtendrían, en caso de permanecer en calidad de arrendatarios de la provincia, eran relaciones objetivas, en las que el canon de arrendamiento sería fijado oficialmente y estarían libres de los abusos de los patrones y de la "obligación de servicio personal", tal como ocurrió en las tierras de Casabindo y Cochinoca luego del fallo de 1877. También existía la posibilidad de que algún gobernador decidiera favorecer la compra por parte de los arrendatarios de algunas de las propiedades denunciadas, y así adquirir la propiedad a título individual o asociándose con otros campesinos y manteniendo algunas prácticas de acceso en común. Esto ocurrió en dos oportunidades, durante la gestión del gobernador Tello, entre 1883 y 1885, en dos haciendas particulares (Yoscaba y Valle Grande), y en 1891 cuando se puso a la venta las tierras fiscales de Casabindo y Cochinoca.

En 1923-1924, la novedad residía en que quien incentivaba la demanda era ministro de gobierno - y luego gobernador, meses antes del Golpe de Estado de 1930-. Me refiero a Tanco, quien, convencido de las teorías de Henry George, sostenía que el problema agrario en Jujuy no admitía otra solución que pasar las tierras mediante la expropiación al dominio del Estado y luego cederlas en arriendo, así "La propiedad individual se transformaría en la propiedad en común del público. En lugar de estar en propiedad particular lo estaría en la del gran cuerpo reunido:

43. Archivo Superior Tribunal de Justicia de Jujuy (ATJ), Carpeta Tanco, 1923.

44. Extractos tomados de Fleitas, María Silvia y Teruel, Ana A., "Política y movilización campesina en el norte argentino. La cuestión de la tierra indígena en el proceso de ampliación de la democracia, Revista Andina, $n^{\circ} 45,2007$, p. 41-65. 
la sociedad. En lugar de arrendar las tierras de un propietario aislado, el campesino las arrendaría de la Nación” ${ }^{45}$. Es difícil saber hasta qué punto los campesinos, que constituían un grupo heterogéneo y con diferenciación social interna, adherían totalmente a la doctrina expresada por Tanco o apostaban a apoyarla como un medio para llegar a obtener luego la propiedad privada. De todos modos, la expropiación de los latifundios se convirtió, en adelante, en bandera de lucha.

Sólo como colofón, agrego que la propuesta de Tanco pudo concretarse en 1949, cuando en calidad de senador nacional por Jujuy, redactó la fundamentación del decreto del presidente Perón que declaró la expropiación de cincuenta y ocho haciendas de la Puna y Quebrada de Humahuaca. Eso originó otra larga historia, cuyas consecuencias prolongan la lucha por la reivindicación de la propiedad de la tierra hasta hoy.

\section{A modo de cierre}

Varios años atrás Stern ${ }^{46}$ propuso el concepto de "adaptación en resistencia” para analizar las estrategias campesinas durante las rebeliones indígenas en los Andes; luego Paz aplicó ese concepto en sus primeros análisis de la rebelión de la Puna de 1872-1875. En lo que atañe a mi propia investigación, sostengo su pertinencia para la comprensión, en la larga duración, del accionar de los campesinos arrenderos frente a las formas de defender, reivindicar o adquirir derechos a la tierra.

Aquí y allá, en Europa y en América, a medida que los antiguos derechos de propiedad empezaban a interpretarse como el derecho unívoco y absoluto de la propiedad privada, se planteó la discusión sobre ¿quién era el verdadero dueño? ¿̨el que ejercía el dominio directo o quien detentaba el indirecto? Los gobernantes de Jujuy en una temprana definición adhirieron al primero, en una decisión política que continuó dejando a los indígenas de los pueblos de indios de la Quebrada de Humahuaca el dominio útil, a través de la enfiteusis.

Para los puneños la cuestión era más difícil, poblaban tierras que en parte habían sido de reducción indígena, pero tempranamente privatizadas por el otorgamiento de mercedes a espańoles (algunas desde el siglo XVII) o "institucionalmente trasmutadas", caso paradigmático de los pueblos de antigua reducción de Casabindo y Cochinoca. Es decir que, en la inaugurada república, ya tenían el carácter de arrenderos.

Lo que este panorama de larga duración permite entrever es que la resistencia se manifestó -además de esporádicamente en el estallido de rebeliones- continuamente con reclamos dirigidos a socavar y poner en duda los derechos de los terratenientes; y reivindicar para sí, otros que consistían, en definitiva, en el antiguo dominio útil aceptado por la interpretación gubernamental. Los fundamentos continuaron basados, hasta principios del siglo xx en los derechos de los que gozaban en tiempos coloniales garantizados, afirmaban, por el pago del tributo.

45. Tanco, 1924, p. 9.

46. Stern, Steve, Resistencia, rebelión y conciencia campesina en los Andes. Siglos XVIII al XX, Lima, IEP, 1990. 
Durante mucho tiempo nos preguntamos ¿por qué los campesinos arrendatarios no reivindicaron la plena propiedad y. por el contrario solicitaban que las tierras se declarasen fiscales? Sostengo que la respuesta está en que las oportunidades políticas no lo hacían factible y prueba de ello es que ninguna sentencia judicial lo reconoció, como tampoco lo hizo la Suprema Corte de Justicia en su fallo de 1877. A la largo de este artículo aposté a demostrar que, circunscriptos a esa realidad, el camino que vislumbraba mayores posibilidades de éxito era el que ofrecía el mismo Estado provincial: acogerse a los procedimientos de la ley de 1864 y denunciar como fiscales las propiedades de los hacendados.

\section{Resumen/Palabras Claves}

El artículo analiza las formas y los procedimientos judiciales y extrajudiciales empleados por los campesinos de las tierras altas de la provincia de Jujuy, Argentina, en defensa y reivindicación de derechos de propiedad afectados desde la desamortización, a fines de 1830. En un recorrido temporal que llega hasta la década de 1920, se expone cómo las cuestiones inherentes a esos derechos se dirimían en el ámbito administrativo de los gobernadores y en los tribunales, a la vez que se explica los cambios en los reclamos campesinos sobre la propiedad.

Justicia, Leyes, Propiedad, Indígena, Provincia argentina

\section{RÉSUMÉ/MOTS-CLÉS}

L'article analyse les voies et procédures judiciaires et extrajudiciaires empruntées par les paysans des hautes terres de la province de Jujuy, Argentine, en défense et revendications de leurs droits de propriété affaiblis par la vente des biens communaux, à la fin des années 1830. Dans une chronologie qui s'étend jusqu'aux années 1920, on observe que les questions inhérentes à ces droits se reglaient dans les domaines administratifs du gouverneur et dans les tribunaux, tout en expliquant les changements dans les réclamations faites par les paysans sur la propriété.

Justice, Lois, Propriété, Indigène, Province argentine

\section{ABSTRACT/KeYWORDS}

This text analyzes the measures and the judicial and extrajudicial procedings used by peasants from the highlands (uplands) in the province of Jujuy, Argentina, to defend and claim property rights concerned with disentailment, since 1830. In a period of time that reaches up to the 1920's, it exposes how questions inherent to those rights were settled by the governors and courts in the administrative sphere. Simultaneously, explaining the changes and farmers' claims on the property.

Justice, Laws, Property, Indigenous, Province of Argentina 
Mélanges 



\title{
A escrita anarquitextual nos romances de viagem latino-americanos
}

\author{
Humbert FoIs-Braga \\ Universidade Federal de Juiz de Fora, Brasil \\ Luiz Guilherme CASTRO \\ Universidade Federal de Juiz de Fora, Brasil
}

\section{Introdução}

Os RELATOS DE VIAGEM, ESCRITOS por europeus em visita ao Brasil, inicialmente foram publicados e direcionados para um público-leitor residente no Velho Continente. Todavia, é inegável que os brasileiros tiveram acesso a tais obras - na língua original ou posteriormente traduzidas - e que, por isso, elas participaram da construção de um imaginário nacional; afinal, não nos esqueçamos que a própria Carta de Pero Vaz de Caminha ou Carta do Descobrimento, enquanto primeiro documento redigido em solos que se tornariam brasileiros e endereçado ao Rei D. Manuel I, possui o formato de relato.

A partir da leitura desses textos do período colonial, bem como daqueles que ainda continuavam a ser produzidos por europeus que no Brasil desembarcavam no período imperial, escritores e intelectuais do romantismo brasileiro estabeleceram um discurso sobre uma nação em formação, recém independente da metrópole portuguesa. Como nos diz Süssekind (1990, p. 20):

Onde menos se esperaria, é aí que se define um começo histórico e se desenha um narrador. Em diálogo com o veículo em que se divulga habilmente a ficção romântica no Brasil nas décadas de 30 e 40 - o periódico -, com um público bastante restrito, com o andamento predefinido do romance-folhetim, com elementos do romance histórico e dos folhetins de variedades. É, em especial, com dois gêneros diversos e às vezes associados, a literatura não-ficcional de viagens - sobretudo a que se refere 
ao Brasil - e o paisagismo - sobretudo o que tematiza vistas e exuberâncias tropicais ou cenas pitorescas do cotidiano ou da "história" local -, que se constrói essa figuração inicial do narrador de ficção na produção literária brasileira da primeira metade do século XIX.

O "começo histórico" do narrador na ficção brasileira estaria atrelado aos viajantes europeus: com seu olhar do exterior, existia neles uma "sensação de não estar de todo" ao descrever as exuberâncias, exotismos, maravilhas e exclusividades da natureza e dos costumes locais. Logo, através de seus narradores e personagens, o autor brasileiro destes folhetins se posicionava também como um estrangeiro e em desacerto com o seu cotidiano: "necessidade que funciona como uma espécie de indicador prévio de deslocamento, distância, desenraizamento, marcas registradas - ora presentes sem que seus autores se apercebam disso, ora trabalhadas propositalmente com eles - da escrita de ficção brasileira" (Süssekind, 1990, p. 21).

Se Candido (1993, p. 24) nos diz que a literatura brasileira se estabeleceu a partir da temática indianista presente no arcadismo do século XvıII, o mesmo autor menciona que os seus contornos seriam melhor definidos no romantismo, pois é a partir desse período que se estruturaria uma tradição contínua de "estilos, temas, formas ou preocupações". Tais contornos propostos pelo romantismo, se levarmos em consideração os estudos de Süssekind (1990), teriam um formato folhetinesco e com temáticas e estilos influenciados pelos viajantes europeus que "ensinaram" ao escritor brasileiro uma forma de ver e narrar o seu próprio país. Logo, inspirado pelos relatos europeus de viagem, o romance brasileiro estabelece uma de suas gêneses no estilo que favorece a presença do narrador distanciado e a referência ao exótico. Por isso, o discurso da mobilidade estaria também, desde o início, impregnando o conteúdo de tais obras ${ }^{1}$.

Como nos diz o pesquisador, a partir da obra $A$ viagem e a escrita, de Claudete Daflon dos Santos (2002):

No entanto, o recurso da viagem enquanto elemento constituidor da narrativa não é novo na literatura brasileira, sendo possível entrevermos ao menos dois usos específicos em nossa série literária que demarcam igualmente dois modos distintos de viajar e de viajantes. No primeiro modo, é possível identificar a explícita admiração pela cultura europeia que impulsiona a ida ao Velho Mundo [i.e., no romantismo]. O outro modelo de viagem e viajantes é experimentado no modernismo, que realiza a ruptura com o modelo hierárquico e subserviente vigente até então ao propor como norte referencial da viagem e do viajante nâo mais a cultura e as letras do velho continente, mas sim o desejo de leitura e compreensão do próprio Brasil. Neste roteiro de viagem modernista, a Europa ainda permanece como possível destino, mas localizamos a emergência do desejo de descoberta do Brasil. A cada modelo de

1. É ainda Süssekind (1990, p. 40) que menciona a novela Olaya e Júlio (ou A periquita) - escrita em 1830 e publicada anonimamente em formato seriado nos números 4, 5 e 6 da revista $O$ Beija-For - como um marco desta presença do viajante nos romances brasileiros. Em tal texto, tanto o narrador quanto o personagem que ele acolhe em uma noite chuvosa são caracterizados enquanto viajantes. 
viagem podemos associar um viajante histórico. No primeiro, temos Joaquim Nabuco como exemplar deste olhar de encantamento para a alta cultura e, por sua vez, na experiência oposta, é possível identificarmos a figura de Mário de Andrade como representativa (Patrocínio in Chiarelli et Oliveira Neto, 2016, p. 67, inserção nossa).

Como veremos posteriormente, esta situação não se restringe ao Brasil, pois os demais países latino-americanos passaram por um processo semelhante de apropriação dos relatos europeus, buscando uma maneira de revisar os seus discursos exotizantes. Portanto, para certos escritores, a desconstrução do conteúdo e da forma desses relatos legitimados pela tradição europeia passou a constituir uma atitude político-estética.

Por isso, o presente artigo visa trazer reflexões sobre como os romances de viagem autoficcionais e latino-americanos constituem uma anarquitextualidade com os relatos dos antigos europeus que mapearam e legitimaram um discurso sobre o Brasil (e a América Latina). Partindo do pressuposto de que tais relatos de viagem constituem uma forma de enunciação toda própria, principalmente a partir do "pacto autobiográfico" (Lejeune, 2008), havendo uma coincidência entre autornarrador-personagem; e também levando em consideração que este gênero foi visto por determinados escritores como uma forma de submissão e de legitimação do discurso europeu, então, pretendemos perceber como tais autores latino-americanos problematizam e descontroem tal forma, propondo uma maneira de enunciação politizada, ressignificando-a por meio da autoficção.

Aqui, sugerimos que os romances contemporâneos de viagem "profanam” o modelo de enunciação dos relatos tradicionais, ou seja, eles promovem uma "anarquia arquitextual”. Daí, nosso neologismo no título: sugerimos o termo anarquitextual porque os autores latino-americanos estariam promovendo um subversão na arquitextualidade, definida por Genette (1982) como a relação de um texto com o estatuto ao qual ele pertence - no nosso caso, a plasticidade do romance, que aceita diversas possibilidades enunciativas, visita o arquivo literário dos relatos de viagem (no que ele têm de conteúdo e forma) para se rebelar contra tal gênero que carrega uma ideologia europeia sobre o mundo. E, no caso dessa anarquismo textual, o que os romances contemporâneos fazem é a problematização daquilo que os antigos relatos traziam como sua premissa, a saber: o discurso da verdade via testemunho do viajante e o posicionamento do europeu como organizador do mundo além-mar ao qual visita.

Para tanto, apoiar-nos-emos nos estudos sobre a presença do exótico na literatura desenvolvidos pelo escritor e tradutor César Aira (1993). Para o argentino, há três momentos de construção do exótico pelos escritores e, após a apresentação dessas fases, na sequência, acrescentaremos o que sugerimos ser a atual quarta etapa, que coincide como a contestação latino-americana, e cujo sintoma seria verificado na anarquitextualidade que ocorre na passagem dos relatos ao romances de viagem. 


\section{A construçáo do exotismo na literatura latino-americana}

Como dissemos, Aira (1993) mapeia três fases de exotização na relação ideológica entre países centrais e periféricos. E, para cada uma dessas etapas, ele percebe o papel desempenhado pelos escritores que propóem e/ou legitimam um discurso sobre o "nós" versus o "outro" - uma alteridade estranha e distante que, todavia, se desloca e nos confronta.

Em uma primeira etapa, teríamos, nas Cartas Persas (1721), de Montesquieu, a invenção de um gênero literário, a "novela exótica", em plena era do Iluminismo e do discurso sobre ser Homem e Universal. Ao construir personagens estrangeiros (persas) em visita à Franca, o filósofo estabeleceu um olhar exótico para e sobre si mesmo. Assim, o autor, europeu-francês, se fez estrangeiro pelo olhar do seu personagem:

mas os persas não são reais; são dispositivos inventados por Montesquieu para gerar o olhar. Com tal dispositivo nasce algo novo: a ficçáo como auxiliar do pensamento. Daí pra frente, a ficção deverá se impor ao ato de pensar, um "como se..." a partir do qual a modernidade se desenrolará em todas as suas cores (Aira, 1993, p. 73, tradução nossa²).

É a partir desses personagens inventados por um europeu, e que atuam como viajantes que desembarcam na Europa, que o escritor constituiria um olhar estrangeiro a respeito de sua própria sociedade, atuando pela ficção como se fosse um outro.

$\mathrm{Na}$ segunda fase, não é mais o estrangeiro que visita a Europa (estrangeiro, vale relembrar, construído por um europeu). Agora, é a vez do autor europeu se posicionar ipsis litteris como tal ao visitar certos países periféricos. Há, então, uma inversão do olhar sobre quem contempla quem:

Estes dois estágios náo fazem mais do que pôr em imagens processos inerentes à literatura. $\mathrm{O}$ "estrangeiro" que contempla meu mundo habitual não é senão eu mesmo enquanto escritor, fazendo meu trabalho de estranhamento e descobrimento. E o "viajante", por sua parte, não é outro que aquele que regressa, contanto o que viu nas ilhas curiosas de sua fantasia ou de seu destino, ou de seu estilo (Aira, 1993, p. 74).

Quem seria esse viajante que retorna à casa, se não o próprio europeu que visitou países distantes e exóticos? Sendo assim, nesses dois momentos, a alteridade é sempre constituída por escritores europeus: são eles os construtores do discurso sobre si (a partir de personagens viajantes fictícios em terras europeias) e sobre o outro (a partir de suas incursóes enquanto viajante em terras alheias). Lá, lidamos com um viajante fictício, aqui, surge o viajante real em seus relatos e romances sobre sociedades distantes: "o primeiro era uma metáfora do escritor em seu trabalho, estranhando-se para constituir um olhar; o segundo é a máquina de fazer

2. Os textos de Aira são, em suas origens, escritos em espanhol. Logo, todas as traduçôes neste artigo são nossas. 
literatura sem trabalho, saltando além da invenção, que deixa a cargo do mundo" (Aira, 1993, p. 74).

A terceira fase viria com a constituição de um mercado editorial para o exotismo, a partir do interesse do público europeu por essas terras distantes. Surge, então, o autor periférico escrevendo sobre suas terras, mas a partir de cores europeias, aceitando os estereótipos que o olhar da fase anterior lhe incutiu. Em uma sobreposições entre virtudes cívicas e artísticas, os latino-americanos, por exemplo, durante muito tempo teriam se promovido no mercado internacional a partir do realismo mágico (Hubert, 2012).

No entanto, nenhuma dessas três fases rompe com o estereótipo do outro; e também não apontam para um exotismo engajado com a diversidade do mundo:

Porque a pobreza final do exotismo está aí: no extremo de sua viagem, nas antípodas, o exotista se limita a reconhecer o que vê, que é o que já havia visto, o que já sabe, e nada mais. Levada a suas últimas consequências, a lógica do exotismo deveria revelar um estranhamento radical, que não entrará nos moldes mentais ou linguísticas do autor. Ao chegar lá, no trópico ou na ilha perdida, não deveria encontrar o que já conhece, mas algo tão distinto que só poderia ser expresso em uma língua nova, um novo saber... Ou, em todo caso, deveria reduzir-se ao silêncio ou ao balbucio, que é o que se passa com Stendhal ao chegar na Itália, no final de La vie Henry Brulard (Aira, 1993, p. 78).

Avançando nas etapas cronológicas de Aira (1993), podemos sugerir uma quarta e contemporânea fase de construção do exótico e que, talvez, atendesse a uma vontade de pluralização dessa diversidade-mundo. Servindo-nos da metáfora empregada pelo autor, dizemos que as três fases do exotismo se resumem da seguinte maneira: do persa na França, passamos ao francês na Pérsia para, finalmente, chegarmos na Persa "persa" "[...] colorida, distinta, exótica. O escritor que utiliza um estranhamento ready-made" (Aira, 1993, p. 75). Atualmente, acreditamos que a quarta fase seria caracterizada pelos "persas no mundo", ou para falarmos de uma proximidade, hoje temos, literalmente, os "escritores latino-americanos pelo mundo". Eles passaram a viajar para relatar suas visões da alteridade, um olhar marginal que lançam aos países centrais ou àqueles que compartilham consigo esse lugar na periferia dos discursos.

\section{Resistências literárias latino-americanas: dos relatos aos romances de viagem autoficcionais}

Atualmente, diversos escritores lutam contra esses exotismo constituído pela Europa e replicado por determinados autores periféricos. Para tanto, problematizam tanto o conteúdo exótico desses relatos de viajantes europeus quanto a forma de expressá-lo, pois passam a compreender tais sistemas enunciativos enquanto representantes de uma submissão; ou seja, o gênero "relato de viagem" teria servido como máquina de dominação posto em prática pela Europa sobre outras partes do 
mundo - como já dizia Edward Said (2007) em seu livro Orientalismo: o Oriente como invenção do Ocidente.

Pela "dupla consciência" (Bhabha, 2007), ou para usar termos mais locais, pela "mirada estrábica" (Piglia, 1991) ou pela "desleitura” e "releitura" (Santiago, 1978), os latino-americanos estão devorando antropofagicamente o relato de viagem produzido pelos europeus. Não será, então, uma batalha entre dois lados - europeus $\mathrm{x}$ brasileiros/latino-americanos - mas, sim, uma ofensiva de (ou para) ultrapassar fronteiras, usar as armas do outro para desconstruí-lo textualmente, por dentro, a partir de seus próprios recursos retóricos e estilísticos.

Para tanto, a forma dos relatos de viagem europeu vêm sofrendo intervençóes políticas, constituindo enunciativas híbridas mais adequadas às temáticas latinoamericanas. Nesta politização do enunciado dos relatos, esses se transformam em romances autoficcionais de viagem, na fronteira entre dois gêneros, impedindo que conteúdo e forma fiquem descompassados e, consequentemente, tragam a sensação de que as ideias estariam "fora do lugar" (Schwarz, 2014). Talvez, e principalmente a partir das viagens internacionais nos romances contemporâneos, seja nossa época a que mais enfaticamente manifesta este movimento latino-americano de desconstrução, opondo-se ao direito europeu de explicar o mundo.

Porém, tal atitude de desconstrução é capaz de ser percebida desde o século XIX, pois diversos foram os movimentos e soluçóes encontradas pelos escritores para problematizar os formatos europeus - e, nesse sentido, a autoficção é apenas a estratégia mais atual, embora não a única possível. Como exemplo, sabemos que os relatos europeus sobre a brasilidade tiveram grande impacto na escrita dos romancistas sertanistas ao longo do século xx. De acordo com Ávila (2008), a literatura mineira pós-colonial e romântica nasce como resposta a tais relatos, pois buscará rever as impressóes negativas e da "retórica da falta" que tais viajantes tinham sobre o interior do Brasil, em oposição ao olhar sedutor que lançavam ao litoral enquanto tropos do locus amoenus:

Diante de um quadro pouco lisonjeiro, a construçâo de um discurso ufanista sobre o sertão passa a ter o caráter inevitável de resposta, de contra-discurso. Render-se à negatividade do olhar estrangeiro sobre os gerais é renunciar a toda identificaçáo com o espaço nacional, com a própria memória e a própria cultura. Resulta que os escritores do século 19 tentam, ao parafrasear, traduzir ou comentar aqueles relatos, minimizar os golpes no orgulho nacional (Ávila, 2008, p. 104).

Guimarães Rosa também buscará reler o sertão mineiro, tomando como base não somente os relatos dos viajantes, mas também os romances desses autores do século XIx. Dito de outra forma, Rosa constitui em seus romances, como O Grande Sertão: Veredas, um diálogo textual com os românticos brasileiros e com os relatos dos viajantes europeus que os antecederam, especialmente o Três mil milhas através do Brasil, escrito pelo inglês James Wells em meados da década de 1870 (Ávila, 2008). A pesquisadora toma como hipótese que "Rosa revisita a literatura do século anterior 
em seu aspecto de resposta ao estímulo representado pelos relatos de viajantes e que ele detecta nessa resposta um não aproveitamento de elementos de grande potencial estético que dão àqueles relatos um encanto peculiar” (Ávila, 2008, p. 102). Em seu romance, o mineiro não buscou agir como os romancistas oitocentistas que contradiziam os discursos da falta presente nos relatos dos viajantes europeus; pelo contrário, ele não recusou tal argumento, mas o ressignificou, alterando as perspectivas de enunciação. Em sua obra, o discurso da falta e da ausência sobre o sertão, pejorativamente construídos por tais viajantes, passa a ser valorizado, pois

Ao contrário do estrangeiro que, em seu relato, deplora a ignorância do sertanejo, Guimarães Rosa vê na ignorância do europeu, na sua perplexidade diante daquilo que não pode classificar como exótico, nem como europeu, um elemento de grande potencial estético. É no trabalho com a linguagem que se mostra de forma mais aguda a presença do estrangeiro em Guimaráes Rosa. Rosa aprende a mimetizar sua escuta não-seletiva, que náo consegue retificar a fala do narrador nativo, limpando-a dos elementos "supérfluos", "redundantes", dos "erros" e das "hesitaçôes”. Brinca com sua dificuldade em grafar os termos nativos, com a similaridade entre seu português estropiado e o português reinventado do sertanejo.

A curiosa sensação que temos, ao ler um relato estrangeiro sobre o Brasil, de estar retraduzido ou destraduzido a nossa ambiência, anteriormente traduzida para o universo mental do inglês ou do alemão, desconfiando que operamos nesse percurso novos desvios entre referente e linguagem, parece-me ter sido responsável por diversas criaçôes linguísticas de Rosa (Ávila, 2008, p. 106).

Rosa propóe uma resposta ao estrangeiro, desconstruindo por dentro tal discurso exógeno e, com isso, serve-se das armas eurocêntricas para subvertê-las em uma nova proposta de olhar que reorganiza o mundo - o que justificaria, por exemplo, em $O$ Grande Sertão, ser o viajante (europeu?) o ouvinte, calado e inapto a descrever o mundo. Então, seu romance se torna uma resposta crítica e "de fora" sobre o conceito de sertão e, por conseguinte, de Brasil. Inclusive tal "convívio intertextual" se percebe na "[...] possível influência do relato de viagem no modus narrandi de Rosa, aquele 'desenredo' que faz Riobaldo comentar: 'Contar seguido, alinhavado, só mesmo sendo as coisas de rasa importância”" (Ávila, 2008, p. 107).

Essa mesma anarquitextualidade que desconstrói os relatos europeus de viagem também se fará presente no modernismo dos anos de 1920, com obras tais como Quelques visages de Paris (de Vicente do Rego Monteiro), O Turista aprendiz (Mario de Andrade), Pathé Baby (de Antônio de Alcântara Machado) e o poema Como se vai de São Paulo a Curitiba (de Raul Bopp). Em suas antropofagias, os modernistas devoraram os relatos europeus:

Nos diferentes manifestos lançados principalmente por ele [Oswald de Andrade] e por Mário de Andrade e no périplo de Macunaíma, Serafim Ponte Grande e João Miramar, personagens-título de narrativas emblemáticas dos dois escritores, a 
viagem modernista é tematizada com esse valor de experiência de reconhecimento, formação e revolução, conjugando revisão e projeto e permitindo deste modo, que experimentação estética e perquiriçáo subjetiva se articulassem a um programa político-cultural coletivo (Pedrosa, 2005, p. 50, inserção nossa).

Tais manifestos, romances e relatos modernistas embaralham as fronteiras do real e do ficcional, alterando o ponto de vista sobre a alteridade, pois, agora, cabe ao autor brasileiro falar sobre o seu próprio país, ou invadir a Europa para relê-la com os olhares de índios antropofágicos, reposicionando o europeu enquanto o exótico e o brasileiro enquanto estrangeiro em terras alheias. No mais, a própria escrita linear, referencial e informativa dos relatos são, aqui, revistas por certos modernistas através de um composição poeticamente fragmentada, algumas vezes recuperando a estética cinematográfica, outras vezes a telegráfica (Daflon, 2011; Caetano, 2013).

Percebemos, então, que a anarquitextualidade com os relatos de viajantes europeus não é uma novidade, e desde o século XIX vem produzindo romances que, por intermédio do recurso narrativo das viagens, pretendem ressignificar o local e o sentido de ser brasileiro. Na contemporaneidade, a proposta se mantém, com os relatos ficcionais promovendo um diálogo anarquista com toda a tradição literária, sendo tal fato percebido por Renata Fernandes Magdaleno (2011), cuja pesquisa se inicia com a prerrogativa de descobrir se "ainda é possível detectar resquícios e heranças da tradição dos relatos de viagem na produção contemporânea” (Magdaleno, 2011, p. 7). Para tanto, ela analisa quatro diários de viagem ficcionalizados (romanceados) e construídos a partir da autoficção - Una luna (Martín Caparrós), Mis dos mundos (Sergio Chejfec), Lorde (João Gilberto Noll) e Nove Noites (Bernardo Carvalho).

Como nos diz Hubert (2012, p. 56):

[...] se o escritor latino-americano do século XIX absorvia a literatura de viagem estrangeira, a fim de dar forma a uma literatura nacional, o escritor do início do século XXI também absorve essa literatura de viagens estrangeira, mas com o propósito de questioná-la, criticá-la e satirizá-la, e assim produzir uma literatura que fale não só da nação como de qualquer outra área remota do globo [tradução nossa ${ }^{3}$.

Os autores contemporâneos (e os modernistas) problematizam aquele olhar de fora, comentado por Süssekind (1990) como modeladores do romantismo brasileiro do século XIX, e não perdem a oportunidade de se servirem da própria forma do relato para realizarem tais críticas desconstrutivistas:

em outras palavras: referencialmente, eles intervêm em uma tradição europeia de escrita da viagem, formalmente revisitando-a. Retoricamente, eles se distanciam de seus antecessores na América Latina, porque a reação deles ao Orientalismo [ou a

3. Os textos de Hubert são escritos em inglês. Logo, todas as traduçóes neste artigo são nossas. 
qualquer outra forma de exotismo produzido pela Europa] não é nada mais do que uma crítica teórica ao exotismo (Hubert, 2012, p. 60).

Principalmente a partir da autoficção, os autores-viajantes latino-americanos estabelecem os relatos-romanceados como a versão contemporânea dos relatos-verdades dos viajantes-europeus dos séculos anteriores ${ }^{4}$. Com isso, dos relatos-confessionais passaríamos aos relatos-ficção:

De modo geral, podemos tentar definir autoficção como uma nova forma de escrita autobiográfica, própria, talvez, da era pós-moderna, em que a narrativa dos fatos da vida do autor é feita através de uma linguagem própria do gênero romanesco, ou seja, de uma escrita que se pretende artística. Além disso, para muitos, a autoficção também porta fabulaçôes, invençóes e distorçôes em relação à verdade dos fatos, uma vez que permite a introdução, no texto autobiográfico, de sentimentos, desejos, sonhos, frustraçóes e devaneios do escritor, numa reconstrução inventada e romanceada daquilo que ele viveu (Silva, 2012, p. 2).

Vemos, então, que os relatos ficcionais latino-americanos reposicionam e invertem as polaridades e as relaçóes entre quem olha para narrar e de quem é observado para ser narrado. Mas, ao mesmo tempo, tal processo também constitui uma estética da resistência ao esvaziar a estrutura mesma do relato, transformando-o do local do testemunho e de pretensão de verdade em um espaço para as dúvidas e incertezas sobre os limites entre realidade e ficção. Afinal, na autoficção embaça-se as fronteiras entre o factual e o ficcional:

Contudo, é inegável que a autoficção porta uma característica fundamental da pósmodernidade, a dúvida sistemática. Não se crê em verdades universais e absolutas, mas se reconhece a existência de percepções relativas, descontínuas e fragmentadas; tudo é uma questão de linguagem, de argumentação. Nestes textos, há recortes, análises, constantes reinterpretaçóes; eles não se propóem lineares, amarrados, cronológicos (Silva, 2012, p. 7).

Por exemplo, em $O$ turista aprendiz, Mario de Andrade já escrevia entre parênteses: "Viagem pelo Amazonas até o Peru, pelo Madeira até a Bolívia, por Marajó até dizer chega” (Andrade, 1976, p. 50), demonstrando um diálogo com os títulos dos relatos dos antigos viajantes, que pretendiam inserir objetivamente todo o itinerário na capa; mas, ao mesmo tempo, ele subverte o título ao deixar ambíguo e indefinido todo o trajeto a ser realizado. De uma vontade de mapeamento e entendimento da alteridade, o "até dizer chega" indica um limite das vontades e do interesse desse autor-viajante que escreve nas bordas da autoficção.

\footnotetext{
4. Ambos, cremos, constroem narrativas de si e são autoficçôes, mas os autores atuais atuam expressamente nesta proposta, tem consciência do efeito e articulam propositalmente estas fronteiras entre realidade e ficção para construir uma impressão estética, enquanto os viajantes dos relatos tradicionais parecem ignorar este efeito e preferem a referencialidade direta.
} 
Para Magdaleno (2011), tais relatos ficcionalizados demonstrariam que a narrativa sobre a alteridade não seria mais um privilégio dos países centrais, chegando ao limite de problematizar a existência deste outro enquanto uma exterioridade:

Ainda há resquícios da tradição desses relatos de viagem na produção contemporânea? Essa era uma das questóes que justificavam uma rápida olhadela para os primeiros textos de viagem produzidos na regiáo. Nesses deslocamentos é possível perceber que há sempre uma busca e um outro como centro. Um outro que o autor desse relato em movimento procura usar como referência para suas açōes. Observei, portanto, essas características nos textos de deslocamento do passado e nos relatos de viagem contemporâneos. Nestes, ainda havia um outro e uma busca que motivava o protagonista em sua partida e, na maioria das vezes permanecia presente ao longo de toda a história. Nos textos atuais que integram a pesquisa, entretanto, os personagens estão diante de uma alteridade que não se rende, e a busca parece revelar uma tentativa de encontrar algum sentido, um pertencimento, uma explicaçáo, algo que acabe com uma sensação de vazio, que explique todos os mistérios (Magdaleno, 2011, p. 14).

Não seria o próprio viajante um estrangeiro para si mesmo e para aqueles que habitam as terras por onde transita?

São pelos relatos romanceados e que, por isso, empregam a autoficção, que os escritores latino-americanos questionam o discurso do exotismo projetado a um corpo exterior (não seria eu também estranho para mim mesmo? O olhar para dentro de si não transladaria o ex-ótico para o in-ótico?) e problematizam a própria estrutura do relato de viagem (o que é verdade e o que é ficçáo no que escrevo sobre mim? Se não sou capaz de falar nem plenamente sobre mim, como poderia me atrever a falar verdades eternas sobre os outros?).

Tais escritores-viajantes latino-americanos buscam desconstruir as percepçóes de mundo que os seus antecessores, os viajantes europeus, estabeleceram como leituras oficiais da alteridade. De um exotismo pautado na diferença que estereotipa, estes latino-americanos, que sabem o significado de serem lidos enquanto os outros periféricos, buscam estabelecer uma leitura do mundo que seja mais ecumênica, saindo da referencialidade exótica para tentar penetrar nas subjetividades universais. Como nos diz Hubert (2012, p. 46),

em outros palavras, essa operação responde a uma relocaçáo da posição do escritor latino-americano, partindo de um ponto de repressáo (marginal) para um de emancipaçáo (cosmopolita) e, portanto, invertendo a fórmula prescritiva do escritor periférico: ele não apresenta uma visão da América Latina para o mundo, mas, ao invés disto, ele apresenta uma visão latino-americana do mundo.

Tais cidades, relevos e construçóes de outros países serviriam para ancorar sentimentos e questōes universais. Mudam-se os cenários, mas mantêm-se os problemas humanos, demasiado contemporâneos. Pelas viagens internacionais na literatura latino-americana contemporânea, os escritores tentam se despregar e encontrar rotas 
de escape para os discursos que lhe foram impostos como sendo seus de direito, e por onde estariam autorizados a transitar, escrevendo e publicando (e.g. realismo mágico, hiper-realismo da violência e estética da fome). Assim sendo, para além de um discurso sociológico sobre a nação, tais obras promovem um manifesto literário sobre as novas possibilidades estéticas e argumentativas da escrita latino-americana.

Então, a literatura de viagem contemporânea não serviria somente para questionar a identidade nacional pelo viés dos sujeitos deslocados e em constante despertencimento. Para Hubert (2012), a literatura transnacional também estaria a serviço de um discurso metaliterário, cujos autores se servem do ultrapassar as fronteiras para estabelecer um cosmopolitismo literário, tornando-se um manifesto daqueles que reivindicam o direito de falar sobre qualquer assunto.

Por isso, a falta de bordas territoriais na literatura latino-americana significaria que a mesma é cosmopolita em suas tradiçóes. Como já dizia Borges (1998, p. 295): "creio que os argentinos, os sul-americanos em geral, estamos numa situação análoga; podemos lançar mão de todos os temas europeus, utilizá-los sem superstiçóes, com uma reverência que pode ter, e já tem, consequências afortunadas". Os autores latinoamericanos seriam modernamente antropofágicos, não precisando de autorização para falar e enunciar seus discursos para além do território americano, pois eles - assim como os escritores nos países centrais - têm o direito de falar de tudo, de qualquer assunto, e não ficar preso às cores locais que o consagraram (e se cristalizaram como referência à literatura por aqui produzida): "[...] é válido argumentar que não é referencialmente mas retoricamente que o escritor latino-americano contemporâneo afirma sua particularidade dentro do reino universal da literatura" (Hubert, 2012, p. 45).

A mesma pesquisadora analisa três obras latino-americanas que colocam o Oriente como local de enunciação - La Gruta del Toscano (do mexicano Ignacio Padilla, 2006), Mongólia (do brasileiro Bernardo Carvalho, 2003) e Los impostores (do colombiano Santiago Camboa, de 2002). Para ela, centrar as narrativas no Oriente é uma forma encontrada pelos autores para traçar paralelos entre o orientalismo e o realismo mágico latino-americano, ou seja, criticar a forma como os países centrais construíram uma alteridade exótica. Portanto, tais obras "removem, refutam e ridicularizam as referências aos recursos nacionais e culturais tanto dos países asiáticos quanto dos latino-americanos em questáo" (Hubert, 2012, p. 46). Da mesma forma, essas obras representam um momento positivo de reação vis-à-vis aos seus predecessores, pois se recusariam a representar o Oriente a partir de um exotismo europeu.

Ao falar desses romances internacionalizados dos latino-americanos, percebemos a existência de dois movimentos que os afastam da literatura de viagem tradicional: primeiramente, os personagens não pretendem seguir uma tradição dos discursos dos viajantes anteriores e, assim, eles reescrevem livremente suas viagens sem se apoiar nos lugares comuns dos seus antecessores. Segundo, e como consequência desse primeiro ponto, os narradores desses romances contemporâneos abraçam a ideia de que a viagem é uma experiência singular e individual, por isso, sobrepóem temporalidades que escapam à linearidade das narrativas tradicionais, 
[...] em outras palavras, esses romances reescrevem a literatura de viagem nas ficçóes de viagem. Este gesto evidencia a atitude cosmopolita do escritor latino-americano. De alguns pontos periféricos de enunciação, ele intervém em um gênero politizado ligado a um status imperial que codificou e direcionou a imaginação orientalista a respeito da Ásia (Hubert, 2012, p. 56).

Por isso, tais diários de viagem romanceados constituem uma forma de resistência dos países periféricos, é um recado dado ao mundo a respeito das possibilidades antropofágicas latino-americanas, cujos escritores estão aptos a falar de tudo e de todos a partir de qualquer lugar de enunciação que desejarem.

\section{Consideraçóes finais}

É importante que a escrita da mobilidade esteja não somente na temática da obra, mas também em seu estilo, pois o que se fala é também perpassado por um como se fala. Cremos que não há uma arbitrariedade no uso dos recursos estilísticos e, assim, eles vêm acompanhados de um propósito cuja crítica é capaz de desvendar ou construir: como cada autor traduz, na forma e no conteúdo de seus romances, o trânsito e a alteridade de ser e estar no estrangeiro?

No caso dos romancistas brasileiros (latino-americanos de modo geral), percebemos a tendência em subverter os relatos tradicionais europeus, inscrevendo-os em uma estética dos relatos autoficcionais (romanceados). Muitas das vezes, também estabelecem seus enredos para além do território-mítico nacional, levando seus personagens para outros países, como forma de se falar dessa fragmentação do sujeito enquanto estrangeiro e, também, como manifesto a favor de uma literatura universal não mais presa aos princípios de um exotismo latino. Desse modo, a literatura de viagem latino-americana se tornaria um manifesto de resistência, pregando o seu direito estético de narrar questóes universais, inserindo-se nos circuitos internacionais de comercialização via tais discursos ecumênicos sobre o ser-humano.

No final, as escritas transnacionais, mais do que simplesmente indicarem uma internacionalização da literatura brasileira que participa da nova fase capitalista de constituição de uma nação global e no fluxo, também serviriam como uma reação às grandes narrativas interpretativas do mundo periférico impostas pela literatura e os seus escritores centrais, principalmente europeus. Para tal, esses textos, muitas das vezes, discutem a própria noção de alteridade, de construção e fixação do outro dentro de alguns estereótipos de leitura reduzida, sendo que essa desconstrução do exotismo é substituída pela universalização das subjetividades. E isso ocorreria principalmente através de textos que se servem da estrutura dos relatos europeus, mas agora estetizando-os com a (auto)ficção dos narradores-viajantes latino-americanos que, ao não terem mais pretensóes de verdade, problematizam os antigos relatos "fundadores" da literatura latino-americana. 


\section{Bibliográfia}

Aira, César, "Exotismo", in Boletin 3 del Grupo de Estúdios de Teoria Literária UNR, Rosario, Argentina, setembro, 1993, p. 73-79.

Andrade, Mário, O Turista Aprendiz, São Paulo, Duas Cidades, Secretaria de Cultura, Ciência e Tecnologia, 1976, p. 328.

Ávila, Myriam, O retrato na rua: memórias e modernidade na cidade planejada, Belo Horizonte, UFMG, 2008, p. 230.

Bhabha, Homi, O local da cultura, Belo Horizonte, MG, Ed. UFMG, 2007, p. 395.

Borges, Jorge Luis, Obras completas de Jorge Luis Borges, São Paulo: Globo, 1998, vol. 1, p. 952.

Caetano, Renata Oliveira, "Viagens modernistas: entre o contato e a invençáo do outro", in IX EHA - Encontro de história da arte, 09, 2013, Campinas (SP), Anais... Campinas (SP), UNICAMP, 2013, p. 315-321.

Candido, Antonio, Formação da literatura brasileira: momentos decisivos (17501836)., Belo Horizonte, Editora Itatiaia Ltda., 1993, v. 1, p. 800.

Chiarelli, Stefania e Oliveira Netto, Godofredo (de) (org.), Falando com estranhos: o estrangeiro e a literatura brasileira. Rio de Janeiro, 7Letras, 2016, p. 269.

Daflon, Claudete, "O percurso escrito da viagem modernista: experimentação em Alcântara Machado e Raul Bopp”, Revista Investigaçóes, vol. 24, n 1, Recife, janeiro/2011, p. 25-53.

---, A viagem e a escrita: uma reflexão sobre a importância da viagem na formação $e$ produção intelectual de escritores-viajantes brasileiros, tese de doutorado em Letras, Pontífica Universidade Católica, Rio de Janeiro, 2002.

Genette, Gérard, Palimpsestes: la littérature au second degré, Paris, Seuil, 1982, p. 480.

Hubert, Rosario, "Rewriting travel litterature: a cosmopolitan critique of exoticism in contemporary latin american fiction", in López-Calvo, Ignacio (org.), Peripheral Transmodernities: South-to-South intercultural dialogues between the Luso-Hispanic World and "the Orient", Newcastle Upon Tyne, Cambridge Scholars Publishing, 2012, p. 42-61.

Lejeune, Philippe, O pacto autobiográfico: de Rousseau à Internet, Belo Horizonte: Ed. UFMG, 2008, p. 404.

Magdaleno, Renata Fernandes, No país da ficçâo: narrativa e viagem na literatura brasileira e argentina contemporâneas, tese de doutorado em Letras, Pontífica Universidade Católica, Rio de Janeiro, 2011. 
Pedrosa, Célia, "Poesia: viagem, anti-viagem. Revista de Letras", vol. 45, n $^{\circ} 1$, São Paulo, 2005, p. 47-70.

Piglia, Ricardo, "Memoria y tradición”, Associação Brasileira De Literatura Comparada: Literatura e memória cultural. Belo Horizonte, ABRALIC, 1991, vol. 1, p. 60-66.

Said, Edward W., Orientalismo: o Oriente como invenção do Ocidente, São Paulo, SP, Companhia das Letras, 2007, p. 528.

Santiago, Silviano, Uma literatura nos trópicos: ensaios sobre dependência cultural, Sáo Paulo, Perspectiva, Secretaria da Cultura, Ciência e Tecnologia do Estado de São Paulo, 1978, p. 219.

Schwarz, Roberto, As ideias fora do lugar: ensaios selecionados, São Paulo, Companhia das Letras, 2014, p. 152.

Silvia, Talles de Paula, "O que dizem os escritores sobre a definição do que se tem chamado de autoficçáo", Revista Palimpsestos, ano 11, n 14, Rio de Janeiro, 2012, p. 1-13.

Sussekinds, Flora, O Brasil não é longe daqui: o narrador, a viagem, São Paulo, Cia. das Letras, 1990, p. 319.

\section{Resumo/Palavras-Chaves}

$\mathrm{O}$ artigo analisa como os romances de viagem latino-americanos descontroem a ideologia dos relatos europeus que legitimam um discurso a respeito dos países periféricos. Para tal, propóe-se um avançar nas discussóes de César Aira (1993) sobre as fases de construção do exótico pela literatura. Vê-se que a autoficção é uma estratégia, pois promove uma anarquitextualidade, uma anarquia na "arquitextualidade" (Génette, 1982) do gênero, rompendo com o pacto de testemunho, o discurso factual da verdade e a linearidade da narrativa.

Relatos, Romances, Viagem, Autoficção, Arquitextualidade

\section{RÉSUMÉ/Mots-CLÉS}

Cet article a pour but de réfléchir à la façon dont les romans de voyage dans les pays d'Amérique Latine déconstruisent l'idéologie des récits européens qui promeuvent la légitimation d'un discours sur les pays périphériques. Pour y parvenir, nous suivons les propos de César Aira (1993) sur les étapes de construction de l'exotique par la littérature. Il est possible de constater que l'autofiction est une stratégie, car elle favorise une anarchitextualité, c'est à dire, une anarchie dans l'architextualité (Génette, 1982) du genre, en rompant avec le pacte de témoignage, le discours factuel de la vérité ainsi que la linéarité du récit.

Récits, Romans, Voyages, Autofiction, Architextualité 


\section{ABSTRACT/KeYWORDS}

This paper aims to analyze how Latin-American travel novels deconstruct the ideology of European stories that legitimize a certain speech about peripheral countries. In order to do so, we propose to follow César Aira's (1993) discussions about the stages of construction of the exotic through literature. It can be seen that self-fiction is a strategy, since it promotes a kind of anarchitextuality, an anarchy in the genre's " architextuality (Génette, 1982), breaking the testimony pact, truth's factual discourse and the narrative's linearity.

Travel stories, Novels, Travels, Self-Fiction, Architextuality 



\title{
Du local à l'impérial : extorsion, insurrection et réforme dans le Haut-Pérou de Charles III (1759-1788)
}

\author{
Philippe CASTEJón \\ Université Lille, EA 4074 CECILLE
}

\begin{abstract}
Les métaux de Potosí et d'Aullagas [...] ont constamment corrompu les oidores [juges] de la Plata, en s'immisçant dans leur propre cœur ou dans celui de leur femme, comme le montrent, dans les deux cas, les exemples récents ${ }^{1}$.
\end{abstract}

DANS UN DISCOURS TEINTÉ DE fatalisme, le gouverneur militaire et président de l'Audiencia de Charcas, Ignacio Flores, s'inquiétait du peu d'intégrité des magistrats de sa juridiction; il se remémorait les accusations de concussion à l'encontre du régent et de deux autres oidores. Tous ces magistrats avaient été suspendus.

Malgré son retentissement, cet événement est resté dans le hors-champ de l'histoire politique. Les faits n'ont ni donné lieu à la construction d'une mémoire autre que celle de ses protagonistes ${ }^{2}$, ni suscité l'intérêt des historiens travaillant sur la région ${ }^{3}$ ou sur les officiers de justice ${ }^{4}$. L'affaire n'est pourtant pas un simple fait divers relevant de la seule histoire locale. Les oscillations de l'événement nous

1. AGI (Archivo General de Indias), Buenos Aires, leg. 65, lettre du 14 avril 1783 du président Flores au vice-roi Vértiz. Traduction de l'auteur de l'article.

2. Sur l'importance de l'événement voir : Farge, Arlette, "Penser et définir l'événement en histoire. Approche des situations et des acteurs sociaux ", Terrains, n 38, mars 2002, p. 67-78. ; Bertrand, Michel, "Penser l'événement" en histoire : mise en perspective d'un retour en grâce », in Bessin, Marc, Bidart, Claire et Grossetti, Michel (dir.), Bifurcations. Les sciences sociales face aux ruptures et à l'événement, Paris, La Découverte, coll. «Recherches ", 2009, p. 36-50.

3. Serulnikov, Sergio, Conflictos sociales e insurgencia en el mundo colonial andino. El norte de Potosí, siglo XVIII, Buenos Aires, Fondo de Cultura Económica, 2006, 468 p. ; Thomson Sinclair, Cuando sólo reinasen los indios. La politica aymara en la era de la insurgencia, La Paz, Muela del Diablo Editores, 2006, 433 p. ; Fisher, John R., « Redes de poder en el Virreinato del Perú, 1776-1824: los burócratas », Revista de Indias, vol. LXVI, n² 236, 2006, p. 149-164.

4. Burkholder, Mark A., Chandler, Dewitt, From Impotence to Authority: Spanish Crown and the American Audiencias, 1687-1808, Columbia, University of Missouri Press, 1977, 253 p. 
plongent dans une histoire sociale du politique aux implications multiscalaires et aux temporalités distinctes 5 . L'événement permet d'appréhender les interactions et jeux de pouvoir entre les représentants du roi et les sociétés locales, dans un des espaces les plus riches de l'Amérique espagnole. De ce point de vue, il s'inscrit dans la riche histoire de la corruption dans le monde hispanique ${ }^{6}$. L'événement agit également comme le révélateur du hiatus qui existe entre les "réformes bourboniennes» et leur mise en œuvre; il confronte enfin les pratiques des magistrats radicados (enracinés localement) à une nouvelle conception du pouvoir et de la justiciabilité défendue par le pouvoir central sous Charles III (1759-1788) 7 .

\section{Des faits divers révélateurs d'un système d'extorsion}

Les affaires de captation d'héritages relevaient de la compétence des Audiencias (cours souveraines), et plus particulièrement du magistrat responsable des biens des défunts. La salle de justice du Conseil des Indes pouvait être saisie en cas de recours. Le 9 octobre 1782, une affaire d'infidélité et de détournement d'héritage amena pourtant le Conseil des Indes à se réunir en session plénière. La gravité des accusations portées par José Benito Rodríguez de Quiroga à l'encontre des magistrats de l'Audiencia de Charcas expliquait l'examen de l'affaire par tous les conseillers.

Ce péninsulaire avait exercé pendant plusieurs années le métier d'avocat dans la juridiction de Charcas. En 1778, il s'était rendu à Madrid afin d'y solliciter une place d'officier de justice ${ }^{8}$. Un séjour à la Cour était pour un avocat exerçant aux Indes le moyen le plus sûr d'obtenir une première nomination. Fort de ses antécédents, il avait été promu procureur de l'Audiencia de Quito.

Cette réussite professionnelle tranchait pourtant avec sa situation conjugale. Pendant son absence, son épouse s'était installée auprès de son amant José Osa, prêtre de Tucobamba. Rodríguez de Quiroga avait entamé, à son retour, une procédure de divorce et dénoncé le séducteur auprès des autorités ecclésiastiques.

La mort en couches de l'adultère ne constitua pas l'épilogue de cette affaire de mœurs. Dans sa fuite, Gabriela Cuenca avait emporté de nombreux objets qui appartenaient à son époux. Certains avaient été vus dans la demeure de Domingo Ángeles, un créole peu scrupuleux soupçonné de recel. À la demande de Rodríguez de Quiroga, l'oidor García de la Plata procéda à leur confiscation. Domingo Ángeles en appela alors aux autres magistrats de l'Audiencia qui récusèrent la légitimité de la confiscation de leur collègue, privant ainsi le mari de ses biens.

5. Saupin, Guy, Histoire sociale du politique. Les villes de l'Ouest atlantique français à l'époque moderne (XVI'XVIII siècle), Rennes, PUR, coll. « Histoire », 2010, 261 p.

6. Voir les travaux de Francisco Andújar Castillo, Pierre Ragon, Anne Dubet, Christoph Rosenmüller ou Michel Bertrand.

7. Le terme de radicado a été popularisé par M. Burkholder dans ses travaux. La notion désignait plus généralement tous ceux qui avaient tissé des liens avec la société locale. Le mariage était le lien le plus facile à appréhender par le pouvoir, mais d'autres types de liens pouvaient exister (parentés spirituelles, clientélisme, échanges économiques...).

8. AGI, Contratación, leg. 5525, n. 1, r. 22. 
Alors que le régent Ruedas lui conseillait de mettre fin au scandale en renonçant aux poursuites, Rodríguez de Quiroga porta l'affaire devant le Conseil des Indes. Il dénonça à la fois le préjudice matériel et la complaisance des juges à l'égard du séducteur $^{9}$; les oidores Pedro Cernadas et Lorenzo Blanco Cicerón ainsi que la femme du régent furent accusés d'avoir protégé le couple adultère et d'avoir pris part à la spoliation ${ }^{10}$.

Le procureur du Conseil des Indes chargé d'instruire le dossier ne manqua pas de pointer les négligences de l'Audiencia et le rôle trouble de certains de ses magistrats ${ }^{11}$. Le verdict du Conseil des Indes fut sans appel tant les faits semblaient accablants : le régent Ruedas, le procureur Pino Manrique, ainsi que trois oidores ${ }^{12}$ furent condamnés à payer de lourdes amendes ${ }^{13}$.

Cette affaire de mœurs révéla la gravité des dysfonctionnements de l'Audiencia de Charcas. Ces agissements ne surprirent pas pour autant le secrétaire des Indes; dès le mois de janvier 1781, ce dernier avait été secrètement alerté par le vice-roi du Río de la Plata du manque de probité de certains juges dans d'autres affaires ${ }^{14}$. Avant même le déclenchement d'une enquête, le régent Ruedas et les oidores Cernadas et García de la Plata avaient été suspendus par un ordre royal du 23 mai 1781.

Les trois magistrats étaient soupçonnés de concussion. La fréquence de ce type d'accusations a contribué à nourrir l'image d'une corruption diffuse aux Indes, d'abord chez les contemporains, puis chez les historiens ${ }^{15}$. Dans la monarchie hispanique, la frontière entre enrichissement personnel et corruption était souvent ténue. Lorsque le marquis de la Corona, procureur du Conseil des Finances, rappelait que "rares étaient les magistrats qui revenaient pauvres des Indes», il suggérait que nombre d'entre eux s'étaient enrichis par des moyens peu scrupuleux ${ }^{16}$.

Des procédures de contrôle existaient pourtant ${ }^{17}$. Du vice-roi au corregidor, chaque détenteur de l'autorité royale devait rendre des comptes (juicio de residencia), au moment où prenaient fin ses fonctions. La procédure était très codifiée et aucun représentant du roi ne pouvait théoriquement s'y soustraire. Le magistrat chargé du juicio de residencia enregistrait les plaintes des administrés, puis rendait un verdict qui était le plus souvent confirmé par l'Audiencia ou le Conseil des Indes. Parallèlement,

9. AGI, Buenos Aires, leg. 68, lettre du 5 février 1784 de Vértiz à Gálvez.

10. Blanco Cicerón fut particulièrement visé. Apparenté à José Osa par sa femme, il l'aurait accueilli dans sa demeure afin de le soustraire à la justice.

11. AGI, Charcas, leg. 423, dictamen du Conseil des Indes du 9 octobre 1782.

12. Il s'agit des oidores Cernadas, González Pérez, et Blanco Cicerón.

13. L'amende était de 500 pesos par magistrat et de 1000 pesos pour le régent Le procureur du Conseil des Indes était également partisan de punir Quiroga pour avoir travesti les faits.

14. AGI, Buenos Aires, leg. 61, lettre du 26 janvier 1781 de Vértiz à Gálvez; AGI, Buenos Aires, leg. 66, lettre du 24 janvier 1783 de Vértiz à Gálvez.

15. Ce champ de recherche a été renouvelé depuis une trentaine d'années par différentes approches : analyse de la vente des offices (Andújar Castillo), histoire sociale de la justice (Herzog), sociologie des réseaux (Bertrand, Rosenmüller, Ragon) ou des conventions (Bertrand) constituent les voies les plus fécondes.

16. AHN (Archivo Histórico Nacional), Estado, leg. 3211-3212, Cuadernos, point 3.

17. Herzog, Tamar, Ritos de control, prácticas de negociación pesquisas, visitas y residencias en las relaciones entre Quito y Madrid (1650-1750), Madrid, Fundación Histórica Tavera, 2000, 196 p. 
une procédure exceptionnelle, la pesquisa, pouvait être déclenchée. Son champ d'action était bien plus limité. Les magistrats incriminés étaient suspendus de leur fonction pendant la durée d'une enquête qui devait corroborer les accusations portées.

Le 12 août 1782, l'oidor Alonso González Pérez fut commissionné par le viceroi pour mener une pesquisa contre trois des juges de l'Audiencia de Charcas ${ }^{18}$. Ses instructions ciblaient plus particulièrement l'oidor García de la Plata, accusé de s'être laissé soudoyer par de riches mineurs d'Aullagas, dans la région de Chayanta. Le régent Ruedas et l'oidor Cernadas, étaient, quant à eux, soupçonnés d'avoir fait preuve de partialité dans leurs verdicts. Le magistrat chargé de faire la lumière sur ces allégations recueillit secrètement une quinzaine de témoignages. Certains témoins, comme le père Gregorio de Merlos, un des protagonistes de la rébellion de Tomás Katari, ou l'avocat José Antonio Castro, dénoncèrent un véritable système d'extorsion ${ }^{19}$.

La première accusation, qui revenait de façon récurrente chez l'ensemble des témoins, était le manquement aux règles de fonctionnement de l'Audiencia. Alors que certains juges, comme Calvo Antequera, étaient présents dès huit heures du matin, le tribunal ne commençait à siéger qu'à l'arrivée du régent et de Cernadas, vers $9 \mathrm{~h} 30-10 \mathrm{~h}$. Le régent Ruedas levait le plus souvent les séances vers $11 \mathrm{~h}-11 \mathrm{~h} 30$, et ce alors même que la loi imposait aux juges de rendre justice pendant trois heures, dès 7 ou 8 heures du matin. L'inobservance des horaires était d'autant plus préjudiciable qu'en raison du nombre de jours fériés ${ }^{20}$, le temps imparti à la procédure judiciaire était limité. Le secrétaire d’État Gálvez avait rappelé, dans les instructions adressées au visiteur général du Pérou, que les oidores devaient respecter scrupuleusement les horaires fixés par les ordonnances ${ }^{21}$.

L'extension, en 1776, de la fonction de régent aux Audiencias américaines s'inscrivait dans cette politique de contrôle de l'action des juges; responsable du bon fonctionnement de l'Audiencia, le régent devait veiller à ce que tous les magistrats soient présents aux heures réglementaires ${ }^{22}$. Les manquements à la discipline de la part de celui qui en était le garant - le régent Ruedas - étaient le signe le plus manifeste de la difficulté à réformer.

L'Audiencia était l'un des alter ego du roi aux Indes. Ses oidores devaient par leur conduite hiératique, ainsi que par leur exemplarité, transmettre l'image d'une justice impartiale; la personne privée du magistrat s'effaçait alors au profit de la personne

18. La procédure avait été lancée par un ordre royal du 15 juillet 1781 . Le 24 décembre 1781 Vértiz informa Gálvez qu’il avait confié la mission à Flores (AGI, Buenos Aires, leg. 62, lettre n 570). Le 12 août 1782, González Pérez entama une enquête secrète (pesquisa) contre les deux oidores incriminés et le régent Ruedas (AGI, Buenos Aires, 66, lettre du 24 janvier 1783 de Vértiz à Gálvez, dans laquelle il adressait l'ensemble des témoignages).

19. AGI, Buenos Aires 66, lettre du 24 janvier 1783 de Vértiz à Gálvez, autos de la pesquisa.

20. AGI, Estado, leg. 42, n. 3, point 29, à propos de l'Audiencia de Mexico. Ils pouvaient représenter jusqu'à la moitié de l'année.

21. AGI, Lima, leg. 1082, Instructions adressées au visiteur général Areche, 17 mai 1776, point 7.

22. AGI, Estado, 86A, n. 13, Instrucción de Regentes, article 25. 
publique, afin qu'aucun élément personnel n'altère son jugement ${ }^{23}$. Cependant, les juges qui faisaient l'objet de la pesquisa étaient loin de correspondre à cet archétype du bon magistrat. Au-delà du caractère altier affiché par ces hommes, de nombreux témoins s'inquiétaient des ingérences du privé dans l'exercice des charges publiques : de nombreux témoins rappelaient l'emprise qu'avait la régente sur son époux ou encore le caractère violent de Cernadas. Ce dernier n'hésitait pas à intimider ceux qui s'opposaient à lui ${ }^{24}$; sa violence était devenue notoire depuis qu'il avait publiquement bastonné un de ses administrés, Juan Bautista Buitrago : ce dernier ne s'était pas découvert devant le magistrat avec suffisamment de promptitude.

L'indépendance et l'impartialité dont devaient faire preuve les juges étaient également remises en cause par de nombreux témoignages. Les amitiés du régent Ruedas, d'abord avec José Castilla Cavallero ${ }^{25}$, puis avec Manuel García de la Plata et enfin avec Pedro Cernadas auraient sensiblement influencé les délibérations. L'accusation était grave, car les magistrats devaient demeurer indépendants et voter en leur âme et conscience. Or, dans de nombreuses affaires impliquant les mineurs d'Aullagas, ces magistrats coligados auraient rendu des verdicts très contestables.

Des soupçons de concussion avaient été à l'origine de la pesquisa. Au cours de l'enquête, de nombreux témoins soulignèrent la partialité des verdicts rendus par les magistrats. Le riche mineur Manuel Álvarez aurait ainsi versé des sommes considérables aux trois juges afin qu'ils statuent en sa faveur ${ }^{26}$. Cernadas fut également suspecté d'avoir tiré profit de sa fonction de juge des défunts en captant des parts d'héritage et García de la Plata fut soupçonné de favoriser les intérêts d'un petit groupe d'avocats.

Les trois magistrats semblaient être au cœur d'un véritable système d'extorsion dans lequel leurs épouses jouaient un rôle clé. Elles faisaient le lien entre des magistrats théoriquement inaccessibles et la société locale. Mariana Baquíjano, la femme de Ruedas était au cour d'une riche sociabilité. Cette créole limeña, fille du comte de Vistaflorida, tenait un salon où se réunissait le Tout-Charcas. On y discutait et on y jouait également aux dés et aux cartes des sommes considérables autour de trois ou quatre tables. Alors que la pratique en était formellement interdite, Mariana Baquíjano recevait chez elle de nombreuses femmes dont les maris étaient impliqués dans des affaires judiciaires. Par des cadeaux somptueux et de fortes sommes d'argent, elles espéraient gagner la bienveillance de la régente. Ainsi, tout le système de perception des pots-de-vin semblait passer par la femme du régent qui agissait de concert avec Cernadas.

23. Garriga, Carlos, "Sobre el gobierno de la justicia en Indias (Siglos XVI-XVII) ", Revista de historia del derecho, no 34, 2006, p. 67-160.

24. Il n'hésitait pas à proférer des menaces de mort, y compris au sein de l'Audiencia contre l'oidor García de la Plata et l'alguacial mayor; il avait menacé de défenestrer la fille du capitaine Juan Bautista Lemoyne (AGI, Buenos Aires 66, autos de la pesquisa).

25. Magdaleno Redondo, Ricardo, Titulos de Indias, Valladolid, Patronato Nacional de Archivos Históricos, 1954, p. 520. José de Castilla avait été promu, le 12 octobre 1778, procureur de Lima.

26. AGI, Buenos Aires 66, lettre du 24 janvier 1783 de Vértiz à Gálvez, autos de la pesquisa, témoignage de Merlos. 
À une autre échelle, la femme de Cernadas, Juana Rivero y Lago, semble avoir joué un rôle actif dans la perception des pots-de-vin. L'avocat José Manuel Arredondo rappelait ainsi qu'à l'occasion de l'inspection de la ville de Córdoba du Tucumán, Juana Rivero y Lago avait reçu la visite de nombreuses femmes de l'oligarchie locale. Celles-ci lui auraient remis en guise de cadeau d'importantes quantités d'or ${ }^{27}$.

Loin de l'image du juge qui se tenait à l'écart de ses administrés, l'enquête d'Alonso González Pérez révéla des magistrats en prise avec la société locale. Ces magistrats radicados intervenaient dans les conflits locaux en tirant profit de cette situation d'arbitre pour s'enrichir.

Le dossier à charge était accablant, pourtant à l'issue d'une procédure qui dura 6 ans les magistrats incriminés furent tous innocentés par le Conseil des Indes. L'affaire s'était révélée beaucoup plus complexe. Sur fond de révolte indienne et de réforme du système judiciaire couvaient, en effet, des conflits d'intérêts. En opérant un changement d'échelles et en confrontant la documentation judiciaire émanant des organismes de contrôles à d'autres sources, un éclairage différent peut être apporté sur ces affaires de corruption.

\section{Jeux de pouvoir et passion du lucre}

[Les magistrats] ne résistent pas aux dons précieux du Pérou, surtout s'ils sont mariés. L'intérêt les unit, l'intérêt les sépare et chaque jour représente une farce ridicule ${ }^{28}$.

L'Audiencia de La Plata (ou de Charcas) se situait au cœur d'un territoire qui avait été, pendant près de deux siècles, l'un des plus prospères de l'empire espagnol. Les mines d'argent de Potosí avaient fait sa fortune, mais l'épuisement progressif des filons et l'essor du secteur minier en Nouvelle-Espagne au XviII ${ }^{\mathrm{e}}$ siècle avaient contribué à déplacer le centre de gravité de l'économie minière espagnole. À la fin du XVIII ${ }^{\mathrm{e}}$ siècle, la région demeurait pourtant un espace d'extraction argentifère qui attisait toutes sortes de convoitises et un espace densément peuplé. L'accroissement des populations indiennes tout au long du XvIII ${ }^{\mathrm{e}}$ siècle s'était traduit par un accroissement considérable des tributaires. Le système d'imposition qui pesait sur les Indiens avait fini par constituer la première source de revenus de la Couronne ${ }^{29}$.

L'intensité de l'activité économique et la croissance démographique avaient justifié la création d'une Audiencia dès 1561. Dans le cursus honorum des magistrats, une nomination à Charcas s'apparentait à une promotion de fin de carrière. Un

27. AGI, Buenos Aires 66, lettre du 24 janvier 1783 de Vértiz à Gálvez, autos de la pesquisa, témoignage de José Manuel Arredondo.

28. AGI, Buenos Aires, leg. 65, lettre du 14 avril 1783 du président Flores au vice-roi Vértiz. Traduction de l'auteur de l'article.

29. Herbert S. Klein, "Impuestos reales, gastos gubernamentales: La Audiencia de Charcas, 1680-1809 ", Data (La Paz), n 6, 1996, p. 23-54. 
avancement à Lima, dernière étape du cursus honorum, n'était pas toujours souhaité tant les salaires étaient élevés à Charcas ${ }^{30}$.

La généralisation de pratiques illicites dans la région - contrebande, corruption ou concussion - avait rapidement conféré à l'Audiencia une réputation sulfureuse. Dans les instructions secrètes rédigées à l'attention du visiteur général du Pérou, le Conseil des Indes lui avait indiqué que " dans la ville de la Plata, il n'est pas possible de trouver une personne digne de confiance». Le seul magistrat sur lequel le visiteur général pouvait compter était le procureur José Castillo Cavallero, un péninsulaire récemment nommé. Un autre acteur du gouvernement central, le contador mayor du Conseil des Indes Ortiz de Landázuri, se remémorait les dispositions qui avaient été prises par le roi à l'encontre de certains juges :

La mauvaise image dont jouissent la plupart des oidores de cette Audiencia, par une conduite déréglée, des attaches multiples et leur implication dans les affaires concernant les mines et le commerce illicite, ont obligé Sa Majesté, sur proposition du Conseil et de la Chambre, à déplacer trois d'entre eux, à Santa Fe, Quito et au Chili31.

Tout au long du règne de Charles III (1759-1788), les dysfonctionnements de cette Audiencia avaient conduit le pouvoir central à intervenir. L'éloignement par Gálvez, en 1782, des trois magistrats incriminés n'était pas une nouveauté. Son prédécesseur Julián de Arriaga (1751-1776) avait déjà été contraint de déplacer quatre oidores. La mutation disciplinaire avait, en théorie, un caractère exceptionnel. Pourtant à Charcas le tiers des magistrats avait été déplacé, entre 1756 et 1783. Melchor José de Santiago Concha avait été muté à Santiago, en 1756, pour s'être marié, sans en avoir obtenu l'autorisation, avec la fille du président de l'Audiencia. L'union sans autorisation de la fille de l'oidor Antonio Sanz Merino et du fils de l'oidor José Giraldes avait eu de lourdes conséquences. Le premier magistrat avait fait l'objet d'une mise à pied et le second avait été " promu " à Santa Fe. Les lois des Indes interdisaient, en effet, que les magistrats d'une même Audiencia aient des liens de parenté. Les nominations de José López Lisperguer à Quito et de Pedro de Tagle à Santa Fe avaient une tout autre origine. Il s'agissait d'écarter deux oidores qui avaient noué trop de liens avec les sociétés locales et qui se livraient à une véritable guerre d'influence au sein de l'Audiencia ${ }^{32}$.

La suspension de ces magistrats et la création de nouvelles places en 1776 avaient eu comme effet de renouveler totalement le corps des juges de l'Audiencia de Charcas. À l'exception de l'oidor Calvo Antequerra, tous les magistrats nommés entre 1776 et 1780 étaient des péninsulaires qui avaient été sélectionnés en pre-

30. AGI, Indiferente, leg. 843, Nota de la graduación, y utilidad, en que se conceptúan las plazas de Ministros de las Audiencias de Indias, du 30 octobre 1772. La cherté de la vie, l'ampleur de la juridiction et l'importance des revenus miniers justifiaient les salaires élevés des magistrats.

31. Ibid.

32. Burkholder, Mark A., Chandler, Dewitt, Biographical dictionary of Audiencia ministers in the Americas, 16871821, Londres, Greenwood, 1984, 491 p. 
mière position par la Chambre des Indes. Les oidores García de la Plata, Cernadas et González Pérez remplacèrent trois des magistrats déplacés. L'oidor Escobedo fut commissionné pour se rendre à Potosí et Juan del Pino Manrique devint le procureur chargé des affaires criminelles. Seul le régent Ruedas avait été directement choisi par Gálvez.

Parallèlement, les tensions au sein de l'Audiencia avaient déterminé le déplacement de deux magistrats (Tagle et López Lisperguer). La nomination de nouveaux magistrats ne signifia pas pour autant un retour à la concorde. L'affaire Rodríguez de Quiroga ainsi que la pesquisa révélèrent des lignes de fracture au sein de l'Audiencia. Les divergences entre García de la Plata et Cernadas étaient connues de tous. Elles étaient autant liées à la défense d'intérêts contraires qu'à une opposition de personnes. D'autres oppositions existaient; le procureur Juan del Pino Manrique, adversaire du régent, entreprit un travail de sape en informant secrètement le viceroi des malversations de ses collègues ${ }^{33}$; le déclenchement d'une pesquisa en fut le résultat. Un autre magistrat, le juge González Pérez, était lui-même un opposant au groupe Ruedas-Cernadas. Chargé de la pesquisa, González Pérez n'avait pas hésité à agir avec partialité en orientant les déclarations des témoins ${ }^{34}$.

Les exils de Ruedas et de Cernadas ne mirent pas fin aux dissensions, mais reconfigurèrent les rapports de force au sein de l'Audiencia. Deux nouvelles factions se formèrent. L'oidor García de la Plata, en prise avec les oidores Blanco Cicerón et Gónzalez Pérez, se rapprocha de l'oidor Calvo Antequera et du procureur Domingo Arnaiz de las Revillas ${ }^{35}$.

Pendant plus de trente ans, l'Audiencia de Charcas fut donc minée par des guerres intestines. Au-delà des oppositions personnelles et des conflits d'intérêts, la pesquisa permit de saisir également les enjeux de pouvoir entre les différents acteurs locaux.

Le vice-roi était, avec l'Audiencia, l'une des rares images vives du roi aux Indes. Détenteur du superior gobierno, le vice-roi présidait cette cour souveraine. Dans la vice-royauté du Río de la Plata, créée en 1776, une singularité existait pourtant. L'absence d'Audiencia à Buenos Aires, siège de la vice-royauté, avait généré une structure bicéphale. Le gouvernement résidait à Buenos Aires et la justice à Charcas. Deux mille kilomètres séparaient le vice-roi de son Audiencia.

Dans les juridictions qui ne pouvaient être présidées ni par un vice-roi ni par un capitaine général, la présidence de l'Audiencia était déléguée à un commandant des armes. Face à l'Audiencia, ce militaire de moindre rang souffrait d'un manque de légitimité. Cette faiblesse structurelle fut accentuée par la création de la régence, en 1776. Dans les Audiencias de Guadalajara et de Quito, la fonction de commandant des armes fut supprimée et les prérogatives de ce dernier furent assumées par le régent. Par analogie avec ces Audiencias, le cas fut également envisagé, mais différé,

33. AGI, Buenos Aires, leg. 61, lettre confidentielle du 15 mars 1781 de Pino Manrique à Vértiz.

34. AHN, Consejos, 20366, exp. 1. Une copie de la plupart des pièces du dossier se trouve dans ce carton de 4886 folios (disponible sur PARES).

35. AGI, Buenos Aires, leg. 65, lettre du 14 avril 1783 de Flores à Vértiz. 
pour l'Audiencia de Charcas. Dans les faits, l'absence prolongée du commandant des armes $^{36}$, puis son décès ${ }^{37}$, conférèrent au régent Ruedas, pendant 3 ans, une autorité sans partage sur sa juridiction. Fort de cette expérience, le régent s'opposa à la nomination d'un nouveau président, estimant être à même d'assumer seul cette fonction.

À l'époque de la pesquisa, deux commandants des armes se succédèrent. Ruedas n'avait que peu d'estime pour le premier, Pinedo, et défendit jalousement l'autorité de l'Audiencia. En tant que représentant du roi, le commandant des armes pouvait être un contrepoids : Pinedo évita de s'opposer au régent, mais il commandita une enquête secrète sur les agissements de Cernadas ${ }^{38}$. La violence de la réaction de Cernadas et la mort du commandant des armes mirent fin à une procédure qui préfigurait la pesquisa.

La nomination d'Ignacio Flores en tant que commandant des armes confirma la volonté du vice-roi de s'ingérer dans les affaires de l'Audiencia. Flores fut chargé, dans un premier temps, d'enquêter sur les magistrats incriminés. Ancien gouverneur de la province de Mojos, Flores avait déjà essuyé les critiques de Ruedas et de Cernadas $^{39}$. Ses interventions dans différents domaines lui valurent l'opposition de l'oidor Blanco Cicerón, proche de Cernadas, et de López Lisperguer, oidor retraité qui servait en qualité de cojuez en l'absence d'autre juge. Les critiques croisées des magistrats de l'Audiencia, du directeur du monopole du tabac Francisco de Paula Sanz - futur surintendant des finances de la vice-royauté - et de l'archevêque eurent raison du président qui, accusé de sédition, termina sa vie en disgrâce à Buenos Aires ${ }^{40}$.

Les dysfonctionnements n'étaient pas uniquement observables au sein du superior gobierno. Ruedas et Cernadas avaient réussi à se couper du cabildo, principal représentant des élites locales. Dans une lettre adressée au secrétaire des Indes, qui dénonçait les irrégularités de la pesquisa, la femme de Cernadas dressait une liste de toutes les personnes dont le témoignage devait être récusé. Le document est exceptionnel, car il permet de saisir l'ensemble des ennemis de Cernadas. Plus d'une trentaine de noms y figuraient, parmi lesquels on retrouvait certains témoins de la pesquisa ainsi que la plupart des regidores. Les immixtions des deux juges dans les affaires municipales étaient mal acceptées : Ruedas avait invalidé les élections municipales (regidores) et les interventions de Cernadas avaient donné lieu à des plaintes ${ }^{41}$.

36. Pinedo avait été nommé le $1^{\text {er }}$ avril 1776, mais il n'était arrivé à Charcas que 22 mois après avoir reçu sa nouvelle affectation, le 20 septembre 1778 .

37. AGI, Charcas, leg. 443, lettre du 15 juillet 1780 de Ruedas à Gálvez annonçant la mort du président de Pinedo le 2 juillet.

38. AGI, Buenos Aires 66, lettre du 24 janvier 1783 de Vértiz à Gálvez, autos de la pesquisa, témoignage d'Antonio Toro, secretario de Cámara.

39. Ancien gouverneur de la province de Mojos, ce créole avait choisi de ne pas secourir la ville de Sonota au moment de la révolte de Tomás Katari. Ces choix tactiques avaient été critiqués par Ruedas et Cernadas.

40. Serulnikov, Sergio (1988), Tomas Catari y la producción de justicia. Análisis de un interrogatorio al líder de la rebelión indigena de Chayanta (1777-1781), Documento CEDES, Buenos Aires, 56 p.

41. AGI, Charcas, leg. 455, Indice del expediente que comprende el negociado de Charcas, 1781, n. 22. 
Pour contrecarrer l'action des deux juges, le cabildo avait noué des liens avec d'autres magistrats. Il avait bénéficié du soutien du procureur Pino Manrique, au moment de l'invalidation des élections municipales, et de l'oidor García de la Plata. Lors de l'examen de l'affaire de concussion par le Conseil des Indes, le cabildo apporta, en retour, son soutien à García de la Plata. L'opposition du cabildo fut probablement un des éléments clés de la chute des deux magistrats.

Dans cette perspective de lutte de pouvoir, la requête du cabildo de transférer le siège de la vice-royauté de Buenos Aires à Charcas pourrait être lue non seulement comme une volonté d'accroître le prestige de la cité, mais également comme une tentative destinée à limiter l'influence du régent par la présence du vice-roi ${ }^{42}$.

Cette affaire de concussion avait également d'autres imbrications. Au moment où l'affaire fut éventée s'achevait, en effet, la révolte de Tomás Katari. Les deux événements n'étaient pas uniquement concomitants, ils entraient directement en résonance. Depuis plusieurs décennies, l'Audiencia de Charcas enregistrait un nombre croissant de révoltes populaires ${ }^{43}$. Ces révoltes sporadiques prenaient le plus souvent pour cible les corregidores. Dans des régions essentiellement peuplées par les Indiens, où les chefs locaux (caciques) administraient les communautés, le corregidor rendait justice au nom du roi. Ce petit officier de justice, espagnol ou créole, était désigné par le vice-roi ou le Conseil des Indes pour une durée de cinq ans. Au cours de cette période, le corregidor s'enrichissait, en toute impunité, en imposant aux Indiens l'achat de marchandises qu'il vendait au prix fort (repartimientos de mercancias). La pratique était encadrée depuis 1751, mais les abus demeuraient nombreux. Les conflits entre les communautés indiennes et les corregidores n'avaient cessé de s'accroître ${ }^{44}$, et en 1780 , Tomás Katari avait pris la tête d'un mouvement de contestation de grande ampleur dans la province de Chayanta ${ }^{45}$.

Soucieux de comprendre les causes de cette révolte, le vice-roi chargea le procureur de l'Audiencia de Charcas d'établir si les troubles avaient un lien avec les dysfonctionnements de l'Audiencia ${ }^{46}$. Pour le procureur, la partialité des trois magistrats et leur soutien à Joaquín Alos, un corregidor âpre au gain, étaient, sans aucun doute, à l'origine du déclenchement de la révolte.

Les exactions d'Alos et de ses lieutenants avaient suscité l'exaspération des communautés indiennes; Tomás Katari s'était alors infructueusement adressé à l'Audiencia, qui l'avait débouté de ses plaintes. Il avait alors entrepris, fin 1778, un voyage de $2000 \mathrm{~km}$ à pied pour en informer le vice-roi Vértiz. Ce dernier

42. AGI, Buenos Aires, leg. 151, lettre du 15 février 1781 du cabildo de la Plata au roi.

43. AGI, Charcas, leg. 592.

44. L'avidité du corregidor de Tinta avait ainsi été à l'origine de la révolte de Tupac Amaru en 1780. La révolte avait embrasé la région de Cuzco, dans la vice-royauté du Pérou, créant ainsi un précédent qui faisait craindre l'extension de révoltes indiennes à d'autres régions d'Amérique méridionale.

45. Pour un récit détaillé des différentes phases de la révolte de Tomás Katari voir : Serulnikov, op. cit. Les troubles se déroulèrent entre la fin de l'année 1777 et le mois d'avril 1781. La rébellion éclata le 26 août 1780 dans le village de Pocoata pour protester contre l'arrestation de Tomás Katari.

46. AGI, Buenos Aires, leg. 61, lettre confidentielle du 15 mars 1781 du procureur Pino Manrique à Vértiz. 
avait renvoyé l'affaire à l'Audiencia, en exigeant néanmoins la nomination d'un enquêteur. La fin de non-recevoir de l'Audiencia et l'arrestation de Tomás Katari, en juin 1780, avaient précipité la révolte ${ }^{47}$. La médiation de Gregorio de Merlos, un des témoins de la pesquisa, et la libération de Katari apaisèrent provisoirement la situation. Cependant, le remplacement d'Alos par Domingo Ángeles, un client du régent à la réputation sulfureuse ${ }^{48}$, puis l'arrestation et l'exécution de Katari par Manuel Álvarez, le riche mineur impliqué dans les affaires de concussion, plongèrent la province de Chayanta dans le chaos.

Le rapport adressé par le procureur Pino Manrique au vice-roi était donc accablant ${ }^{49}$. Il accusait Cernadas d'avoir couvert les malversations d'Alos et les deux autres magistrats de servir les intérêts d'Álvarez. Le déclenchement de la révolte de Tomás Katari fut donc le catalyseur de la pesquisa, et conduisit le secrétaire des Indes à prendre des mesures radicales à l'encontre des magistrats. L'événement avait donc une dimension locale et régionale, mais il faut également l'articuler avec la politique réformatrice menée par José de Gálvez à l'échelle de l'empire.

\section{Un changement de paradigme, la recherche du magistrat intègre?}

L'image du bon magistrat se dessinait au moment de sa promotion : il était de bonne conduite, s'appliquait dans ses tâches, avait conscience de ce qui était bien et était désintéressés0. Ces qualités morales trouvaient implicitement un prolongement dans la société des hommes : le respect des lois et le refus du lucre en découlaient. Cet idéal du bon magistrat, qui n'était pas spécifique à l'époque de Charles III, détonnait pourtant avec la perception négative que le gouvernement central avait des juges qui exerçaient outre-mer; leur enrichissement était immanquablement associé aux compromissions ${ }^{51}$ et leur pauvreté à la probité.

Les Lois des Indes avaient certes dressé des garde-fous. Dans un souci de rendre la justice impartiale, le magistrat ne devait tisser aucun lien avec ses administrés. Il ne pouvait ni entretenir des relations personnelles - par mariage, baptême ou par sa naissance - avec la société locale, ni posséder des biens dans sa juridiction d'exercice $^{52}$; toute transaction commerciale ou financière ayant pour finalité de s'enrichir était exclue. Ces dispositions légales conduisaient à choisir le juge en dehors de la

\footnotetext{
47. Serulnikov, op. cit., p. 20-25.

48. Il avait été Justicia mayor (juge de première instance) de Chichas où il avait dû faire face à des révoltes indiennes. Il avait également été impliqué dans l'affaire Rodríguez de Quiroga.

49. AGI, Buenos Aires, leg. 61, lettre confidentielle du 15 mars 1781 de Pino Manrique à Vértiz.

50. AGI, Buenos Aires, leg. 13, lettre du 16 octobre 1781 du visiteur général Areche à Gálvez.

51. AGI, Estado, leg. 42, n. 3, point 59.

52. Recopilación de las Leyes de Indias, loi 82, titre 16, livre 2. Phelan, John Leddy, «El auge y la caída de los criollos en la Audiencia de la Nueva Granada 1700-1781 », Boletín de Historia y Antigüedades, n 52 (novembredécembre 1972), p. 597-8, rappelle toute une série d'interdits : les magistrats ne pouvaient contracter de parenté spirituelle - en devenant parrain - ou posséder des biens dans leur juridiction d'exercice. Ils ne pouvaient ni recevoir de cadeaux ni se mêler de transactions commerciales. Ces mesures étaient étendues aux femmes et aux enfants des magistrats.
} 
société locale, afin que les attaches et les liens de l'homme privé n'interferent pas sur la personne publique, image vive du roi justicier ${ }^{53}$.

Ces interdits avaient pourtant souffert de nombreuses exceptions entre 1687 et 1751. Pour parer aux besoins les plus pressants du Trésor, les souverains Charles II, puis Philippe $\mathrm{V}$ avaient multiplié les ventes de grâces ${ }^{54}$. Cette pratique avait instauré une vénalité des offices de justice, contraire à la tradition castillane, permettant aux juges de nouer, en toute légalité, des liens avec leurs administrés. De nombreux magistrats avaient obtenu une grâce royale leur permettant de choisir leur affectation, d'exercer dans leur Audiencia de naissance (natural) ou d'épouser une femme de leur juridiction (radicado). Malgré ces exceptions, le cadre légal visant à préserver l'indépendance du magistrat demeurait théoriquement le même. Il imposait aux créoles naturales et aux radicados de ne pas statuer dans les affaires où ils étaient directement ou indirectement impliqués. Dans la pratique, l'importance des connexions de ces magistrats et l'absence de contrôle rendaient ce cadre légal inapplicable.

La vente de ces dispenses prit fin en 1751, marquant, selon M. Burkholder et D. Chandler, la fin de «the Age of Impotence» et le début d'une reprise en main des Audiencias par la Couronne espagnole. Pourtant, jusqu'en 1776, de nombreux magistrats créoles ou péninsulaires furent autorisés par la Chambre des Indes à épouser des femmes originaires de leur juridiction d'exercice, ce qui en faisait des radicados. L'abrogation de la vénalité des offices avait donc été plus une étape qu'un tournant dans une politique visant à rétablir l'indépendance des magistrats. La véritable rupture intervint avec la nomination de José de Gálvez au secrétariat des Indes, en 1776. En prolongeant les études de M. Burkholder et de D. Chandler ainsi que celles de C. Garriga, il conviendrait de se demander si la crise intervenue à Charcas ne serait pas un soubresaut, révélateur des tensions inhérentes à la mise en place d'un programme visant à réformer la justice royale; les onze années du secrétariat de Gálvez ont, en effet, constitué un moment unique dans l'histoire des Indes, à la fois par les changements introduits et par le retour à la stricte observance des obligations des magistrats.

Dès 1776, Gálvez créa de nouvelles magistratures et augmenta le nombre des juges dans toutes les Audiencias. Ces mesures étaient destinées à rapprocher la justice royale des justiciables, mais également à préserver l'intégrité des magistrats; l'augmentation du nombre des magistrats, en renforçant la collégialité, permettait d'accroître le contrôle des décisions prises par les juges. De même, la création de la fonction de régent, en 1776, introduisait une dimension hiérarchique dans un système où la collégialité et l'égalité des votes primaient. Le régent devenait ainsi le garant du bon fonctionnement de l'Audiencia.

Pour Gálvez, la protection du magistrat passait aussi par l'amélioration de ses conditions matérielles. Dès 1777, le salaire des juges officiant aux Indes fut aug-

53. Garriga, Carlos (2006), "Sobre el gobierno de la justicia en Indias (Siglos XVI-XvII) ", Revista de historia del derecho, no 34, 2006, p. 67-160. L'auteur montre très bien les obligations imposées aux magistrats qui devaient provenir du dehors.

54. Burkholder, Mark, Chandler, Dewitt, op. cit. 
menté en moyenne de 440 pesos $^{55}$. La mesure était destinée à couper les racines de la corruption, en assurant aux juges une aisance financière garante de leur intégrité. Cette mesure eut peu d'incidences à Charcas. Avec des salaires de 4860 pesos, les magistrats de Charcas étaient déjà, avec ceux de Lima, les mieux payés de la Monarchie catholique. L'augmentation du nombre de magistrats, la création de la régence et le maintien de salaires élevés étaient autant de mesures destinées à éviter la corruption à Charcas. Les conclusions de la pesquisa démontrèrent pourtant à Gálvez l'inefficacité de ces mesures extrêmement coûteuses.

La stricte observance des interdictions imposées aux magistrats apparaissait comme une des solutions réformatrices destinées à préserver l'intégrité des magistrats. Dès son arrivée, Gálvez se refusa à promouvoir des naturales dans leur Audiencia de naissance et il repoussa toutes les requêtes de magistrats qui désiraient épouser une natural: José Gorvea y Badillo, oidor de Santiago ${ }^{56}$, Juan Francisco de Anda, alcalde del crimen de Mexico ${ }^{57}$ ou encore Joaquín Cabeza Enriquez, alcalde del crimen à Lima ${ }^{58}$, se virent déboutés de leur demande. La Chambre des Indes avait pourtant émis un avis favorable. Le cas se produisit de nouveau en 1782, lorsque l'oidor de Charcas chargé de la pesquisa, Alonso González Pérez, demanda à son tour une dispense. Le secrétaire d'État Gálvez s'y opposa formellement et réprimanda la Chambre des Indes qui soutenait la demande du magistrat ${ }^{59}$. Le refus d'accorder une dispense ne fut pas la seule réponse apportée par le secrétaire des Indes. Une dizaine de magistrats reçurent, en effet, l'autorisation de se marier avec une natural moyennant une promotion vers une autre Audiencia. Le cas s'était posé pour deux magistrats affectés à l'Audiencia de Charcas : Lorenzo Blanco Cicerón, procureur de Santiago, et l'oidor de Lima Ruedas.

Par une politique cohérente de nominations, Gálvez avait évité de nommer des naturales mais également des radicados. Un des magistrats de Charcas, González Pérez, était pourtant un radicado. Il vivait secrètement avec une natural, dont il avait eu deux filles ${ }^{60}$. La révélation de cette situation renforça la nécessité de le muter.

À la suite des travaux de John Leddy Phelan sur Santa Fe, M. Burkholder et D. Chandler ont émis l'hypothèse qu'à l'issue d'une longue période d'exercice dans une Audiencia, tous les magistrats pouvaient nouer des liens préjudiciables à l'indépendance de la justice. La promotion d'un magistrat vers une Audiencia plus prestigieuse était le seul régulateur pour limiter ce phénomène.

Les déplacements de magistrats de la seconde moitié du XVIII ${ }^{\mathrm{e}}$ siècle ont été analysés par Burkholder et Chandler comme une des manifestations de la politique

55. AGI, Indiferente, leg. 843, Nota de la graduación, y utilidad, en que se conceptúan las plazas de Ministros de las Audiencias de Indias, du 30 octobre 1772.

56. AGI, Chile, leg. 172B, avis de la Chambre des Indes des Indes du 13 avril 1785.

57. AGI, México, leg. 1119, avis favorable de la Chambre des Indes du 17 avril 1780.

58. AGI, Lima, leg. 598, avis favorable de la Chambre des Indes du 11 mars 1782.

59. AGI, Indiferente leg. 1814 (Montepio), note de Gálvez sur un avis de la Chambre du 16 octobre 1782 : «Se dignó VM prevenirla se abstuviera de proponer semejantes gracias mediante era su voluntad se observasen las Leyes prohibitivas en este punto."

60. AGI, Buenos Aires, leg. 65, lettre du 14 avril 1783 du président Flores au vice-roi Vértiz. 
visant à éradiquer les créoles des Audiencias ou des hommes mariés à des naturales. Pourtant dans le cas de l'Audiencia de Charcas de 1781 le seul créole présent, Juan de Dios Calvo y Antequera, ne fut jamais inquiété tant son attitude était exemplaire ${ }^{61}$. Tous les magistrats déplacés étaient des péninsulaires arrivés depuis peu : Ruedas et Cernadas avaient pris leur poste en 1777, García de la Plata en 1778 et Blanco Cicerón en 1779. Leur nomination s’inscrivait même dans la politique réformatrice de Gálvez. Ce dernier voyait en eux des hommes intègres capables d'insuffler les changements nécessaires. Comme beaucoup de régents, Ruedas avait été choisi directement par Gálvez sur une base de confiance ${ }^{62}$. Il s'agissait d'un magistrat expérimenté, qui avait fait ses études au prestigieux collège des Espagnols de Bologne, dont l'intégrité n'était pas questionnée. Les autres magistrats avaient été nommés par Gálvez sur proposition de la Chambre des Indes. Il s'agissait essentiellement d'avocats péninsulaires qui, en raison de leurs mérites, avaient été classés en première position au moment des consultas.

L'affaire Quiroga et la pesquisa révélèrent au contraire des magistrats en prise avec la société locale. Moins de trois ans après leur arrivée, ces magistrats avaient noué des liens avec leurs administrés, ce qui les assimilait à des radicados. Ils arbitraient les affaires locales, en tirant profit de la situation. Toutes les réformes destinées à éviter les interférences entre la personne publique et la personne privée du magistrat avaient donc échoué. Le décalage entre la volonté de promouvoir des magistrats intègres et la situation de l'Audiencia de Charcas expliquait les mesures radicales prises par le secrétaire des Indes.

Le déplacement ou la mise en retraite représenteraient le pan répressif de cette politique visant à préserver l'intégrité des magistrats. Avant même le déclenchement de l'enquête, trois d'entre eux furent exilés : le régent Ruedas fut sommé de quitter la ville dans les vingt jours et de se rendre à Buenos Aires auprès du vice-roi ; autorisé par la suite à s'installer à Mendoza, il y demeura jusqu'à sa mort, en 1786. Pendant six ans, l'Audiencia de Charcas fut donc privée de régent. L'oidor García de la Plata fut d'abord exilé à Potosí, avant d'être enfin autorisé à demeurer à Charcas, sans pour autant être réintégré dans son office de juge ${ }^{63}$. L'oidor Cernadas fut, quant à lui, suspendu et exilé à Lima.

La suspension d'un magistrat était une mesure rare, qui se traduisait à l'image de celle de José Tagle y Bracho, par une longue procédure de réfutations des charges, suivie le plus souvent de la réintégration ou de la mise en retraite. La décision de suspendre la moitié des juges de l'Audiencia de Charcas, avant même le déclenchement d'une pesquisa, était une mesure exceptionnelle dans le gouvernement des Indes. On ne peut manquer de faire le rapprochement entre la célérité de cette décision et le renvoi du surintendant des finances de Mexico, en octobre 1782. Ce

61. Ibid.

62. AGI, Charcas, leg. 423, consulte de la Chambre des Indes du 23 septembre 1776. Les camaristas lui ont préféré d'autres candidats. Il a été nommé par une intervention directe du secrétaire d'État Gálvez.

63. AGI, Buenos Aires, leg. 65 lettre du 22 févier 1783 de Vértiz à Gálvez. 
dernier avait été relevé de toutes ses fonctions alors qu'aucune procédure n'avait été déclenchée contre lui ${ }^{64}$. Cet homme, qui avait de longue date la confiance de Gálvez, avait été accusé de favoritisme et d'enrichissement. Les preuves envoyées au secrétaire Gálvez avaient suffi à l'évincer de sa place.

La fermeté du secrétaire des Indes s'expliquait également par son propre parcours. L'action réformatrice de Gálvez s'étayait sur la construction d'une image, celle d'un réformateur incorruptible, soucieux de la défense des intérêts du roi ${ }^{65}$. La fabrique de cette image, dénoncée par certains de ses opposants ${ }^{66}$, était néanmoins une réussite. Le zelo et le desinterés étaient les qualités qui étaient prêtées à Gálvez. Elles étaient porteuses d'une abnégation à servir les intérêts du roi qui valait aussi bien pour lui que pour l'ensemble des hommes qui l'entouraient ${ }^{67}$. Le corollaire de cette construction était la lutte contre toutes les pratiques illicites ${ }^{68}$. La lutte contre la corruption avait alors acquis une dimension programmatique. Les magistrats de l'Audiencia de Santiago avaient été déplacés, dès 1776, pour leur implication dans des affaires locales et leur opposition aux réformes. Les magistrats qui s'étaient opposés à la visite générale à Lima et à Santa Fé avaient eux aussi été déplacés. Pourtant à Charcas, une étape supplémentaire avait été franchie. Les magistrats avaient été immédiatement suspendus.

\section{Épilogue : une victoire à la Pyrrhus?}

On ne peut comprendre la décision de destituer la moitié des juges de l'Audiencia de Charcas qu'en articulant plusieurs échelles d'analyse. L'événement relève, tout d'abord, de la contingence du fait divers. L'infidélité de l'épouse de Rodríguez de Quiroga et la spoliation des biens du magistrat ont révélé une situation locale où régnaient les compromissions. L'absence de concorde au sein du "gouvernement supérieur» et les conflits d'intérêts favorisèrent le déclenchement de la procédure judiciaire à l'encontre des trois magistrats et la découverte de pratiques de concussion. Ces affaires s'inscrivaient également dans un contexte régional, celui des révoltes populaires. Les agissements des oidores furent le catalyseur de la révolte de Tomás Katari. L'ampleur du mouvement détermina le gouvernement central à prendre, en retour, des mesures contre les magistrats soupçonnés de concussion. Enfin, en opérant un changement de focale, nous pourrions replacer ces événements dans le contexte des transformations politiques impériales. La lutte contre la corruption était consubstantielle à la mise en place de réformes. Or, ces affaires étaient l'illustration de l'échec des réformes initiées par José de Gálvez.

64. Navarro García, Intendencias en Indias, EEHA, Séville, 1959, p. 55-57. Il a été le premier à saisir le rôle secret de Cossío en tant que surintendant occulte des finances de Nouvelle-Espagne.

65. AGI, México, leg. 2256, lettre du 20 novembre 1765 de Gálvez à Grimaldi et Squillace. Gálvez s’y présente comme « un hombre a quien no pueden corromper».

66. HL, Brannan Collection, lettre du 15 février 1769 de Gamboa au vice-roi Bucareli.

67. AGI, México, leg. 1241, lettre du 23 novembre 1776 du secrétaire d’État Múzquiz au vice-roi Bucareli. Il y commente la nomination du procureur Areche et revient sur le zelo qui le caractérise.

68. Bertrand, Michel, «Penser la corruption », e-Spania, [http://e-spania.revues.org/ 22807 (consulté le 24/03/2017)]. 
Dans les affaires de concussion, la destitution d'un magistrat était difficile à obtenir. Les trois accusés multiplièrent les recours. À défaut de prouver leur innocence de façon irréfutable, ils démontrèrent les irrégularités de la pesquisa et la partialité de l'enquêteur. Le dénouement juridique de cette affaire arriva à son terme le 22 décembre 1786 lorsque la salle de justice du Conseil des Indes innocenta les trois accusés et condamna le procureur Pino Manrique pour ses propos calomnieux et l'oidor González Pérez pour sa partialité. Le Conseil préconisa également de rétablir les magistrats dans leur charge, voire de leur octroyer une promotion.

La décision du secrétariat d'État, ce qui était peu fréquent, entrait totalement en dissonance avec celle du Conseil ${ }^{69}$. Le nouveau secrétaire des Indes, Antonio Porlier, s'inscrivait dans la droite ligne de Gálvez. Il n'était pas dupe des agissements des magistrats incriminés. Il déplora les négligences ainsi que les irrégularités commises par González Pérez; celles-ci avaient invalidé la pesquisa. Le magistrat fut muté à Buenos Aires, puis à Santiago. Il avait fait certes preuve de partialité, mais les accusations n'en demeuraient pas moins fondées. Ruedas étant mort, Cernadas fut transféré à Quito et García de la Plata à Lima. L'affaire avait également révélé des agissements peu scrupuleux du procureur Blanco Cicerón qui quitta Charcas pour Buenos Aires. Pour chacun de ces magistrats la mutation s'accompagna d'un avertissement. À la moindre plainte ou au moindre manquement à la discipline, ils seraient immédiatement démis de leurs fonctions.

Les changements qui affectèrent les magistrats de Charcas furent à l'origine d'une reconfiguration de l'Audiencia. De nouveaux juges furent rapidement désignés. Le choix du nouveau régent se porta ainsi sur Antonio Boeto, un magistrat pourtant peu expérimenté. Agent zélé de la visite générale du Pérou, Boeto fut promu à cette place par Gálvez sur la base de la confiance. Cette promotion inhabituelle était justifiée par l'urgence de la situation.

Dans une monarchie juridictionnelle où chaque action de l'autorité publique pouvait être contestée au sein d'une procédure judiciaire, le règlement de l'affaire était donc sorti du cadre juridictionnel pour entrer dans les canaux de l'économie de la grâce. Porlier avait mis fin à la pesquisa, réintégré tous les magistrats et renoué avec la politique de déplacement forcé. Il était sorti de l'impasse juridictionnelle qui aurait mené à l'acquittement des juges incriminés, montrant ainsi les limites de la politique réformatrice.

Cette marche arrière s'explique par un changement de focale. La sévérité des sanctions était avant tout le choix d'un acteur individuel, José de Gálvez. Or, le système de gouvernement mis en place par Gálvez ne survécut pas à son fondateur. Sa mort, en 1787, marqua un terme à un programme réformateur cohérent et se traduisit par la scission, puis la disparition du secrétariat des Indes. L'annulation des sanctions à l'encontre des magistrats témoignait de la fragilité des réformes portées par des acteurs individuels.

69. AHN, Consejos, leg. 20366, exp. 1. 


\section{RÉSUMÉ/MOTS-CLÉS}

Au cours de la décennie 1780, la multiplication des affaires de concussion impliquant des juges royaux fut à l'origine de grands bouleversements au sein du territoire de la cour souveraine de Charcas. Ces évènements permettent d'appréhender les interactions et jeux de pouvoir entre les représentants du roi et les sociétés locales, mais agissent également comme le révélateur du hiatus qui existait entre les « réformes bourboniennes» et leur mise en œuvre.

Charcas, Réformes bourboniennes, José de Gálvez, Concussion, Tomás Katari

\section{Resumen/Palabras Claves}

Durante la década de 1780, la proliferación de la corrupción entre los jueces de la Audiencia de Charcas fue el origen de grandes trastornos. La oposición entre los diversos representantes de la autoridad real, los conflictos permanentes entre los oidores y la revuelta india de Tomás Katari fueron las manifestaciones más evidentes de esos trastornos. Esos acontecimientos llevaron al despido y exilio de la mitad de los jueces de la audiencia de Charcas. Estos eventos nos sumergen en una historia social de lo político con implicaciones de escala múltiple. Permiten comprender las interacciones y los juegos de poder entre los representantes del rey y las sociedades locales. También actúan como reveladores del hiato que existió entre las "reformas borbónicas" y su implementación.

Charcas, Reformas borbónicas, José de Gálvez, Corrupción, Tomás Katari

\section{AbSTRaCt/KeYwordS}

During the decade of 1780, the increasing corruption among the judges of Charcas' Audiencia caused a series of disturbances, including opposition among various representatives of royal authority, permanent conflict among oidores and Tomás Katari's Indian revolt. As a consequence, half of the judges of Charcas' Audiencia were dismissed and exiled. These events reveal a social history of politics with its multiple implications. They allow us to understand the interactions and the power game between royal representatives and local societies and show the hiatus between the "Bourbon Reforms" and their implementation.

Charcas, Bourbon reforms, José de Gálvez, Corruption, Tomás Katari 



\section{En una literatura sin figuras fundacionales, la propuesta perdida del escritor costarricense de fin de siglo Argüello Mora}

Verónica Ríos QUESADA

Universidad de Costa Rica

ENTRE I 855 Y I 857 EL FILIBUSTERo William WaLKeR INTENTó asegurar su dominio sobre Nicaragua y activar su plan expansionista en Centroamérica. Había llegado a dicho país con el fin de vencer a la facción conservadora, a petición del bando liberal nicaragüense. En Costa Rica, sus ambiciones provocaron gran alarma y el presidente Juan Rafael Mora Porras le declaró la guerra en 1856. Después de una campaña militar llena de altibajos, gracias a la coalición centroamericana y la intervención de Cornelius Vanderbilt, Walker es derrotado y expulsado de Centroamérica el 1 de mayo de 1857. Recién obtenida la victoria, Mora quiso instrumentalizarla como parte de su proyecto autolegitimador ${ }^{1}$. Cabe destacar que, a mediados del siglo XIX, no había un proyecto nacional consolidado en Costa Rica, ni tampoco existía el antecedente de un germen derivado de las guerras de independencia, pues Centroamérica no luchó por la independencia de Espańa. De la utilidad de integrar los recientes acontecimientos militares en una narrativa nacional ${ }^{2}$, se deriva el plan de Mora. Sin embargo, este se vio frustrado por su destitución y posterior fusilamiento en 1860 .

Tres décadas después, se había consolidado un Estado-nación cuyo imaginario se basa en la igualdad, la paz y la blancura de piel. La Campaña Nacional del 56 se recupera en ese contexto finisecular y se convierte en una pieza más del engranaje, pues "lo que harán los liberales costarricenses es otorgarle identidad cultural al

1. Cabrera Geserick, The Legacy of the Filibuster War: National Identity, Collective Memory, and Cultural AntiImperialism, Arizona State University, 2012, p. 1-19.

2. Méndez Alfaro, Imágenes del poder. Juan Santamaría y el ascenso de la nación en Costa Rica (1860-1915), 2007, San José, p. 52-53. 
Estado que han construido" 3 . Dados los valores identitarios del proyecto y la figura todavía controversial de Mora, la "imaginación histórica" más bien impulsó progresivamente al tamborilero Juan Santamaría ${ }^{4}$ como figura heroica a partir de 1885 y así se promovió la identificación de las masas con el proyecto modernizador, a partir de una figura popular ${ }^{5}$. Además, aunque se instituye como lugar de memoria, la campaña del 56 se mantuvo lejos de la ficcionalización hasta el siglo $\mathrm{xxI}^{6}$. La "generación del Olimpo"7, apelativo de la primera generación literaria, optó por pensar la literatura costarricense en franca disociación de la lucha contra Walker. Por eso, en este escenario tan reticente a la ficcionalización de las figuras asociadas con este hito, sobresalen tres textos narrativos breves de Manuel Argüello Mora, pues en ellos se representa el fusilamiento de su tío, el malogrado presidente Mora. Estos son Margarita, Elisa Delmar y La trinchera, publicados en el compendio Costa Rica pintoresca: sus leyendas y tradiciones, colección de novelas y cuentos, historias $y$ paisajes de 1899.

Los textos mencionados fueron severamente descalificados por la crítica literaria posterior debido a su indefinición genérica ${ }^{8}$. Si bien se escriben bajo el modelo del romance nacional, un género que le daba coherencia narrativa a la historia y así se forjaba una unidad nacional a través de la literatura a mediados del siglo xIX ${ }^{9}$, efectivamente no cumplen a cabalidad con las características de dicho género. Sin embargo, desecharlos por impuros significa pasar por alto su intención patrióticopedagógica, similar a la que se afincó en países como Chile y Argentina a mediados del siglo XIX ${ }^{10}$. Dado el contexto ya referido, dicha intención resulta atípica en la

3. Díaz, D., "La invención de las naciones en Centroamérica, 1821-1950", Boletín AFEHC, n 15, 2005, p. 12.

4. Santamaría murió el 11 de abril de 1856 quemando un mesón de Rivas, Nicaragua, en el cual se refugiaban los filibusteros.

5. Méndez, R., Imágenes del poder. Juan Santamaría y el ascenso de la nación en Costa Rica (1860-1915), 2007, San José, 2007, p. 50.

6. El artículo "La Campaña Nacional (1856-1857): investigación histórica y producción literaria” del historiador Iván Molina Jiménez es el único texto académico que presenta un balance sobre las representaciones literarias de la campańa y de Mora. Publicó posteriormente una versión actualizada de dicho balance en el libro La cicatriz gloriosa. Estudios y debates sobre la Campaña Nacional: Costa Rica (1856-1857).

7. La generación del Olimpo se debatía entre la asimilación de un modelo europeo y la posibilidad de consolidar una identidad propia. Se da una relación compleja entre lo que ellos desean proyectar y difundir y lo que intentan definir como cultura letrada modelo (Quesada Soto, Breve historia de la literatura costarricense, San José, Editorial Costa Rica, 2008, p. 17).

8. Valeria Grinberg, en su artículo "El narrador Argüello Mora entre la literatura y la historia”, resume las posiciones desmerecedoras en cuanto a estos textos en la crítica literaria costarricense. Grinberg Pla, V., "El narrador Argüello Mora entre la literatura y la historia”, Istmo: revista virtual de estudios literarios y culturales centroamericanos, $\mathrm{n}^{\circ}$ 4, 2002 [http://istmo.denison.edu/n04/proyectos/mora.html (consultado el 15/04/2010)].

9. Unzueta, "Scenes of Reading: Imagining Nations/Romancing History in Spanish America", in Castro Klarén, Sara y Chasteen, John (ed.) Beyond imagined communities: Reading and writing the nation in nineteenthcentury Latin America, Washington, D.C, Baltimore, Woodrow Wilson Center Press, 2003, p. 129.

10. El crítico Durán Luzio señala que Martín Rivas. Novela de costumbres político-sociales (1862) del chileno Alberto Blest Gana pudo haber influenciado a Argüello, en particular en la escritura de su novela Misterio. Escenas de la vida en Costa Rica (Durán L., "Manuel Argüello Mora: primer novelista costarricense", VIII Congreso de Filología, Lingüística y Literatura, Cartago, Costa Rica, 24-26 de noviembre 1999, p. 8). 
literatura costarricense y, por su singularidad, merece atención crítica ${ }^{11}$. A fin de sortear su indefinición genérica, considero estos textos como ficciones de memoria. Bajo este concepto acuñado por Birgit Neumann, se enfatiza la creación de nuevos modelos de memoria y su contribución activa a la negociación de la memoria cultural a través de los textos literarios ${ }^{12}$. A partir de esta caracterización, retomo la diminuta trilogía escrita por Argüello, a fin de demostrar la propuesta de un proyecto nacional que refuerza los mitos identitarios ya consolidados, pero cuyo origen está ligado a la figura de Mora, mártir de un pueblo fiel y héroe cultural que se sacrifica para cimentar la conciliación como valor del imaginario nacional. Sin embargo, su narrativa no logró consolidarse, pues más allá de la difícil clasificación genérica señalada por la crítica, no se actualiza en función de nuevos conflictos internos que habrían justificado la necesidad de conciliación y también debido a la emergencia del costumbrismo que, desprovisto de turbulencia histórica, se consolida como carta de presentación de Costa Rica en el extranjero ${ }^{13}$.

\section{Mora, mártir de un pueblo fiel}

Como punto de partida, estas ficciones de memoria de Argüello discursivizan el origen de la comunidad costarricense. En ese sentido, la representación de Mora, como veremos a continuación, encaja en lo que McKenna denomina el papel expiatorio de la realeza. Esta función supone tanto la emergencia de una figura fundadora, salvadora de la comunidad, como la destrucción necesaria de ésta y, por tanto, su victimización ${ }^{14}$. Dicho en otras palabras, en los textos de Argüello, la figura de Mora se potencia como un mesías secular que salva la nación costarricense gracias a su sacrificio y así le da sentido a la violencia social experimentada.

En Margarita, los soldados desobedecen la orden de fusilar a Mora, pues tan sólo tres años antes él había sido su máxima autoridad en la campaña contra William Walker y los filibusteros. Con el fin de detener el derramamiento de sangre, en la ficción, Mora asume nuevamente la posición de mando y ordena su propia ejecución ${ }^{15}$. Es evidente la representación del temor al padre mediante la actitud de los soldados y sobre todo el sacrificio realizado por el líder. Esa inmolación, retomando a McKenna, cimentaría el origen de la nación costarricense.

11. En este punto coincido con Grinberg, quien publica el primer acercamiento crítico al respecto de estos textos. Sin embargo, no comparto su interpretación pues considera que la propuesta de Argüello se asocia con el nacimiento de la democracia costarricense. Esta discrepancia se elaborará más adelante en este artículo.

12. Además, se resalta que dichas ficciones hacen uso de las ideas contemporáneas, predominantes en términos culturales, sobre la memoria. Neuman, B., "The Literary Representation of Memory", in Erll, Astrid y Nünnig, Ansgar, A companion to cultural memory studies, Berlin, New York, De Gruyter, 2010, p. 334-335.

13. Las líneas básicas del argumento central al respecto de estas ficciones de memoria se exponen en el artículo “CCómo sobrevive un héroe en la sociedad costarricense? Juan Rafael Mora, 156 años de altibajos heroicos”. Revista Comunicación, vol. 21, n 2, 2012, p. 13-20.

14. Mckenna, "Violence and the Origin of Language", Mckenna, Andrew (ed.), Violence and Difference: Girard, Derrida, and Deconstruction, Chicago, University of Illinois Press, 1992, p. 85.

15. Argüello M., Manuel, "Margarita”, in Argüello, M. (ed.), Obras literarias e históricas, San José, Editorial Costa Rica, 2007, p. 301. 
El Mora mesíanico supone la llegada de tiempos mejores en los cuales la sociedad, gracias al ejemplo del héroe, se unirá. En consonancia, el motivo de la adoración se repite con frecuencia en las tres ficciones de memoria. Por ejemplo, el narrador de La trinchera señala cómo se sentía su protegido Julio Valera con respecto a él: "fue desde ese momento el compañero inseparable de Mora, a quien servía como escribiente secretario y a quien quería y veneraba con un cariño que rayaba en la adoración" 16 o en el caso de la protagonista de la novela epónima Margarita: "tanto más cuanto que ella [Margarita], como casi todas las mujeres, era partidaria ardiente del presidente caído" ${ }^{17}$.

Asimismo, las mujeres en estos textos se involucran en diferentes grados de la vida política, desde sus relaciones afectivas. Curiosamente su nivel de intervención depende de la condición social y de la nacionalidad: mientras más abajo se encuentran en la escala social y más "extranjeras" resultan, mayor es su participación. La nicaragüense Lorenza, quien aparece en La Trinchera como dueña de un restaurante en Puntarenas, planea un elaborado escape que requiere la complicidad de algunos moristas. En Elisa Delmar, la protagonista salvadoreña-chiricana del mismo nombre, se disfraza de soldado con el fin de rescatar a su padre, el general Cañas, figura histórica de la Campaña Nacional ${ }^{18}$. Margarita, personaje costarricense de la metrópoli en la novela homónima, convence a sus pretendientes de alistarse en las filas moristas por influencia del sacerdote de su parroquia ${ }^{19}$. Por último, en La trinchera, Ester Montealegre - hija del archienemigo y cuñado de Mora ${ }^{20}-$ se limita a escribir una carta destinada para quienes se baten a duelo por su amor, es decir, el joven Julio, protegido de Mora que pretende limpiar el nombre del líder caído, y el misterioso pretendiente Mr. X.

Por una parte, pareciera que Argüello escogió deliberadamente no romper la concepción de mujer ideal de la alta sociedad. Por otra, la participación popular femenina podría asociarse con cierta voluntad de ampliar el espectro de los personajes representados, tal y como en los romances nacionales latinoamericanos de 1850, escritos con la intención de que la novela funcionara como puente entre clases sociales y forjara la unidad nacional ${ }^{21}$. De hecho, Argüello en varias ocasiones interpela a la audiencia con las siguientes palabras: "queridas lectoras".

16. Argüello M., Manuel, "La trinchera”, in Argüello, M. (ed.), Obras literarias e históricas, San José, Editorial Costa Rica, 2007, p. 169.

17. Argüello M., Manuel, "Margarita", in Argüello, M. (ed.), Obras literarias e históricas, San José, Editorial Costa Rica, 2007, p 297.

18. El general Cañas era la mano derecha de Mora en el ejército y, además, eran cuñados.

19. Argüello M., Manuel, "Margarita", in Argüello, M. (ed.), Obras literarias e históricas, San José, Editorial Costa Rica, 2007, p. 297.

20. José María Montealegre, cuñado de Mora, fue uno de los líderes del derrocamiento de Mora en 1859. Para ese momento, ya había enviudado. Asumió la presidencia inmediatamente después del golpe de Estado.

21. Unzueta, F., "Scenes of Reading: Imagining Nations/Romancing History in Spanish America", in Castro Klarén, Sara y Chasteen, John (ed.) Beyond imagined communities: Reading and writing the nation in nineteenthcentury Latin America, Washington, D.C, Baltimore, Woodrow Wilson Center Press, 2003, p. 115-160. Juan Poblete señala la importancia de espacios en los que todas las clases sociales se reconozcan y celebren 
La actitud de las mujeres extranjeras se aclara al considerar la modelación de los hombres extranjeros en estas ficciones. Como señala Grinberg Pla, Argüello Mora, construye un muro prácticamente infranqueable entre costarricenses y extranjeros ${ }^{22}$. En la diégesis, los únicos hombres leales a Mora y que no le temen a la muerte son los costarricenses. La distancia entre hombres de diferentes nacionalidades se expresa claramente en las palabras con las que Julio Valera, el protagonista de La Trinchera, resume el combate: "Todo lo que no era costarricense de raza blanca huyó"23. No sólo se apunta la cobardía de los combatientes extranjeros de las filas moristas, sino que se subraya la blancura de la piel como epíteto, pues en el discurso nacional contemporáneo se consideraba el epítome de lo costarricense ${ }^{24}$. Por extensión, dado que los hombres extranjeros no cumplen con las características de dicho ciudadano modelo, las mujeres extranjeras se travisten para suplir las deficiencias masculinas de sus contrapartes, tal y como se produce en las comedias del Siglo de Oro.

Retomando el patrón de las tramas, a pesar de los planes y de la valentía demostrada, no se puede evitar la tragedia, es decir, el fusilamiento y muerte de Mora. En las ficciones, el desenlace es obra del destino, un mal necesario. Cuando los personajes están en el campo de batalla, surge una serie de infortunios, traiciones y demás, es decir, indicadores de la confabulación del universo para que la empresa fracase y el apoyo popular se desmorone. Por ejemplo, señala el narrador en Elisa Delmar: "Luego siguieron los fatales e inexplicables desastres que condujeron a Mora y a Cañas al banquillo de los ajusticiados" 25 . Esa condición ineludible modela la violencia sacrificial de la cual es objeto Mora e implica que el pueblo no elige ni conserva a los gobernantes, a pesar de su participación activa.

En razón de la ineficacia popular, no comparto la hipótesis de Grinberg, para quien la propuesta de Argüello se asocia con el nacimiento de la democracia costarricense y, más específicamente, de una continuidad democrática. El término "democracia" recién se empieza a utilizar en Costa Rica en la esfera política a partir del siglo xx. Al principio significa "alternabilidad en el poder" y luego se le añade el sentido de "autenticidad y pureza del acto de sufragio" 26 . Por su parte, los textos de Argüello señalan otra acepción de "democracia", pues aparece en contraste con "aristocracia", entendiendo por estas respectivamente pueblo y gente acomodada:

un rito nacional para la construcción de la sociabilidad nacional. Consultar Poblete, J., Literatura chilena del siglo XIX: entre públicos lectores y figuras autoriales. Santiago, Editorial Cuarto Propio, 2003, p. 65-96.

22. Grinberg Pla, V., "El narrador Argüello Mora entre la literatura y la historia", Istmo: revista virtual de estudios literarios y culturales centroamericanos, $\mathrm{n}^{\circ}$ 4, 2002 [http://istmo.denison.edu/n04/proyectos/mora.html].

23. Argüello M., Manuel, "La trinchera", in Argüello, M. (ed.), Obras literarias e históricas, San José, Editorial Costa Rica, 2007, p. 182.

24. Consultar Acuña O., V., "La invención de la diferencia costarricense" Revista de Historia (Costa Rica), $\mathrm{n}^{\circ} 45,2002$.

25. Argüello M., Manuel, "Elisa Delmar”, in Argüello, M. (ed.), Obras literarias e históricas, San José, Editorial Costa Rica, 2007, p. 151.

26. Acuña Ortega, V., "Historia del vocabulario político en Costa Rica. Estado, república, nación y democracia (1821-1949)”, in Taracena, A. y Piel, J. (ed.), Identidades nacionales y estado moderno en Centroamérica, $1^{\mathrm{a}} \mathrm{ed}$. , San José, Costa Rica, Editorial de la Universidad de Costa Rica, 1995, p. 69-70. 
La Lorenza cultivaba amistad con todo el mundo y lo mismo empleaba su lenguaje familiar, salpicado de chistes y de bromas, con la aristocracia, como ella llamaba a las gentes ricas y bien acomodadas del lugar, que con sus infinitos amigos y amigas de la democracia que eran sus iguales, quienes lo mismo que aquéllas la estimaban de todo corazón ${ }^{27}$.

La interpretación presentada en este artículo en cuanto al sacrificio del héroe y la concepción de un pueblo fiel se refuerza al leer el cuento de Argüello "Los cuatro hijos de Ambrosio" que pertenece a la misma compilación de 1899. El protagonista le entrega personalmente al presidente a cada uno de sus hijos, en diferentes estadios de la campaña, con el fin de apoyar la lucha contra Walker. Con la muerte de sus cuatro hijos durante la campaña de 1856 a cuestas, el Abraham criollo participa en la insurrección morista de 1860, pues considera que "la patria es don Juanito" 28. Tras la derrota y fusilamiento de Mora, encuentran su cadáver. El sacrificio de su familia y de su vida, según el narrador, es digno de emular:

Puede ser que el cariño al terruño me engañe; puede ser que el autor de esta historia-cuento, sea un irremediable optimista; pero tengo para mí que el proceder de Ambrosio no es tan singular y aislado como parece. Lo que falta a los héroes son las ocasiones de serlo. ¡Que ellas se presenten, y estoy seguro que no faltarán Ambrosios en Costa Rica ${ }^{29 !}$

En definitiva esa lealtad popular mezclada con identificación religiosa dista de una experiencia democrática. Por el contrario, refuerza la dependencia del pueblo con respecto a la elite. De esta manera, Argüello se apega a la necesidad de promover la identificación de las masas con el proyecto modernizador seńalada anteriormente. Sin embargo, hacerlo a partir de una figura de elite y no de una popular, contraviene la manera en que se recuperó la Campańa Nacional como sitio de memoria.

\section{Conciliación, la metáfora-puente entre la trama histórica y la pasional}

Para la emergencia de "un cuerpo potente, simbólico" que "le dé abrigo al cuerpo 'natural' de la nación" 30 , en términos de Ernst Kantorowicz, en los textos fundacionales latinoamericanos se recurre a estrategias diferenciadoras entre bandos, por ejemplo, servirse "de las distinciones sexuales para expresar las nuevas condiciones de la pretendida autonomía nacional”, una estrategia común en las novelas históricas

27. Argüello M., Manuel, "Margarita”, in Argüello, M. (ed.), Obras literarias e históricas, San José, Editorial Costa Rica, 2007, p. 298.

28. Argüello M., Manuel, "Los cuatro hijos de Ambrosio", in Argüello, M. (ed.), Obras literarias e históricas, San José, Editorial Costa Rica, 2007, p. 364.

29. Ibid., p. 365.

30. Jing, Xuan, "Sacrificio sublime, sacrificio obsceno. La fundación del cuerpo nacional en La cautiva y El matadero de Esteban Echevarría”, Folger, R. y Leopold, S. (ed.), Escribiendo la independencia: Perspectiva postcoloniales sobre la literatura hispanoamericana del siglo XIX, Madrid, Frankfurt am Main, Iberoamericana, Vervuert, 2010, p. 122. 
mexicanas de la segunda mitad del siglo XIX para virilizar a quien representa al cuerpo simbólico $^{31}$. En las ficciones de memoria analizadas, Argüello no puede valerse de ese tipo de estrategias para distinguir al bando morista del antimorista porque la elite costarricense, por más dividida que esté, es absolutamente endogámica ${ }^{32}$. Es un drama intrafamiliar y esto se representa claramente en la trama romántica de los textos analizados. En el caso de La Trinchera se ficcionaliza el conflicto histórico entre concuños, es decir, entre Mora como ex presidente derrocado y Montealegre como golpista, casado con una de las hermanas del primero. En este texto, el conflicto se representa, en la trama romántica, a través del joven protegido de Mora, Julio Valera, y Ester Montealegre, hija de Montealegre y por tanto miembro de la familia antimorista. Por su parte, en Margarita, la protagonista del mismo nombre y su primo Jorge están enamorados. En definitiva, no puede plantearse la captura de Mora como violación y virilización, como se presenta en el cuento "El matadero" del escritor argentino Esteban Echeverría ${ }^{33}$.

Para distanciarse de diferenciaciones estériles y con el fin de que Mora sea ese cuerpo simbólico, en estas ficciones, se le saca partido a las implicaciones sociales de la línea histórica con respecto a la romántica, propias del romance nacional. Como indica Doris Sommer, el género en sí conlleva el desarrollo de una fórmula narrativa en la que la conciliación se construye como valor postépico para convertir a los antiguos enemigos en aliados ${ }^{34}$. A partir de la modelación sacrificial de Mora, la estrategia consiste en construir especularmente a los protagonistas masculinos pertenecientes a la elite costarricense. Dado que la muerte de Mora supone el grado cero de la comunidad, para darle continuidad a la tabla rasa, los personajes Julio Valera y Jorge, respectivamente de Margarita y La Trinchera ${ }^{35}$ se representan huérfanos ${ }^{36}$. Se rompe la posibilidad de una memoria familiar y masculina, asociada con la campaña del 56 y con los conflictos ya existentes entre moristas y antimoristas. Ésta se borra como hito y, en su lugar, se sitúa la lucha por la recuperación del poder por parte de Mora, en la que sí participan los personajes mencionados, como parteaguas nacional.

31. Hölz, K., "Conciencia nacional y herencia colonial. El orden de los sexos en la literatura patriótica de México", in Schmidt-Welle, F. (ed.), Ficciones y silencios fundacionales. Literaturas y culturas poscoloniales en América Latina (siglo XIX), Madrid, Iberoamericana, 2003, p. 197.

32. Sobre la endogamia de la elite costarricense, consultar Stone, S. Z., El legado de los conquistadores: Las clases dirigentes en la América Central desde la Conquista hasta los Sandinistas, 1, San José, Costa Rica, Editorial Universidad Estatal a Distancia, 1993.

33. Jing, Xuan, "Sacrificio sublime, sacrificio obsceno. La fundación del cuerpo nacional en La cautiva y El matadero de Esteban Echevarría”, Folger, R. y Stephan Leopold (ed.), Escribiendo la independencia: Perspectiva postcoloniales sobre la literatura hispanoamericana del siglo XIX, Madrid, Frankfurt am Main, Iberoamericana, Vervuert, 2010, p. 122.

34. Sommer, D., Ficciones fundacionales. Foundational Fictions. The National Romances of Latin America, Bogotá, Fondo de Cultura Económica, 2004, p. 29.

35. Se trata de una orfandad compartida por el propio Argüello, quien fue criado por su tío, el ex presidente Mora.

36. La orfandad representa una vía para hacer tabla rasa con la historia cultural y la colonia en las décadas post independencia. Schmidt-Welle, F., "El liberalismo sentimental hispanoamericano", in Schmidt-Welle, F. (ed.), Ficciones y silencios fundacionales. Literaturas y culturas poscoloniales en América Latina (siglo XIX), Madrid, Iberoamericana, 2003, p. 325. 
Asimismo, como señala Grinberg Pla, el desenlace de la trama romántica de La Trinchera es variante del motivo del fusilamiento de Mora y Cańas ${ }^{37}$. En esta ficción, Valera, enamorado de Ester, se enfrenta a duelo contra Mr. X., un pretendiente británico de la muchacha al parecer aprobado por su padre y cuñado de Mora, Montealegre. En el duelo, Valera se deja asesinar por Mr. X. En el momento de su agonía, su sacrificio cobra sentido. La sirvienta de Ester, Ramona, lleva a la escena del duelo una carta escrita por su ama. La muchacha declara allí que, si alguno muere en el enfrentamiento, a ese será al que recuerde y, al asesino, lo aborrecerá ${ }^{38}$. Julio muere escuchando estas palabras: "Su memoria tendrá carińosa tumba en el corazón de Ester"39. Este fin, si bien abrupto e incoherente, es una metáfora para demostrar que la memoria trasciende la ambición de poder. Apunta hacia la convivencia y sanación de la elite-familia-nación desgarrada. En ese sentido, la emisaria Ramona es la figura popular que une a la elite. Fue la nodriza del joven Valera y en el presente del texto es la sirvienta de confianza de Ester. Además, esta observación de Grinberg se extiende hasta cierto punto a Margarita. En esta ficción, gracias al ejercicio de conciencia de Ricardo, finalmente se pueden casar los primos y se modela una nación que enfatiza la conciliación y protege los intereses de la elite a través de la endogamia. En contraste, el desenlace de Elisa Delmar evidencia la tensión ya señalada a la hora de construir al extranjero. La hija bastarda de Cañas y su enamorado foráneo luchan al lado de Mora y, sin embargo, su amor fracasa ${ }^{40}$.

\section{Propuesta marginada}

El enfoque en la muerte de Mora en los textos analizados permite la construcción de una metáfora que le da continuidad a la trama histórica a través de la romántica. Se conecta la muerte de Mora como sacrificio fundacional con la emergencia de una comunidad exclusivamente costarricense que antepone la convivencia pacífica a la violencia. Argüello se concentra en su fusilamiento y lo establece como grado cero de la comunidad costarricense. Mora se perfila entonces como un héroe cultural, aquel que se distingue por imponer el orden ante el caos, quien trae regalos que permiten la mejoría de las condiciones de vida de la humanidad ${ }^{41}$. Apela así a la Costa Rica de los albores del siglo xx, a punto de entrar en un período de reformismo liberal abocado a la internacionalización de la economía y que paulatinamente disminuyó la influencia del ejército para invertir en educación, consolidar la burocracia estatal

37. Grinberg Pla, V., "El narrador Argüello Mora entre la literatura y la historia", Istmo: revista virtual de estudios literarios y culturales centroamericanos, $\mathrm{n}^{\circ}$ 4, 2002 [http://istmo.denison.edu/n04/proyectos/mora.html

38. Argüello M., Manuel, "La trinchera”, in Argüello, M. (ed.), Obras literarias e históricas, San José, Editorial Costa Rica, 2007, p. 195.

39. Ibid.

40. La imposibilidad de integrar al extranjero es una constante en la obra de Argüello. Ovares et al. la demuestran en su análisis de Misterios (Ovares et al., La casa paterna. Escritura y nación en Costa Rica, San José, Editorial de la Universidad de Costa Rica, 1993, p. 40).

41. Consultar Long, J., "Culture Heroes", in Jones, Lindsay (ed.), Encyclopedia of Religion, $2^{\mathrm{a}}$ ed, v. 3, Detroit: Macmillan Reference USA, 2005, 2090-2093. 
y garantizar mano de obra para la recolección de café y banano ${ }^{42}$. Asimismo, en un momento decisivo en el contexto latinoamericano -basta con subrayar la intervención finisecular de los Estados Unidos en el Caribe y su creciente influencia sobre los gobiernos centroamericanos, Argüello marca claramente su distancia ante la posibilidad de que el centroamericano errante ${ }^{43}$, bautizado así por la crítica Margarita Rojas, emerja heroico en su país de acogida. De esta manera se evidencia la voluntad por distanciarse de Centroamérica como región en aras de promover la supuesta excepcionalidad costarricense.

Sin embargo, pese a su apropiación de los mitos identitarios y de la construcción de un marco que permitiera la incorporación de Mora, su propuesta conciliatoria no hizo mella. Difícilmente resuena por la ausencia de conflictos civiles contemporáneos que sirvan de espejo para evidenciar la pertinencia de su propuesta. En todo caso, tampoco hay antecedentes históricos de conflictos internos y sangrientos de gran envergadura. En las primeras décadas de vida independiente, la principal función del ejército consistió en dirimir batallas entre facciones de la elite ${ }^{44}$. Es más, según el historiador Víctor Hugo Acuña, el fusilamiento de Mora no se percibió como un acontecimiento desgarrador en el plano social y político, por lo que la imagen ya consolidada de Costa Rica como país pacífico no se vio afectada ${ }^{45}$. Casi cuarenta años después, el fortalecimiento de dicha imagen es tal que no tenía cabida una propuesta que, para empezar, problematizaba un drama social no compartido por el grueso de la población. El hecho de signar la conciliación, más bien, apunta a contra corriente que se trata de una sociedad con sed de paz y no una sociedad pacífica per se.

En el fondo, la propuesta de Argüello de presentar a Mora como figura fundacional de la nación costarricense nace sin energía. Se distancia considerablemente de las representaciones de figuras fundacionales latinoamericanas ${ }^{46}$ porque lo presenta incompleto. Como señalamos anteriormente, los textos de Argüello narran únicamente los últimos días del gobernante $y$, en consecuencia, la modelación heroica de Mora resulta inacabada. De ninguna manera se podría afirmar que la figura de Mora funda la literatura costarricense, a diferencia del papel que cumple un Juan Manual Rosas en las letras argentinas ${ }^{47}$.

42. Cabrera Geserick, The Legacy of the Filibuster War: National Identity, Collective Memory, and Cultural AntiImperialism, Arizona State University, 2012, p. 159-99.

43. Rojas utiliza la expresión "centroamericano errante" para referirse al fenómeno migratorio intelectual de la región en la segunda mitad del siglo xIx y principios del siglo xx (Rojas, M., "El centroamericano errante: nacionalismo y modernismo en la época liberal”, Revista de Historia, no 24, 1991, p. 9-20).

44. Molina Jiménez, I., "El 89 de Costa Rica: otra interpretación del levantamiento del 7 de noviembre", Revista de Historia, $\mathrm{n}^{\circ} 20,1989$, p. 181.

45. Acuña O., V., "La invención de la diferencia costarricense." Revista de Historia, n 45, 2002, p. 214.

46. Consultar Nitschack, H., "Entre el poema épico y la novela: La fundación de la literatura brasileña”, SchmidtWelle, F. (ed.), Ficciones y silencios fundacionales. Literaturas y culturas poscoloniales en América Latina (siglo XIX), Madrid, Iberoamericana, 2003, 257-72.

47. Area, L., "Sombra terrible de un antihéroe", Revista Iberoamericana, n²13, 2005, p. 1018. 


\section{Epílogo}

Con excepción de Argüello, la generación del Olimpo no ficcionalizó a Mora como ejercicio sistemático de la construcción nacional. Por tanto, de la producción intelectual de esta se desprende una dinámica muy particular entre la historia y la literatura como campos emergentes asociados al proyecto nacional. Mientras la historia necesita fijar un hito épico, ergo señalar un punto de origen, con el fin de visibilizar a Costa Rica en el mapamundi y demarcar fronteras ${ }^{48}$; la literatura se ocupa de proyectar la nación hacia el futuro, distanciándose de dicho referente y mostrando una imagen neutra ante el mundo y el extranjero. Esta división tácita de labores explicaría por qué los literatos costarricenses de fin de siglo se enfocaron en el costumbrismo. Ese es el movimiento por excelencia de la naciente literatura costarricense por su efectividad a la hora de imponer una domesticidad ligada a la idealización de la sociedad pre-Campaña de 1856-185749. Refuerza la noción de un pasado común, punto relevante en los relatos históricos latinoamericanos decimonónicos para la unidad nacional ${ }^{50}$ y consolida los mitos identitarios ya señalados, a saber paz, igualdad y blancura de la piel. Además, resultó una excelente carta de presentación en el extranjero por su estrategia diferenciadora con respecto al resto de Centroamérica ${ }^{51}$.

En conexión con este rol de la literatura, resulta interesante retomar las conclusiones de Jorge Valdeperas en cuanto a la formación de un imaginario antiépico en la novelística costarricense de la primera mitad del siglo xx. Señala el crítico la presencia abrumadora de novelas producidas por la generación del Olimpo que articulan la huida como resolución estética en ese período. Es el caso de El moto (1900) de Joaquín García Monge, la primera novela nacional según el canon ya establecido. En otras palabras, el mito identitario de una Costa Rica pacífica se representa, en términos literarios, enfatizando la domesticidad, la huida, es decir, la sumisión popular. En definitiva, la propuesta patriota-pedagógica de un Mora como héroe cultural cuyo sacrificio sana las heridas de la elite y permea hasta las capas populares para posibilitar la paz, es inusual. Las ficciones analizadas son una excepción en la historiografía literaria nacional del siglo xIx y del siglo xx inclusive, dado el énfasis en instrumentalizar el conflicto morista-antimorista, mostrar la sangre derramada y darle un propósito edificante.

48. Consultar Quesada Camacho, J., Historia de la historiografía costarricense 1821-1940, San José, Editorial de la Universidad de Costa Rica, 2001.

49. Ovares et al., La casa paterna. Escritura y nación en Costa Rica, San José, Editorial de la Universidad de Costa Rica, 1993, p. 45.

50. Betancourt, A., "La nacionalización del pasado. Los orígenes de las 'historias patrias' en América Latina”, in Schmidt-Welle, F. (ed.), Ficciones y silencios fundacionales. Literaturas y culturas poscoloniales en América Latina (siglo XIX), Madrid, Iberoamericana, 2003, p. 87.

51. Ríos, V., "De incipientes literaturas centroamericanas, traducciones tempranas y hambre neoimperial-hispanista en los Estados Unidos". Istmo. Revista virtual de Estudios Centroamericanos, n 32, 2016 [http://istmo.denison. edu/n32/articulos/11.html]. 


\section{Bibliografía}

Acuña Ortega, Víctor H., "Historia del vocabulario político en Costa Rica. Estado, república, nación y democracia (1821-1949)", in Taracena Arriola, Arturo y Piel, Jean (ed.), Identidades nacionales y estado moderno en Centroamérica, $1^{\mathrm{a}} \mathrm{ed}$., San José, Costa Rica, Editorial de la Universidad de Costa Rica, 1995, p. 63-74.

---, "La invención de la diferencia costarricense", Revista de Historia, n 45, 2002, p. 191-228.

Area, Lelia, "Sombra terrible de un antihéroe", Revista Iberoamericana LXXI, n 213 , 2005, p. 1015-28.

Argüello Mora, Manuel, "Elisa Delmar", in Argüello, Manuel (ed.), Obras literarias e históricas, San José, Editorial Costa Rica, 2007, p. 141-60.

---, "La Trinchera", in Argüello, Manuel (ed.), Obras literarias e históricas, San José, Editorial Costa Rica, 2007, p. 161-95.

---, "Los cuatro hijos de Ambrosio", in Argüello, Manuel (ed.), Obras literarias e históricas, San José, Editorial Costa Rica, 2007, p. 361-65.

---, "Margarita”, Argüello, Manuel (ed.), Obras literarias e históricas, San José, Editorial Costa Rica, 2007, p. 293-305.

---, Obras literarias e históricas, San José, Editorial Costa Rica, 2007, 495 p.

Betancourt Mendieta, Alexander, "La nacionalización del pasado. 'Los orígenes de las historias patrias' en América Latina”, in Schmidt-Welle, Friedhelm (ed.), Ficciones y silencios fundacionales. Literaturas y culturas poscoloniales en América Latina (siglo XIX), Madrid, Iberoamericana, 2003, p. 81-99.

Cabrera Geserick, Marco, The Legacy of the Filibuster War: National Identity, Collective Memory, and Cultural Anti-Imperialism, tesis de Doctorado, Arizona State University, 2012.

Díaz, David, "La invención de las naciones en Centroamérica, 1821-1950", Boletin AFEHC, $\mathrm{n}^{\circ}$ 15, 2005 [http://afehc-historia-centroamericana.org/index. php?action=fi_aff\&id=367/].

Durán Luzio, Juan, "Manuel Argüello Mora: primer novelista costarricense", VIII Congreso de Filología, Lingüística y Literatura, Cartago, Costa Rica, 24-26 de noviembre 1999.

---, Escritos selectos de Juan Rafael Mora Porras, 2011, 140 p. 
Grinberg Pla, Valeria, "El narrador Argüello Mora entre la literatura y la historia", Istmo. Revista virtual de estudios literarios y culturales centroamericanos, $\mathrm{n}^{\circ}$ 4, 2002 [http://collaborations.denison.edu/istmo/n04/proyectos/mora.html].

Hölz, Karl, "Conciencia nacional y herencia colonial. El orden de los sexos en la literatura patriótica de México", in Schmidt-Welle, Friedhelm (ed.), Ficciones y silencios fundacionales. Literaturas y culturas poscoloniales en América Latina (siglo XIX), Madrid, Iberoamericana, 2003, p. 189-210.

Jing, Xuan, "Sacrificio sublime, sacrificio obsceno. La fundación del cuerpo nacional en La cautiva y El matadero de Esteban Echevarría", in Folger, Robert y Leopold, Stephan (ed.), Escribiendo la independencia: Perspectiva postcoloniales sobre la literatura hispanoamericana del siglo XIX, Madrid, Frankfurt am Main, Iberoamericana; Vervuert, 2010, p. 97-124.

Long, Jerome H., "Culture Heroes", in Jones, Lindsay (ed.), Encyclopedia of Religion, $2^{a}$ ed., v. 3. Detroit, Macmillan Reference USA, 2005, p. 2090-2093.

McKenna, Andrew, "Violence and the Origin of Language", in Mckenna, Andrew (ed.), Violence and Difference: Girard, Derrida, and Deconstruction, Chicago, University of Illinois Press, 1992, p. 66-115.

Méndez Alfaro, Rafael A., Imágenes del poder. Juan Santamaría y el ascenso de la nación en Costa Rica (1860-1915), San José, Editorial de la Universidad Estatal a Distancia, 2007, 175 p.

Molina Jiménez, Iván, "La Campaña Nacional (1856-1857): investigación histórica y producción literaria”, in Díaz, David y Molina, Iván (ed.), La Campaña Nacional (1856-1857): historiografia, literatura y memoria, San José, Editorial de la Universidad de Costa Rica, 2008, p. 1-36.

---, La cicatriz gloriosa. Estudios y debates sobre la Campaña Nacional: Costa Rica (1856-1857), San José, Editorial Costa Rica, 2014, 179 p.

Neumann, Birgit, "The Literary Representation of Memory", in Erll, Astrid y Nünning, Asgar (ed.), A companion to cultural memory studies, Berlin, New York, De Gruyter, 2010, p. 333-343.

Nitschack, Horst, "Entre el poema épico y la novela: La fundación de la literatura brasileña”, in Schmidt-Welle, Friedhelm (ed.), Ficciones y silencios fundacionales. Literaturas y culturas poscoloniales en América Latina (siglo XIX), Madrid, Iberoamericana, 2003, p. 257-72.

Ovares, Flora, et al, La casa paterna. Escritura y nación en Costa Rica, San José, Editorial de la Universidad de Costa Rica, 1993, 361 p. 
Poblete, Juan, Literatura chilena del siglo XIX: entre públicos lectores y figuras autoriales, Santiago, Editorial Cuarto Propio, 2003, 283 p.

Quesada Camacho, Juan R., Historia de la historiografía costarricense (1821-1940), San José, Editorial de la Universidad de Costa Rica, 2001.

Quesada Soto, Álvaro, Breve historia de la literatura costarricense, San José, Editorial Costa Rica, 2008.

Ríos Quesada, Verónica, “¿Cómo sobrevive un héroe en la sociedad costarricense? Juan Rafael Mora, 156 años de altibajos heroicos”, Revista Comunicación, vol. 21, $\mathrm{n}^{\circ} 2,2012$, p. 13-20.

---, "De incipientes literaturas centroamericanas, traducciones tempranas y hambre neoimperial-hispanista en los Estados Unidos", Istmo. Revista virtual de Estudios Centroamericanos, $\mathrm{n}^{\circ}$ 32, 2016 [http://istmo.denison.edu/n32/articulos/11.html].

Rojas, Margarita, "El centroamericano errante: nacionalismo y modernismo en la época liberal", Revista de Historia, n 24, 1991, p. 9-20.

Schmidt-Welle, Friedhelm, "El liberalismo sentimental hispanoamericano", in Schmidt-Welle, Friedhelm (ed.), Ficciones y silencios fundacionales. Literaturas y culturas poscoloniales en América Latina (siglo XIX), Madrid, Iberoamericana, 2003, p. 317-336.

Sommer, Doris, Ficciones fundacionales. Foundational Fictions. The National Romances of Latin America, Bogotá, Fondo de Cultura Económica, 2004.

Stone, Samuel Z., El legado de los conquistadores: Las clases dirigentes en la América Central desde la Conquista hasta los Sandinistas, $1^{a}$ ed. de la $1^{a}$ traducción autorizada, San José, Costa Rica, Editorial Universidad Estatal a Distancia, 1993.

Unzueta, Fernando, "Scenes of Reading: Imagining Nations/Romancing History in Spanish America”, in Castro-Klarén, Sara y Chsteen, John C. (ed.), Beyond imagined communities: Reading and writing the nation in nineteenth-century Latin America, Washington, D. C., Baltimore, Woodrow Wilson Center Press, Johns Hopkins University Press, 2003, p. 115-160.

Valdeperas, Jorge, Para una nueva interpretación de la literatura costarricense, San José, Editorial Costa Rica, 1991, 127 p. 


\section{Resumen/Palabras Claves}

El autor costarricense de fines de siglo Manuel Argüello Mora representa los últimos días de Juan Rafael Mora Porras, el presidente y líder de la campaña contra el filibustero William Walker (1856-1857), en tres textos literarios publicados en 1899. En estos, el fusilamiento de Mora se construye como un sacrificio fundacional que supone reconciliación para un pueblo fiel. Sin embargo, a pesar de que la narrativa de Argüello se propuso al calor de la recuperación de Campaña Nacional como lugar de memoria, no se consolidó.

Manuel Argüello Mora, Juan Rafael Mora Porras, Literatura costarricense, Ficciones de memoria, Campaña Nacional

\section{RÉSUMÉ/MotS-CLÉS}

L'auteur costaricien de la fin du XIX ${ }^{\mathrm{e}}$ siècle, Manuel Argüello Mora met en scène les derniers jours de Juan Rafael Mora Porras, le président et leader de la campagne contre le flibustier William Walker (1856-1857), en trois textes littéraires publiés en 1899 . Se concentrer sur son exécution permet d'ériger en symbole la mort de Mora comme un sacrifice fondateur pour un peuple loyal, avide de réconciliation. Cependant, malgré le fait d'avoir été formulée au moment de la récupération de la «Campaña Nacional » comme lieu de mémoire, cette oeuvre n'as pas eu de succès.

Manuel Argüello Mora, Juan Rafael Mora Porras, Littérature costaricienne, Fictions de mémoire, Campaña Nacional

\section{ABSTRACT/KeYWORDS}

The fin-de-siècle Costa Rican author Manuel Argüello Mora depicts the last days of Juan Rafael Mora Porras, president and leader of the 1856-1857 Campaña Nacional against filibuster William Walker in three literary works published in 1899. In them, Mora's death by firing squad is portrayed as a foundational sacrifice that brings national reconciliation to a loyal population. Nevertheless, although Argüello's narrative was proposed at the time when the recuperation of the Campaña Nacional as a site of memory was at its height, it was not successful.

Manuel Argüello Mora, Juan Rafael Mora Porras, Costa Rican literature, Fictions of memory, Campaña Nacional 


\section{Comptes rendus}



Bernard Lavallé, Pacifique : à la croisée des empires : XVI -XIX siècle, Paris, Éditions Vendémiaire, 2018, 353 p.

Bernard Lavallé - membre du comité de rédaction de la revue Caravelle - continue son travail de passeur : depuis des années les étudiants d'histoire et de civilisation hispanique compulsent son manuel maintes fois réédité L'Amérique espagnole : de Colomb à Bolivar (Belin, 1993); aussi le lectorat français (tant spécialiste qu'éclairé) profite de ses précieuses synthèses sur les Eldorados d'Amérique: mythes, mirage et réalités (Payot, 2011) et d'Une histoire de l'évangélisation en Amérique espagnole, $X V I^{e}-X V I I T^{e}$ siècle (Payot, 2014). Avec son nouveau livre, Bernard Lavallé s'attaque à l'histoire d'un espace peu connu, le Pacifique, comparé à l'Atlantique et l'Amérique. Certes l'historiographie française est pionnière dans ce domaine avec les travaux de Pierre Chaunu (amplement cité par B. Lavallé), et des publications récentes (les livres de Clotilde Jacquelard, voir Caravelle, $\mathrm{n}^{\circ}$ 104, p. 211-213, et de Romain Bertrand, voir Caravelle, $\mathrm{n}^{\circ} 108$, p. 173-176) qui ont pointé les projecteurs sur les Philippines espagnoles. Toutefois, le Pacifique attendait un auteur capable de donner à lire une synthèse historique reposant sur la meilleure et la plus actuelle bibliographie. Bernad Lavallé, disposant d'une connaissance encyclopédique de l'Amérique espagnole - qui plus est spécialiste de la région andine, donc du Pacifique sud-est -, était l'historien idoine pour mener à bien cette entreprise. Néanmoins, l'ampleur du sujet appelait à faire des choix qui se sont portés sur les échanges commerciaux et la géopolitique comme thématiques privilégiées par l'auteur. Aussi le point de vue est-il surtout hispanique. De plus, une grande partie du livre porte sur le Pacifique de la première mondialisation, au XVI siècle, au temps des «découvertes» européennes de l'Amérique et de l'Asie du Sud-Est à la recherche d'or et d'épices, puis la mise en place d'un pouvoir et d'un commerce européen dans la région.

L'ouvrage permet ainsi de "décentrer le regard " d'une histoire atlantique devenue monumentale et de renouveler les questions sur la dimension planétaire des empires ibériques, la colonisation, la navigation, l'économie, l'expansion européenne avec les rivalités entre puissances.

L'océan Pacifique, pour reprendre la formule de Chaunu, ce sont quinze Méditerranées ou trois Atlantiques : un immense espace maritime qui finit par connecter deux continents qui s'ignoraient jusque-là, l'Amérique et l'Asie. Ses littoraux sont explorés par les Européens à partir de 1512 quand les Portugais arrivent sur sa façade occidentale, aux Moluques - les fameuses îles aux Épices. Parallèlement, en 1513, 
le conquistador Vasco Nuñez de Balboa traverse l'isthme de Panama, contemple la " Mer du Sud » dont il prend possession au nom de la Couronne espagnole. Les multiples entreprises hispaniques pour atteindre les Moluques en traversant le Pacifique échouent (la plus célèbre est celle menée par Magellan), jusqu'en 1565 : année durant laquelle fray Andrés de Urdaneta réussit pour la première fois la traversée d'ouest en est - des Philippines aux côtés mexicaines - du Pacifique. Dès lors, la connexion des quatre parties du monde est accomplie et change pour toujours le visage de l'économie mondiale : l'argent américain est échangé contre des produits chinois et sud asiatiques vendus en Amérique et en Espagne, via le fameux "Galion de Manille ». C'est d'abord cette question économique - centrée sur le monde hispanique - qui a longtemps retenu l'attention des historiens : le Manila Galleon (Manille, 1939) de William L. Schurz, la thèse complémentaire de Pierre Chaunu déjà citée, Les Philippines et le Pacifique des Ibériques (Paris, 2 vol., 1960-1966) et le Spanish Lake (Canberra, 1979) d'Oskar Spate, jusqu'aux travaux plus récents de Carmen Yuste et Mariano Bonialian ou les recherches sur la fiscalité et du "situado" de Luís Alonso. Le corollaire de cette histoire du galion se trouve dans le thème de la navigation étudié par Gabriela Pinzón ou Thomas Calvo; ou l'histoire des sciences portée par Salvador Abreu par exemple. L'autre volet important de la recherche sur le Pacifique s'est naturellement focalisé sur la colonisation espagnole des Philippines : pionnier en la matière en France, Xavier Huetz de Lemps (spécialiste du XIX siècle), suivi par Clotilde Jacquelard et JeanNoël Sanchez; au Mexique, les travaux de Paulina Machuca portent sur les échanges de plantes comme le palmier de coco. Cette liste est loin d'être exhaustive, elle vise simplement à montrer l'ancrage, le dynamisme et la dimension internationale de l'historiographie sur le Pacifique dans laquelle Bernard Lavallé a pu puiser pour sa synthèse.

Au fil des siècles de l'ère moderne, le Pacifique devient un (autre) terrain de rivalités européennes, une aire d'échanges et de transferts à la «croisée des empires " soumis à l'immensité des distances, à l'imprévisibilité des ruptures de communications; c'est aussi un espace de contacts inédits et nouveaux entre des peuples qui s'ignorent jusque lors. L'impact de l'ouverture d'un commerce transpacifique à partir des années 1570 fut considérable tant en Asie, où l'argent américain a probablement joué un rôle important dans l'économie monétaire et la politique chinoise, jusqu'à la diffusion de produits asiatiques dans tout le continent américain.

Le livre est divisé en douze chapitres. Les cinq premiers reviennent précisément sur les moments fondateurs d'un Pacifique espagnol : 1513, Nuñez de Balboa traverse l'isthme de Panama ; 1519-1522, la circumnavigation de Magellan-Elcano; 1530-1530, les tentatives de Cortes d'ouvrir une voie vers l'Asie; fin Xvi siècle, les expéditions de Mendaña et Quiros en Océanie; à partir de 1565, la conquête des Philippines par Legazpi. Les trois chapitres suivants traitent des espaces commerciaux constitués par le Galion de Manille et les échanges interaméricains via le Pacifique oriental, ainsi que des appétits que suscitent les nouvelles richesses chez 
les rivaux européens, Hollandais, Anglais et Français. Les quatre derniers chapitres portent sur les XVIII ${ }^{\mathrm{e}}$ et $\mathrm{XIX}^{\mathrm{e}}$ siècles, les reconfigurations commerciales opérées par la politique des Bourbons et la fin de l'hégémonie hispanique, l'autonomisation progressive du commerce américain, jusqu'aux indépendances américaines du début

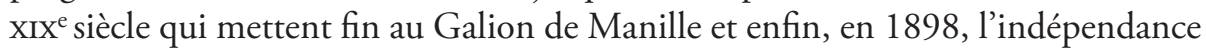
des Philippines.

En dernière analyse, la synthèse de Bernard Lavallé permet de comprendre que le Pacifique est surtout un vaste espace vide (le plus vaste de notre planète). Les îles du Pacifique sont longtemps méconnues des Européens ou bien constituent seulement des étapes dans la navigation (les îles Mariannes), puis viennent les expéditions scientifiques du XviII ${ }^{\mathrm{e}}$ siècle (Bougainville, Cook, Malaspina), et enfin la colonisation du XIx ${ }^{e}$ siècle (le protectorat français sur Tahiti date de 1843). Ainsi, l'histoire du Pacifique de B. Lavallé est davantage l'histoire des deux façades océaniques plus que de l'océan, lequel était franchi une fois l'an (dans le meilleur des cas) par un fragile fil de communication que constituait le Galion de Manille.

Guillaume Gaudin Université Toulouse 2 - Jean Jaurès

Juan Marchena Fernández, Justo Cuño Bonito (ed.), Vientos de Guerra, apogeo y crisis de la Real Armada (1750-1823), Aranjuez, Ediciones Doce Calles-Junta de Andalucía-Universidad Pablo de Olavide, 2018, 3 vol., 683 p., 933 p. 529 p.

Ces trois volumes d'un total de quelque 2150 pages et produits des contributions d'une douzaine de collaborateurs venus d'horizons très divers, constituent un ensemble désormais fondamental pour la connaissance de la marine espagnole à une période cruciale de son histoire, c'est-à-dire du milieu du XviII siècle à la fin des indépendances américaines : sa renaissance du fait de la politique bourbonienne, son essor et sa place retrouvée dans un concert international fait de rivalités impériales plus vives que jamais, puis sa crise finale avec les guerres de la Révolution française, de l'Empire et celles des Indépendances.

Le premier, Política, ciencia, ingeniería y hacienda, réunit six études qui s'ouvrent sur une étude très fouillée de la politique navale espagnole de l'époque replacée dans le cadre général des voies nouvelles suivies par la nouvelle dynastie (Allan Kuethe). La suivante, sous la plume de María Baudot Monroy s'attache plus particulièrement à cette question à l'époque de Julián Arriaga au milieu du siècle (1754-1759). Les contributions suivantes situent cet effort spectaculaire de la Couronne dans le contexte de ce siècle, du point de vue de ses retombées (et de ses implications) multiples, que ce soit sur la formation des officiers de marine, le développement et les innovations scientifiques des Lumières (Marta García Garralón), compte tenu aussi de la politique fiscale alors suivie et des moyens dont elle disposait (Rafael Torres Sánchez), sans oublier la gestion économique complexe d'un ensemble aussi lourd que la flotte et ses nombreuses installations à terre (José Manuel Serrano 
Álvarez) et la grande question de la construction navale précisément étudiée tout au long de la période 1750 à 1820 (Francisco Fernández González).

Le tout second volume (Los buques de la Real Armada, 1700-1825) de plus de 900 pages est tout entier dû aux recherches et à la plume de Juan Marchena Fernández. Ce gros travail, à la fois énorme somme de connaissances et source d'abondantes informations nouvelles, se fonde d'abord sur les navires comme unités d'étude. Il montre comment au cours de la première moitié du XviII ${ }^{\mathrm{e}}$ siècle on est passé en Espagne des "reliques " d'une époque antérieure et dépassée dont avait hérité le nouveau roi Philippe $V$, à un nouveau type de navires en fonction des changements intervenus dans la construction navale européenne (apparition des bateaux de ligne en Hollande et en Angleterre) et par conséquent dans les impératifs et les conditions des batailles navales auxquelles les nouveaux navires pourraient se voir impliqués.

La partie suivante de l'étude s'attache à présenter cette nouvelle Armada au cours de la seconde moitié du siècle, lorsque tant du côté français qu'anglais se démontre l'importance du pouvoir maritime et du contrôle de la mer dans les luttes impériales qui opposent alors les puissances impériales.

Le livre se conclut sur une étude très fine et poussée des conséquences, directes ou induites, de la stratégie navale de l'époque et, dans ce nouveau contexte, de l'examen d'une question centrale, celle de l'opérativité de la flotte espagnole du temps. Ce dernier point est l'objet d'une très longue analyse articulée autour des diverses phases de la question : 1749-1761, l'époque de la paix armée; 1762-1775, les débuts du règne de Charles III après la prise de La Havane par les Anglais; 1776-1783, une époque de guerre déclarée contre les autres puissances européennes; 1784-1795, avec l'application des nouvelles mesures stratégiques mises en œuvre à l'époque d'Antonio Valdés; 1796-1807, les années d'alliance avec la France révolutionnaire puis impériale, marquées par de très grosses pertes ( 83 navires en onze ans); enfin 1808-1825, étape qui fut pratiquement celle de la fin de la Real Armada, puisqu’à son terme celle-ci ne comptait pas plus de onze unités, six navires et cinq frégates.

Il faut préciser que ces explications, toujours resituées dans leur contexte de politique générale de l'Espagne, sont accompagnées de nombreuses cartes (une trentaine), de répertoires détaillés (avec lieu de construction, équipages et armement, lieu d'exercice et naufrage, etc.) de 420 bâtiments entrés en service entre 1700 et 1825 , de près d'une centaine de tableaux et de graphiques, enfin d'une bibliographie de plus de 85 pages...

Le troisième et dernier volume est consacré lui à l'étude des principaux arsenaux qui connurent tout au long de cette période des moments d'activité plus ou moins brillants et des phases de déclin plus ou moins accentuées : El Ferrol (1750-1820) (José Manuel Vázquez Lijó), Cartagena (1750-1824) (Juan José Sánchez Baena et Cristina Roda Alcantud), La Carraca dans la baie de Cadix (José Quintero González) et, en Amérique, celui de La Havane (José Manuel Serrano Álvarez). Le livre offre ensuite un panorama de la marine de guerre espagnole dans une région qu'il ne 
faut pas oublier dans le développement de la politique espagnole de cette époque, le Pacifique (1739-1808) (Sabrina Guerra Moscoso) où, là aussi, la crise finit par arriver après des années d'un essor remarquable.

Le livre se termine sur une longue étude très intéressante, illustrative et détaillée de Justo Cuño Bonito, sur la vie à bord, le sort des équipages sur ces bâtiments, finalement très incommodes pour les hommes du rang au cours de périodes en mer interminables entrecoupées de combats aux résultats souvent incertains.

Ces trois volumes constituent une somme désormais incontournable sur l'histoire de la marine espagnole, mais aussi sur les évolutions et les avatars de la politique étrangère, européenne et américaine, de Madrid au cours de la seconde moitié du XVIII ${ }^{\mathrm{e}}$ siècle et durant les trois premières décennies du suivant, en liaison avec l'ensemble des autres facteurs qui orientèrent de façon volontariste l'évolution de l'Espagne, ou pesèrent sur elle à son corps défendant, au cours de décennies qui virent la Péninsule retrouver une partie de son lustre d'antan, avant d'être dépassée par un contexte international qui eut sur son avenir des effets négatifs et pour certains longtemps délétères.

Bernard LAvallé

Jean-Pierre Tardieu, El Negro Guillermo, Venezuela (1769-1771), Sevilla, Ediciones Alfar, 2018, 94 p.

Les éditions Alfar de Séville publient le dernier volet d'une trilogie que JeanPierre Tardieu, professeur émérite de l'Université de la Réunion, consacre aux esclaves Marrons dans la Capitainerie du Venezuela. Le marronnage était déjà le sujet de Resistencia de los negros en la Venezuela colonial. Representaciones y planteamientos semiológicos (Frankfurt/Madrid, ed. Iberoamericana/Vervuet, 2013) et de Andresote. Le dessein d'un esclave rebelle. Venezuela (1730-1733), (Paris, éd Indes Savantes, 2015).

Entre 1769 et 1771 le Negro Guillermo se soulève dans l'actuelle région de Miranda et devient le chef de la communauté d'Ocoyta. Aux Archives Nationales de Caracas sont conservés les "Autos criminales seguidos de oficio de justicia contra el Moreno Guillermo y sus secuaces, todos esclavos fugitivos, sobre estar levantados en un cumbe en los Montes de Ocoyta, jurisdicion de Panaquire, haciendo muertes, rovos y otros excesos", corpus exceptionnel, souligne l'auteur, car les autorités coloniales usaient peu de la possibilité que leur octroyaient les Lois des Indes d'instruire un procès contre ces insurgés.

Jean-Pierre Tardieu propose une analyse sémiotique de ces documents juridiques rares, présentés de façon linéaire tout au long des cinq chapitres de l'ouvrage, en la plaçant sous le signe du désormais classique linguistic turn de Hayden White. Son objectif est de montrer l'évolution de la stratégie discursive de la société esclavagiste vénézuélienne de la fin du XviII ${ }^{\mathrm{e}}$ siècle, face au phénomène déstabilisateur du marronnage. Il s'agit, de ce fait, d'une étude qui sépare la réalité des événements, 
que la justice coloniale reproche au fugitif, des textes qui la consignent. Cette prévalence de l'analyse rhétorique et métahistorique fait passer au second plan le côté exceptionnel de l'archive.

Carla Fernandes

Université Bordeaux Montaigne

Catherine LaCaze, Francisco Morazán. Le Bolivar de l'Amérique Centrale?, Rennes, Presses Universitaires de Rennes, Institut des Amériques, 2018.

Avec cette nouvelle publication de la collection "Des Amériques ", on ne peut que se réjouir du soutien qu'apporte l'IDA à la rapide publication de bonnes thèses; en l'occurrence, celle-ci reçut le prix Alfred Dumézil en 2017. L'ouvrage de Catherine Lacaze présente deux caractères exceptionnels. Le premier est d'offrir une histoire issue d'une recherche dans cinq pays d'Amérique Centrale et en Espagne - plus approfondie dans certains cas en fonction de la disponibilité des sources - loin des histoires nationales auxquelles nous sommes habitués, aboutissant à une histoire croisée où les interprétations de l'histoire se répondent et se concurrencent pour donner corps et légitimité aux projets politiques régionaux. Le second consiste dans le choix délibéré de reconstruire une histoire post-mortem d'une figure politique centrale de la fabrication de cette région du XIx ${ }^{\mathrm{e}}$ siècle, sans chercher à resituer cette construction discursive dans une "vérité historique ", mais en se focalisant sur ce que cette histoire nous enseigne le mieux : non pas la trajectoire de Morazán, mais ce que celle-ci dit des intérêts et convictions de ceux qui en ont été les auteurs.

Comme le souligne le sous-titre du livre par la comparaison de Morazán au Libertador Simón Bolívar, le cœur de la recherche est constitué par les tensions entre les projets politiques antagonistes d'une confédération d'Amérique Centrale - rappelons au passage que Morazán a dirigé la République fédérale d'Amérique centrale de 1830 à 1839 - et l'éclatement de l'ancien Royaume du Guatemala en plusieurs États, avec le résultat que l'on sait. Cette question n'est pas nouvelle dans l'historiographie latino-américaine et a été posée de bien des façons. Si l'on prend le cas du Brésil, elle a été soulevée par Richard Graham qui y voyait le processus inverse : un vaste territoire conquis par des militaires, comme un agrégat de capitaineries et qui avait toutes les chances d'exploser en une multitude d'États. L'historien entreprit de résoudre cette énigme en analysant les réseaux des députés, juges et autres potentats locaux et leurs liens avec le centre, créant une toile au tissage serré dans laquelle l'interpénétration des intérêts donnait aux institutions fédérales la force d'une construction sociale solide. Catherine Lacaze a, elle, opté pour une approche culturelle du politique à partir de l'instrumentalisation complexe de l'histoire, dans laquelle plusieurs pays et partis politiques se disputent le monopole du discours dans le processus d'héroïsation de Francisco Morazán. Ces deux aspects - national et partisan - permet à l'auteur de poursuivre sans heurt son analyse, y compris lorsque l'enjeu fédéral disparaît au profit des enjeux nationaux. 
À travers les trois étapes identifiées et qui structurent les trois parties du livre, c'est à ce glissement depuis le héros centraméricain au héros libéral qu'on assiste sur une période qui s'étend sur plus d'une centaine d'années.

Trois périodes ont été sélectionnées par C. Lacaze au cours desquelles la figure héroïque de Morazán a été fabriquée, modifiée et adaptée aux nouveaux enjeux régionaux et nationaux en fonction d'événements qui ont donné lieu à des commémorations, elles-mêmes largement rapportées par les journaux consultés. La première de ces périodes est constituée par la fin de vie, la mort et la construction de l'image de Morazán par ceux qui l'ont connu; puis la période libérale avant et autour de la célébration du centenaire de sa naissance et les 400 ans de la découverte de l'Amérique ; enfin une partie qui s'étend du centenaire de l'indépendance à celui de la mort de Morazán, années au cours desquelles l'image du caudillo a été largement mobilisée afin de donner une légitimité au militarisme ambiant. Ce faisant, l'auteur analyse les modes d'articulation variables entre plusieurs identités en fonction des configurations politiques et des relations de pouvoir non moins changeantes : citons d'abord l'identité centraméricaine et les nationales évidemment, mais aussi les partisanes, les civiques avec une réflexion sur la place de l'armée dans la nation, et enfin religieuses avec un Morazán brandi comme une icône de l'anticléricalisme, ce qui n'empêcha pas le Te Deum de résonner en son honneur. Loin d'être une liste exhaustive des enjeux mobilisés autour de Morazán, il faut encore citer les relations internationales puisque les hiérarchies entre les pays d'Amérique Centrale (surtout la compétition entre le Guatemala et le Salvador) ont concouru à structurer et orienter le discours officiel sur le personnage. À la fin de la période, en pleine seconde guerre mondiale, ce sont les relations avec les États-Unis qui ont également joué un rôle dans ces histoires officielles. Mais reprenons plus en détail ces constructions car l'ouvrage permet de restituer une géographie surprenante de la construction de l'image du héros. La surprise vient surtout du Honduras, berceau du caudillo dont on aurait pu s'attendre à ce qu'il s'empare plus fermement de ce personnage pour l'insérer dans son histoire nationale. Or, ce n'est que tardivement qu'il s'y emploie en omettant sa dimension unioniste. Mais ce sont le Salvador et le Guatemala qui se disputaient le leadership de l'Amérique centrale et, pour le second, dominé d'abord par les conservateurs, Morazán le libéral faisait figure de repoussoir, avant que le changement du rapport de force au sein du pays ne permette sa récupération au sein d'un groupe de héros libéraux. Le Costa Rica, pays où Morazán a été exécuté, est bien plus gêné par cet héritage embarrassant.

Si certains aspects de cette longue histoire ne sont pas l'objet d'une analyse assez poussée - parfois par manque de sources - et laisse le lecteur sans réponse (c'est le cas par exemple sur la participation de Morazán lui-même à la création de sa légende avec son imitation des 100 jours de Napoléon, ou l'attitude du Costa Rica qui veut une exécution rapide, mais lui laisse le temps de rédiger un testament politique, texte essentiel puisqu'il permet d'établir un lien fondateur entre Morazán et sa postérité), le difficile sujet de l'appropriation par les masses d'une 
figure créée par les élites politiques en destination d'un public urbain est particulièrement bien traité. Ce processus est resitué dans son contexte mondial des deux grandes révolutions du début du $\mathrm{xx}^{\mathrm{e}}$ siècle, la mexicaine et la russe, puis sous la montée de dictatures populistes. Alors que Morazán avait, au cours du XIX ${ }^{e}$ siècle été un personnage clivant qui permettait aux libéraux d'afficher leur anticléricalisme, son image devient de plus en plus lisse à mesure que l'on essaie de convaincre des secteurs amples et disparates de la population dans une idéologie défendant l'idée d'une union nationale, à cent lieues de l'unionisme centraméricain porté par le personnage. Catherine Lacaze montre ainsi, avec une efficacité incisive, les logiques des histoires officielles où les enjeux nationaux prennent le pas sur les enjeux régionaux centraméricains relégués au rang d'histoire révolue. Ce faisant, le parallèle avec Simón Bolívar n'en semble que plus justifié : comme le Libertador, Morazán a été tour à tour symbole d'union, de militarisme, d'appropriation partisane puis nationale. De ce fait, l'ouvrage de C. Lacaze comble un vide historiographique que les histoires nationales étaient, par nature, incapables d'appréhender.

Evelyne SANCHEZ CNRS-FRAMESPA

Leticia Mayer Celis, Un crimen en Durango en el siglo XIX. Doña Nepomucena Alcalde y el terrible asesinato de su marido, México, El Colegio de México, Serie: Historia-Investigación, 2018, 132 p.

Il y a 35 ans, Nathalie Zemon Davis publiait son Retour de Martin Guerre, une microanalyse devenue un classique et rendue possible grâce à une source peu commune. En effet, l'affaire étudiée relevait de la justice, mais la disparition des documents du procès empêchait une étude directe. C'est alors le caractère exceptionnel des événements survenus dans le village d'Artigat qui en avait maintenu la mémoire, notamment grâce au récit des événements produit par le juge qui en instruisit l'affaire. Avec le crime dont Nepomucena Alcalde fut accusée dans les années 1830, il y aurait eu matière à construire une microhistoire où la relation entre justice et opinion publique se trouvait incarnée dans des acteurs heureusement bavards. C'est donc avec déception que l'on ne découvre dans ce petit livre guère plus qu'un récit des faits, tous tirés d'une source unique - la plaidoirie que l'avocat de l'accusée publia lors du procès en appel dans l'espoir de retourner l'opinion publique en faveur de sa cliente - sans qu'à aucun moment ne soit même mentionnée la possibilité de consulter les sources des deux procès (en première instance et en appel). Plutôt que partir du procès, Leticia Mayer Celis a en effet consacré les deux premières parties de son ouvrage au récit très personnel de son processus de recherche, expliquant notamment l'histoire du fonds dont la plaidoirie a été extraite, soit la bibliothèque privée de l'avocat José Fernando Ramírez, qui se trouve, après maintes péripéties, à Londres. L'auteur part ensuite du travail statistique réalisé par Ramírez pour consacrer la deuxième partie de son livre à ce thème, 
qui fut par ailleurs celui de sa thèse. On peut y regretter le manque de distance par rapport aux sources. Ainsi, elle confond le nombre de prisonniers avec le taux de criminalité, comme si chaque crime était dénoncé et que chaque dénonciation débouchait sur une arrestation. Néanmoins, ces relevés statistiques permettent de situer le caractère exceptionnel du procès intenté contre Nepomucena Alcalde; en effet peu de procès pour meurtre étaient menés contre des femmes et aucun autre ne met en scène une femme de l'élite locale.

La description que fait Ramírez des circonstances du crime conforte l'historien dans la conviction que les sources judiciaires constituent le principal instrument de connaissance de la vie quotidienne. L'avocat décrit ainsi la vie d'un couple constitué d'une jeune femme issue d'une des principales familles de Durango et d'un homme plus âgé et qui se situe un peu plus bas dans la hiérarchie sociale, les tensions existantes dans la maison, notamment entre l'épouse et sa belle-mère, le mépris affiché par les deux époux vis-à-vis de leurs serviteurs. À cela s'ajoutent encore les différentes médiations tentées lors de conflits antérieurs dans le couple et l'échec de chacune d'elle. Au cours de cette lecture, on ne peut que regretter qu'aucune autre source (pas même bibliographique qui aurait pu aider à situer la famille Alcalde dans la société de Durango) n'ait été utilisée pour contextualiser ce qui n'est finalement que la version d'un avocat publiée dans l'espoir de faire acquitter sa cliente.

Mais cette source a une autre valeur car la plaidoirie de Ramírez est devenue une référence en matière juridique. L. Mayer précise ainsi que «Este caso fue tan famoso que la defensa de Ramírez se reeditó en El Ateneo Mexicano, lo cual sucedió en el primer volumen, en seis entregas diferentes. También mereció que el jurista español Marcos Gutiérrez lo reprodujera en su conocido libro Práctica criminal forense, en la edición mexicana de 1850 » (p. 67). À travers l'argumentation de l'avocat, c'est l'évolution du concept de preuve qui est au cœur de cette affaire. Les témoignages, autrefois au centre des procédures criminelles, n'ont plus qu'un poids relatif et ne peuvent plus prétendre - selon Ramírez - compenser l'absence de preuves physiques. On comprend ainsi son choix de rendre publics ses arguments : selon lui, l'opinion condamnait sa cliente alors qu'elle ne s'appuyait que sur des témoignages qui n'étaient pour lui rien d'autre que l'expression d'opinions malveillantes. Il est dommage que l'auteur n'ait pas remarqué que pour en arriver à ces conclusions, l'avocat avait ignoré bon nombre de preuves physiques accablantes pour discréditer les témoignages. Le double discours de l'avocat sur l'opinion aurait aussi mérité d'être souligné : d'un côté, il se gaussait de la vox populi, lui opposant un droit modernisé et objectif, d'un autre côté il s'adressait à cette même opinion dans l'espoir qu'elle ferait plier le tribunal en faveur de sa cliente, ce qui n'est pas sans rappeler les stratégies d'avocats médiatiques plus actuels.

Cependant, si l'on ignore si la démonstration fut efficace dans le procès de Nepomucena (puisqu'il n'a pas été consulté, nous en ignorons l'issue), il s'agit assurément d'un moment clef de l'évolution des procédures et qui mériterait une 
étude bien plus approfondie. On s'étonne en effet de constater le peu de poids des témoignages dans les affaires pénales du début du $\mathrm{Xx}^{\mathrm{e}}$ siècle. Même le témoignage que des victimes pouvaient présenter avant de succomber était dédaigné s'il n'était pas confirmé par des preuves matérielles, favorisant une impunité grandissante. Faire disparaître le témoignage de la liste des preuves crédibles alors même que la justice n'était pas à même d'en présenter d'autres (les rapports des légistes jusqu'au début du $\mathrm{XX}^{\mathrm{e}}$ siècle ne servaient à rien d'autre que remplir une formalité administrative) ne pouvait en effet aboutir à rien d'autre. En cela, l'affaire présentée ici permet une incursion dans ce qui est présenté par l'avocat comme la modernisation nécessaire de la justice et qui se manifeste alors comme le détricotage d'une procédure héritée, mais en l'absence d'instruments efficaces de remplacement.

On ne peut qu'espérer que ce petit livre aura un effet positif : celui d'encourager une véritable microanalyse de cette affaire à partir de sources plus complètes et de l'élaboration d'un questionnement qui permette de dépasser le côté anecdotique du procès.

Evelyne SANChEz CNRS-FRAMESPA

Pilar Cagiao Vila (ed.), Donde la politica no alcanza. El reto de diplomáticos, cónsules y agentes culturales en la renovación de las relaciones entre España y América, 18801939, Madrid, Iberoamericana Vervuert, 2018, 285 p.

Au croisement de l'histoire des relations diplomatiques, des relations culturelles et des migrations internationales, tous thèmes récurrents de l'historiographie américaniste y compris et depuis la commémoration du $\mathrm{V}^{\mathrm{e}}$ Centenaire, cet ouvrage se propose d'aborder l'action des diplomates, consuls et " agents culturels " du monde espagnol et américain, là où, parfois, le cadre politique n'est pas toujours opérant en termes de définitions. L'échelle des individus importe ici autant que l'insertion des personnages identifiés dans des " circuits " reliant les républiques ibéro-américaines et l'Espagne, et vice-versa. L'ouvrage se propose par conséquent de considérer des liens qui ne sont pas à strictement parler bilatéraux mais plutôt transnationaux, transcendant par là-même les trajectoires individuelles de diplomates ou d' " agents culturels ", eux-mêmes intégrés dans des pactes et alliances diverses et plus ou moins formelles. L'hypothèse majeure de cette "monographie collective " issue d'un programme de recherche, réside dans le fait que ces «trajectoires biographiques» et les expériences qui en découlent, influent de manière décisive sur les comportements publics et privés du point de vue politique, social, économique et culturel. Cette approche permet dès lors d'identifier des réseaux dans toute leur complexité sociale. Elle permet également de déceler les motivations qui président à leur projection dans la sphère publique et au-delà, ainsi que la distance établie par rapport à des politiques officielles. En d'autres termes, ce sont non seulement les liens sociaux et politiques inhérents aux professions et charges exercées mais 
aussi les liens personnels et familiaux qui retiennent ici l'attention. L'introduction s'interroge à cet égard sur le rôle des tertulias, associations, institutions et manifestations scientifiques et culturelles, voire les maisons d'édition et la presse, en tant que points de départ d'actions à caractère collectif entre l'Amérique et l'Espagne, qui s'inscrivent indéniablement dans le cadre d'une histoire des idées confrontée alors à la montée des courants nationalistes, des théories de la "régénération » ou promouvant un américanisme diffus.

Les cas singuliers qui inspirent cet ouvrage remettent certes en question la centralité des politiques officielles, malgré la profusion de traités bilatéraux signés pendant la période considérée. Mais les "périphéries " examinées ici, en termes de lieux, d'activités ou de réseaux, semblent en fait les prolonger, les compléter ou les renouveler dans une perspective incontestablement "transnationale ". Tel est le cas, jusqu'alors peu abordé par l'historiographie américaniste, de l'Espagnol Matías Alonso Criado, philosophe et juriste docteur de l'université de Valladolid, «chronique vivante d'Amérique» et la personne la plus au fait des questions d'actualité d'après le journal madrilène El Globo. Fondateur du journal La Colonia Española, philanthrope et mécène, Matías Alonso Criado fut conseiller à Montevideo puis consul du Paraguay à Madrid, dans la République orientale d'Uruguay (y représentant également le Chili), sans compter d'autres activités de représentation au profit d'autres pays latino-américains) soit une carrière qui couvre quatre décennies (Pilar Cagiao Vila). La plupart des représentants diplomatiques nommés en Espagne ont ainsi pour particularité de joindre l'aspect culturel aux impératifs diplomatiques, dans une conjoncture qui voit s'affirmer des États nationaux sur la base de modèles politiques d'inspiration libérale et dans un contexte économique favorable, marqué par la croissance des exportations et les investissements étrangers. Ainsi le juriste, journaliste et écrivain mexicain Vicente Riva Palacio, à la fin du XIx ${ }^{e}$ siècle (étudié par A. Sanchez Andrés), s'affirme-t-il comme le grand normalisateur des relations hispano-mexicaines pendant le Porfiriat - alors que s'opère la stabilisation du pays, coïncidant avec la première étape de la Restauration promue par les secteurs conservateurs de la bourgeoisie espagnole -. Il est le maittre d'œuvre de la diffusion d'une image hautement positive du Mexique, à travers la littérature notamment. C'est à lui que l'on doit en grande partie la bonne tenue des relations culturelles entre les deux pays dans le premier tiers $\mathrm{du} \mathrm{xx}^{\mathrm{e}}$ siècle, après plusieurs décennies plutôt tourmentées compte tenu de l'instabilité politique et financière du Mexique, sans compter le souhait de l'Espagne d'y installer un monarque hispano. L'intensification des relations culturelles entre les deux pays est particulièrement marquée dans le domaine de la presse, de nombreux journalistes et intellectuels espagnols gagnant alors le Mexique pour y travailler aussi bien dans des publications d'inspiration libérale que conservatrice, de diffusion nationale ou plus orientées vers la communauté espagnole résidant au Mexique (La Colonia Española, El Siglo XIX, La Iberia, El Búcaro, La Razón de México). À noter que la plupart de ces journalistes furent également écrivains ou éducateurs, d'autres émigrés se signalant également dans le 
domaine de la musique ou du théâtre : après la fondation du Théâtre national du Mexique en 1864 par Maximilien, ce fut le Don Juan Tenorio de Zorrilla qui ouvrit la saison. L'histoire ne fut pas davantage oubliée si l'on considère la publication de la monumentale histoire de México a través de los siglos, que dirigea précisément Vicente Riva Palacio, qui en vint ultérieurement à représenter le gouvernement de Porfirio Díaz en Espagne. Davantage centrés sur des questions "pratiques » que les diplomates de carrière, les consuls se consacrent tout aussi bien à l'image qu'ils se doivent d'offrir de leur pays, qu'il s'agisse du domaine économique ou plus encore commercial, de la promotion culturelle ou de l'attention à leurs ressortissants : au début du xx ${ }^{e}$ siècle, le consulat du Pérou à Barcelone joua ce rôle, s'appuyant sur des écrivains et politiques que l'on peut qualifier précisément d' "hommes de réseaux " (Ascensión Martínez Riaza). En retour, ces intermédiaires ou passeurs d'une diplomatie culturelle avérée présentent une vision non dénuée d'intérêt de leur pays de résidence, qu'il s'agisse de l'Espagne ou de la Catalogne. L'Institut diplomatique et consulaire de Madrid (créé en 1911 et encore peu étudié) exerce par ailleurs une fonction de formation des représentants espagnols destinés à l'Amérique ibérique ou encore au Maroc (Palmira Vélez Jiménez).

Toute une diplomatie parallèle se déploie également aux côtés ou au-delà de la diplomatie formelle : commerçants, dirigeants d'entreprises ou " agents culturels » dans le domaine littéraire, artistique ou de la presse sont extrêmement présents, comme le démontre l'un des derniers travaux de Gabriela Dalla Corte, «Federico Rahola y la revista Mercurio: diplomacia consular iberoamericana entre la Guerra de Cuba y la Primera Guerra Mundial », consacré à cette revue commerciale « ibéro américaine " qui disposait d'une édition illustrée publiée à Madrid et d'une section commerce et transport fonctionnant à Barcelone, et à la Casa de América de Barcelona. Toutes deux furent des initiatives de la bourgeoisie catalane destinées à renforcer les liens économiques et culturels avec l'Amérique, par l'intermédiaire des consuls espagnols en Amérique comme des consuls ibéro américains présents à Barcelone tout particulièrement.

Ces « expériences américanistes » trouvent également un terrain fécond aux ÉtatsUnis, avec le «bureau d'information pro Espagne » (crée en 1925 à l'instigation de la compagnie International Telephone and Telegraph), dont la directrice fut Carolina Marcial Dorado, Espagnole résidant aux États-Unis, un cas exceptionnel de présence féminine dans cette entreprise de valorisation des échanges culturels entre les deux pays mais sur un pied d'égalité et dans une perspective non plus exotique mais résolument moderne en ce qui concerne l'Espagne. Cette projection internationale de l'Espagne détermina en effet la politique culturelle de Primo de Rivera, contribuant à renforcer la collaboration et les réseaux tissés entre les deux pays (étude de Rosario Márquez Macías). La dernière contribution (Manuel Andrés García) porte également sur une autre personnalité du « mouvement hispano américaniste ", le journaliste José María González, extrêmement représentatif du rôle de la presse et du positionnement des intellectuels sur ce point : bien que 
passablement oublié de nos jours, il joua en effet un rôle essentiel dans la promotion des commémorations du 12 octobre.

Certes, Donde la politica no alcanza se présente au premier abord comme un recueil de biographies. Au fil des chapitres, on voit cependant que celles-ci se répondent comme en écho, en vertu de ce fil conducteur qui les parcourt dans la longue durée, celui des trajectoires croisées d'acteurs de la diplomatie et de la culture parfois reconnus, souvent beaucoup plus discrets et en d'autres occasions tombés dans l'oubli. L'intérêt de ces biographies est par ailleurs de mettre en évidence le déploiement des trajectoires individuelles à différentes échelles, et de faire se répondre problématiques locales et internationales entre deux continents, les influences comme les effets en retour. L'étude de ces «connexions bilatérales et transnationales» telles que les évoque Pilar Cagiao Vila offre par conséquent une approche plus précise et nuancée des relations entre l'Espagne et ses anciens territoires d'Amérique que ne pourraient le proposer des synthèses plus globales. En ce sens, on ne peut qu'espérer qu'une approche plus systématique de ces réseaux et le choix d'une démarche prosopographique à l'endroit de ces " passeurs » dans l'ordre diplomatique et culturel, deux orientations pour lesquelles l'historiographie américaniste peut se valoir de travaux d'envergure et de discussions épistémologiques non moins fructueuses, vienne compléter et enrichir encore davantage ce passionnant projet à long terme.

Frédérique LANGUE CNRS-IHTP

Marina Franco, El final del silencio. Dictadura, sociedad y derechos humanos en la transición (Argentina, 1979-1983), Buenos Aires, FCE, 2018, 411 p.

Auteure de nombreux travaux consacrés à l'histoire récente du Cône sud et tout particulièrement de Un enemigo para la nación. Orden interno, violencia y subversión 1973-1976 (également publié au FCE en 2012), Marina Franco ne se contente pas avec ce nouvel ouvrage de débroussailler un champ de recherche sujet à maints débats car centré sur un passé récent, qui ne " passe pas " toujours. Elle poursuit ici une réflexion sur les conditions de la sortie de dictature, du retour à la démocratie et du modèle transitionnel adopté dans le cas de l'Argentine, en liaison avec la question persistante des droits humains dont les échos persistent dans le temps présent. Mères de la Place de Mai, bébés volés devenus des adultes recherchant leurs parents, souvent des militants assassinés par la dictature, centres d'emprisonnement et de torture transformés en musées ou mémoriaux, l'histoire du temps présent argentin et plus généralement des dictatures du Cône sud renvoie indéniablement à ce que l'auteur qualifie, sous forme de questionnement ouvert, de "culture des droits humains ». La seule mention des archives utilisées, ainsi du ministère de la Défense et de sa "direction des droits humains " (sic) atteste de l'intérêt porté à ce passé récent, douloureusement inscrit dans les mémoires, 
à ses victimes et à ses formes de justice et de réparation. D'autres images contribuent de fait à ce déplacement de focale. Comme en attestent les véritables «récits mémoriels» que constituent les images, la guerre des Malouines elle-même (1983) passe en effet à un second plan face à la rupture constitutionnelle et politique du 10 décembre 1983. Cette date signe en effet la fin de la dictature, la reconnaissance des luttes pour les droits humains et le triomphe d'Alfonsín. D'autres aspects furent, en revanche, oubliés voire durablement occultés en cette sortie de dictature, que cet ouvrage vise précisément à (re)mettre en lumière.

Afin de dépasser ces images comme cristallisées dans la mémoire, Marina Franco a choisi de centrer son propos sur la répression, en d'autres termes la violence d'État. Entre hasard - la découverte d'une vieille pile de journaux portant sur la période étudiée - et nécessité d'un questionnement quant à la manière dont une société se définit face à une extrême violence d'État, le premier constat est celui d'une permanence des figures de la subversion, autrement dit de menaces implicites pour l'ordre social dès les années 1970 et avant même que ne survienne le coup d'État de 1976. Ce discours n'aurait pas seulement été le fait des Forces armées, mais de l'ensemble de la classe politique et de la société civile : le gouvernement péroniste, les dirigeants d'opposition, les élus, syndicalistes, prélats, chefs d'entreprise, etc. Le contraste avec l'année 1983, celle des images des Mères de la Place de Mai et des manifestations en faveur des victimes et, partant, droits humains, ou encore la publication du Nunca más (1984) et les procès de 1985, est donc flagrant. Sur la base d'un état des lieux historiographiques pour l'ensemble des sciences humaines et sociales, M. Franco en vient à interroger les modalités de cette évolution, afin d'identifier le moment où les droits humains et le thème des disparus ont commencé à s'imposer dans la société argentine, dans l'opinion publique ainsi que dans les discours politiques voire gouvernementaux. Elle souligne à cet égard le consensus qui prévaut à l'endroit de la " transition " qui couvre la période intermédiaire entre la guerre des Malouines et le début de la présidence d'Alfonsín (18 mois en tout, contre sept ans pour la dictature). Il reste que ce consensus n'explique guère le déphasage entre la perception collective d'un ennemi, la demande d'autorité d'un État, et la condamnation ultérieure de la répression à partir de ces années. De même le déterminisme qui préside à l'interprétation de cette période (à l'exception de certaines études publiées sur la question) pose-t-il problème, comme si le retour de l'État de droit, de la justice et de la démocratie découlait en toute logique d'une prise de conscience politique et sociale. L'historiographie de la "transitologie ", particulièrement développée sur le continent latino-américain et plus encore dans les pays du Cône sud, ne l'explique pas davantage.

Cette réflexion d'une historienne recoupe par ailleurs ses souvenirs, non pas tant d'un témoin de ce temps présent que sa jeunesse n'autorisait guère à entrer dans des considérations politiques, mais de l'émotion qui accompagna la chute de la dictature, et de la sensation qu'une période nouvelle commençait. Cet ouvrage intègre par conséquent la nécessité de comprendre ce ressenti émotionnel de 
phénomènes politiques, dans le contexte de la montée en puissance du paradigme des droits humains, de la demande de justice en ce moment charnière. L'ouvrage de M. Franco prolonge en ce sens et remet à la fois en question les travaux de «transitologie » réalisés sur les dernières années de la dictature, en d'autres termes sur la "transition à la démocratie ", ses modèles, qui incluent généralement la première étape du gouvernement d'Alfonsín. Elle souligne à cet égard que l'un des points clé de la discussion fut l'absence de pacte conclu avec les Forces armées, malgré la « concertation " de 1982 et que le thème des disparus et des procès intentés à des responsables des Forces armées fut l'objet de longues négociations avec les partis politiques. De même, une périodisation plus fine de cette période s'avère-t-elle incontournable, non plus en ce qui concerne la transition proprement dite, mais bel et bien le processus de consolidation de la démocratie. Cette démarche conduit notamment à en identifier les indicateurs en terme de limitation de la violence d'État exercée par les militaires. Comment appréhender également des aspects aussi essentiels que l'amnistie ou l'impunité, comment considérer la démocratisation de la société à l'aune d'un processus de transition ? Le propos de l'ouvrage se différencie sans conteste des études de sciences politiques volontiers centrées sur une modélisation institutionnelle, promptes à multiplier les références à un idéal type au détriment des imaginaires et cultures politiques, dont participent cependant les refondations démocratiques.

Ce moment si spécifique de la fin de dictature en appelle dès lors à d'autres concepts, notamment celui de crise, qui autorise la prise en compte d'un certain nombre de "déplacements " propres à cette période complexe du point de vue idéologique, politique et culturel, et pas seulement d'instabilité et de réaccommodements. La Guerre des Malouines (défaite et affaiblissement conséquent du secteur militaire lui-même soumis à des tensions internes) apparaît ainsi comme le point de départ d'une mutation, de la dénonciation morale des violations des droits humains et du terrorisme d'État, dont les conséquences sociales ne sont cependant pas toujours perceptibles. Ce sont en effet les acteurs les plus visibles, issus majoritairement de classes moyennes urbaines et la dimension éthique, occupant le devant de la scène politique et qui se font l'expression des aspirations à un changement culturel fondé sur la démocratie et le retour de l'État de droit. D'où la présence des partis (les syndicats ne sont pas abordés dans cet ouvrage), des médias, de l'Église catholique, de la justice et des organisations de défense des droits humains. La surreprésentation des acquis sociaux à la fin de la dictature en liaison avec la problématique de la démocratie n'est pas sans renvoyer à un autre horizon d'attente : celui de la «transition» et des droits humains comme "promesse de futur". L'un des points de départ, chronologique, de l'ouvrage, est d'ailleurs la visite effectuée par la Commission interaméricaine des droits humains en 1979 (à l'occasion de laquelle la propagande militaire tenta de lier le thème des disparus à celui des «subversifs» de retour), et l'étude se clôt, certes, sur l'auto-amnistie 
militaire et les élections de 1983, mais également sur la création d'un organisme essentiel, la Comisión Nacional sobre la Desaparición de Personas (CONADEP).

Tout au long des différents chapitres, il s'agit par conséquent de problématiser et discuter une tendance à ne voir dans la fin de la dictature qu'un moment, une évolution linéaire, orientée vers le jugement des crimes commis pendant la dictature et la condamnation généralisée des violations des droits humains, en particulier à la fin de la Guerre des Malouines, dans un contexte qui mit à mal la légitimité de la Junte militaire et plus généralement des Forces armées (déroute, crise économique et sociale, échec politique). Comme le montre l'auteure, un deuxième axe de réflexion consiste dès lors à explorer la manière dont le thème de la répression s'est imposé dans l'opinion publique en tant que question éminemment politique à la fin de la dictature (l'« éclosion anti- dictatoriale »), selon quels critères, quelles manifestations et quels canaux (rôle essentiel sur ce point des organisations de défense des droits humains). M. Franco ouvre de fait un questionnement quant à la nature des acteurs politiques et à la réponse apportée par les politiques, peu soucieux de voir se poursuivre la quête des disparus au cours d'une nouvelle période constitutionnelle. L'hypothèse majeure, essentielle pour la compréhension de ce temps présent argentin, consiste à poser l'émergence du thème des droits humains comme conséquence de la perte de légitimité et de l'effondrement du régime militaire et non l'inverse. Troisième aspect de cette analyse, et de l'omniprésence du sujet : la teneur du discours, pas seulement fondée sur la question humanitaire (qui émerge comme facteur d'opposition vers 1981) et la condamnation de crimes imprescriptibles. En d'autres termes, le récit de l'horreur orchestrée par la répression d'État n'a pas conduit systématiquement à des enquêtes ou à l'intervention de la justice. La relation n'est donc pas de cause à effet et la reconnaissance des droits humains procèderait d'un ensemble de forces évolutives et de facteurs complexes qui se sont mis en place à la fin de la dictature.

Cet ouvrage foisonnant comporte par ailleurs une dimension épistémologique essentielle, coïncidant en cela avec d'autres travaux récents comme ceux d'Emilio Crenzel, Daniel Lvovich, Lucrecia Escudera, Claudia Feld, Juan Pablo Boholavsky, Hugo Vezzetti, Silvina Jensen ou Elizabeth Jelín, pour ne citer que quelques auteurs. Il s'agit en effet de penser ce type de récit portant sur "l'histoire récente ", son fondement historiographique, ses sources (ici hémérographiques en grande partie, des témoignages d'acteurs, à travers des publications ou prises de position publiques, les archives militaires récemment ouvertes, à partir de 2013, sur l'Opération Condor et les actes de la Junte, les archives orales conservées par exemple par l'Instituto de Investigaciones Gino Germani, et enfin, des entretiens avec les témoins et survivants) et sa conceptualisation, à partir d'une base commune : le rejet du terrorisme d'État, ce qui conduit à appréhender la "subversion " et la guerre intérieure dite "antisubversive», étudiée dans un ouvrage précédent, non plus comme contenu politique, mais comme la perception sociale d'une époque. L'émergence sur la scène publique du thème de la répression pose donc cette autre 
question de l'historicité des processus sociaux et des conflits de mémoire sur la période considérée, et contribue très fortement à relativiser la thèse des " deux démons " (le terrorisme des extrêmes et la réponse répressive des Forces armées). La " mémoire sociale » dans ses diverses acceptions se trouve donc au centre de cette déconstruction et réélaboration d'un récit sur la violence d'État, celui du « Nunca más ». Justice et mémoire ont en effet valeur de réparation du lien social mis à mal par la dictature, sans pour autant effacer ce passé encore trop présent, encore en partie à élucider, et dont le lecteur, le chercheur, ne peut qu'espérer qu'il donne lieu à une autre étude aussi précise et indispensable d'un passé traumatique, mais également fondateur de nouvelles formes de démocratie, ancrées précisément dans la défense des droits humains.

Frédérique LANGUE CNRS-IHTP

Susana Gertopán, Todo pasó en setiembre, Asunción, Editorial Servilibro, 2019, $267 \mathrm{p}$.

La última obra de la novelista paraguaya Susana Gertopan, Todo pasó en setiembre, se puede ubicar en la corriente de las creaciones de las terceras generaciones latinoamericanas, descendientes de abuelos europeos y recuerda el movimiento vivencial característico de toda transmisión intergeneracional de la migración y del exilio.

Tres épocas, tres territorios, tres generaciones de mujeres dan pie a la serie de encuentros y desencuentros de la memoria y del olvido: "[...] en mi infancia y adolescencia estuve acompañada de mi familia hasta que cada uno tomó rumbos diferentes. La abuela se quedó. Siempre dijo que por ninguna razón volvería a mudarse ni de casa ni de país, y se mantuvo firme en su decisión. Resistió en solitario los avatares de la existencia. Todos nos fuimos; sin embargo, ella permaneció en su lugar sin aguardar regresos hasta el día en que también se marchó, cuando dejó de vivir, y se fue. Yo, después de mucho tiempo, regresé." (p. 14)

Sarah, la abuela judía, llega a Asunción después de haber huido, de la Europa sometida al terror del nazismo; Frede, a la vez nieta de Sarah y madre de la compleja Brenda, es la narradora protagonista femenina y la columna vertebral del relato familiar, en el cual se puede percibir la ausencia de la hija de Sarah y madre de Frede. Tal ausencia le confiere al texto su identidad de testimonio literario de la tercera generación. Regresa Frede al lugar de la infancia, donde la educó la abuela ahora muerta y trata de tejer los hilos separados o perdidos de la tela del pasado. En su centro, encuentra los secretos callados por la abuela, que son también el secreto de la vida que cada mujer de la familia conserva y transmite en su lengua. Susana Gertopan incluye un "Glosario" final con palabras en yiddish, inglés y guaraní paraguayo. Ésta tal vez sea la elección estilística menos acertada pero también la que nos recuerda que la novelística paraguaya nace y crece en un contexto plurilingüe. 
Todo pasó en setiembre es la undécima novela de Susana Gertopan que se hizo acreedora de los títulos siguientes: Barrio Palestina (1998), El nombre prestado (2000), El retorno de Eva (2004), El otro exilio (2007), El equilibrista (2009), El callejón oscuro (2010), El guardián de los recuerdos (2012), El fin de la memoria (2014), El señora Antúnez (2015), Primera pregunta (2017). Precisamente Primera Pregunta es una novela coral concebida en el espacio metaficcional donde se produce el punto de encuentro entre novelista, personajes y lector(a). Es una novela agónica, donde combaten estas tres instancias, cada una luchando por su autonomía, tratando de liberarse de la dependencia de las demás en un vano combate de fantasmas que rondan y de sombras. Y es tal vez la novela más experimental de la autora, quien inauguró su trayectoria novelística con relatos de la memoria familiar judía. De hecho, las dos vertientes de la obra de Susana Gertopan son el pasado familiar y nacional y la forma adecuada para recordarlo y narrarlo: Todo pasó en setiembre las funde magistralmente y marca un hito en la producción de su autora y sin duda de la narrativa femenina paraguaya.

Carla Fernandes Université Bordeaux Montaigne 


\section{Table des matières des comptes rendus}

Bernard Lavallé, Pacifique : à la croisée des empires : XVI -XIXe siècle

(Guillaume GAUdiN)

Juan Marchena Fernández, Justo Cuño Bonito (ed.), Vientos de Guerra, apogeo y crisis de la Real Armada (1750-1823)

(Bernard Lavallé)

Jean-Pierre Tardieu, El Negro Guillermo, Venezuela (1769-1771)

(Carla Fernandes)

Catherine LaCaze, Francisco Morazán. Le Bolivar de l'Amérique Centrale?

(Evelyne SANCHEZ)

Leticia MaYer Celis, Un crimen en Durango en el siglo XIX.

Doña Nepomucena Alcalde y el terrible asesinato de su marido

(Evelyne SANCHEZ)

Pilar Cagiao Vila (ed.), Donde la política no alcanza. El reto de diplomáticos, cónsules y agentes culturales en la renovación de las relaciones entre España y América, 1880-1939

(Frédérique Langue)

Marina Franco, El final del silencio. Dictadura, sociedad y derechos humanos en la transición (Argentina, 1979-1983)

(Frédérique Langue)

Susana Gertopan, Todo pasó en setiembre

(Carla Fernandes) 



\section{Consignes aux auteurs}

Les consignes aux auteurs sont disponibles sur : https://journals.openedition.org/caravelle

Les articles sont à soumettre par mail à : caravelle@univ-tlse2.fr 



\section{Déjà parus}

1- Mélanges, 1963

2- Numéro consacré au Mexique, 1964

3- Le problème des capitales en Amérique latine, 1964

4- Mélanges, 1965

5- Numéro consacré au Brésil, 1965

6- Mélanges, 1966

7- Littérature et Histoire du Pérou (I), 1966

8- Littérature et Histoire du Pérou (II), 1967

9- Mélanges, 1967

10- Numéro consacré à l'Argentine, 1968

11- Mélanges, 1968

12- Numéro consacré au Mexique, 1969

13- Mélanges, 1969

14- Numéro consacré au Paraguay, 1970

15- Numéro consacré au Brésil, 1970

16- Numéro consacré à Cuba, 1971

17- Mélanges, 1971

18- Numéro consacré à Puerto Rico, 1972

19- Mélanges, 1972

20- Numéro consacré au Chili, 1973

21- Mélanges, 1973

22- Numéro consacré au Brésil, 1974

23- Mélanges, 1974

24- Numéro consacré à l'Uruguay, 1975

25- Mélanges, 1975

26- Numéro consacré à la Colombie, 1976

27- Hommage à Paul Mérimée, 1976

28- La terre et les paysans en Amérique latine, 1977

29- Mélanges, 1977

30- Numéro consacré au Brésil, 1978

31- Mélanges, 1978

32- Numéro consacré au Venezuela, 1979

33- Mélanges, 1979

34- Numéro consacré à l'Équateur, 1980

35- Mélanges, 1980

36- Numéro consacré à l'Amérique centrale, 1981

37- Mélanges, 1981

38- Consciences nationales dans le monde ibérique et ibéro-américain, 1982

39- Mélanges, 1982

40- Théâtre en Amérique latine, 1983

41- Mélanges, 1983

42- Littérature et Société en Amérique latine, 1984

43- Mélanges, 1984

44- Numéro consacré à la Bolivie, 1985

45- Mélanges, 1985

46- Contre-cultures, Utopies et Dissidences en A. latine, 1986

47- Mélanges, 1986

48- Musiques populaires et identités en A. latine, 1987

49- Mélanges, 1987

50- 25 ans d'Amérique latine, 1988

51- Mélanges, 1988

52- Mélanges, 1989

53- Mélanges, 1989

54- L'Amérique latine face à la Révolution française, 1990

55- Mélanges, 1990

56- Mélanges, 1991

57- Numéro consacré au Brésil, 1992

58- L'image de l'Amérique latine en France depuis cinq cents ans, 1992

59- Sens et non-sens d'une commémoration : les Amérindiens face au Ve Centenaire, 1993
60- Mélanges, 1993

61- Les cultures du café, 1994

62- L'expression des identités américaines à partir de 1492, 1994

63- 501 ans plus tard: Amérique indienne 1993, 1995

64- Mélanges, 1995

65- Les cultures populaires en Amérique latine, 1996

66- Mélanges, 1996

67-Les élites latino-américaines, 1997

68- Mélanges, 1997

69- Ports d'Amérique latine, 1998

70- Mélanges, 1998

71- Senteurs et saveurs d'Amérique latine, 1999

72- Héros et nation en Amérique latine, 1999

73- La fête en Amérique latine, 2000

74- Mélanges, 2000

75- Nouveaux Brésils fin de siècle, 2001

76/77- Hommage à Georges Baudot, 2001

78- Mélanges, 2002

79- Paysanneries latino-américaines : mythes et réalités, 2002

80- Arts d'Amérique latine : marges et traverses, 2003

81- Mélanges, 2003

82- Mélanges, 2004

83- La France et les cinémas d'Amérique latine, 2004

84- Plèbes urbaines d'Amérique latine, 2005

85- Grandes plantations d'Amérique latine, 2005

86- L'Amérique latine et l'histoire des sensibilités, 2006

87- La ville et le détective en Amérique latine, 2006

88- Chanter le bandit. Ballades et complaintes d'A. latine, 2007

89- Le sport en Amérique latine, 2007

90- Journalisme et littérature en Amérique latine, 2008

91- Migrants d'A. latine. Penser et vivre le retour, 2008

92- Cinémas du réel en Amérique latine (XXIe siècle), 2009

93- Homenaje a Jacques Gilard, 2009

94- Les indépendances en Amérique latine, 2010

95-Mélanges, 2010

96-Les Amazonies : unité et diversité, 2011

97-La Révolution mexicaine et ses représentations, 2011

98- Icônes d'Amérique latine, 2012

99- Le Brésil caipira. Une culture, ses représentations, 2012

100-Regards sur 50 ans de latino-américanisme, 2013

101- Sociabilités d'Amérique latine, 2013

102- Citoyenneté et formes de violence, 2014

103-La Bolivie contemporaine et ses représentations, 2014

104-Amérique latine, mémoires et histoires nationales, 2015

105-Cuba, cultures contemporaines, 2015

106- Constuire l'État, moderniser le pays : Pérou (18211930), 2016

107-Indiens, Noirs et marrons dans le Brésil septentrional: XVII - XIX $X^{e}$ siècle, 2016

108 - Croire aujourd'hui en Amérique latine, 2017

109 - Canne à sucre en Caraïbe - Héritages et recompositions, 2017

110 - Bêtes et Plantes en Amérique Latine. Savoirs, pratiques et représentations (XVI'-XXIe siècles), 2018

111 - La mine hier et aujourd'hui en Amérique latine, 2018 



\title{
Abonnements et ventes au numéro
}

Adresser les commandes à :

\section{Presses Universitaires du Midi}

Université Toulouse 2 - Jean Jaurès

5, allées Antonio-Machado, 31058 TOULOUSE cedex 9

Courriel : pum@univ-tlse2.fr

Tél. : 0561503810

\author{
Abonnement annuel (deux numéros par an) \\ Institutions françaises : 57 euros \\ Institutions étrangères : 61 euros \\ Particuliers France et étranger : 46 euros \\ Étudiants : 32 euros \\ Les frais de port sont inclus
}

\section{Prix au numéro}

France et étranger : 27 euros

+ frais de port (France : 3,80 euros/UE : 7 euros/hors UE : 8,90 euros)

Les frais de port sont offerts à partir de trois ouvrages

\section{Modalités de paiement :}

- par chèque (à l'ordre du Régisseur des Presses Universitaires du Midi)

- par carte bancaire (Visa, Mastercard ou Eurocard)

- par virement (Trésor public de Toulouse - Régie de recettes des PUM, 10071310000000100154322 TPTOULOUSE)

- par facture (pour les institutions) 
